\title{
Exploring Social Sustainability and Economic Practices
}




\section{Exploring Social Sustainability and Economic Practices}





\section{Exploring Social Sustainability and Economic Practices}

Selected Articles Published by MDPI 
This is a reprint of articles published online by the open access publisher MDPI (available at: http: //www.mdpi.com). The responsibility for the book's title and preface lies with Giuseppe T. Cirella, who compiled this selection.

For citation purposes, cite each article independently as indicated on the article page online and as indicated below:

LastName, A.A.; LastName, B.B.; LastName, C.C. Article Title. Journal Name Year, Article Number, Page Range.

ISBN 978-3-03928-554-9 (Pbk)

ISBN 978-3-03928-555-6 (PDF)

Cover image courtesy of Giuseppe T. Cirella.

(C) 2020 by the authors. Articles in this book are Open Access and distributed under the Creative Commons Attribution (CC BY) license, which allows users to download, copy and build upon published articles, as long as the author and publisher are properly credited, which ensures maximum dissemination and a wider impact of our publications. 


\section{Contents}

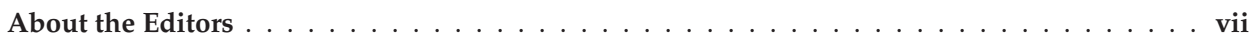

Giuseppe T. Cirella, Anatoliy G. Goncharuk, Corrado lo Storto and Alessio Russo

Exploring Social Sustainability and Economic Practices: Multi-Journal Compendium

Reprinted from: Sustainability 2020, 12, 1718, doi:10.3390/su12051718 . . . . . . . . . . . . . .

Jaime de Diego, Antonio Rúa and Mercedes Fernández

Designing a Model to Display the Relation between Social Vulnerability and Anthropogenic

Risk of Wildfires in Galicia, Spain

Reprinted from: Urban Science 2019, 3, 32, doi:10.3390/urbansci3010032 . . . . . . . . . . . . . 9

Chunzhu Wei, Mark Padgham, Pablo Cabrera Barona and Thomas Blaschke

Scale-Free Relationships between Social and Landscape Factors in Urban Systems

Reprinted from: Sustainability 2017, 9, 84, doi:10.3390/su9010084 . . . . . . . . . . . . . . 25

Oleksandr Velychko, Liudmyla Velychko and Mykola Kharytonov

Managing Efficiency in Higher Education: A Case of Ukrainian Universities

Reprinted from: Social Sciences 2018, 7, 138, doi:10.3390/socsci7080138 _ . . . . . . . . . . 45

Letícia Sarmento dos Muchangos and Philip Vaughter

Gender Mainstreaming in Waste Education Programs: A Conceptual Framework

Reprinted from: Urban Science 2019, 3, 29, doi:10.3390/urbansci3010029 . . . . . . . . . . . . . 61

Ricardo Cruz de Carvalho, Zulema Varela, Teresa Afonso do Paço and Cristina Branquinho

Selecting Potential Moss Species for Green Roofs in the Mediterranean Basin

Reprinted from: Urban Science 2019, 3, 57, doi:10.3390/urbansci3020057 . . . . . . . . . . . . . 73

Crisanta-Alina Mazilescu and Bernard Gangloff

Value Assigned to Employees Who Preserve the Social and Organizational Environment

Reprinted from: Sustainability 2017, 9, 170, doi:10.3390/su9020170 . . . . . . . . . . . . . 83

Iryna Nyenno, Natalia Rekova and Svetlana Minakova

Joint Value as a Measure of Sea Trade Port Stakeholder Effect

Reprinted from: Social Sciences 2019, 8, 120, doi:10.3390/socsci8040120 . . . . . . . . . . . 101

Patrizia Gazzola, Gianluca Colombo, Roberta Pezzetti and Luminița Nicolescu

Consumer Empowerment in the Digital Economy: Availing Sustainable Purchasing Decisions

Reprinted from: Sustainability 2017, 9, 693, doi:10.3390/su9050693 . . . . . . . . . . . . . . 117

Andrzej Paczoski, Solomon T. Abebe and Giuseppe T. Cirella

Debt and Deficit Growth Rate Reporting for Post-Communist European Union Member States

Reprinted from: Social Sciences 2019, 8, 173, doi:10.3390/socsci8060173 . . . . . . . . . . . . 137 



\section{About the Editors}

Giuseppe T. Cirella, Dr., is Professor of Human Geography at the Faculty of Economics, University of Gdansk, Sopot, Poland. He received his Ph.D. in Environmental Engineering (specialization: sustainability) from Griffith University, Australia. He is the founder of the Polo Centre of Sustainability and is Director and Head of Research. Prior to working for the University of Gdansk, Dr. Cirella was Professor at Saint Petersburg State University, Russia, as well as Research Scientist at both the Free University of Bozen and Ca' Foscari University of Venice in Italy. He has also held a number of short-term professorships in China (Beijing Forestry University and Inner Mongolia University of Science and Technology), South Africa (University of Pretoria), and Ukraine (International Humanitarian University). He has acted as a principal investigator and coordinator in a number of international projects and is a reviewer and member of the editorial board of several reputed international journals on sustainability and the environment. He has extensive interdisciplinary and cross-cultural experience in socioeconomics as well as expertise in landscape architecture, urban planning, and societal development.

Anatoliy G. Goncharuk, Dr., is Professor of Management and Finance and currently works as the Vice-Rector for Research and Education at the International Humanitarian University, Odessa, Ukraine. He received his Ph.D. in Organizing Management, Planning, and Regulation of Economy from Odessa State Economic University, Ukraine, and Doctor of Economic Science (Habilitation Degree) in Business Economics and Management from the National Academy of Sciences of Ukraine. He has received a number of grants from the President of Ukraine, DAAD (Germany), and European Commission (H2020, COST) as well as served as a visiting professor and researcher at Paris Diderot University UP7 (France), Geisenheim University (Germany), University of Banja Luka (Bosnia and Herzegovina), and Children Rehabilitation Hospital in Ameryka (Poland). He is a member of the Scientific Council of the National Research Foundation of Ukraine and editor-in-chief for the Journal of Applied Management and Investments. His research interests include performance measurement and management, motivation, efficiency analysis, benchmarking tools, and their application at various management levels in the food and beverage industry, energetics, education, and healthcare.

Corrado Lo Storto, Dr., is Professor of Applied Economics in the Department of Industrial Engineering, University of Naples Federico II, Naples, Italy, where he leads the research team Applied Market Economic Analytics and Policy. He received his Ph.D. in Science of Industrial Innovation from the University of Padua and holds a Laurea in Aeronautical Engineering from the University of Naples. His main research interests include technology and innovation economics, efficiency and productivity analysis, strategic benchmarking, and performance analysis. On these topics, Dr. Lo Storto has published a number of academic papers in refereed international journals, book chapters, and conference proceedings. He is currently the Chair of Italy IEEE-Technology and Engineering Management Chapter and editor-in-chief of the International Journal of Engineering Management and Economics published in Inderscience. 
Alessio Russo, Dr., is Senior Lecturer and Academic Course Leader in the Master of Landscape Architecture at the University of Gloucestershire, Cheltenham, United Kingdom. Before joining the University of Gloucestershire, he worked in Russia as an Associate Professor at RUDN University in Moscow and Professor and Head of Laboratory of Urban and Landscape Design at Far Eastern Federal University in Vladivostok. He holds a B.S. in Plant Production from the University of Naples, post-graduate specialization in Healing Garden Design from the University of Milan, and M.S. in Landscape Design and Planning from the University of Pisa. He received his Ph.D. in Urban Forestry from the University of Bologna. Outside of academia, Dr. Russo has worked as a landscape architect in the United Kingdom, Italy, and the United Arab Emirates, dealing with sustainable design and planning. He is a member of the International Scientific Committee on Cultural Landscapes ICOMOS-IFLA, International Federation of Landscape Architects (IFLA) Advisory Circle, and International Union for Conservation of Nature Commission on Ecosystem Management. 


\title{
Editorial \\ Exploring Social Sustainability and Economic Practices: Multi-Journal Compendium
}

\author{
Giuseppe T. Cirella ${ }^{1, *(\mathbb{C}}$, Anatoliy G. Goncharuk ${ }^{2}$, Corrado lo Storto ${ }^{3}(\mathbb{C})$ and Alessio Russo ${ }^{4}$ (i) \\ 1 Faculty of Economics, University of Gdansk, 81-824 Sopot, Poland \\ 2 Department of Management, International Humanitarian University, 65009 Odessa, Ukraine; agg@ua.fm \\ 3 Department of Industrial Engineering, University of Naples Federico II, 80125 Naples, Italy; \\ corrado.lostorto@unina.it \\ 4 School of Arts, University of Gloucestershire, Francis Close Hall Campus, Cheltenham GL50 4AZ, UK; \\ arusso@glos.ac.uk \\ * Correspondence: gt.cirella@ug.edu.pl
}

Received: 18 February 2020; Accepted: 21 February 2020; Published: 25 February 2020

\begin{abstract}
In consideration of the three pillars of sustainability, alongside the environment, social and economic dimensions interplay valuable insight into how society is molded and what key components should be considered. In terms of social sustainability, there are processes and framework objectives that promote wellbeing integral to the balance of people, planet, and profit. Economic practices consider the system of production, resource allocation, and distribution of goods and services with respect to demand and supply between economic agents. As a result, an economic system is a variant of the social system in which it exists. At present, the forefront of social sustainability research partially encompasses the impact economic practices have on people and society-with notable emphasis centered on the urban environment. Specific interdisciplinary analyses within the scope of sustainability, social development, competitiveness, and motivational management as well as decision making within the urban landscape are considered. This book contains nine thoroughly refereed contributions that interconnect detailed research into the two pillars reviewed.
\end{abstract}

Keywords: sustainability; social development; economics; wellbeing; stakeholders; competitiveness; motivational management; sustainable decision making; urban landscape; research methods

\section{Introduction}

This multi-journal compendium is made up of three special issues from Sustainability, Urban Science, and Social Sciences; it examines a broad array of research activities within two of the three pillars of sustainability [1-3]. It includes nine thoroughly refereed contributions that, respective of the environment, focus on the social and economic dimensions. Valuable discernment into how society and its key components are organized takes into account social sustainability alongside sound economic practices $[4,5]$. Social sustainability specifically pieces together the processes and framework of balancing people, planet, and profit in terms of wellbeing and future generational perspectives [6,7]. Social sustainability has been defined as the "neglected component of sustainability" [8] that incorporates both social equity and community concerns [9]. Particular importance is stressed upon community- and urban-oriented measures. Integrative economic practices intersect the economic system of production, resource allocation, and distribution of goods and services between economic agents. Economists and policymakers alike have generally examined variances of efficiency into these elemental attributes. Political debate has been, and actually still is, a principal concern of where the applied cut-off point should be in terms of government expenditure at central and local levels. The rationale of how spending cuts can offer relief, or even strengthen a country's economy, interplays a significant role in the modernity of economic thinking $[10,11]$. With respect to these developmental 
concerns, this book explores the utility of economic practices by way of social interaction within the bounds of society-based studies.

It is important to identify that facets of society predominately are applied within the urban setting and, hence, require urban-specific decision making. Since the world's population is rapidly increasing and will top 9.7 billion by 2050 and two thirds of the world's population will be concentrated in urban areas by 2025 [12], increasing the importance of providing not only environmental quality but livable and socially acceptable spaces [13] become paramount to healthy and educative-oriented societies. Advanced rates of urbanization coincide with global environmental degradation, increase the consumption of natural resources, habitat loss, and overall ecosystem change [14-16]. A cause-and-effect reproach from escalating global population brings to the forefront the need to re-examine how urban spaces are developed, used, and urban inhabitants interact respective of social and economic wellbeing. These benefits are referred to as nature-based solutions which-to some degree-complement umbrella-like concepts of green economics [17] and full-cost accounting [18] as well as overarching measuring tools (e.g., Human Development Index, ecological footprint, and index of sustainable functionality [19-21].

Within the framing of social sustainability, clearly a wealth of literature has been dedicated to the study of social development of what equates to "social capital, social cohesion, and social exclusion" [22]. As such, necessary goods and services at the societal level [23,24] should address "on what might be called 'higher-order' needs" [22]. As a new strand of discourse on sustainability, social sustainability comes at the response and "dominance of environmental concerns and technological solutions in urban development and lack of progress in tackling social issues" [25]. Issues such as financial austerity and public sector budget cuts as well as social degeneration at the relational level of wellbeing and development are essential concerns to contemporary societies. This book pieces together, predominately, socially oriented inquiries within a variety of studies that include an urban overtone. Exemplar economic practices are also intertwined in the latter part and complement the overall outlook of the compendium.

Dating back to 2015, a number of countries have made notable gains in meeting the Millennium Development Goals since their adoption in 2000, however, progress against these goals were-generally-inconsistent [26]. A more holistic approach for the implementation of the current Sustainable Development Goals (SDGs) is needed [27]. As a result, we should reposition social sustainability at the forefront of the SDG-dilemma since it negatively generates higher environmental impacts [28]. In view of this importance, quantitative relations between the SDGs should be well-established so that integrative policies can be implemented where possible [28]. To ensure that social sustainability does not come at the expense of economic or environmental sustainability, a balance between the different dimensions of sustainability is required [29-31]. As research findings are still not widely accepted in the policy process, it is hopeful this book will add informative expertise for policymakers as well as regional planners, that have a pivotal role, in ensuring sound sustainable development for future generations.

\section{Synopsis}

The central argument of this multi-journal compendium is to present innovative contributions that offer novel and intriguing linkages within the subject matter of social sustainability and economic practices. The book is broken down to include geographical country-specific research, i.e., from Spain, Ecuador, Ukraine, France, and Italy, and region-based studies from the Mediterranean and the European Union (EU). The collection of contributions provided a number of methods and novel approaches that add to the overall knowledge-base of scholarly and academic expertise. In accordance with MDPI's review guidelines, the contributions partook thorough, single-blinded review before being accepted for publication. The contributions are summarized and provide case study insight into sustainability thinking with respect to social and economic emergences. A synopsis on the book consists of five social sustainability studies followed by four economically related ones. 
Diego et al. [32] examine socioeconomic factors (i.e., population structure, density, livestock farms, education, among others) within the Galician municipalities of northern Spain-an area that comprises of up to $50 \%$ of total wildfires nationally. These factors comprise of probable pre-forest fire circumstances that have a prevalent vulnerability to the local population. Linkages show that socioeconomic variables can influence fire occurrence-both positively and negatively. The study analyzes the relationship between wildfire events and socioeconomic variables to ensure best practices for territorial integrity. To this effect, a thorough examination and selection of the most relevant socioeconomic variables was carried out. Using statistics, a linear regression model was executed from wildfire data between 2001 and 2015. The resulting model allowed for an optimum socioeconomic awareness to be maintained when wildfires occur. As such, the results identified existing relational interchange between socioeconomics and wildfire events and, consequently, offer enhancement and intervention aid territory wide. The research stresses it is one of the best ways to carry out prevention action in order to reduce vulnerability to forest fire occurrences.

Wei et al. [33] look at scale-free relationships between social and landscape factors in Quito, Ecuador. The debate between urban landscapes and social activities is explored in terms of scales of observation. This study applied a hierarchical zoning technique, by examining how relationships between typical spatial landscape metrics and social indicators stand up against zoning scales. Results indicated that the estimates of both landscape heterogeneity features and social indicators significantly depend on the level of zoning scale. As a result, the mean values of the typical landscape metrics in accordance with social indicators all exhibited predictable responses to a changing zoning scale-suggesting a consistent and significant scaling relationship within multiple zoning. Quantitative methods applied to the urban spaces included deprivation and public service accessibility. The relationships between social indicators and a typical landscape aggregation metric significantly depended on scale, suggesting the importance of zoning scale decisions for analyzing these relationships is essential. The involvedness of the study also suggests complex socioecological systems in other cities, which are shaped by conflated influences of both anthropogenic and natural factors, could share a significant role in developing scale-free relationships. Moreover, the behavior challenges from the traditional modifiable area unit problem may provide mechanistic insight into the conflicts and compatibilities between human activities and human-induced land use change.

Velychko et al. [34] explore a societal-oriented case study by investigating the efficiency in higher education in Ukraine. This research spurred from the fact that Ukrainian higher educational establishments, in the global international environment, have not implemented significant positive changes since it gained state sovereignty from the Soviet Union in 1990. Progressive regulatory changes are necessary to stimulate internal university reforms within the context of European integration. The study developed organizational and methodological measures in order to increase the efficiency of scientific-pedagogical activity by using monographic, historical, comparative, generalization, formal-logical, analysis and synthesis, categorical approach, observation, interviewing, graphic, benchmarking, and forecasting. The mechanisms of utilizing re-engineering and motivational management, in the process of implementing European integration objectives, is suggested. The system of normative indices is formed to stimulate the effectiveness of the scientific-pedagogical activities of universities in terms of marketing educational services, innovation, and quality. The social development of stimulating scientific-creative activity is pre-tested and put into practice.

Muchangos and Vaughter [35] piece together a conceptual framework by focusing on gender issues in waste-related educational programs. Gender issues are presented as internal to waste management, i.e., from daily handling activities through to decision making processes. In waste educational programs, the disregard for views of and contribution by women has resulted in strategies that do not comprehensively address the waste issue, preventing long-standing and sustainable outcomes, while increasing existing gender inequities. Three critical waste matters on education and gender are identified. Social research explores this relationship by proposing the use of a participatory framework for gender mainstreaming in waste education. The framework included components to assess promoting the 
program at all its stages. The framework represented a novel theory and practical concept for waste education development-by supporting academics, practitioners, and policymakers—in the quest of achieving equitable and sustainable waste management systems society-wide.

Cruz de Carvalho et al. [36] conceptualize the use of selecting potential moss species for green roofs in the Mediterranean Basin. This socio-urban study examines green roof infrastructure by addressing the effects of climate change in urban areas. Throughout the Mediterranean Basin-where the summers radiate higher temperatures and water is scarce-the use of vascular plants to increase water consumption during warmer periods is examined. The use of mosses is presented due to their poikilohydric nature in which they respond to the environmental availability of water (i.e., completely drying out and recovering upon rehydration). Although criteria for the selection of vascular plants adapted to the Mediterranean and suitable for green roofs have been explored, new information is made available in regard to the selection of mosses based on scientific criteria. The proposed research is based on ecological preferences according to Ellenberg's [37] values and helps to define moss traits suitable for non-irrigated, nature-based green roofs tolerable to the Mediterranean climate. The main result is a table of potential candidate mosses that can be either used as standalone or in conjunction with vascular plants to decrease water usage and manage stormwater through an easily applicable selection methodology. The study, albeit technical in nature, has an underlying scope in which practitioners could utilize these advancements for best fit green infrastructure development in extreme climatic regions that endure scarce water resources.

Mazilescu and Gangloff [38] examine individual behaviors in Rouen, France, by looking at social and organizational environments of small and medium-sized enterprises (SMEs) by assigning social value scores. This social sustainability study looks at individuals that maintain allegiant behaviors. Numerous studies have highlighted the normative character of allegiance within the field of social norms and values. As such, the research questioned 170 employees on social values attributing terms of desirability and utility within the context of future colleagues (i.e., subordinate or peer). Individuals scored future colleagues in terms of an allegiance questionnaire. It was observed that desirability and utility made reference to two independent dimensions. It was also noted that there was greater severity assigned to endo-group targets (i.e., future peers) than to exo-group targets (i.e., future subordinates). The study closed by noting a rejection of rebel targets, which raised the question of the bi-dimensionality of the valuation-devaluation process.

Nyenno et al. [39] explore economic practices in terms of joint value as a measure of sea trade ports in Ukraine by using the stakeholder effect approach. The research followed an efficiency measurement within the maritime industry by assessing joint value of varying industry stakeholders. A list of factors contributing to the efficiency of the state maritime policy, as well as factors in the development of the industry, were defined and separated into four groups: infrastructure, management, marketing, and service. The joint value was analyzed for both macroeconomic and microeconomic levels and combined into a multivariate regression model—tested using Statistica 8.0. The complexity of the results, created for the maritime industry, led to a revealing conclusion that an optimum alternative to the development of the port industry suggests state modernization and corporatization by way of a port business model.

Gazzola et al. [40] research consumer empowerment in the digital economy in Italian universities. Economic practices examine the advent of the digital economy and, implicitly, of competition in the online marketplace-with respect to consumer protection approaches. Online, consumer skills are expected to be improved and the level of consumer awareness and engagement increased. As a baseline requisite, the study intended to advance and test a research model integrating five main constructs, namely: competition in the online marketplace, online consumer skills, online consumer awareness, online consumer engagement, and sustainable purchasing decisions. A total of 318 university students-a representative population of the new Millennial generation-accepted the invitation to participate in a questionnaire-based survey. In order to pertinently analyze the collected data, a structural equation modeling technique, based on partial least squares, was employed for the 
assessment of the measurement and structural model. The findings indicated that $24.4 \%$ of variance was found for sustainable purchasing decisions in which the highest influence came from the improvement of online consumer skills. The study implied that online providers should revisit their products' sustainability standards to preserve their competitive edge.

Finally, Paczoski et al. [41] piece together a debt and deficit growth rate study for post-communist EU Member States (MSs). A focalized analysis and reporting of the problems of general government debt (GGD) and government deficit (GD) and their influencing factors on economic growth rate tell the story of positive, neutral, and negative economies. Research was conducted over a 19-year period between 2000 and 2018 on all 11 post-communist MSs. Reviewed literature examined different types of GGD and GD with denoted influence on each MS's economy and government. GGD and GD increased as a result of state intervention by reacting to economic fluctuations needed in creating redistributive-related fiscal policy. A breakdown of the problems of fiscal policy is explained. Histo-geographical research was considered and a comparative examination of GGD, GD, and growth rate illustrated. In all, negative or stagnant periods revealed a general positive trend throughout the study with the exception of the world financial crisis of 2008 which marked a deteriorative period on growth rate. In the latter years of the study, MSs' economic promise signaled a high potential for renewed public finance and stability initiatives.

\section{Conclusions}

The contributions were divulged from three special issues in which each included three published articles. The source of the journals are as follows: (1) Sustainability Special Issue on "Multi-disciplinary Sustainability Research", (2) Urban Science Special Issue on "Urban Sustainability: A Smart, Compact Future in Landscape Architecture", and (3) Social Sciences Special Issue on "Measuring Efficiency Considering Efficacy, Fairness and Uncertainty: Current Trends in Methods, Practice, and Policies". The ordering of the contributions was in relation to the two themes: social sustainability and economic practices. The initial five contributions exhibit renewed ideas into social sustainability in terms of social vulnerability, scale-free relationships, managing efficiency, gender mainstreaming, and socio-urban infrastructure. The latter four engaged in economic practices with respect to social and organizational behavior of SMEs, industry stakeholders, and digital economy as well as comparative research into GGD, GD, and growth rate. These four papers focused on economic practices that closely coincide with sustainable development concerns. In particular, scholars have examined such linkages by either looking inside the organizational boundaries or outside by considering different actors relative to the economic environment. Results that have emerged from the contributions, often indicated that several variables can affect the linkage between economic practice and sustainable development-at the individual, organization, and system level-making it complex and not easily understood, e.g., employee motivation, manager leadership, organization and business environment culture (i.e., by supporting less versus additional collaboration), and shared values. The growing awareness of market customers, considering their relevance to sustainability and environmental concerns, requires companies to pay greater attention to the type of products they sell, resource consumption, and manufacturing. Scholars also illustrated how the need to pursue greater sustainability often requires the joint contribution from several entities (i.e., within the organization or from several organizations and institutions) relevant to that economic environment. Such collaboration allows for the exploitative synergies and increased integration among actors, rationalization of resource utility, creation of business value, and—finally—increased sustainability performance.

Author Contributions: Conceptualization, Investigation, Resources, Writing—original draft preparation: G.T.C.; Validation and Writing-review and editing: G.T.C., A.G.G., C.I.S., and A.R. All authors have read and agreed to the published version of the manuscript.

Funding: This research was funded by the Polo Centre of Sustainability-Southeast Asia Office under the "Sihanoukville Social and Economic Development" (SikDev) Cambodia Project, Grant Number: SDEV101. 
Acknowledgments: The editors are grateful to the reviewers for their support and critical and constructive comments. We also extend our appreciation to the editorial assistance office of MDPI for their support throughout the review and publication process of the respective journals.

Conflicts of Interest: The authors declare no conflict of interest.

\section{References}

1. Elkington, J. Towards the Sustainable Corporation: Win-Win-Win Business Strategies for Sustainable Development. Calif. Manag. Rev. 1994, 36, 90-100. [CrossRef]

2. Elkington, J. Cannibals with Forks: The Triple Bottom Line of 21st Century Business; New Society Publishers: Stony Creek, CT, USA, 1998; ISBN 1841120847.

3. Cirella, G.T.; Zerbe, S. Quizzical societies: A closer look at sustainability and principles of unlocking its measurability. Int. J. Sci. Soc. 2014, 5, 29-45. [CrossRef]

4. Shoreman-Ouimet, E.; Kopnina, H. Culture and Conservation: Beyond Anthropocentrism; Routledge: New York, NY, USA, 2016; ISBN 9780415721981.

5. Kim, M.; Xie, Y.; Cirella, G.T. Sustainable Transformative Economy: Community-Based Ecotourism. Sustainability 2019, 11, 4977. [CrossRef]

6. Eizenberg, E.; Jabareen, Y. Social Sustainability: A New Conceptual Framework. Sustainability 2017, 9, 68. [CrossRef]

7. Blanc, H.; Raymond, A. Prise en compte de la durabilité dans la représentation sociale de la croissance économique. Dév. Durable Territ. 2011, 2,1-10. [CrossRef]

8. Kandachar, P. Materials and Social Sustainability. In Materials Experience: Fundamentals of Materials and Design; Elsevier Inc.: Oxford, UK, 2013; pp. 91-103. ISBN 9780080993591.

9. Bramley, G.; Power, S. Urban form and social sustainability: The role of density and housing type. Environ. Plan. B Plan. Des. 2009, 36,30-48. [CrossRef]

10. Goncharuk, A.G. Using the DEA in efficiency management in industry. Int. J. Product. Qual. Manag. 2007, 2, 241-262. [CrossRef]

11. Goncharuk, A.G. Enterprise performance management: A three-level approach. Int. J. Bus. Perform. Supply Chain Model. 2009, 1, 162-186. [CrossRef]

12. United Nations. World Population Prospects: The 2015 Revision, Key Findings and Advance Tables; Working Paper No. ESA/P/WP.241; UN DESA Population Division: New York, NY, USA, 2015.

13. Haberman, D.; Gillies, L.; Canter, A.; Rinner, V.; Pancrazi, L.; Martellozzo, F. The Potential of Urban Agriculture in Montréal: A Quantitative Assessment. ISPRS Int. J. Geo-Inf. 2014, 3, 1101-1117. [CrossRef]

14. Daily, G.C. Restoring Value to the World's Degraded Lands. Science 1995, 269, 350-354. [CrossRef] [PubMed]

15. McDonald, R.I.; Marcotullio, P.J.; Güneralp, B. Urbanization and Global Trends in Biodiversity and Ecosystem Services. In Urbanization, Biodiversity and Ecosystem Services: Challenges and Opportunities; Elmqvist, T., Fragkias, M., Goodness, J., Güneralp, B., Marcotullio, P.J., McDonald, R.I., Parnell, S., Schewenius, M., Sendstad, M., Seto, K.C., et al., Eds.; Springer: Dordrecht, The Netherlands, 2013; p. 755, ISBN 978-94-007-7087-4.

16. McNeill, J.R. Something New Under the Sun: An Environmental History of the Twentieth-Century World; W.W. Norton and Company: New York, NY, USA, 2000.

17. Mell, I.C.; Henneberry, J.; Hehl-Lange, S.; Keskin, B. To green or not to green: Establishing the economic value of green infrastructure investments in The Wicker, Sheffield. Urban For. Urban Green. 2016, 18, 257-267. [CrossRef]

18. Antheaume, N. Valuing external costs-from theory to practice: Implications for full cost environmental accounting. Eur. Account. Rev. 2004, 13, 443-464. [CrossRef]

19. Imberger, J.; Mamouni, E.D.; Anderson, J.; Ng, M.; Nicol, S.; Veale, A. The index of sustainable functionality: A new adaptive, multicriteria measurement of sustainability-Application to Western Australia. Int. J. Environ. Sustain. Dev. 2007, 6, 323-355. [CrossRef]

20. Cirella, G.T. Developing a Quantitative Multi-Criteria Method of Sustainability Assessment: With Application in Queensland, Australia; Griffith Library Press: Gold Coast, Australia, 2009.

21. Cirella, G.T.; Zerbe, S. Index of sustainable functionality: Procedural developments and application in Urat Front Banner, Inner Mongolia Autonomous Region. Int. J. Environ. Sustain. 2014, 10, 15-31. [CrossRef] 
22. Vallance, S.; Perkins, H.C.; Dixon, J.E. What is social sustainability? A clarification of concepts. Geoforum 2011, 42, 342-348. [CrossRef]

23. Evans, R.; Marvin, S. Researching the sustainable city: Three modes of interdisciplinarity. Environ. Plan. A 2006, 38, 1009-1028. [CrossRef]

24. Blunt, A. Cultural geography: Cultural geographies of home. Prog. Hum. Geogr. 2005, 29, 505-515. [CrossRef]

25. Woodcraft, S. Understanding and measuring social sustainability. J. Urban Regen. Renew. 2015, 8, $133-144$.

26. United Nations. Emerging Issues: Contributions of Social Development to the Transition from the Millennium Development Goals to the Sustainable Development Goals; Commission for Social Development: Brussels, Belgium, 2015.

27. SDG. United Nations Sustainable Development Goals. Available online: http://www.un.org/ga/search/view_ doc.asp?symbol=A/RES/70/1\&Lang=E (accessed on 3 May 2019).

28. Scherer, L.; Behrens, P.; de Koning, A.; Heijungs, R.; Sprecher, B.; Tukker, A. Trade-offs between social and environmental Sustainable Development Goals. Environ. Sci. Policy 2018, 90, 65-72. [CrossRef]

29. Dempsey, N.; Bramley, G.; Power, S.; Brown, C. The social dimension of sustainable development: Defining urban social sustainability. Sustain. Dev. 2011, 19, 289-300. [CrossRef]

30. UN-HABITAT. ESCAP. The State of Asian Cities 2010/11, 1st ed.; United Nations Human Settlements Programme: Fukuoka, Japan, 2010; ISBN 9789211322743.

31. Bigio, A.G.; Dahiya, B. Urban Environment and Infrastructure; The World Bank: Washington, DC, USA, 2004.

32. Diego, J.; de Rúa, A.; Fernández, M. Designing a Model to Display the Relation between Social Vulnerability and Anthropogenic Risk of Wildfires in Galicia, Spain. Urban Sci. 2019, 3, 32. [CrossRef]

33. Wei, C.; Padgham, M.; Barona, P.C.; Blaschke, T. Scale-free relationships between social and landscape factors in urban systems. Sustainability 2017, 9, 84. [CrossRef]

34. Velychko, O.; Velychko, L.; Kharytonov, M. Managing Efficiency in Higher Education: A Case of Ukrainian Universities. Soc. Sci. 2018, 7, 138. [CrossRef]

35. Muchangos, L.; dos Vaughter, P. Gender Mainstreaming in Waste Education Programs: A Conceptual Framework. Urban Sci. 2019, 3, 29. [CrossRef]

36. Cruz de Carvalho, R.; Varela, Z.; do Paço, T.A.; Branquinho, C. Selecting Potential Moss Species for Green Roofs in the Mediterranean Basin. Urban Sci. 2019, 3, 57. [CrossRef]

37. Ellenberg, H.; Weber, H.E.; Düll, R.; Wirth, V.; Werner, W.; Paulissen, D. Zeigerwerte von Pflanzen in Mitteleuropa, 2nd ed.; Goltze, Scripta Geobotanica: Göttingen, Germany, 1992; ISBN 9783884525180.

38. Mazilescu, C.A.; Gangloff, B. Value assigned to employees who preserve the social and organizational environment. Sustainability 2017, 9, 170. [CrossRef]

39. Nyenno, I.; Rekova, N.; Minakova, S. Joint Value as a Measure of Sea Trade Port Stakeholder Effect. Soc. Sci. 2019, 8, 120. [CrossRef]

40. Gazzola, P.; Colombo, G.; Pezzetti, R.; Nicolescu, L. Consumer empowerment in the digital economy: Availing sustainable purchasing decisions. Sustainability 2017, 9, 693. [CrossRef]

41. Paczoski, A.; Abebe, S.T.; Cirella, G.T. Debt and Deficit Growth Rate Reporting for Post-Communist European Union Member States. Soc. Sci. 2019, 8, 173. [CrossRef]

(C) 2020 by the authors. Licensee MDPI, Basel, Switzerland. This article is an open access article distributed under the terms and conditions of the Creative Commons Attribution (CC BY) license (http://creativecommons.org/licenses/by/4.0/). 

Article

\title{
Designing a Model to Display the Relation between Social Vulnerability and Anthropogenic Risk of Wildfires in Galicia, Spain
}

\author{
Jaime de Diego ${ }^{1, *(\mathbb{D}}$, Antonio Rúa ${ }^{2}$ (D) and Mercedes Fernández ${ }^{1}$ (D) \\ 1 University Institute of Studies on Migration, Comillas Pontifical University, 28015 Madrid, Spain; \\ mercedes@comillas.edu \\ 2 Faculty of Economics and Business Administration, Comillas Pontifical University, 28105 Madrid, Spain; \\ rvieites@icade.comillas.edu \\ * Correspondence: jdediego@comillas.edu
}

Received: 14 January 2019; Accepted: 6 March 2019; Published: 12 March 2019

\begin{abstract}
Since the beginning of the 21st century, most of the forest fires that have occured in Spain have taken place in the northern region of Galicia. This area represents $5.8 \%$ of the Spanish territory, but compromises, in certain years, up to $50 \%$ of the total number of wildfires. Current research on forest fires is focused mostly on physical or meteorological characteristics, post-fire situations, and their potential destructive capacities (main areas burnt, type of vegetation, economic loses, etc.). However, the academic research to date has not delved into other socioeconomic factors (population structure, density, livestock farms, education, among others), which compromise the existing pre-fire situation in the affected territories, and subsequently reflect the prevailing vulnerability of the population. Indeed, these socioeconomic variables can influence fire occurrence, whether positively or negatively. To fill in this knowledge gap, this article analyzes the relationship between wildfire events and the socioeconomic variables that characterize the Galician municipalities affected. To that effect, first, a thorough examination and selection of the most relevant socioeconomic variables, and their subsequent justification will be carried out. Then, using IBM SPSS statistics 24, a linear regression is executed using the data of wildfires that occurred in Galicia between 2001-2015. The resulting model allows a better knowledge of the importance of the socioeconomic situation in Galician municipalities when wildfires occur. Therefore, this result identifies the existing relationship between the socioeconomic variables and wildfire events, and consequently will help to optimize the interventions that must be done. This may be the best way to carry out prevention actions in order to reduce vulnerability to forest fires.
\end{abstract}

Keywords: socioeconomic variables; Spain; Galicia; wildfires; multiple linear regression

\section{Introduction}

Forest fires are natural disasters that are mostly associated with countries that have specific climatic characteristics and fire-prone vegetation. Spain is situated within the list of countries annually affected by these events together with the United States (US) and Australia. Moreover, in the United States, forest fires have increased their size and destructive potential [1]. In Australia, in the last century, grassland fires have been the fourth risk associated with catastrophes, after heatwaves [2]. Even though it is considered as a natural disaster, the origin of forest fires is usually of human cause, which is around $96 \%$ in the case of Spain [3].

As pointed out in Section 2.1 of this paper, the current research on forest fires mostly focuses on physical or meteorological characteristics, post-fire situations, and their potential destructive capacities (main areas burnt, type of vegetation, economic losses, etc.). However, the academic research has not 
delved into the other socioeconomic factors (population structure, density, livestock farms, education, among others), that configure the existing pre-fire situation in the affected territories, and subsequently reflect a prevailing population vulnerability. Therefore, taking into account the characteristics of the existing population is crucial within the research on forest fires [4].

This perspective is taken from firefighting, which has globally emphasized post-fire actions, without giving priority to prevention efforts and action before a wildfire [5]. Hence, as a fundamental aspect in prevention, it is necessary to know the variables that influence the characteristics of social groups within environments where fires occur, in order to reduce the impacts and occurrence of forest fires [6]. Also, if we focus on Spain, this situation can be observed when analyzing the current legislation about forest fires: the action against wildfires is transferred to the emergency plans, which are emphasized in post-fire situations [7].

Although forest fires are a natural component and necessary within the ecological cycle of certain ecosystems, often, different variables such as the weather or existing populations alter natural fire patterns. This may modify the negative effects of fire so much that the positive consequences that could contribute to the ecosystem are bypassed [8]. In fact, variables such as unequal social and economic structure, where class, ethnicity, sex, and poverty factor in, are very relevant for determining and predicting the occurrence of wildfires.

The Autonomous Community of Galicia has been the Spanish region with the highest number of forest fires in the 21st century. According to the specialized studies quoted in Section 2.2 (Galicia, social vulnerability, and wildfires), forest fires in Galicia might be directly related to a mixture of socioeconomic factors (such as population aging or low population density among with low economic development) and natural or environmental factors (such as extensive livestock farming, abandoned areas, or urban-forest interface areas).

All these factors mean that forest fires, year after year, continue occurring in Galicia, and the measures that have been taken do not seem to be enough for a problem of this magnitude. The situation described in Galicia reinforces the objective of investigating the connection between socioeconomic variables and forest fires in Galicia and, specifically, to find out which variables have the greatest weight.

The aim of this article is to establish the relationship between the socioeconomic aspects that reflect the reality of Galician municipalities and the number of forest fires that have occurred between 2001-2015, and to know which variables carry the greatest weight. A multiple linear regression model, estimated by ordinary least squares (OLS) method, was used to perform this analysis. The observational unit was the municipalities, since it was the smallest unit of information related to wildfires; in addition, it is the minimum territorial unit for which precise and uniform socioeconomic information exists. The model was firstly carried out for all of the municipalities of Galicia. Secondly, with the purpose of analyzing its structural stability, the model was run separately in the municipalities of each province. Finally, to determine if there were differences between provinces, Chow test was executed for the northern region (A Coruña and Lugo), the southern region (Ourense and Pontevedra), and within each region to compare each pair of provinces. This analysis offers action guidelines for the authorities in matters of prevention and awareness.

\section{Materials and Methods}

\subsection{Social Vulnerability and Wildfires}

The qualities that make a natural event a disaster are determined by the territory and the population within the exposed areas. To demarcate risks seems complicated because of this variability [9]. Disasters present multiple dimensions that can be classified as follows [10]:

- Social and population dimension: Includes aspects such as justice, social differences, and social organization and individual strengths. Some studies have incorporated variables such as poverty, social marginalization, demographics (age vulnerable groups), education, health and welfare, 
migration, and risk perception [11]. The factors that determine this dimension are influenced by specific conditions and are very different development processes, depending on the country or region and the kind of danger faced [12].

- Economic dimension: Deals with occupation, income, economic effects, consumption, property, and savings [13]. This dimension also contemplates housing and habitability issues together with livelihood, which may be an aspect to consider in cases where it is based on a single sector (agriculture, fisheries, etc.) [14].

- Environmental or territorial dimension: Even though the environment is the source of the natural processes that can cause a disaster, it is at the same time an important resource for people who have a high hazard exposure [15]. This dimension is related to the environmental destruction effects that cause changes in the natural ecosystem at different scales (melting, destruction of natural barriers in coasts, emissions, etc.) [16]. Therefore, this dimension examines both the population dependence to certain environmental services, and the sensitivity of these environmental services to certain hazards [17].

Social groups with certain characteristics of social vulnerability have a higher risk of suffering the effects of a disaster [18]. The socioeconomic features of a person (such as class, ethnicity, gender, and poverty) or a group of people (unequal social or economic structure) influence their ability to anticipate, cope with, resist, and recover from the impact of a natural disaster $[19,20]$. People in social disadvantage are more likely to suffer from scenarios that worsen their already adverse situation [21].

Within a natural disaster, such as forest fires, certain social, economic and political processes come into play; so, preventive actions should be targeted to people's characteristics. This reinforces the idea of studying the population's peculiarities in the analysis of forest fire risk rather than just looking at the post-disaster effects [22].

Vulnerable social groups become the main victims of forest fires. Nevertheless, individuals can play different roles [23]:

- Vulnerable to fire danger: Any individual or element to be affected by a wildfire.

- Generators of fire risk: They are the source of fire hazard by inappropriate use of the forest, traditional practices, negligence, etc.

- Relievers of fire risk: Those for whom the natural environment, and specifically the forest environment, is paramount.

Yet, what role does society play in forest fires? The responsiveness of citizens to an emergency depends largely on their conception of risk. This also affects their support for forest management policies and actions carried out by the emergency services. In fact, although in general fires are perceived as a catastrophic and random element, there are two underlying and coexistent stances about this assertion [23]:

- The fire as a threat to fight against: This attitude prevails in areas where there is a close relationship between the urban and natural environment. In this case, the perception is negative, because there is a sense of danger associated with fire; also, adverse effects, such as a loss of quality of land, vegetation, forest landscape, etc., are considered

- Fire as a land management tool: This perception is common in mountain and rural areas with the presence of an agricultural and livestock sector. This view can lead to the expansion of small fires and can cause forest fires of greater intensity and extent.

Human factors as a cause of forest fires are very relevant in Mediterranean Europe and specifically in Spain [24]. One of the most important characteristics is their randomness. Therefore, it seems particularly difficult to predict the behavior of a fire, such as where and when it will begin [25].

Current changes in climate, as well as changes in land use, are unfavorable aspects for forest fire risk reduction in Spain, as they affect the occurrence and intensity. An increase in episodes that exceed the capabilities of extinguishing devices is expected to become a national emergency [26]. 
Although wildfires, in some cases, may be favorable for the biodiversity and ecological characteristics of a given area, this can have huge economic and social costs [27]. In recent years, these costs have increased considerably in the transition zones between urban and forestry [28]. Recent studies have shown a positive correlation between fire prevention spending and the presence of private land and buildings [29]. This type of land is predominant in northern Spain, where there are large numbers of smallholdings. Specifically, the autonomous community of Galicia stands out as a forest fires benchmark in Europe. However, this is not the only negative socioeconomic characteristic present in this community. Therefore, is necessary to inquire into the reality that characterizes Galicia.

\subsection{Galicia, Social Vulnerability, and Wildfires}

According to Spanish statistics, the autonomous community of Galicia (Figure 1) has shown the highest rate of fires in Spain for the last decades [30].

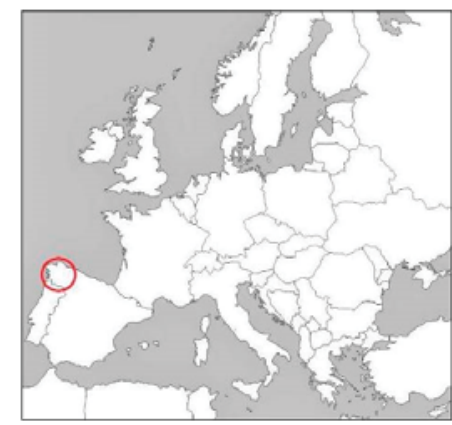

Figure 1. Situation of Gailica (Red). Own elaboration.

The objective of this paper is to establish the relationship between socioeconomic aspects that reflect the reality of the Galician municipalities and the number of forest fires from 2001 to 2015 (most recent official data available).

The first step is to establish the relevant socioeconomic variables available. For this purpose, it is paramount to have a broad knowledge of the relevant questions related to social vulnerability within a country.

Galicia has been the Spanish autonomous community most affected by forest fires since the beginning of the 21st century [31]. This can be seen in Figure 2, which compares Galicia and Spain in terms of hectares burnt and number of wildfires. In addition, recent reports show that fire seasons are lengthening and, within Europe, northern Spain and Portugal are the most critical areas [32].

Fires in Galicia have weighed significantly in Spain's general statistics. As shown in Figure 2, in certain years, both the number of wildfires occurred and burnt hectares in Galicia exceed $50 \%$ of Spanish fire disasters (Figure 3). Moreover, although the number of fires has decreased, burnt hectares follow a cyclical nature, and their mean is constant. Forest fires are known as one of the most important environmental problems in Galicia [30]. They have a far-reaching impact on the regional economy and cause greater risks for people and ecosystems, which are all linked to public spending [3].

According to specialized studies [30-35], forest fires in Galicia are directly related to a mixture of environmental-territorial plus social-economic factors. These factors can be considered well-known and predictable, but they typically exceed the capabilities of extinction means. Below, we detail the influence of both types of factors for the Galician case. 


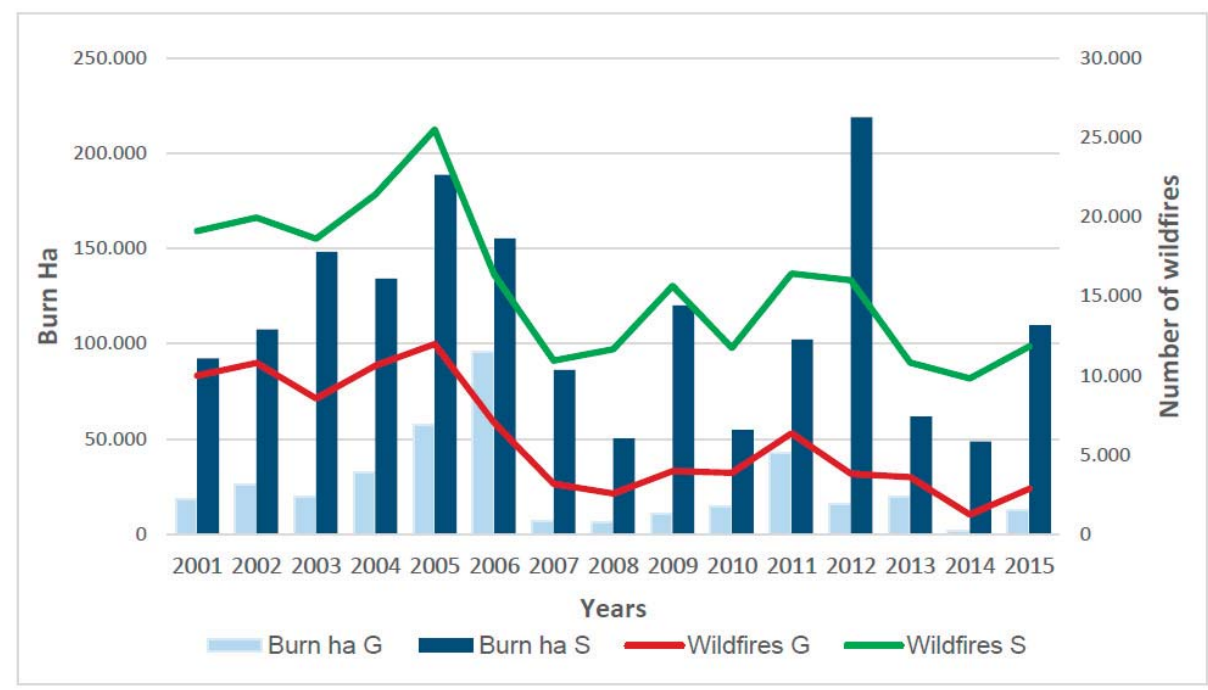

Figure 2. Relation between Galicia (G) and Spain (S). 2001-2015. Burnt hectares (ha) and number of wildfires. Source: Own elaboration from Nature Data Bank.

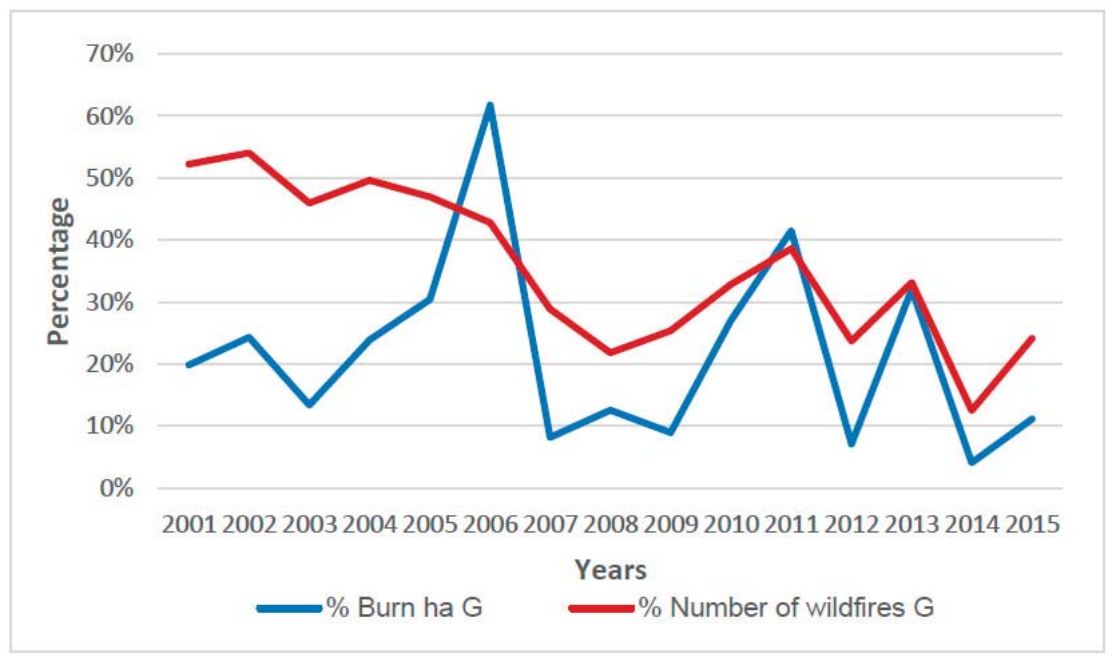

Figure 3. Burn ha and number of wildfires in Galicia in relation to Spain. 2001-2015. Source: Own elaboration from Nature Data Bank.

Environmental or territorial factors [36]:

- Deficient land management: Galicia is one of the regions with the highest vegetal production and plant growth in Spain. Galician territories have been increasing their areas with highly flammable shrubs and trees. This has been due to the lack of forest management, together with the abandonment of land used for agriculture and livestock.

- $\quad$ Extended livestock farming: Livestock owners make use of abandoned forest land. To acquire grass, small fires are set, increasing the chances of a huge wildfire. 
- Wastelands: They are characterized as the industrial parks, residential areas, and suburban areas of cities and towns, where shrub land and waste are mixed. They are not considered forest areas; however, they are areas where the work of extinguishing media is very intense.

- Wildland-urban interface areas: These can be defined as spaces where the surroundings of homes, neighborhoods, and urbanizations are embedded in adjacent forest areas with green spaces. They are considered high-risk areas because here, the occurrence and negligence in fire management multiply. There are large numbers of population centers with these characteristics and a higher risk of fires [37].

- Fire as a tool: Although there are permits for controlled burns, this practice is widespread in Galicia regarding both residues and forest scrub. This practice is very common in depressed and aged areas.

The above territorial factors are bound to the predominant types of land in Galicia and accordingly influence the fire data. In this region, lands are mostly privately ownership $(97.26 \%)$. Within these private properties, $32.77 \%$ are common lands, and the rest is another undetermined type of private ownership; therefore, many plots are abandoned or neglected. According to the Galicia Forest Plan, private property in the region is completely fragmented: the number of forest owners, is above 650,000 and the average plot size is two to three hectares [38].

The cause of forest fires in Galicia relates directly to the archaic habits in depressed areas and negligent use of fire as a management tool [30]. There is a lack of knowledge about such disasters, a lack of awareness and forest culture, and, obviously, there are economic interests associated with livestock and agricultural uses, which are at odds with land and forest management [34]. In the long term, these imbalances cause an increase in forest fires, and thus the further degradation of natural areas [39]. On the other hand, the large abandoned agriculture areas and the lack of land management in forest production have a positive side effect, insofar as they favor industry related to combating desertification and rural mountain management.

Social and Economic Factors

The Galician territory is complex; concentrated settlements are combined with other dispersed areas. Demographically and economically dynamic areas coexist with others characterized by a lack of vitality, but even within them there are some cities, headwaters of the region, which act as focal points of activity.

The rural depopulation is one of the major problems in Spain and, in particular, Galicia, where it is considered a demographic and territorial phenomenon. Indeed, the population in the region has dropped by $9.2 \%$ since 2008 . As far as the foreign population is concerned, the increase of immigrants helped mitigate rural depopulation before the economic downturn [40].

Other critical points related to the depopulation of rural areas are the aging population or population density that is so low, it doesn't permit economic development. However, imbalances in age and gender structures may be to blame [30]. Rural masculinization occurs at young ages due to a predominantly female migration, and also due to a lack of equal productive and reproductive work, which results in a search of a higher educational level and job opportunities associated with urban areas [23]. For its part, the low density presents common problems, such as aging, geographical isolation, a lack of spatial integration with other adjacent areas, bad connection and difficulty in transport, a lack of adequate social services, and lower levels of human capital and employment opportunities. All this inevitably leads to economic decline [12].

The impact of human resource losses, lack of territory development, and the inability to maintain economic activities, has not only economic, but also patrimonial and environmental impacts [30]. With regard to environmental effects, the abandonment of livestock and traditional agricultural uses represents a risk factor for natural environment conservation. This is because landscape transformations occur without control, and forest land management associated with rural areas are located mostly within individual plots [34]. 
Extensive livestock used to have an impact on the forest landscape, favoring the mosaics and reducing fuel in the mountains of Galicia [35]. The decline in extensive livestock farming that has taken place in Spain (around 30\% between 2004-2015) is thus considered an aggravating factor of forest fires [40].

The progressive abandonment of rural areas can be considered negative in the medium term, as the environmental effects, such as soil loss and exposure to erosive phenomena in large areas, are extensive [31]. In addition, a lack of forest land management occurs, increasing the risk of fire. In Galicia, traditional burning activities and the traditional use of fire in mountain management can lead to an increased fire occurrence [41].

All these factors ensure that forest fires continue to occur year after year in Galicia and the measures taken seem to be not enough to solve a problem of this magnitude. This situation reinforces the aim of investigating the relationship between socioeconomic variables and forest fires in Galicia and, specifically, uncovering which variables have greater explanatory power.

\subsection{Methodology}

As explained above, the main objective of this work is to establish the relationship between socioeconomic aspects of the Galician municipalities and the number of forest fires between 2001-2015.

To analyze this relationship, a quality dataset corresponding to Galician wildfires is required. Fire data were obtained from the Nature Data Bank, which has extensive information on fires in Spain. The data were separated into municipalities, and we had to choose which variables were more suitable for research, such as burnt hectares, type of terrain, etc. Afterwards, Galician municipalities socioeconomics data were joined, which were obtained from the IGE (Galician Statistics Institute).

Previous studies have established various time horizons: 2001-2006 [33], 2001-2009 [34], 2006 [30], and 2001-2010 [31]. In this sense, as information was available, it was decided to extend the time scope of research, selecting the updated data spanning from 2001 to 2015. The observational unit has been set at the municipal level, as it has proven to be the most accurate when allowing display territory differences [33]; it is also the minimum territorial unit that provides precise and consistent socioeconomic information.

To establish the relationship between the occurrence of wildfires and the socioeconomic variables, the variables described in prior sections were considered (density, aging population, type of terrain, etc.), to allow observations of the actual effect of these data over wildfires, neglecting environmental issues. The reason for this is that in the case of a number of wildfires, the environmental impact, including the temperature, wind, and humidity is not as critical as in the case of burnt hectares [33].

Socioeconomic data were related to the Galician municipalities, so the number of fires and burnt hectares were pooled along with the Galicia socioeconomic data from each municipality. These data were adjusted to 15 years by the mean and median of every year for selected variables. Subsequently, they were adapted to avoid very large paths, positive asymmetries, or not constant marginal variations. Finally, to make these variables more representative and comparable, we made some transformations and produced some ratios with variables such as municipal hectares or population size. As has been mentioned above [10], the variables can be grouped into three dimensions: social (population), economic, and environmental/territorial. The following variables (Table 1) were obtained: 


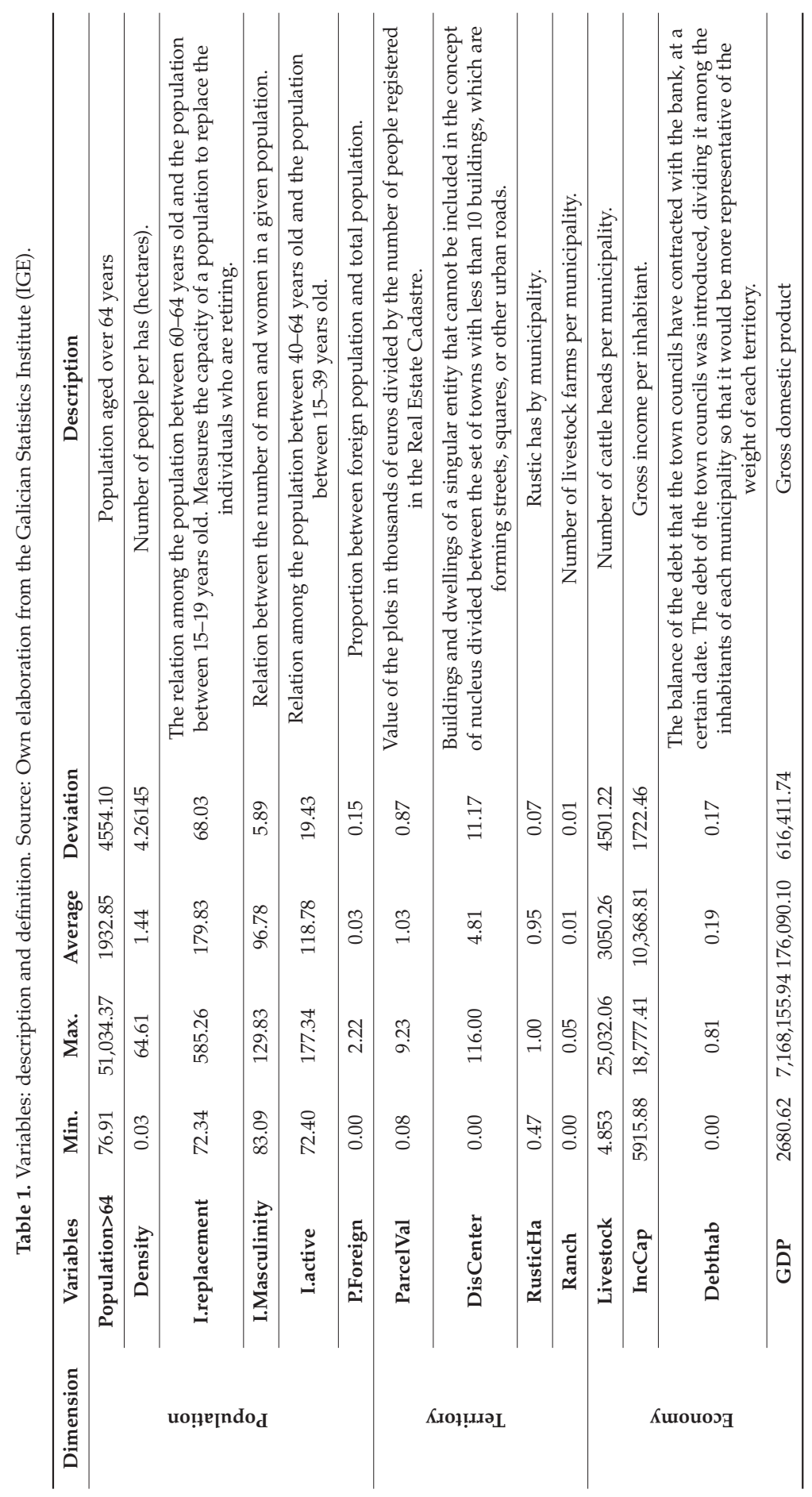


To analyze the socioeconomic variables influence in the number of wildfires in Galicia between 2001-2015, a model of multiple linear regression estimated by ordinary least squares (OLS) method was used. The observational unit was the municipality, since it was the smallest unit of information on forest fires; also, it is the minimum territorial unit where there is accurate and consistent socioeconomic information.

The model was carried out for all of the municipalities of Galicia and later for the municipalities of each province separately, in order to analyze the structural stability of the model. To determine if there were differences between provinces, the Chow test was executed [42] for the northern region (A Coruña and Lugo) and southern region (Ourense and Pontevedra). The same test was set within each region to compare each pair of provinces. The results are the following:

\section{General Model:}

The null hypothesis is that there is structural stability between north and south Galicia; the Chow contrast of a structural difference from north and south yielded a value of the statistic test. F $(15,284)$ $=7.20223 p$-value 0.0000 , so the null hypothesis is REJECTED, and therefore, there exists a structural difference between the north and south.

We proceed to see if there are structural differences within the north provinces (A Coruña and Lugo) and south provinces (Ourense and Pontevedra):

\section{North Model:}

Chow contrast for the structural difference in the North Model

$\mathrm{F}(15,130)=1.32671 p 0.1952$ value

Not reject the null hypothesis; therefore, no structural difference between the two northern provinces.

\section{South Model:}

Chow contrast for the structural difference in the South Model

$\mathrm{F}(15,124)=0.948374 p$-value 0.5135

Not reject the null hypothesis; therefore, no structural difference between the two southern provinces.

Moreover, to solve the heteroscedasticity problems presented in the model, robust standard deviations were used. To avoid other problems (variables with a large range of variation and/or skewness to the right, or not constant marginal effects), logarithms were taken when it was necessary.

\section{Results}

Model specification to explain the impact of the selected variables in the number of wildfires that occurred in Galician municipalities between 2001-2015 is:

$$
\begin{aligned}
\text { Number of Wildfires }= & \beta_{0} \\
& +\beta_{1} \text { LnPopulation }>64+\beta_{2} \text { LnDensity }+\beta_{3} \text { IncCap }+\beta_{4} \text { I.Masculinity } \\
& +\beta_{5} \text { I.active }+\beta_{6} \text { LnP.Foreign }+\beta_{7} \text { LnParcelVal }+\beta_{8} \text { LnDisCenter } \\
& +\beta_{9} \text { LnRanch }+\beta_{10} \text { LnRusticHa }+\beta_{11} \text { LnGDP }+\beta_{12} \text { LnLivestock } \\
& +\beta_{13} \text { I.replacement }+\beta_{14} \text { LnDebtHab }+\epsilon
\end{aligned}
$$

The obtained results for each model are shown in Table 2. For the General Model, the variables that show a negative relationship with the number of wildfires are density, per-capita gross income, active population index, plot value, and the relation between lone buildings and nucleus. In the same way, the population over age 64, masculinity index, and proportion of foreigners have a positive relationship with the number of wildfires. For the North Model, the variables per-capita gross income and the relation between lone buildings and nucleus show a negative relationship with the number of wildfires, while the population over 64 and gross domestic product (GDP) have a positive relationship. Finally, in the South Model, wildfires show a negative relationship with density and active population index, and a positive relationship with the population over 64 and the masculinity index. 
Table 2. Empirical results of the model. Dependent variable: number of wildfires.

\begin{tabular}{|c|c|c|c|c|c|c|}
\hline \multirow{2}{*}{$\begin{array}{l}\text { Independent } \\
\text { Variables }\end{array}$} & \multicolumn{2}{|c|}{ General Model } & \multicolumn{2}{|c|}{ North Model } & \multicolumn{2}{|c|}{ South Model } \\
\hline & $\begin{array}{c}\text { Coefficients } \\
(\beta)\end{array}$ & $p$ Value & $\begin{array}{c}\text { Coefficients } \\
(\beta)\end{array}$ & $p$ Value & $\begin{array}{c}\text { Coefficients } \\
(\beta)\end{array}$ & $p$ Value \\
\hline Constant & -931.816 & 0.002 & -1207.57 & 0.000 & -1750.38 & 0.000 \\
\hline LnPopulation $>64$ & $189.671^{* * *}$ & 0.000 & $132.692 * * *$ & 0.000 & $273.830^{* * *}$ & 0.000 \\
\hline LnDensity & $-212.140^{* * *}$ & 0.000 & -19.9101 & 0.573 & $-273.462 * * *$ & 0.000 \\
\hline IncCap & $-0.0584683^{* * *}$ & 0.000 & $-0.0394832^{* * *}$ & 0.000 & -0.0223893 & 0.264 \\
\hline I.Masculinity & $5.68822 * *$ & 0.010 & 1.71407 & 0.369 & $13.1212 * * *$ & 0.000 \\
\hline I.active & $-3.11713 *$ & 0.051 & -1.26194 & 0.384 & $-3.55956 *$ & 0.079 \\
\hline LnP.Foreign & $53.7118^{* * *}$ & 0.002 & -12.8223 & 0.291 & 50.9607 & 0.121 \\
\hline LnParcelVal & $-60.4937^{* * *}$ & 0.001 & 4.24432 & 0.850 & -36.5176 & 0.194 \\
\hline LnDisCenter & $-30.7492 * * *$ & 0.001 & -14.9480 * & 0.063 & 15.6403 & 0.379 \\
\hline LnRanch & 35.4466 & 0.138 & -21.3153 & 0.527 & 33.6097 & 0.158 \\
\hline LnRusticHa & -275.325 & 0.119 & 95.0943 & 0.659 & -223.834 & 0.114 \\
\hline LnGDP & 52.6489 & 0.119 & $46.6009 * *$ & 0.011 & -17.6842 & 0.766 \\
\hline LnLivestock & -2.94676 & 0.846 & 27.7159 & 0.194 & 10.2266 & 0.546 \\
\hline I.replacement & 0.108139 & 0.714 & -0.0719371 & 0.863 & -0.207825 & 0.523 \\
\hline LnDebtHab & 27.3305 & 0.676 & 47.9772 & 0.549 & -2.70796 & 0.972 \\
\hline$R^{2}$ & \multicolumn{2}{|c|}{0.421} & \multicolumn{2}{|c|}{0.547} & \multicolumn{2}{|c|}{0.501} \\
\hline Sample size & \multicolumn{2}{|c|}{314} & \multicolumn{2}{|l|}{160} & \multicolumn{2}{|c|}{154} \\
\hline
\end{tabular}

\section{Discussion}

Table 2 shows the three models for the whole region (General Model), the north, and the south of Galicia. Thus, the differences in significance for each different model can be displayed.

The $\mathrm{R}^{2}$ values of the models can be considered representative, because a high predictive ability of the dependent variable in the General, North, and South models is achieved $(42.1 \%, 54.7 \%$, and $50.1 \%$, respectively). Therefore, the number of forest wildfires in Galicia has a high relationship with the socioeconomic variables that characterize the municipalities of this community, as the estimated models together are significant.

The only variable that keeps the significance at $1 \%$ in the three models is the "population over 64 years old", so it is one of the most explanatory variables of forest fires in Galicia.

The variables "population density" and "gross income per capita" are also significant at $1 \%$ for two of the models (the South and General models in the case of the "population density", and the North and General models in the case of "gross income per capita").

The "index of masculinity", meanwhile, is significant at $1 \%$ in the South Model, and at $5 \%$ in the General Model.

The "proportion of the assessed value by cadastral holder", the "proportion of scattered/core", and the "proportion of foreign" are only significant at $1 \%$ in the case of the General Model, while the "proportion of scattered/core" is $10 \%$ in North Model.

When analyzing the coefficients $(\beta)$ sign, the relations, direct or inverse, with the dependent variable, the "number of wildfires", are the same for all three models. More details are set out below:

- There is an inverse relationship among "density", "gross income per capita," the "active population index", the "plot value per holder", and the "proportion of scattered/cores", indicating that the lower the value of these variables, the greater the number of wildfires. In the case of the "active population index", if the value decreases, it means a more aged population. In the case of property value, a decrease means that the plots are less valuable. As to the ratio "scattered/cores", a decrease in its value shows that there are fewer scattered areas and subsequently more wildfires; this is related to the forestry-urban interface fields (transition lands) associated with population centers. 
- The relationship is direct to "population over 64 years," which clearly shows that there are more wildfires within aging population environments; this relies on burning-land traditions and cultural habits, a lower level of education and, in particular, a higher vulnerability. These territories also present a higher "masculinity index", since there has been a historical female abandonment of rural areas; as a result, the population density is lower. The positive association between wildfire numbers and the rate of foreign population could be connected with their higher presence in vulnerable areas with lower incomes, precarious services, exclusion factors, etc. A positive GDP ratio (higher GDP, means more wildfires) would be explained by the existence of a larger number of urban cores. This means higher municipality richness, and consequently, the existence of more forestry-urban interface, and a higher likelihood of wildfires.

These data show clear differences between the North and South models. So, a lesson to learn is that the fire-fighting actions that are to be carried out must be different depending on the municipality geographical location. While in the north, the economic aspects should be more considered in more depth, in the south, it would be necessary to delve into the social and demographic aspects. Indeed, this does not mean that all of the community problems cannot be solved with community activities.

Within the population and social variables, the strong positive relationship between the aging population and the increasing number of wildfires is remarkable, as is the strong negative relationship between density and wildfires: the lower the population, more wildfires occur because of an abandonment of the territory. These two variables together reflect that depressed areas, with higher aging rates, produce higher number of wildfires. In these areas, there is also a greater number of foreigners with fewer resources and lower incomes. In addition, a reduction in the cadastral value of plots occasions an abandonment of land, which in turn favors the number of fires.

\section{Conclusions}

The object of this paper is to establish the relationship between socioeconomic aspects that reflect the reality of the Galician municipalities and the number of forest fires between 2001-2015. The ultimate goal of our work is to identify those socioeconomic issues for achieving a greater impact on prevention actions.

At this point, the most explanatory variables in our model are an aged population and low population density; the community actions of the competent authorities should take into account the negative connotation of both variables on the intervention action planning. This is difficult in the short term, but a greater impact on improving rural life quality in these areas predictably would alter these variables positively toward their relation to forest fires. By promoting the participation and improvement of education, the variables that influence the occurrence of wildfires could be modified, changing the beliefs and activities linked to aged populations with lower levels of education. The need to establish models of sustainable development is detected, taking into account the social aspects that stand out as a cause of forest wildfires.

Regarding those dimensions related to the territory, the use of biomass has been carried out in Galicia, but the design of criteria that guarantee their sustainability still remains open. Avoiding ground affections and competition with other sectors such as livestock and agriculture would also help give value to the forest. These measures would help increase the plots' cadastral value and, as shown by the results, would lower the occurrence of wildfires. Synergies should be encountered between agroforestry mosaics systems and holding investments. All of these measures are ultimately targeted to the quality improvement of life in rural areas, influencing variables such as population density and income per capita. Adding value to the land would help people change their perception of forest resources, and therefore could reduce wildfires.

Looking not to lose the forest value, a priority is to increase spending on prevention and elaborate long-term strategies. It is also necessary to restore damaged areas to prevent further deterioration in later adverse environmental conditions. The most efficient way to maintain economic, social, and environmental functions of an area is through trying to emphasize their importance before the 
occurrence of an event. By including social variables as a cause of the wildfires, authorities can insist on reducing these. It is important to emphasize the most meaningful variables related to wildfire production and carry out actions designed for their reduction (for instance, managing the wildland-urban interface areas, which are related to variables such as the ratio scattered/cores and GDP). It is also important to improve working conditions for women in rural areas, in order to reduce the masculinity index, and therefore increase the population density.

The works carried out on prevention and extinction are the responsibility of public institutions. Although in Spain, the central government is responsible for basic legislation and public policy design, competences have been transferred to the autonomous communities. It is necessary to involve local bodies for the better management of natural hazards and specifically for forest wildfires, taking into account the socioeconomic variables that affect each. Therefore, it is important to establish the differences between existing social groups in a given area, analyze the exposure and risk involved, and educate these social groups. As it has been seen throughout the study, it is important to take into account the differences between northern and southern Galicia, working on the most important variables in each area. This will ensure that the actions are more efficient and better results against wildfires are achieved.

Changes should be planned for the mid-long term, promoting interactions between different population sections and age cohorts directed to influence certain harmful traditional behaviors associated with aging societies. This would make it possible to improve the labor force turnover rate and demographic structure. One of the great pending challenges is to establish unity among all the factors involved in a wildfire, from prevention to extinction, understanding their behavior and minimizing their effects.

The relevance of the findings of this paper, which establish a relationship between socioeconomic variables and the number of wildfires, must be considered by technical authorities and policymakers. It is not only necessary to act on climate, environmental, and natural issues when it comes to reducing the risk of occurrence. Actions must also affect all of the aspects that influence the risk of occurrence. Authorities must develop strategies that are complementary to prevention efforts, where these variables representing social vulnerability (such as aspects of exclusion, low income, or aging) are mitigated. The existing research shows this relationship, and therefore highlights an existing problem in society. Its severity can be reduced through strategies and policies that will have their effect in the long and mid-term.

In short, we have demonstrated the influence of social variables on the production of wildfire. Therefore, by working on these issues, the occurrence of anthropogenic wildfires could be reduced.

\section{Future Research Lines and Limitations}

The main limitation of the research is related to the data. Some very important variables in the socioeconomic sphere have not been selected because of the difficulty of obtaining them at the municipal level. In addition, it is very difficult to obtain prevention and extinction spending data, even making a request to different Galician agencies. We should also mention that another limitation comes from the inability of the model to predict indirect relationships between variables, although this leads us directly into the future course of our investigation.

In order to deepen the relations established between socioeconomic variables and forest fires, a structural equation model (SEM) will be elaborated. This is a multivariate statistical technique for testing and estimating causal relationships from statistical data. SEM allows drawing qualitative assumptions on causality, developing different constructs by the data. The behaviors of the variables in the linear regression deserve to be studied more precisely. It is necessary to establish the intensity of relations, their direction, and more importantly, establish direct and indirect correlations between variables, in order to create constructs. These constructs will be composed of interrelated economic, climatological, environmental, or social variables. We propose a more precise way to study social 
vulnerability and its effect on forest fires, and investigate whether reducing vulnerability in all its components can reduce the risk of wildfire more efficiently.

Author Contributions: All the author of this article has contributed in the elaboration and designing of the model. They also collaborate in the writing of the main body of the paper.

Funding: This research was funded by Fundación AON España (http:// fundacionaon.es/).

Conflicts of Interest: The authors declare no conflict of interest.

\section{References}

1. Ager, A.; Evers, C.; Day, M.; Preisler, H.; Barros, A.; Nielsen-Pincus, M. Network analysis of wildfire transmission and implications for risk governance. PLoS ONE 2017, 12, e0172867. [CrossRef] [PubMed]

2. Haynes, K.; Handmer, J.; Mcaneney, J.; Tibbits, A.; Coates, L. Australian bushfire fatalities 1900-2008: Exploring trends in relation to the 'Prepare, stay and defend or leave early' policy. Environ. Sci. Policy 2010, 13, 185-194. [CrossRef]

3. Hernández, L. Dónde arden nuestros bosques. Análisis y Soluciones de WWF 2016, 1, 64. Available online: http:/ / awsassets.wwf.es/downloads/dondeardennuestrosbosques2016.pdf (accessed on 22 April 2018).

4. Padilla, M.; Vega-García, C. On the comparative importance of fire danger rating indices and their integration with spatial and temporal variables for predicting daily human-caused fire occurrences in Spain. Int. J. Wildland Fire 2011, 20, 46-58. [CrossRef]

5. Kocher, S.; Butsic, V. Governance of Land Use Planning to Reduce Fire Risk to Homes Mediterranean France and California. Land 2017, 6, 24. [CrossRef]

6. Murphy, B. Enhancing Local Level Emergency Management: The Influence of Disaster Experience and the Role of Households and Neighborhoods; ICLR Research: Toronto, ON, Canada, 2005

7. Ley 43/2003, de 21 de noviembre, de Montes. BOE» núm. 280, de 22/11/2003. BOE-A-2003-21339. Available online: https://www.boe.es/eli/es/1/2003/11/21/43/con (accessed on 16 May 2018).

8. Bentley, P.D.; Penman, T.D. Is there an inherent conflict in managing fire for people and conservation? Int. J. Wildland Fire 2017, 26, 455. [CrossRef]

9. Del Moral Ituarte, L.; Pita López, M.F. El papel de los riesgos en las sociedades contemporáneas. In Riesgos Naturales; Ayala-Carcedo, F.J., Olcina Cantos, J., Eds.; ARIEL: Barcelona, Spain, 2002; pp. 75-86.

10. Birkmann, J. Measuring Vulnerability to Natural Hazards: Towards Disaster Resilient Societies, 2nd ed.; United Nation University Press: Tokyo, Japan; New York, NY, USA, 2013.

11. Donner, W.; Rodríguez, H. Population Composition, Migration and Inequality: The Influence of Demographic Changes on Disaster Risk and Vulnerability. Soc. Forces 2008, 87, 1089-1114. [CrossRef]

12. Bergstrand, K.; Mayer, B.; Brumback, B.; Zhang, Y. Assessing the Relationship between Social Vulnerability and Community Resilience to Hazards. Soc. Indic. Res. 2015, 122, 391-409. [CrossRef] [PubMed]

13. Ashe, B.; Mcaneney, K.J.; Pitman, A.J. Total cost of fire in Australia. J. Risk Res. 2009, 12, 121-136. [CrossRef]

14. Elliott, J.R.; Pais, J. When Nature Pushes Back: Environmental Impact and the Spatial Redistribution of Socially Vulnerable Populations. Soc. Sci. Q. 2010, 91, 1187-1202. [CrossRef]

15. Molina, J.; Rodríguez, Y.; Silva, F.; Herrera, M. Economic vulnerability of fire-prone landscapes in protected natural areas: Application in a Mediterranean Natural Park. Eur. J. For. Res. 2017, 136, 609-624. [CrossRef]

16. Iyalomhe, F. Understanding developing countries vulnerability and adaptation to climate change using theoretical change vulnerability framework. Afr. J. Comput. ICT 2011, 4, 33-40.

17. Sharma, S.; Pant, H. Vulnerability of Indian Central Himalayan Forests to Fire in a Warming Climate and a Participatory Preparedness Approach Based on Modern Tools. Curr. Sci. 2017, 112, 2100. [CrossRef]

18. Cirella, G.T.; Iyalomhe, F.O.; Russo, A. Vulnerability and risks related to climatic events in urban coastal environments: Overview of actuality and challenges of methodologies and approaches. J. Urban Plan. Landsc. Environ. Des. 2016, 1, 67.

19. Wisner, B.; Blaikie, P.; Cannon, T.; Davis, I. At Risk: Natural Hazards, People's Vulnerability and Disasters, 2nd ed.; Routledge: New York, NY, USA, 2004; 471p, ISBN 0415-252164.

20. Morrow, B.H. Identifying 3nd Mapping Community Vulnerability. Disasters 1999, 23, 1-18. [CrossRef]

21. Fogel, S.J. Reducing Vulnerability for Those Who Are Homeless during Natural Disasters. J. Poverty 2017, 21, 208. [CrossRef] 
22. Alonso Climent, I. Tercer mundo, desarrollo, desastres y tecnología. Una mirada desde la geografía. Ser. Geográfica 2002, 10, 11-26.

23. Ballart, H.; Vázquez, I.; Chauvin, S.; Gladine, J.; Plana, E.; Font, M.; Serra, M. La comunicación del riesgo de incendios forestales. Recomendaciones operativas para mejorar la prevención social; Projecte eFIRECOM (DG ECHO 2014/PREV/13); Ediciones CTFC: Boadilla del Monte, Spain, 2016; 30p.

24. Martínez-Fernández, J.; Chuvieco, E.; Koutsias, N. Modelling long-term fire occurrence factors in spain by accounting for local variations with geographically weighted regression. Nat. Hazards Earth Syst. Sci. 2013, 13, 311-327. [CrossRef]

25. Paveglio, T.B.; Edgeley, C.M.; Stasiewicz, A.M. Assessing influences on social vulnerability to wildfire using surveys, spatial data and wildfire simulations. J. Environ. Manag. 2018, 213, 425-439. [CrossRef]

26. Moreno, J.M. Evaluación Preliminar de los Impactos en España por Efecto del Cambio Climático. Boletín CF+S 38/39. 2014. Available online: http://polired.upm.es/index.php/boletincfs/article/view/2617/2683 (accessed on 11 September 2018).

27. Crompton, R.; Mcaneney, J.; Chen, K.; Pielke, R.; Haynes, K. Influence of Location, Population, and Climate on Building Damage and Fatalities due to Australian Bushfire. Weather. Soc. 2010, 2, 300-310. [CrossRef]

28. Bouillon, C.; Fernandez Ramiro, M.M.; Sirca, C.; Fierro Garcia, B.; Casula, F.; Vila, B.; Long Fournel, M.; Pellizzaro, G.; Arca, B.; Tedim, F.; et al. A tool for mapping rural-urban interfaces on different scales. Adv. For. Fire Res. 2014. [CrossRef]

29. Stein, S.M.; Menakis, J.; Carr, M.A.; Comas, S.J.; Stewart, S.I.; Cleveland, H.; Bramwell, L.; Radeloff, V.C. Wildfire, Wildlands, and People: Understanding and Preparing for Wildfire in the Wildland-Urban Interface-A Forests on the Edge Report; Gen. Tech. Rep. RMRS-GTR-299; Department of Agriculture, Forest Service, Rocky Mountain Research Station: Fort Collins, CO, USA, 2013; 36p.

30. Balsa Barreiro, J.; Hermosilla, T. Socio-geographic analysis of the causes of the 2006's wildfires in Galicia (Spain). For. Syst. 2013, 22, 497-509. [CrossRef]

31. Loureiro, M.; Barreal, J. Modelling spatial patterns and temporal trends of wildfires in Galicia (NW Spain). For. Syst. 2015, 24, e022. [CrossRef]

32. San-Miguel-Ayanz, J.; Durrant, T.; Boca, R.; Libertà, G.; Branco, A.; de Rigo, D.; Ferrari, D.; Maianti, P.; Artés, T.; Costa, H.; et al. Forest Fires in Europe, Middle East and North Africa 2017; EUR 29318 EN; Publications Office of the European Union: Luxembourg, 2018; ISBN 978-92-79-92831-4. [CrossRef]

33. Barreal, J.; Loureiro, M.; Picos, J. Estudio de la incidencia de los incendios en Galicia: Una perspectiva socioeconómica. Revista Galega de Economía 2011, 20. Available online: https:/ / www.redalyc.org/comocitar. oa?id=39121275013 (accessed on 14 March 2018).

34. Rigueiro, A.; Mosquera, M.R.; López, L.; Pastor, J.C.; González, M.P.; Romero, R.; Villarino, J.J. Reducción del riesgo de incendios forestales mediante el pastoreo del caballo gallego de monte. Cuadernos de la Sociedad Española de Ciencia Forestal 2002, 14, 115-118.

35. Barreal, J.; Loureiro, M.; Picos, J. Estudio de la causalidad de los incendios forestales en Galicia. Economia Agraria y Recursos Naturales 2012, 12, 101-116. [CrossRef]

36. COSE Selvicultores. Informe: El problema actual de los incendios forestales en Galicia. Informe de la Confederación de Organizaciones de Selvicultores de España 2015, 1, 40. Available online: https://studylib.

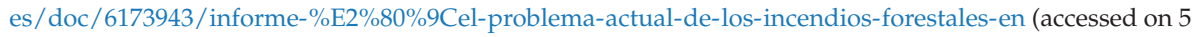
April 2018).

37. Galiana Martín, L. Las interfaces urbano-forestales: Un nuevo territorio de riesgo en España. Boletín de la Asociación de Geógrafos Españoles 2012, 58, 205-226. [CrossRef]

38. PLADIGA 2018. Memoria. Plan de Prevención e Defensa Contra os Incendios Forestais de Galicia; Xunta de Galicia, Consellería do Medio Rural: Santiago, Spain, 2018.

39. Vilariño, J.P. Desarrollo corporativo del sector forestal. Agricultura y Sociedad 1998, 85, 15-42.

40. Consejo Económico y Social (CES). Informe 01/2018, El medio rural y su vertebración social y territorial; Consejo Económico y Social: Madrid, Spain, 2018; Número 01; ISBN 978-84-8188-374-9. 
41. Wigtil, G.; Hammer, R.B.; Kline, J.D.; Mockrin, M.H.; Stewart, S.I.; Roper, D.; Radeloff, V.C. Places where wildfire potential and social vulnerability coincide in the coterminous United States. Int. J. Wildland Fire 2016, 25, 896. [CrossRef]

42. Fisher, F.M. Tests of equality between sets of coefficients in two linear regressions. Econometrica 1970, 38, 361-366. [CrossRef]

(C) (1) BY
(C) 2019 by the authors. Licensee MDPI, Basel, Switzerland. This article is an open access article distributed under the terms and conditions of the Creative Commons Attribution (CC BY) license (http:/ / creativecommons.org/licenses/by/4.0/). 



\title{
Article \\ Scale-Free Relationships between Social and Landscape Factors in Urban Systems
}

\author{
Chunzhu Wei *, Mark Padgham, Pablo Cabrera Barona and Thomas Blaschke \\ Department of Geoinformatics_Z__GIS, University of Salzburg, Schillerstrasse 30, 5020 Salzburg, Austria; \\ mark.padgham@sbg.ac.at (M.P.); pablo.cabrera-barona@stud.sbg.ac.at (P.C.B.); Thomas.Blaschke@sbg.ac.at (T.B.) \\ * Correspondence: weichunzhuzhu@gmail.com; Tel.: +43-662-8044-7553 \\ Academic Editor: Giuseppe T. Cirella \\ Received: 20 October 2016; Accepted: 4 January 2017; Published: 9 January 2017
}

\begin{abstract}
Urban planners and ecologists have long debated the relationship between the structure of urban landscapes and social activities. There have, however, been very few discussions as to whether any such relationships might depend on the scales of observation. This work applies a hierarchical zoning technique to data from the city of Quito, Ecuador, to examine how relationships between typical spatial landscape metrics and social indicators depend on zoning scales. Our results showed that the estimates of both landscape heterogeneity features and social indicators significantly depend on the zoning scale. The mean values of the typical landscape metrics and the social indicators all exhibited predictable responses to a changing zoning scale, suggesting a consistent and significant scaling relationship within the multiple zoning scales. Yet relationships between these pairs of variables remain notably invariant to scale. This quantitative demonstration of the scale-free nature of the relationship between landscape characteristics and social indicators furthers our understanding of the relationships between landscape structures and social aspects of urban spaces, including deprivation and public service accessibility. The relationships between social indicators and one typical landscape aggregation metric (represented as the percentage of like adjacencies) were nevertheless significantly dependent on scale, suggesting the importance of zoning scale decisions for analyzing the relationships between the social indicators and the landscape characteristics related with landscape adjacency. Aside from this typical landscape aggregation metric, the general invariance to the zoning scale of relationships between landscape structures and socioeconomic indicators in Quito suggests the importance of applying these scale-free relationships in understanding complex socio-ecological systems in other cities, which are shaped by the conflated influences of both anthropogenic and natural factors. Moreover, this scale-free behavior of landscape-social relationships challenges the traditional modifiable area unit problem, and provides mechanistic insight into the conflicts and compatibilities between human activities and human-induced land use change.
\end{abstract}

Keywords: modifiable area unit problem; landscape spatial metrics; deprivation; healthcare accessibility; education accessibility; scale-free behavior; urban complex systems

\section{Introduction}

Spatial urban landscape metrics provide quantitative insights into complex natural systems, and are often used to characterize the heterogeneity of urban landscape composition and associated ecological processes [1-6]. Landscape ecologists and urban planners have long debated potential relationships between spatial patterns of urban development and ecological conditions, including the validity of spatial landscape metrics for purposes such as monitoring urban land use and sustainable urban planning [7-9]. Spatial landscape metrics can not only quantify ecological processes reflecting urban environmental change, but are also able to provide evidence of potential mechanisms linking 
urban form to social function. Furthermore, they can offer valuable insights into the resource distribution of urban socio-ecological systems by determining the distributional characteristics of energy, materials, or other properties [10-12]. Configurational characteristics may also influence demographic processes such as population growth, household locations, and migration [13]. Different landscape structures may lead to differences in economic development as a result of household income disparities [14]. The size of a single district within a city may influence gentrification processes of surrounding neighborhoods and result in the development of hierarchical structures that both promote and reflect differences in levels of accessibility to public services such as education or health $[14,15]$. Many previous studies that have examined the relationships between landscape configuration and social aspects such as urban poverty, health, or socioeconomic vulnerability [16-19] have done so on a qualitative level, yet often without quantitatively discussing how urban spatial metrics (such as composition or configuration) might characterize and influence social indicators. A truly integrative approach to identifying urban environmental heterogeneity demands that we address the quantitative relationships between urban spatial metrics and social activities, in order to provide concrete and meaningful knowledge for geographically contextualized urban planning, design, and management [20-22].

Spatial landscape metrics are useful for quantitatively describing and representing the heterogeneity of urban spaces. However, heterogeneity is also a function of scale [23-26], and the use of districts or blocks of fixed sizes is problematic for quantifying spatial landscape metrics. Several studies have clearly demonstrated that spatial metrics of community organization or landscape complexity differ with scale and scope $[1,27,28]$. This dependence of landscape heterogeneity on the scale of the zones used for its quantification reflects the well-known modifiable areal unit problem (MAUP) [29-31]. New technologies for user-controlled and flexible zoning schemes offer a practical solution to the MAUP. Automated zoning procedures, in particular, have been proposed to offer efficient, systematic, and objective methodologies for identifying functional zones based on social indicators such as population size, deprivation, or health [32-34]. Nevertheless, such zoning procedures still ignore more general issues of the representability of spatial landscape heterogeneity characteristics, especially in regard to whether or not a given set of boundaries makes any sense in relation to the spatial landscape metrics and processes relevant to the social activities that they represent.

One of the most powerful ways to understand the influence of landscape structures on socio-political processes is through cross-scale comparisons, as has been demonstrated by the relationships between spatial landscape metrics and socioeconomic indicators such as health outcomes, urban accessibility, and other social processes used to support social planning $[35,36]$. The present study therefore implements a hierarchical zoning strategy to analyze how quantitative relationships between spatial landscape metrics and social activities change across scales.

\section{Study Area and Data Collection}

Urban sprawl occurs around the world, and Latin America in particular is characterized by rapid urban growth and high inequality in terms of public services accessibility and other socioeconomic variables [37]. The capital city of Ecuador, Quito, is a representative example of how Latin American cities have faced significant growth in the last decades. The city has extended approximately $35 \mathrm{~km}$ in length and its suburban areas now occupy lands that only a few years ago were rural and agricultural areas. According to the Ecuadorian Institute of Statistics and Census, more than 1.5 million inhabitants live in Quito and its surrounding urban areas (Figure 1). However, considering the whole metropolitan district, including rural areas, the population is over 2 million. Some illegal constructions have gradually emerged in the peripheral areas of the city, mainly on the hills and steep lands. This dynamic landscape structure has generated obvious urban segregation in terms of social deprivation and public service inequality. It is thus worth investigating how the landscape structure characteristics differ in their corresponding social indicators connected to the urban environment. 


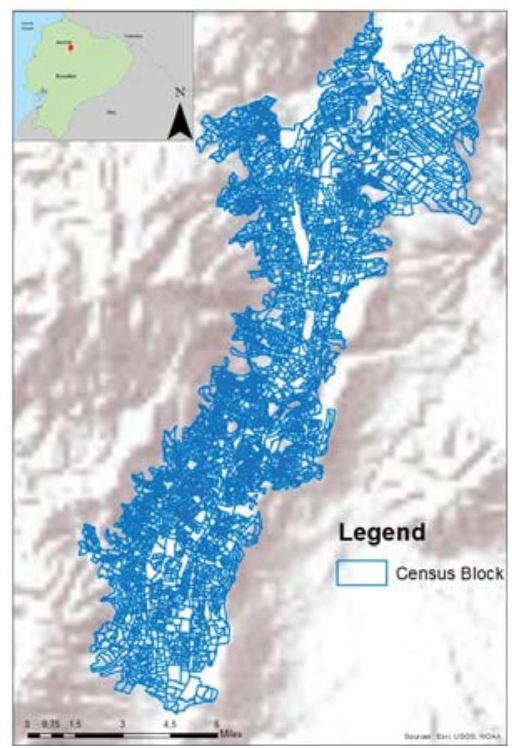

Figure 1. The study area.

Following a rights-based perspective of quality of life [38,39], good access to urban services is indispensable to ensure good conditions/prerequisites for quality of life. Keeping this in mind, we did a thorough and succinct literature review [39-47] and selected three indicators (deprivation, accessibility to healthcare services, and accessibility to educational services) to characterize the socioeconomic situation in Quito. These indicators support the identification of social inequalities and segregation with important implications for the sustainability and quality of life of a city $[38,43,47]$. We used data from 5000 census blocks, extracted from the 2010 Ecuadorian Population and Housing Census, as well as information regarding the locations of health and educational services, provided by the Ecuadorian Ministry of Health and the Ecuadorian Ministry of Education, respectively. Since all these indicators are elementary indicators based on census blocks (dissemination areas), our methodology is also transferable and may be applied to other Latin American cities. In addition, land survey data and 2010 Rapid Eye satellite data for Quito were provided by the Ecuadorian Ministry of Environment, and were used to extract information on land use and land cover (LULC). Spatial landscape metrics were estimated based on this LULC information.

\section{Methods}

We implement a hierarchical framework (shown in Figure 2) based on the combination of land use and land cover data with census data to explore how the zoning scale might influence the relationships between landscape heterogeneity features and the chosen social indicators. Four metrics of landscape configuration (including Shannon's Diversity metric, Number of Disjunct Core Areas metric, Proportion of Like Adjacencies metric, Fractal Dimension metric) are described first, followed by methods for analyzing and aggregating three social factors (including deprivation, healthcare accessibility, and education accessibility). Finally, this research describes how social and landscape measures were combined within the automated zoning analysis and how the relationships between the spatial landscape metrics and social factors vary between different zoning scales. Integrating the concept of multiple zoning scales into the urban landscape-social relationships analysis is central to this framework, and it is important to investigate the multi-scale neighborhood effects on the complex urban system. 


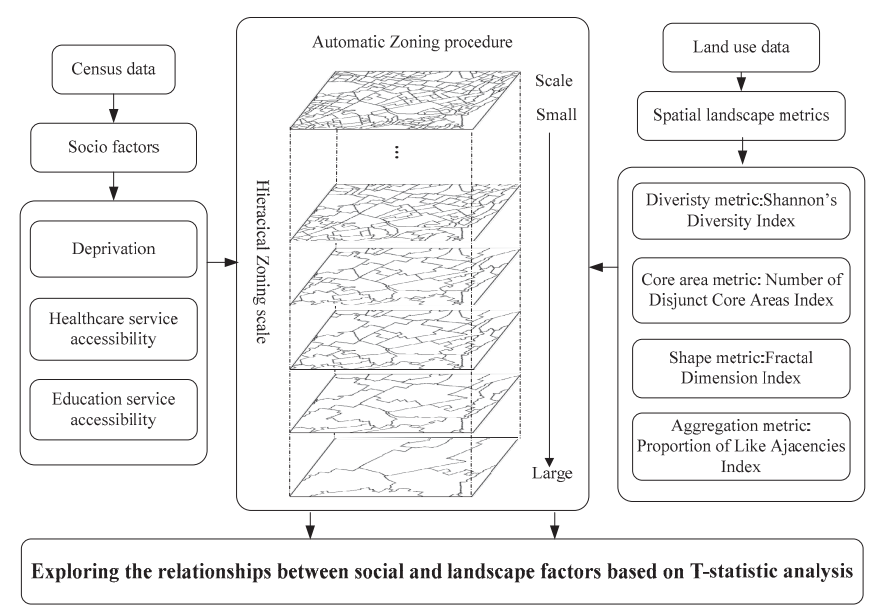

Figure 2. The framework of landscape-social relationships analysis within multi-level zoning systems.

\subsection{Analysis of Landscape Spatial Metrics}

Categories of land use and land cover for Quito included residential areas, multi-type residential areas, industrial areas, cultivated areas, water areas, and vegetated areas including grass, eucalyptus, shrubbery, mountain shrubs, soil, and other vegetation cover.

The configurational properties of these different LULC classes were quantified using free Fragstats software (University of Massachusetts Amherst, Amherst, MA, USA) [48]. Fragstats quantifies landscapes in terms of both configuration and composition, with configuration further quantified in terms of the shape, area, and aggregation properties. For each of these four categories, we selected the single metric that most strongly correlated with all other metrics within that category. For the composition this was the Shannon's diversity index (SHDI); for the shape this was the area-weighted mean patch fractal dimension index (FRAC_AM); for the core area it was the number of disjunct core areas (NDCA), and for aggregation it was the proportion of like adjacencies (PLADJ). Shannon's diversity metric (SHDI; correlation with other aggregation metrics $\geq 0.8$ ) reflects the landscape composition rather than the spatial configuration, and quantifies the amount of 'information' per individual landscape patch. The fractal dimension index (FRAC_AM; correlation with other shape metrics $\geq 0.355$ ) equals the sum of the corresponding patch fractal dimension values multiplied by the proportional abundance of the patch. The number of disjunct core areas (NDCA; correlation with other core area metrics $\geq 0.32$ ) quantifies how many small patches within a given interior belong to a large patch. The proportion of like adjacencies (PLADJ; correlation with other aggregation metrics $\geq 0.505$ ) computes the sum of the diagonal elements of the adjacency matrix divided by the total number of adjacencies in such a way that landscapes containing greater local aggregations of patch types (for example, by having larger patches with compact shapes) will contain a higher proportion of like adjacencies than landscapes containing disaggregated patch types.

\subsection{Social Indicators Estimation}

We used census data and the location of healthcare and educational services to estimate three social indicators that are reflective of more general yet intangible societal processes: a composite indicator of deprivation (DP); and indicators of accessibility to healthcare services (DH) and educational services (DE).

The composite indicator of deprivation was measured by combing four simple indicators: (1) the percentage of houses without access to the sewerage system; (2) the percentage of houses 
without a connection to the electrical system; (3) the percentage of houses without a connection to the drinking water supply system, and (4) the percentage of houses without a garbage collection service. These indicators were chosen because they are related to basic human needs, represent social disadvantages, and can be related to health issues [38,39,47,49-51]. Information pertaining to these indicators was extracted from the 2010 Ecuadorian Population and Housing Census.

The deprivation information was geocoded in census tracts and compiled in the shapefile of the study areas. The variance inflation factors (VIFs) for all indicators confirmed no strong co-linearities between the selected indicators, enabling them all to be used in the composite indicator of deprivation, constructed by adding the four indicators and normalizing the result to the unit scale. The final composite indicator of deprivation then has values between 0 and 1 , where values closer to 1 represented higher levels of social deprivation.

The accessibility indicators (to both health and educational services) were calculated in terms of Euclidean distances between the centroids of each census block and the location points representing the nearest healthcare or educational services.

\subsection{AZPTool-Automatic Zoning Software}

The automatic zoning procedure (AZP) (University of Southampton, UK) was developed by Openshaw [31] to explore scale and aggregation effects on the choice of zonal boundaries. This was extended by Martin [33], who developed an automated zone matching (AZM) algorithm that iteratively combines target population sizes, zonal compactness and other variables into the zone design process. This study used the AZTool system, based on the AZM algorithm, which has the advantage of minimizing the mismatch between different zones [33,52]. We created zones that maximized the internal homogeneity of independent variables. This regionalization algorithm is a heuristic procedure involving the following steps [30-33]:

- $\quad$ Step 1. Select zone design options and targets.

(i) Set the threshold variable which can indicate the homogeneity of the boundary;

(ii) Set the minimum and maximum threshold of target value $M$ to randomly generate $M$ small zones from the original zoning system $N(M<N)$;

(iii) Set the iteration number to control the regionalization process.

- $\quad$ Step 2. List the $M$ regions.

- $\quad$ Step 3. Randomly select and remove any region from this list.

- $\quad$ Step 4. Identify zones that border members of region $K$ that could be moved into region $K$ while maintaining the internal contiguity of the donor region(s).

- Step 5. Select zones randomly until one of the following conditions is met: (1) there is a local improvement in the current value of the objective function (seen Formula (1) and (2)); (2) a move that is at least as good as the current best. Then repeat step 5 until the list ends.

- Step 6. When the list for region $K$ is exhausted return to step 3, select another region, and repeat steps 4-6.

- Step 7. Repeat steps 2-6 until no further improvement can be made or a maximum number of iterations is reached.

The AZTool maximizes the internal homogeneity of zones as quantified by the parameterintra-area correlation (IAC). The IAC depends on the variable $\partial_{k}$, which is the contribution of category $k$ to the IAC (shown in Equation (1)):

$$
\partial_{k}=\frac{\frac{1}{M-1} \sum_{g=1}^{M} N_{g}\left(P_{g k}-P_{k}\right)^{2}}{\left(\bar{N}^{*}-1\right) P_{k}\left(1-P_{k}\right)}-\frac{1}{\left(\bar{N}^{*}-1\right)},
$$


where $M$ is the number of areal units in the original zoning system, $N_{g}$ is the value of the target threshold variable in the areal unit $g, \bar{N}^{*}$ is the mean of target threshold variable in the original zoning system, $P_{g k}$ is the value of homogeneity feature $k$ in the areal unit $g$, and $P_{k}$ is the overall mean of the homogeneity feature $k$. This formula is approximately the ratio of the area-level variance to the individual-level variance. Having calculated the intra-area correlations $\partial_{k}$ for each zoning variable, an overall intra-area correlation measure $\partial$ can be calculated as in Equation (2), which then provides a statistically valid measure with which to compare different zoning scales with different target features:

$$
\partial=\frac{1}{k-1} \sum_{k=1}^{K}\left(1-P_{k}\right) \partial_{k}
$$

Each potential modification to the zonal configuration is evaluated in terms of its marginal impact on ICA, and AZM provides various constraints and values for the control of zone design. In our study, the four spatial landscape metrics (FRAC_AM, NDCA, PLADJ, and SHDI) and the three social indicators (DP, DE, and DH) were chosen as the threshold variables to construct separate zoning schemes.

The choice of these design constraints and target values is subjective, but serves to ensure consistency between different zone design runs. Values were selected to achieve reasonably compact and hierarchical levels, in order to quantify the effect of the MAUP on resultant relationships in a consistent and reproducible way. Accordingly, the 5000 original census blocks were aggregated into six hierarchical levels containing 130, 420, 800, 1000, 2000, and 3500 zones.

\subsection{Statistical Tests}

We first tested the scale-dependence of the four landscape metrics and the three social indicators, hereafter referred to as landscape/social (LS) variables, by applying linear regressions to the logarithm of the zoning scale (quantified as the number of polygons listed above). The data for each scale were grouped into 130 evenly-spaced bins (equal to the number of points at the coarsest zoning level), so that regressions considered equal numbers of data points for each zoning level.

We then considered the mutual influences of other LS variables and zoning scales by performing multiple linear regressions (MLRs) between each pair of variables and including the zoning scale as an additional independent variable. For the $n=7$ variables, this involved $n(n-1) / 2=21$ MLRs, each of which had one landscape metric or social indicator as the dependent variable and two independent variables, namely the zoning scale and the other LS variable. The relative influences of the zoning scale and the other LS variables were then quantified by comparing T-statistics. The MLRs also considered potential interactions between scale and the other independent variables, with relative effects of interactions also quantified by associated $T$-statistics.

Finally, we examined whether the scale directly affects relationships between the different LS variables by calculating linear regressions of each pair of LS variables for each distinct zoning scale. As described in the first paragraph above, all variables had equal numbers of observations for each scale, enabling $T$-statistics from the linear regressions to be directly compared across scales. The $T$-statistics quantify the strength of the relationship between each pair of LS variables at each zoning scale. Linear regressions were subsequently performed through each series of $T$-statistics to ultimately quantify the extent to which relationships between each pair of variables were themselves dependent on the zoning scale. Relationships between LS variables for any given scale may not be significant, in which case the $T$-statistics may not be presumed meaningful. These subsequent regressions therefore considered only those $T$-statistics representing significant relationships at $p=0.05$. 


\section{Results}

\subsection{The Influences of the Zoning Effect on Landscape Metrics Estimation}

As shown in Figure 3a, the top three land use and land cover (LULC) types in Quito were residential areas, other green spaces, and mountain shrub areas, making up $46.38 \%, 12.53 \%$, and $11.28 \%$, respectively; industrial areas $(8.38 \%)$, shrub areas $(7.1 \%)$, multiple-use residential areas $(6.64 \%)$, grassland $(5.04 \%)$, eucalyptus $(1.82 \%)$, cultivated land $(0.66 \%)$, and bare soil $(0.15 \%)$ are the other LULC types, followed by water, which makes up the smallest percentage of the LULC with only $0.02 \%$. Residential areas are distributed all over the city of Quito, but are particularly concentrated in the northern area and the suburban area of the city. Industrial and commercial areas, as well as low-income residential areas are mainly concentrated in the southern part of Quito. Figure 3b provides an example of SHDI representations at seven zoning levels (130, 420, 800, 1000, 2000, 3500, and 5000) produced through the aggregation process in the original census blocks. The spatial pattern results of the SHDI in these five zoning scales, which range from 0 to 1.92, lead to very different spatial cluster distributions.

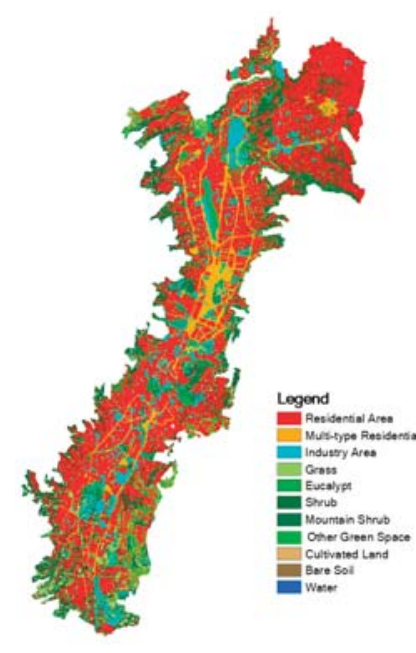

(a)

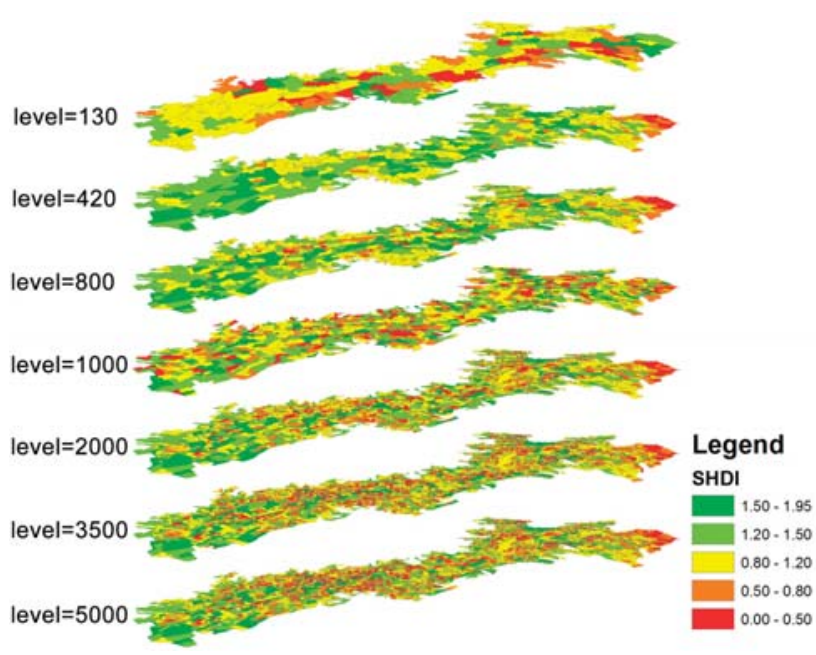

(b)

Figure 3. (a) LULC in Quito, 2012; (b) SHDI representations, with reporting units based on the multi-level zoning scales.

\subsection{Scale-Dependence of Landscape and Social Factors}

All four landscape metrics and all three social indicators were significantly dependent on the zoning scale (Figures 4 and 5, respectively). All relationships with the landscape metrics were highly significant $\left(p<10^{-10}\right)$. The notably low values of all strengths of relationship (given in the legend of Figures 4 and 5) reflect the fact that these spatial metrics vary to a far greater extent across the study area than they do across zoning scales; that is, spatial heterogeneity within each zone is far greater than systematic variation between zones. The high significance of all observed relationships nevertheless shows that the zonal scale does significantly influence all landscape and social indicators.

Finer zoning scales (that is, those containing a greater numbers of polygons) were associated with increases in both fractal dimension (FRAC_AM) and number of disjunct core areas (NDCA), yet with decreases in both landscape diversity (SHDI) and the proportion of like adjacencies (PLADJ). In contrast, all three social indicators (DE, DH, and DN) significantly decreased at finer zoning scales. 

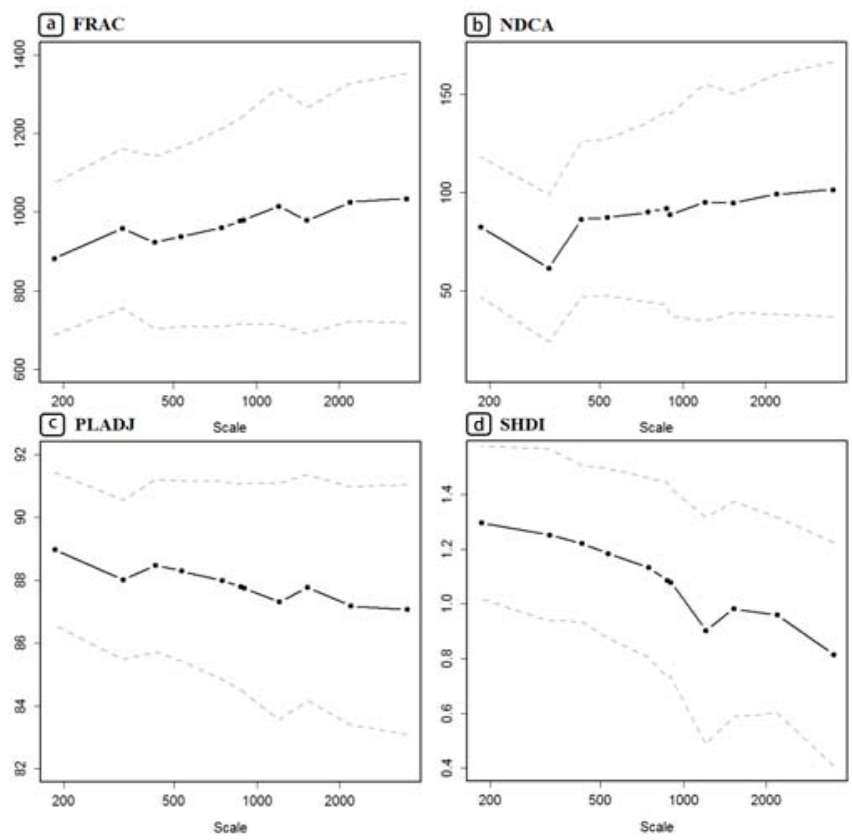

Figure 4. Relationships between four landscape metrics and the zoning scale (in terms of mean values in black + / - one standard deviation in gray).
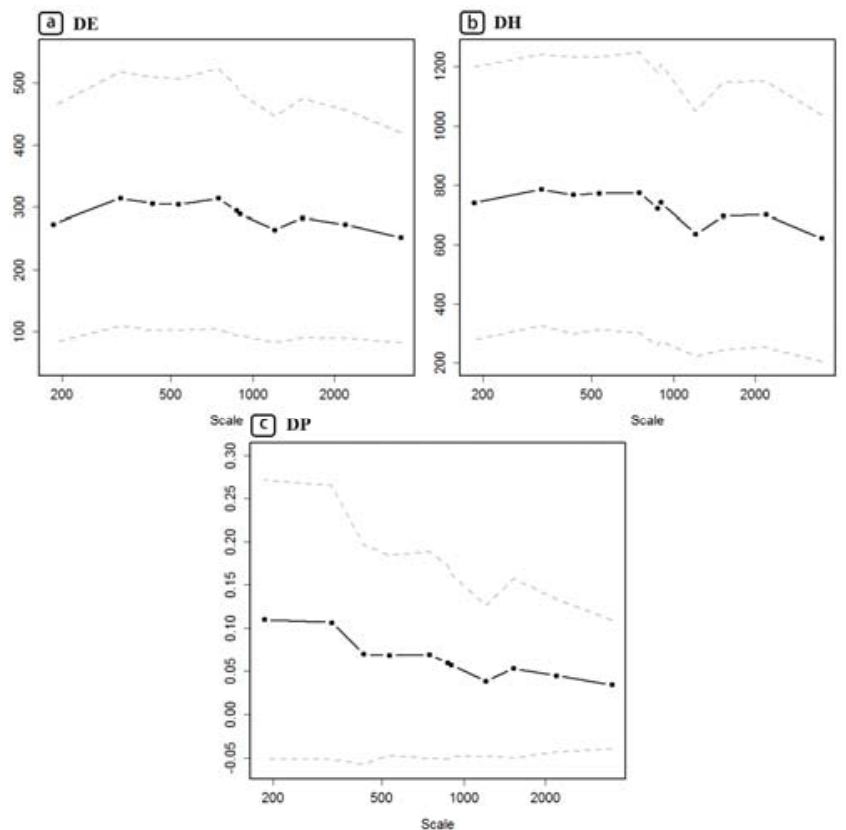

Figure 5. Relationships between three social indicators and the zoning scale (in terms of mean values in black + / - one standard deviation in gray). 


\subsection{The Mutual Influences of LS Variables and the Zoning Scale}

Multiple linear regressions (MLRs) for each landscape/social (LS) variable using both zoning scale and every other LS variable in combination yielded T-statistics indicating that the mutual influences of the LS variables on one another was always stronger than the influence of the zoning scale (Table 1), with the single exception of SHDI being more strongly influenced by scale than by NDCA. (The $T$-statistics of Table 1 reflect relationships that were all entirely significant, with the largest $p$-value $<10^{-5}$ ). Taken together, $T$-statistics for the mutual influence of other variables were significantly higher for the influences of other variables (mean $T=29.9$ ) than for the influence of the scale (mean $T=13.2 ; T$-test for differences: $\mathrm{df}=25, T=-4.9, p<10^{-4}$ ). In the context of these pair-wise comparisons, scale thus explained less of the variance in the LS variables than did the influence of other LS variables.

Table 1. T-statistics for the mutual influence of variables and the zoning scale.

\begin{tabular}{ccccc}
\hline Independent Variable & Dependent Variable & $\boldsymbol{T}$ (Variable) & $\boldsymbol{T}$ (Scale) & $\boldsymbol{T}$ (Variable \& Scale) \\
\hline FRAC_AM & SHDI & 34 & -14 & -13 \\
FRAC_AM & NDCA & 9 & -6 & 7 \\
FRAC_AM & PLADJ & 31 & -9 & -8 \\
FRAC_AM & DE & 41 & 19 & -27 \\
FRAC_AM & DH & 41 & 16 & -26 \\
FRAC_AM & DP & 19 & 9 & -14 \\
SHDI & NDCA & 5 & 10 & 7 \\
SHDI & PLADJ & 23 & 13 & 4 \\
SHDI & DE & 22 & 20 & -11 \\
SHDI & DH & 23 & 20 & -11 \\
SHDI & DP & 17 & 13 & -12 \\
NDCA & PLADJ & 24 & -12 & -37 \\
NDCA & DE & 55 & 13 & -38 \\
NDCA & DH & 57 & 10 & -20 \\
NDCA & DP & 27 & 6 & -21 \\
PLADJ & DE & 35 & 21 & -21 \\
PLADJ & DH & 36 & 22 & -18 \\
PLADJ & DN & 22 & 17 & 6 \\
DE & DH & 61 & -15 & -13 \\
DE & DN & 22 & 5 & -14 \\
DH & DP & 23 & 7 & \\
\hline
\end{tabular}

\subsection{The Scale-Dependence of Relationships between LS Variables}

Finally, linear regressions were calculated between all LS variables for each zoning scale and strengths of relationship were quantified in terms of $T$-statistics. These $T$-statistics were able to be directly compared across scales because sample sizes were identical in all cases (equal to 130 points). The scale-dependence of the relationships between the landscape metrics is shown in Figure 6; that of the relationships between the social indicators in Figure 7; and that of the relationship between landscape and social measures in Figure 8. (To aid visual interpretation, the strengths of relationship in all of these figures are depicted in terms of correlation coefficients, while all statistics were calculated from associated T-statistics.)

The relationships between the different landscape variables generally remained independent of the zoning scale (Figure 6), with the exception of SHDI-PLADJ $\left(R^{2}=0.61, p=0.005\right)$. Relationships between all other landscape metrics attained maximal correlations with a scale of $R^{2}<0.25(p>0.06)$. By contrast, relationships between social indicators were more strongly influenced by scale, and, in fact, had average $T$-statistics for dependence on scale of $T=4.8$ in comparison with equivalent values for landscape variables of $T=1.4$ ( $T$-test for differences in these statistics: $T=2.8, \mathrm{df}=3.1, p=0.06$ ). The weakest dependence on scale of a relationship between social indicators corresponded to a correlation of 
$R^{2}=0.58(p=0.006)$. Relationships between social indicators were thus significantly dependent on the zoning scale in all cases.

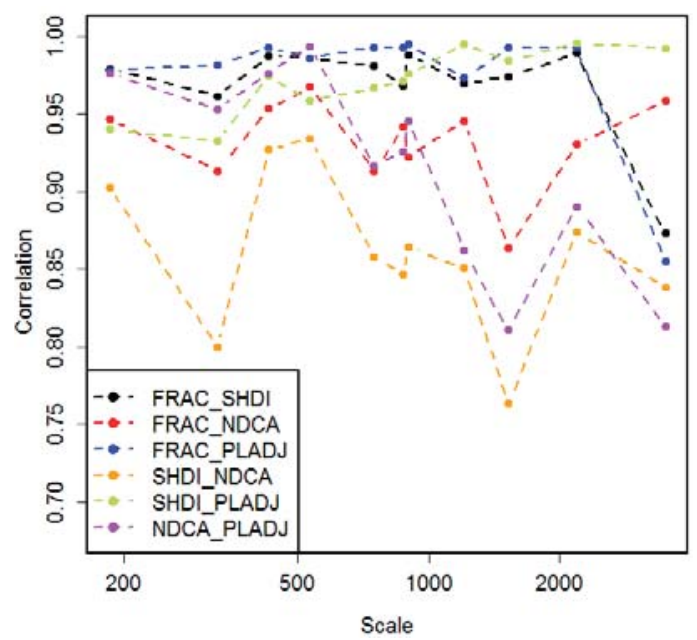

Figure 6. Dependence of the relationships between the four landscape metrics on the zoning scale.

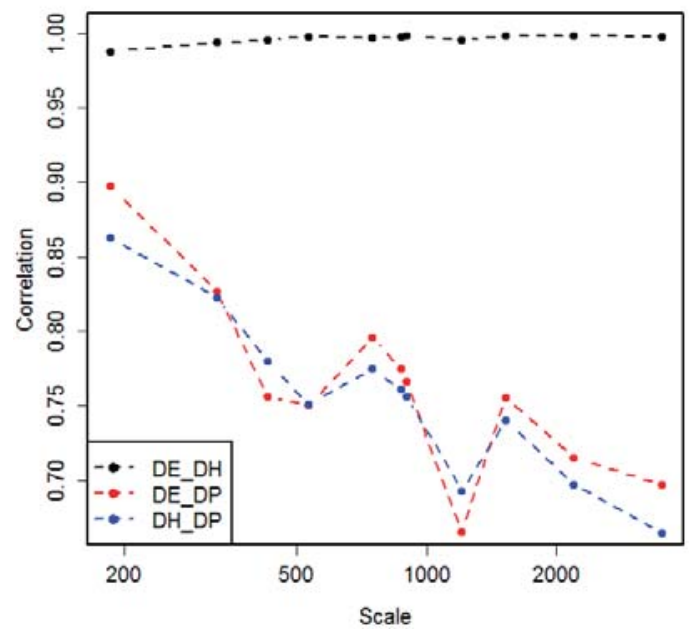

Figure 7. Dependence of the relationships between the three social indicators on the zoning scale.

Finally, seven of the 12 relationships between landscape and social indicators were not significant, while five were. Of these latter five, however, three described the relationships with PLADJ. Excluding this variable, only two of the remaining 9 variable relationships indicate a significant dependence on scale (FRAC_AM-DE and SHDI-DP). This supports the general conclusion that relationships between landscape metrics and social indicators generally remained independent of the zoning scale. Reasons for the significant dependence on PLADJ are discussed below. 
a
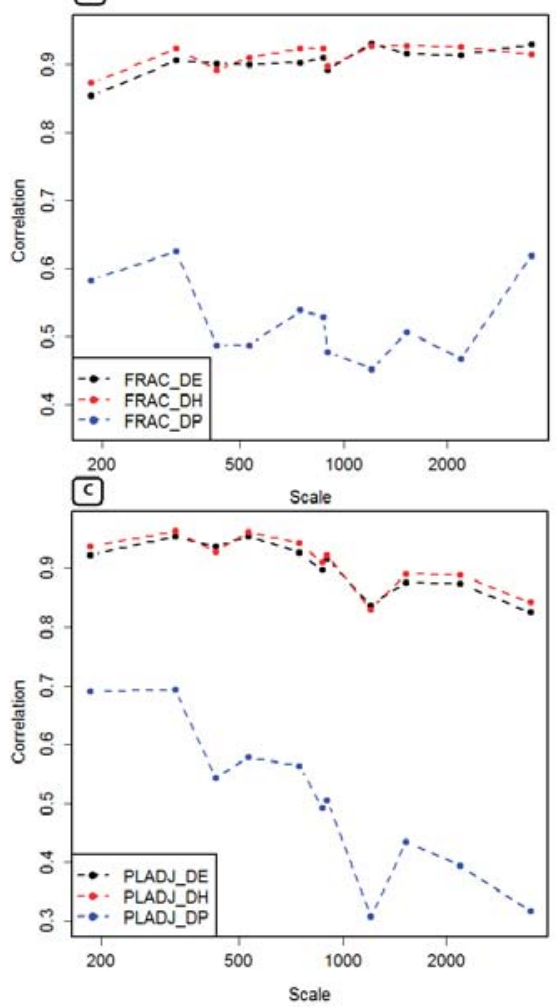

b)
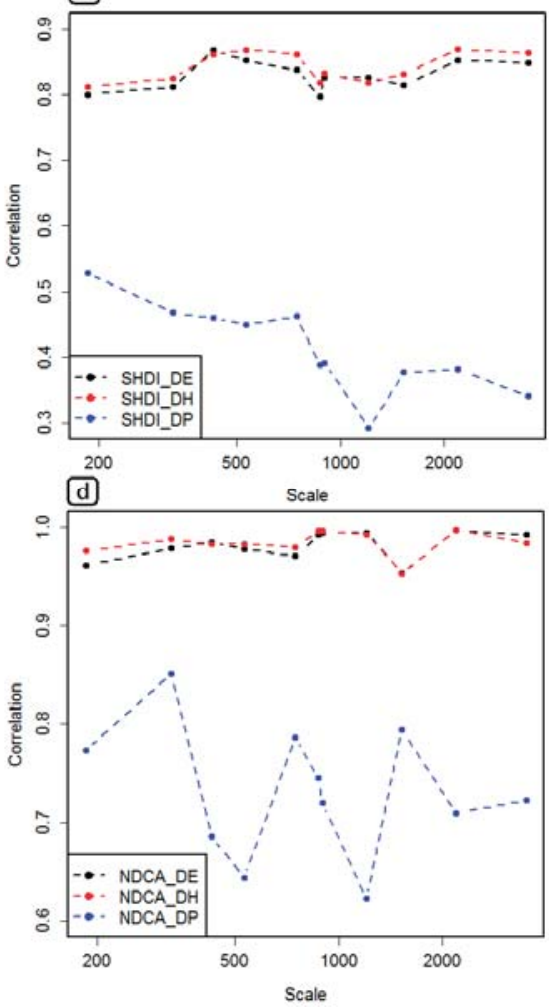

Figure 8. Dependence on zoning scale of relationships between landscape and social metrics.

\section{Discussion}

\subsection{Scale-Dependent Landscape Metrics}

The effect that changing the scale has on landscape metrics has generally been considered in terms of both grain size and extent, yet rarely in terms of the zoning scale. Our study thus examined how a typical group of landscape metrics responds to the zoning scale [53]. All landscape metrics exhibited significant relationships with the zoning scale, with mean values of metrics of both contagion (PLADJ) and diversity (SHDI) increasing with increasing zoning scale (that is, increasing with a decreases in the numbers of zoning units), and mean values of shape and core area metrics (FRAC_AM and NDCA, respectively) decreasing with increasing zoning scale. Similar results for metrics of diversity, shape, and core area have been reported by Wu et al. [23] and Alhamad et al. [54].

Notably, although Wu et al. [23] pointed out the erratic and generally unpredictable behavior of contagion metrics in response to changing grain size, it was possible within the present study to derive explicit scaling functions for the contagion metric used here across multiple zoning scales in Quito. This may suggest that different aggregation methods have significant effects on the characteristics of landscape metrics in response to changes in scale.

\subsection{Scale-Dependent Social Indicators}

Previous research on the spatial concentration of social and economic conditions has resulted in several important questions regarding the role of spatial scale. Our results show that the means 
values of all three social indicators quantified here (deprivation and accessibility to both healthcare and educational services) significantly increased with increasing zoning size. These social indicators thus manifest a general and predictable tendency across multiple scales of 'neighborhood' units, confirming a previous assertion that cross-scale interaction studies provide useful insights into complex urban systems $[55,56]$.

\subsection{Scale-Free Relationships between Social and Landscape Factors in Urban Systems}

Although the significant scale-dependence of landscape metrics and social indicators supports the claim that there is no single 'correct' or 'optimal' scale for characterizing and monitoring complex urban systems, the scale-free relationships between landscape metrics and social indicators discerned here are likely to be of immediate interest to landscape ecologists aiming to understand relationships between demographic changes and transformations of landscape heterogeneity.

The effects of the relationships between landscape metrics and social indicators on the zoning scale can be grouped into three general types: type I, for which all relationships are scale-free; type II, for which some but not all relationships are scale-free; and type III, for which all relationships manifest significant dependence on scale.

The first type (type I) included all relationships with the NDCA metric (number of disjunct core areas), with which all correlations with social indicators (including the composite indicator of deprivation and the accessibility indicators) were very strong while remaining statistically independent of the zoning scale. This confirms that the NDCA metric indeed provides a highly useful metric of habitat quality [57], because its relationship with social processes is independent of the scale of observation. NDCA is simply the total number of disjunct core areas contained within a single zone. Low values of NDCA in Quito arose in regions of low deprivation and high accessibility to health and educational services, mainly in residential areas. In contrast, high values of NDCA were associated with high deprivation and low accessibility to health and educational services in urban areas with a high vegetation cover. The scale-free relationships between NDCA and social indicators actually provides a first insight into likely relationships between the spatial structure and social characteristics of neighborhoods that may lead to an understanding of how social, health, and ecological processes might influence the quality of life in Quito.

The second type (type II) of relationships included the relationships between social indicators (including the composite indicator of deprivation and accessibility to education services) with the fractal dimension index (FRAC_AM), which shows scale-free relationships with deprivation (DP) and accessibility to healthcare services (DH). However, the relationships between the FRAC_AM with accessibility to education services (DE) increased significantly with increasing zoning scale. The areal-weighted mean patch fractal dimension (FRAC_AM) metric provides a way to summarize the shape complexity of patches in a landscape [58]. As built-up areas are more intensively and regularly aggregated than the natural resources across all zoning scales, the areal-weighted mean FRAC_AM metric in the residential areas in Quito is generally lower than in the vegetated areas. FRAC_AM metric significantly decreased with increases in zonal sizes, reflecting the agglomeration of built-up areas into large, more densely built-up patches. The high-degree of correlation and scale-free relationship between FRAC_AM and the composite deprivation indicator further confirm the dominance of residential areas in Quito, with high density built-up areas closely related to low deprivation states. The significant dependence on the zoning scale of the relationships between FRAC_AM and accessibility to health and educational services likely reflects the highly uneven distributions of health and education services within the study area.

Relationships between socioeconomic indicators and the Shannon diversity index (SHDI) were also only partly independent of the zoning scale. While most of the relationships were generally independent of scale, the relationship between SHDI and the composite indicator of deprivation depended significantly on the zoning scale. The SHDI index accounts for both the abundance and evenness of land cover types. In the original census blocks, the diversity in residential areas with 
low levels of deprivation is much lower than the equivalent diversity in suburban areas with higher proportions of natural land cover. Increasing the zone size resulted in the SHDI metrics becoming increasingly influenced by different land use covers, such as multiple types of residential, industrial, or vegetated areas, which illustrates the observed scale-dependence of the relationship between SHDI and deprivation. Similar results in relation to land cover, as quantified by the SHDI metric, have been observed by Nagendra [59]. The scale-dependent relationship between SHDI and deprivation may also reflect the aspects of viability and the social-ecological resilience of landscape.

The third and final category (type III) of relationships represents those where all relationships between landscape and socioeconomic metrics were significantly dependent on scale, most notable for the proportion of like adjacencies (PLADJ). This metric has been widely used to quantitatively assess changes in landscape patterns associated with urbanization [58], mainly because it has the advantage of being intuitive and computationally simple. Low PLADJ values correspond to high fragmentation or areas otherwise comprising numerous distinct units [59], such as regions of scattered urban sprawl in suburban Quito. Nevertheless, although the PLADJ metric can describe whether inhabited areas are maximally contagious at each zoning scale, its measurement is sensitive to other types of large land use patches, such as industrial or park areas, which also obviously influence the degree of conjunction with the surrounding patches. The small patchiness of residential areas may show up as disaggregated in small zoning scales while being conjunction in larger zoning scales. In Quito, as the zoning size increases, residential areas gradually become the dominant land cover type that maximally joins with other land use classes in each zoning areas, leading to the relationships between PLADJ and social indicators becoming steadily stronger. The PLADJ is frequently used to categorize urbanization in terms of urban fragmentation, but the scale-dependent relationships revealed here show that associations between built-up areas and social processes are in this sense dynamic and dependent on scale.

The landscape of Quito thus reveals how relationships between landscape metrics and social indicators are shaped by both anthropogenic and natural factors, and, in particular, by interactions between these two. The relationships between social indicator and spatial landscape metrics on the multiple zoning scales revealed here may be extrapolated to suggest the likely directionality or orientation of landscape patterns across multiple scales in other urban systems subject to analogous urbanization process to Quito.

\subsection{Complex Urban Systems: The Issue of Zoning Scale}

It is becoming increasingly clear that current knowledge and the perspective of a human-dominated system is insufficient, particularly regarding the scale mismatch problems behind the different roles of urban socio-ecological systems functions $[60,61]$. This paper has highlighted how important the scale is when studying social and landscape relationships and how important it is to consider scale issues in urban planning. The prevalence of cross-scale interaction studies means that the most useful insights into the complex urban system comes from multi-scale studies [53,54]. The hierarchical framework in this study has captured the scale-free behaviors concerning the connections and organization between natural entities (e.g., landscape configuration and composition) and anthropogenic derivatives alike (e.g., urban poverty, public education service and public healthcare service). Such scale-free relationships likely also suggest that landscape properties, functions and processes have been strongly influenced by human activities in similar ways across a wide range of scales. This new view of the city structures and dynamics can offer urban planners unexpected perspectives and aid in improving the quality of life in cities.

Neighborhood is most often referred to as the 'place bases' or the 'contextual unit' of urban segregation analyses. The neighborhood delineation is an essential prerequisite to the implementation of public health policy [62] and urban planning policy for the well-being of citizens [63,64]. Many previous neighborhood analyses only combined multi-dimensional socioeconomic indicators (e.g., income, access to clean water, electricity, education, health care), based on their spatial correlations 
and spatial heterogeneities [65-68], to delineate the socially meaningful neighborhoods. Whether the spatial landscape features of urban ecological environments can be confirmed to account for neighborhood-level variations is still in its theoretical infancy, we still lack well-developed 'theories of the middle-range' that can systematically delineate the spatial unit combining different social and landscape characteristics with other contextual characteristics [69,70]. Zoning-based organization systems in this study provide a new approach to understanding the hierarchical characteristic variability of neighborhoods. It is important to consider the whole study area, which was stratified into hierarchical 'neighborhood' units, in order to characterize the spatial landscape features with minimal socioeconomic development bias, and to avoid spurious relationships between variant attributes in aggregating different neighborhood units.

The findings of the three kinds of relationships between landscape metrics and social indicators can support several specific insights with implications for urban planning. For example, the type I scale-free relationships have important implications for answering some decision making questions, such as whether the same urban land uses with several core areas can be functional at several scales? Our results suggest that it is possible. As natural core land covers (e.g., forests) with compact shapes are more resilient to harms (e.g., fires), and this structural reliance could be assigned to several scales, compact urban structures may be resilient to specific damages at different scales. The type II relationships can function as an indicator for measuring the urbanization progress. When the fractal dimension of land use and land cover is generally inconsistent with the socioeconomic activities in other case studies in future, it may imply an urbanization process that leads to built-up areas being more intensely and regularly aggregated than the natural resources across all zoning scales. The type III relationships suggest that it is necessary to take the scale issue into consideration if applying some specific landscape metrics (e.g., PLADJ) when describing the landscape-social relationships. Especially urban areas with fragmented land use may represent different social dynamics across different scales. To deal with such situations, dividing the city into big administrative zones may be more manageable for decision makers.

An important aim for future studies should be to better understand what kinds of socio-ecological environments can be represented as scale-free fractal structures. Although interactions between social activities and landscape heterogeneity have been subject to extensive previous consideration [71,72], the dependence of their relationship at changing domain scales has rarely been reported on, either due to difficulties in terms of data or computation, or due to difficulties in identifying appropriate domains of scale [73]. In this study, integrating spatial landscape metrics and social indicators into an automatic zoning procedure represents a first attempt to link the contexts of the social and landscape characteristics into a multi-scale urban regionalization, which enables the quantitative exploration of the scaling relationships between complex socio-ecological urban processes.

Automatic zoning procedures can take into consideration potential relationships and homogeneity characteristics of inputs, and can allow zones to be aggregated in a hierarchical way. However, identifying suitable zoning scales for landscape-social analysis is still not easy, as parameters are required for automatic zoning procedures to remain subjective to some extent. Although the multi-scale zoning levels used herein were determined through several tests, the uncertainty and robustness of zonation aggregation remain important aspects for future research to address. Moreover, while the shapes of zoning may change drastically depending on the procedure of zoning aggregation, the specific landscape metrics associated with various landscapes may also change in different contexts.

Another issue to understand here is whether spatial patterns of social dynamics may also show fractals' behaviors not only in pre-defined administrative areas (e.g., census block) but in other zoning scales too. Area-level social indicators are usually expressed in pre-defined administrative areas such as census blocks. It is expected that census blocks have more simple shapes, that is, lower values of fractal dimension. This research thus aggregated the hierarchical zoning levels based on the census block. Nevertheless, some scholars have questioned the ability of census blocks to capture basic functional socio-ecological units [74,75]. More and more relevant social, economic, political 
and ecological indicators in different study areas should be taken into consideration in the future to determine the causes of the socio-ecological factors in the context of the complex urban system, including questions such as: At which cross-scale scope may the urban landscape characteristics be used to determine the type of social network? Or in which range of zoning size does the landscape patches correspond well to the social public services organization? This new view of the city structures and dynamics can offer a solution to handle the sustainable regional partition problem between landscape biodiversity protection and public service construction, or between reducing the urban poverty and scientifically exploiting the natural resources.

\section{Conclusions}

We are living in an era where the main problems of sustainability can be resolved in cities. Major conversations of urban sustainability and planning for development are related to inequality and social resilience. Critical points in terms of urban studies are the need for multi-scale perspectives and the application of mixed methods. The methodology presented in this study addresses both these issues.

We applied an automatic zoning procedure to aggregate the census blocks into multiple zoning scales. $T$-statistics revealed that both landscape metrics and social indicators depend strongly on the zoning scale. Taken alone, this result suggests that any particular scale chosen for the measurement of spatial patterns may be inappropriate or difficult to apply in different environments. Although some aspects of landscape and social measures seem more generally predictable across zoning scales, the scaling behaviors of landscape metrics and social indicators will likely differ in different urban systems, suggesting the abiding importance of investigating the scaling behaviors of such metrics in different urban environments.

However, regardless of such potential scale-dependence of individual landscape or social indicators, relationships between the two classes of metrics within the present study generally remained independent of the zoning scale. This scale-free behavior challenges the modifiable unit area problem, enhances understanding of the causes and consequences of spatial heterogeneity and how they vary with scale, and has important implications for the management of both natural- and human-dominated environments. Through combining remote sensing data and statistical census data from Quito, the results of this study are expected to assist local officials in their understanding of urban dynamics, and, in so doing, to promote future sustainable growth.

The rapid development of earth observation technologies enables increasing amounts of spatio-temporal data to be used as a basis for modeling urban ecosystems. Relationships between landscape structures and characteristics of human societies will accordingly become increasingly easy to quantify more accurately, enhancing the mechanistic understanding or drivers and services of complex urban systems.

Acknowledgments: Work performed by the editorial office and the two anonymous referees is greatly appreciated, and their comments and suggestions have significantly improved this manuscript. The authors gratefully acknowledge the use of the AZTool software copyrighted by David Martin, Samantha Cockings, and the University of Southampton. We would also like to thank Ecuador's Ministry of Environment for providing land use and land cover information. We also like to thank Ecuador's Ministry of Health and Ministry of Education for providing geo-referenced health and educational services data for the city of Quito. Part of the research has been supported by the Austrian Science Fund (FWF) through the Doctoral College GIScience (DK W 1237-N23) and the China Scholarship Council Scholarship (contract No. CSC 201306070014).

Author Contributions: Chunzhu Wei made substantial contributions to the design of the study, participated in the analysis and the interpretation of data, and drafted the manuscript. Mark Padgham participated in the design of the study, did part of the statistical analysis, and drafted part of the manuscript. Pablo Cabrera Barona participated in part of the study design, performed the data collection, and drafted part of the manuscript. Thomas Blaschke participated in the design of the study and helped to draft the manuscript. All authors read and approved the final manuscript.

Conflicts of Interest: The authors declare no conflict of interest. 


\section{References}

1. Wiens, J.A.; Milne, B.T. Scaling of 'landscapes' in landscape ecology, or, landscape ecology from a beetle's perspective. Landsc. Ecol. 1989, 3, 87-96. [CrossRef]

2. Wiens, J.A. Spatial Scaling in Ecology. Funct. Ecol. 1989, 3, 385-397. [CrossRef]

3. Wagner, H.H.; Fortin, M.-J. Spatial Analysis of Landscapes: Concepts and Statistics. Ecology 2005, 86, 1975-1987. [CrossRef]

4. Blaschke, T. The role of the spatial dimension within the framework of sustainable landscapes and natural capital. Landsc. Urban Plan. 2006, 75, 198-226. [CrossRef]

5. Nuissl, H.; Haase, D.; Lanzendorf, M.; Wittmer, H. Environmental impact assessment of urban land use transitions-A context-sensitive approach. Land Use Policy 2009, 26, 414-424. [CrossRef]

6. Syrbe, R.-U.; Walz, U. Spatial indicators for the assessment of ecosystem services: Providing, benefiting and connecting areas and landscape metrics. Ecol. Indic. 2012, 21, 80-88. [CrossRef]

7. Lausch, A.; Herzog, F. Applicability of landscape metrics for the monitoring of landscape change: Issues of scale, resolution and interpretability. Ecol. Indic. 2002, 2, 3-15. [CrossRef]

8. Leitão, A.B.; Ahern, J. Applying landscape ecological concepts and metrics in sustainable landscape planning. Landsc. Urban Plan. 2002, 59, 65-93. [CrossRef]

9. Fragkias, M.; Seto, K.C. Modeling Urban Growth in Data-Sparse Environments: A New Approach. Environ. Plan. B Plan. Des. 2007, 34, 858-883. [CrossRef]

10. Vaz, A.S.; Marcos, B.; Gonçalves, J.; Monteiro, A.; Alves, P.; Civantos, E.; Lucas, R.; Mairota, P.; Garcia-Robles, J.; Alonso, J.; et al. Can we predict habitat quality from space? A multi-indicator assessment based on an automated knowledge-driven system. Int. J. Appl. Earth Obs. Geoinf. 2015, 37, 106-113. [CrossRef]

11. Vaz, E. The future of landscapes and habitats: The regional science contribution to the understanding of geographical space. Habitat Int. 2016, 51, 70-78. [CrossRef]

12. Cirella, G.T. Developing a Quantitative Multi-Criteria Method of Sustainability Assessment: With Application in Queensland, Australia; Griffith University: Logan, Australia, 2010.

13. Ktitorov, P.; Bairlein, F.; Dubinin, M. The importance of landscape context for songbirds on migration: Body mass gain is related to habitat cover. Landsc. Ecol. 2007, 23, 169-179. [CrossRef]

14. Iverson, L.R.; Cook, E.A. Urban forest cover of the Chicago region and its relation to household density and income. Urban Ecosyst. 2000, 4, 105-124. [CrossRef]

15. You, H. Quantifying urban fragmentation under economic transition in Shanghai city, China. Sustainability 2016, 8, 21. [CrossRef]

16. Cushman, S.A.; Landguth, E.L. Spurious correlations and inference in landscape genetics. Mol. Ecol. 2010, 19, 3592-3602. [CrossRef] [PubMed]

17. Lambin, E.F.; Meyfroidt, P. Land use transitions: Socio-ecological feedback versus socio-economic change. Land Use Policy 2010, 27, 108-118. [CrossRef]

18. Frumkin, H. Urban sprawl and public health. Public Health Rep. 2002, 117, 201-217. [CrossRef]

19. Hall, G.B.; Malcolm, N.W.; Piwowar, J.M. Integration of Remote Sensing and GIS to Detect Pockets of Urban Poverty: The Case of Rosario, Argentina. Trans. GIS 2001, 5, 235-253. [CrossRef]

20. Lugeri, F.R.; Farabollini, P.; Greco, R.; Amadio, V. The Geological Characterization of Landscape in Major TV Series: A Suggested Approach to Involve the Public in the Geological Heritage Promotion. Sustainability 2015, 7, 4100-4119. [CrossRef]

21. Loures, L.; Loures, A.; Nunes, J.; Panagopoulos, T. Landscape Valuation of Environmental Amenities throughout the Application of Direct and Indirect Methods. Sustainability 2015, 7, 794-810. [CrossRef]

22. Hacker, K.P.; Seto, K.C.; Costa, F.; Corburn, J.; Reis, M.G.; Ko, A.I.; Diuk-Wasser, M.A. Urban slum structure: Integrating socioeconomic and land cover data to model slum evolution in Salvador, Brazil. Int. J. Health Geogr. 2013, 12, 45. [CrossRef] [PubMed]

23. Wu, J.; Shen, W.; Sun, W.; Tueller, P.T. Empirical patterns of the effects of changing scale on landscape metrics. Landsc. Ecol. 2002, 17, 761-782. [CrossRef]

24. Herold, M.; Couclelis, H.; Clarke, K.C. The role of spatial metrics in the analysis and modeling of urban land use change. Comput. Environ. Urban Syst. 2005, 29, 369-399. [CrossRef] 
25. Frate, L.; Saura, S.; Minotti, M.; di Martino, P.; Giancola, C.; Carranza, M.L. Quantifying Forest Spatial Pattern Trends at Multiple Extents: An Approach to Detect Significant Changes at Different Scales. Remote Sens. 2014, 6, 9298-9315. [CrossRef]

26. Cadenasso, M.L.; Pickett, S.T.A.; Schwarz, K. Spatial heterogeneity in urban ecosystems: Reconceptualizing land cover and a framework for classification. Front. Ecol. Environ. 2007, 5, 80-88. [CrossRef]

27. Levin, S.A. The Problem of Pattern and Scale in Ecology: The Robert H. MacArthur Award Lecture. Ecology 1992, 73, 1943-1967. [CrossRef]

28. Burnett, C.; Blaschke, T. A multi-scale segmentation/object relationship modelling methodology for landscape analysis. Ecol. Model. 2003, 168, 233-249. [CrossRef]

29. Openshaw, S.; Rao, L. Algorithms for Reengineering 1991 Census Geography. Environ. Plan. A 1995, 27, 425-446. [CrossRef] [PubMed]

30. Openshaw, S. A Geographical Solution to Scale and Aggregation Problems in Region-Building, Partitioning and Spatial Modelling. Trans. Inst. Br. Geogr. 1977, 2, 459-472. [CrossRef]

31. Openshaw, S. An optimal zoning approach to the study of spatially aggregated data. In Spatial Representation and Spatial Interaction; Masser, I., Brown, P.J.B., Eds.; Springer: Heidelberg, Germany, 1978; pp. 95-113.

32. Brunsdon, C.; Fotheringham, A.S.; Charlton, M. Spatial Nonstationarity and Autoregressive Models. Environ. Plan. A 1998, 30, 957-973. [CrossRef]

33. Cockings, S.; Martin, D. Zone design for environment and health studies using pre-aggregated data. Soc. Sci. Med. 2005, 60, 2729-2742. [CrossRef] [PubMed]

34. Longley, P.A.; Batty, M. Spatial Analysis: Modelling in a GIS Environment; John Wiley \& Sons: Hoboken, NJ, USA, 1996.

35. Cen, X.; Wu, C.; Xing, X.; Fang, M.; Garang, Z.; Wu, Y. Coupling Intensive Land Use and Landscape Ecological Security for Urban Sustainability: An Integrated Socioeconomic Data and Spatial Metrics Analysis in Hangzhou City. Sustainability 2015, 7, 1459-1482. [CrossRef]

36. Buyantuyev, A.; Wu, J.; Gries, C. Multiscale analysis of the urbanization pattern of the Phoenix metropolitan landscape of USA: Time, space and thematic resolution. Landsc. Urban Plan. 2010, 94, 206-217. [CrossRef]

37. Hoffman, K.; Centeno, M.A. The Lopsided Continent: Inequality in Latin America. Annu. Rev. Sociol. 2003, 29, 363-390. [CrossRef]

38. Cabrera-Barona, P.; Wei, C.; Hagenlocher, M. Multiscale evaluation of an urban deprivation index: Implications for quality of life and healthcare accessibility planning. Appl. Geogr. 2016, 70, 1-10. [CrossRef]

39. Mideros, A. Ecuador: Defining and measuring multidimensional poverty, 2006-2010. CEPAL Rev. 2012, 108, 49-67.

40. Schkolnik, S.; Chackiel, J. América Latina: Aspectos conceptuales de los censos del 2000. In CEPAL/ECLAC. Serie Manuales; United Nations: San Diego, USA, 1999. (In Spanish)

41. Neugebauer, S.; Traverso, M.; Scheumann, R.; Chang, Y.-J.; Wolf, K.; Finkbeiner, M. Impact Pathways to Address Social Well-Being and Social Justice in SLCA-Fair Wage and Level of Education. Sustainability 2014, 6, 4839-4857. [CrossRef]

42. Nevado-Peña, D.; López-Ruiz, V.-R.; Alfaro-Navarro, J.-L. The Effects of Environmental and Social Dimensions of Sustainability in Response to the Economic Crisis of European Cities. Sustainability 2015, 7, 8255-8269. [CrossRef]

43. Cabrera-Barona, P.; Murphy, T.; Kienberger, S.; Blaschke, T. A multi-criteria spatial deprivation index to support health inequality analyses. Int. J. Health Geogr. 2015, 14, 1-14. [CrossRef] [PubMed]

44. Apparicio, P.; Abdelmajid, M.; Riva, M.; Shearmur, R. Comparing alternative approaches to measuring the geographical accessibility of urban health services: Distance types and aggregation-error issues. Int. J. Health Geogr. 2008, 7, 7. [CrossRef] [PubMed]

45. Lalloué, B.; Monnez, J.M.; Padilla, C.; Kihal, W.; Meur, N.; Zmirou-Navier, D. A statistical procedure to create a neighborhood socioeconomic index for health inequalities analysis. Int. J. Equity Health 2013, 12, 45-56. [CrossRef] [PubMed]

46. De la Fuente, H.; Rojas, C.; Salado, M.J.; Carrasco, J.A.; Neutens, T. Socio-Spatial Inequality in Education Facilities in the Concepcion Metropolitan Area (Chile). Curr. Urban Stud. 2013, 1, 117-129. [CrossRef]

47. Wei, C.; Cabrera-Barona, P.; Blaschke, T. Local Geographic Variation of Public Services Inequality: Does the Neighborhood Scale Matter? Int. J. Environ. Res. Public Health 2016, 13, 10. [CrossRef] [PubMed] 
48. Mcgarigal, K.; Cushman, S.; Neel, M.; Ene, E. FRAGSTATS: Spatial Pattern Analysis Program for Categorical Maps. 2002. Available online: http:/ / www.umass.edu/landeco/research/fragstats/fragstats.html (accessed on 10 April 2016).

49. Ramírez, R. La Vida (Buena) Como Riqueza de los Pueblos: Hacia una Socio Ecología Política del Tiempo; Economía e Investigación IAEN: Quito, Ecuador, 2012. (In Spanish)

50. Cabrera-Barona, P.; Blaschke, T.; Kienberger, S. Explaining Accessibility and Satisfaction Related to Healthcare: A Mixed-Methods Approach. Soc. Indic. Res. 2016, 7, 1-21. [CrossRef]

51. Pampalon, P.; Pamel, D.; Gamache, P.; Raymond, G. A deprivation index for health planning in Canada. Chronic Dis. Can. 2009, 29, 178-191. [PubMed]

52. Flowerdew, R.; Manley, D.J.; Sabel, C.E. Neighbourhood effects on health: Does it matter where you draw the boundaries? Soc. Sci. Med. 2008, 66, 1241-1255. [CrossRef] [PubMed]

53. Martin, D. Automatic neighbourhood identification from population surfaces. Comput. Environ. Urban Syst. 1998, 22, 107-120. [CrossRef]

54. Alhamad, M.N.; Alrababah, M.A.; Feagin, R.A.; Gharaibeh, A. Mediterranean drylands: The effect of grain size and domain of scale on landscape metrics. Ecol. Indic. 2011, 11, 611-621. [CrossRef]

55. Allen, T.F.; Starr, T.B. Hierarchy: Perspectives for Ecological Complexity; University of Chicago Press: Chicago, IL, USA, 1982; Volume 10, pp. 305-306.

56. Root, T.L.; Schneider, S.H. Ecology and climate: Research strategies and implications. Science 1995, 269, 334-341. [CrossRef] [PubMed]

57. Temple, S.A.; Cary, J.R. Modeling Dynamics of Habitat-Interior Bird Populations in Fragmented Landscapes. Conserv. Biol. 1988, 2, 340-347. [CrossRef]

58. Riitters, K.H.; O’Neill, R.V.; Hunsaker, C.T.; Wickham, J.D.; Yankee, D.H.; Timmins, S.P.; Jones, K.B.; Jackson, B.L. A factor analysis of landscape pattern and structure metrics. Landsc. Ecol. 1995, 10, $23-39$. [CrossRef]

59. Nagendra, H. Opposite trends in response for the Shannon and Simpson indices of landscape diversity. Appl. Geogr. 2002, 22, 175-186. [CrossRef]

60. Grimm, N.B.; Foster, D.; Groffman, P.; Grove, J.M.; Hopkinson, C.S.; Nadelhoffer, K.J.; Pataki, D.E.; Peters, D.P. The changing landscape: Ecosystem responses to urbanization and pollution across climatic and societal gradients. Front. Ecol. Environ. 2008, 6, 264-272. [CrossRef]

61. Cummins, S.C.; McKay, L.; MacIntyre, S. McDonald's Restaurants and Neighborhood Deprivation in Scotland and England. Am. J. Prev. Med. 2005, 29, 308-310. [CrossRef] [PubMed]

62. World Health Organization. Environment and Health Risks: A Review of the Influence and Effects of Social Inequalities; World Health Organization: Geneva, Switzerland, 2010.

63. Caspi, A.; Taylor, A.; Moffitt, T.E.; Plomin, R. Neighborhood Deprivation Affects Children's Mental Health: Environmental Risks Identified in a Genetic Design. Psychol. Sci. 2000, 11, 338-342. [CrossRef] [PubMed]

64. Caughy, M.O.; Nettles, S.M.; O'Campo, P.J.; Lohrfink, K.F. Neighborhood matters: Racial socialization and the development of young African American children. Child Dev. 2006, 77, 1220-1236. [CrossRef] [PubMed]

65. Gao, Y.; Gao, J.; Chen, J.; Xu, Y.; Zhao, J. Regionalizing aquatic ecosystems based on the river subbasin taxonomy concept and spatial clustering techniques. Int. J. Environ. Res. Public Health 2011, 8, 4367-4385. [CrossRef] [PubMed]

66. Hosking, J.R.M.; Wallis, J.R. Some statistics useful in regional frequency analysis. Water Resour. Res. 1993, 29, 271-281. [CrossRef]

67. Guo, J.Y.; Bhat, C.R. Operationalizing the concept of neighborhood: Application to residential location choice analysis. J. Transp. Geogr. 2007, 15, 31-45. [CrossRef]

68. Lotfi, S.; Koohsari, M.J. Measuring objective accessibility to neighborhood facilities in the city (A case study: Zone 6 in Tehran, Iran). Cities 2009, 26, 133-140. [CrossRef]

69. Jelinski, D.E.; Wu, J. The modifiable areal unit problem and implications for landscape ecology. Landsc. Ecol. 1996, 11, 129-140. [CrossRef]

70. Fotheringham, A.S.; Wong, D.W.S. The modifiable areal unit problem in multivariate statistical analysis. Environ. Plan. A 1991, 23, 1025-1044. [CrossRef]

71. Giampietro, M.; Mayumi, K.; Ramos-Martin, J. Multi-scale integrated analysis of societal and ecosystem metabolism (MuSIASEM): Theoretical concepts and basic rationale. Energy 2009, 34, 313-322. [CrossRef] 
72. Scholes, R.; Reyers, B.; Biggs, R.; Spierenburg, M.; Duriappah, A. Multi-scale and cross-scale assessments of social-ecological systems and their ecosystem services. Curr. Opin. Environ. Sustain. 2013, 5, 16-25. [CrossRef]

73. Wheatley, M. Domains of scale in forest-landscape metrics: Implications for species-habitat modeling. Acta Oecol. 2010, 36, 259-267. [CrossRef]

74. Fang, J.; Madhavan, S.; Bosworth, W.; Alderman, M.H. Residential segregation and mortality in New York City. Soc. Sci. Med. 1998, 47, 469-476. [CrossRef]

75. Diez Roux, A.V. Investigating Neighborhood and Area Effects on Health. Am. J. Public Health 2001, 91, 1783-1789. [CrossRef] [PubMed]

(C) 2017 by the authors. Licensee MDPI, Basel, Switzerland. This article is an open access article distributed under the terms and conditions of the Creative Commons Attribution (CC BY) license (http://creativecommons.org/licenses/by/4.0/). 



\title{
Managing Efficiency in Higher Education: A Case of Ukrainian Universities
}

\author{
Oleksandr Velychko $^{1, *(\mathbb{D})}$, Liudmyla Velychko ${ }^{2}$ and Mykola Kharytonov ${ }^{3}$ \\ 1 Department of Management and Law, Dnipro State Agrarian and Economic University, \\ 49600 Dnipro, Ukraine \\ 2 Department of Economics, Entrepreneurship and Management of Enterprises, \\ Oles Honchar Dnipro National University, 49600 Dnipro, Ukraine; lyudmilavel@ukr.net \\ 3 Department of Breeding and Seed Production, Dnipro State Agrarian and Economic University, \\ 49600 Dnipro, Ukraine; mykolakh@ua.fm \\ * Correspondence: olvel@ukr.net; Tel.: +38-067-949-2739
}

Received: 30 June 2018; Accepted: 12 August 2018; Published: 14 August 2018

\begin{abstract}
The rating positions of most Ukrainian higher educational establishments in the global international environment have not received any positive changes over a long period of time. Progressive regulatory changes are necessary to stimulate internal university reforms within the context of European integration. The purpose of the present work is to develop organizational-methodological measures in order to increase the efficiency of scientific-pedagogical activity in higher educational establishments of Ukraine. The following methods were used for the research: Monographic, historical, comparative, generalization, formal-logical, analysis and synthesis, categorical approach, observation, interviewing, graphic, benchmarking and forecasting. The concept and methodology of managing efficiency in the post-Soviet transformation of higher education has been grounded. The mechanism of utilizing re-engineering and motivational management in the process of implementing European integration objectives for university education in Ukraine has been suggested. The system of normative indices has been formed to stimulate the effectiveness of the scientific-pedagogical activities of universities, with the complex focus on the marketing of educational services, innovations and quality. The authors' mechanism of the accumulating system to stimulate scientific-creative activity of workers has been developed and put into practice. Procedures for scoring theproductivity level of scientific staff in universities have been described based on grading.
\end{abstract}

Keywords: higher education; efficiency; re-engineering; competitiveness; motivational management; grading

\section{Introduction}

Progressive democratic reforms in post-Soviet countries have been focused on encouraging new ideas and decreasing the level of constant control. The decisive condition for achieving success in any activity is efficient management (Illés et al. 2015; Vasylieva and Velychko 2017). Good examples of this method include the USA (Brooks and Kakabadse 2014), France (Hradilova 2015) and Singapore (Low and Tan 2017), which mainly due to a high level of organization and management in different fields, have transformed themselves into high-developed and wealthy countries. Nowadays management plays an important role in all fields of life in the society, including the area of educational services. Therefore organization of management in the area of higher education in Ukraine which would be built not on declarative, but on real deep democratic fundations, could provide far better improvement of the quality of work in many modern universities during the preparation of high-qualified specialists, carrying out scientific research, the provision of consulting services and so on. 
In the last 20 years there have been great changes in the environment where the higher educational establishments of Ukraine operate: Structural changes at the labor market have taken place; requirements to prepare specialists have became more dynamic and changeable; the level of competitiveness at the market of educational services has increased significantly. In addition, the official state document indicating the completion of higher education has begun to play a less significant role in the labor market. In past decades, the special level of knowledge and skills of graduates have increasingly been taken into account. It also became possible to use alternative sources of financing for the preparation of specialists; the philosophy of higher education has become completely different. Recently the process to provide universities with more autonomy, which is the generally accepted practice for most successful countries, has become more evident in Ukraine. This process would increase the level of responsibility of universities and stimulate them to develop unconventional educational, educational-professional and educational-scientific programs. The purpose of the latter is to provide progressive development and to increase the efficiency at the market of educational, scientific and consulting services. However in practice, many universities are not motivated to achieve constant improvement in all areas of activity.

Management of efficiency in higher education is directly linked with the strategy of the government policy and implementation of progressive reforms. In this context Tvaronavičienè et al. (2017) underline that the efficient policy in the area of higher education provides the solution for many essential economic and social problems. On the other hand, Goncharuk (2015) and Oganisjana et al. (2017) stress the importance of universities in generating social and economic innovations. Many studies in the process of developing and implementing the models of management in higher education within the global context testify to the requirement to consider historic prerequisites, structural limitations, cultural traditions, impact on the environment and other special circumstances.

In particular, this confirms the study of educational reforms and features of stimulating systems for efficient work of universities in such countries as the USA (Bowen 2017), Great Britain (Moodie 2014), Germany and Italy (Dobbins and Knill 2017), Austria, Finland, The Netherlands, Portugal (Krüger et al. 2018), Switzerland (Hoidn and Olbert-Bock 2016), Denmark (Hansen 2011), Poland (Kwiek 2017), Hungary (Berács 2014), Serbia (Avramovic 2016), Australia, New Zealand (Christensen 2011), the Russian Federation (Popova et al. 2017), China (Yang 2015), Singapore (Low and Tan 2017) and others. Furthermore there is a certain complexity in the creation of a unified universal system for evaluating the efficiency of higher education (Goncharuk 2016).

Agasisti and Pérez-Esparrells (2010) pay attention to the expediency of the analysis and comparison of efficiency between universities of different countries. Researchers such as Johnes and Johnes (2009), as well as Koshal and Koshal (1999) consider the costs on the services of universities to be an essential criterion for efficiency in higher education. However the foundation for most successful practices of national models in university education has become the management of efficiency through mechanisms of competitiveness and motivation. Thus Berács (2014) and Berghman et al. (2013) stress the efficiency of enterprises in the area of higher education and the requirement to stimulate universities for creating their own entrepreneurial models. Particularly Slaughter and Rhoades (2004) at the beginning of the XXI century considered those issues through the prism of academic capitalism. The conclusions of scientists are focused on the progressive role in the implementation of market instruments into the system of management in universities. In the research carried out by Krüger et al. (2018), and Kwiek (2017) and Moodie (2014), the advantages of the entrepreneurial approach to efficient university management have been systematized. Particular attention has been paid to the formation of a successful marketing strategy at the market of educational, scientific and consulting services. Typical threats to the process of bureaucratization in higher education from the point of view of M. Veber were generalized by Sedláček (2017), and Taib and Abdullah (2016). At that the scientists paid much attention to the need to develop the concept of government policy to support the efficiency of higher education. Gormally et al. (2014) focuses on risks of resistance to the existing higher education system on the implementation of certain changes. 
The issues of integration of Ukrainian universities into the European educational area are the object of attention for many scientists. Nalyvaiko (2015) paid particular attention to the need for deep reformation of higher education in Ukraine, considering both certain national features and European traditions. Gedikova (2016) suggested key directions to increase the competitiveness of universities at the market of educational services and defined certain instruments for providing a high level of quality for higher education in Ukraine.

At that time Burbyka and Telizhenko (2015) pay attention to the fact that current strategies of state regulation are not sufficiently effective in many spheres of activity. In turn Hudym and Khalatur (2016), as well as Sardak and Sukhoteplyi (2013) underline the contemporary problems of maximizing staff potential at the national labor market. Grynko et al. (2017) in turn stress the low motivation of many workers in the service sector. All these factors negatively affect the development of educational and scientific services in Ukraine.

At the same time many modern universities in Ukraine (mainly state-owned) remain establishments with a bureaucratic type of business activity which they inherited from the Soviet era and have not yet reformed. Under the conditions of international globalization, this slows the progressive development of the domestic science field and weakens competitiveness of most Ukrainian universities at the European market. Moreover even in comparison with many universities of post-Soviet countries, the leading Ukrainian universities now lag behind in the ratings (Table 1).

Table 1. Top-rating of universities in post-Soviet countries as of 1 July 2018.

\begin{tabular}{|c|c|c|}
\hline University & Place among Post-Soviet Countries & Place in the World \\
\hline Lomonosov Moscow State University & 1 & 213 \\
\hline University of Tartu & 2 & 418 \\
\hline Saint Petersburg State University & 3 & 424 \\
\hline Belarusian State University & 4 & 487 \\
\hline Tallinn University of Technology & 5 & 560 \\
\hline $\begin{array}{l}\text { National Research University Higher School } \\
\text { of Economics }\end{array}$ & 6 & 587 \\
\hline Vilnius University & 7 & 755 \\
\hline $\begin{array}{l}\text { Peter the Great Saint Petersburg } \\
\text { Polytechnic University }\end{array}$ & 8 & 759 \\
\hline Tomsk State University & 9 & 773 \\
\hline Moscow Institute of Physics and Technology & 10 & 778 \\
\hline Kazan (Volga Region) Federal University & 11 & 834 \\
\hline University of Latvia & 12 & 998 \\
\hline Novosibirsk State University & 13 & 1077 \\
\hline Ural Federal University & 14 & 1117 \\
\hline Tallinn University & 15 & 1158 \\
\hline $\begin{array}{l}\text { Taras Shevchenko Kyiv National } \\
\text { University (Ukraine) }\end{array}$ & 16 & 1267 \\
\hline
\end{tabular}

Source: systematized by the authors according to (Ranking Web of Universities 2018).

The corresponding world rating of universities is made by "Cybermetrics Lab" of the Spanish National Research Council at the Ministry of Science and Innovation in Spain. The rating of post-Soviet universities was extracted from the data provided by Ranking Web of Universities by Webometrics. This situation requires progressive regulatory changes which will stimulate reforms inside universities. This defines the importance of the topic for scientific research. But the existing research is not focused on regulatory changes made to stimulate the internal university reforms under the conditions of integration into the educational area of the EU. Specific mechanisms to 
improve educational-pedagogical efficiency which consider evolutionary, mental, social, legal and opportunistic features of this process in the contemporary context of the post-Soviet transformation of higher education in Ukraine, have been studied insufficiently. This mainly concerns the mechanism of motivation of such activities aimed at improving the quality of science and education.

The purpose of the research is to develop certain organizational-methodological measures to increase the efficiency of scientific-pedagogical activity focused on globalization of the educational environment in Ukrainian universities. The main tasks of the scientific research were then set: Identification and analysis of key reasons for low efficiency and competitiveness in most Ukrainian universities in the international area; creation of mechanisms for stimulating internal university reforms under conditions of post-Soviet transformations of the higher education in Ukraine; formation of methodology of managing work efficiency in Ukrainian universities as well as development of the accumulating system of stimulating scientific-creative activity for university staff under the conditions of the transitional period.

\section{Methodology}

The themethodological foundation for the research is the dialectical method of cognition, as well as the general scientific and special methods of the research. They are: The historical method, comparison and generalization, formal-logical method, analysis and synthesis, categorical approach, method of monograph observation, interviewing, calculating-constructive method, graphical method, method of benchmarking, forecasting method and so on (Cohen et al. 2017; Schulz 2017). The research has been made in two stages.

\subsection{Systems of Providing Efficiency for Higher Educational Establishments (System of External Provision of Efficiency)}

At the first stage the authors' mechanism of re-engineering and motivational management for the system of implementing transformational challenges for higher education in Ukraine has been developed. One of the key output moments of this mechanism are the classical principles of managing efficiency of F. Taylor on clear dependence of awards on the results of work (Taylor 1911). Moreover, the author's developments are based on certain principles of re-engineering (cardinal change) in some managerial processes (Mircea et al. 2016). Application of the concept of constant quality improvement based on rationalistic logistics (Velychko and Velychko 2017a, 2017b) and providing logistics (Velychko 2015) has been essential. Afterwards, the attention was paid to the fact that achievement of task implementation in the area of making Ukrainian achieve European standards is rather complicated without complex application in the system of public administration and management of higher educational establishments in those output moments.

Taking this into account, it has been suggested to include a set of efficient motivational mechanisms on constant improvement of university work into the program of implementing the strategy of reforming higher education in Ukraine. A competitive mechanism toward sustaining study in universities at the state budget's expense has been available since 2016. But such a competitive system does not stimulate universities towards complex development. For that to occur, it is necessary to also have working influence on the system of private financing of higher education and the process of supporting a multi-vector competitive environment within it. Such an environment implies the presence of a high level of competition between universities not only in the area of providing educational services, but also in the system of scientific, innovative and consulting activities.

Currently, Ukrainian legislation uses the term "Licensed amount of specialists". It refers to a maximal number of students allowed by the government for a certain direction in the current year. It concerns all students, whose study is financed by the government and private persons or corporations. The purpose of such a limitation is to carry out control over the availability of resources at universities for preparing specialists. This limitation is not widespread in international practice and it represents the remains of the post-Soviet transformation in the system of higher education in 
Ukraine. However in the near future, it can be used for modernization in the process of managing efficiency in university education.

One of such mechanisms can be the connection of licensed number of students with the results of annual professional, complex and objective estimation of activity in universities. Therefore a system of new normative notions should be formed (Table 2).

Table 2. System of normative indexes for stimulating effectiveness in scientific-pedagogical activity of universities in Ukraine.

\begin{tabular}{|c|c|c|c|}
\hline No. & Name of the Index & Method of Definition & Value (Role) \\
\hline 1 & $\begin{array}{l}\text { Basic licensed number } \\
\text { of specialties }\end{array}$ & $\begin{array}{l}\text { Calculated by the procedure of licensing the } \\
\text { major according to the current legislation }\end{array}$ & $\begin{array}{l}\text { Forms initial condition } \\
\text { for activity }\end{array}$ \\
\hline 2 & $\begin{array}{l}\text { Current licensed } \\
\text { number of specialties }\end{array}$ & $\begin{array}{l}\text { Calculated as arithmetical mean for enrollment } \\
\text { of students for last } 3-5 \text { years }\end{array}$ & $\begin{array}{l}\text { Stimulates marketing of } \\
\text { educational services }\end{array}$ \\
\hline 3 & $\begin{array}{l}\text { Factual licensed } \\
\text { number of specialties }\end{array}$ & $\begin{array}{l}\text { I variant: Calculated as multiplication of index } \\
\text { \# } 1 \text { (for } 3-5 \text { years after obtaining the license) by } \\
\text { the coefficient of the annual change in the } \\
\text { ranking position of the university } \\
\text { II variant: Calculated as multiplication of index } \\
\text { \# } 2 \text { (after } 3-5 \text { years of university's work by the } \\
\text { license) by the coefficient of the annual change in } \\
\text { the ranking position of the university }\end{array}$ & $\begin{array}{l}\text { Stimulates innovations } \\
\text { and quality }\end{array}$ \\
\hline
\end{tabular}

Source: Developed by the first author.

The process of calculating average indexes can be carried out either by the method of mean arithmetical, or by the method of moving average (Huber 2011; Velychko and Velychko 2017b). Hence the adjustment of the current annual licensed number by all accredited programs of universities should take place annually by the coefficient of changes in ranking of this educational establishment in a transparent, objective and authoritative general Ukrainian rating, which will be formed by the National Agency for Quality Assurance in Higher Education of Ukraine (NAQAHEU) according to the articles of The Law of Ukraine "On Higher Education" (The Law of Ukraine 2014), or by the Ministry of Education and Science of Ukraine (MESU).

Such a system will stimulate both state and private universities towards constant improvement of "soft spots" as well as the cumulative improvement of the general quality of educational, scientific and consulting services of universities. Under those conditions alternative actions will lead to a gradual loss of potential amounts of private and possibly, budget financing of higher educational establishments. In addition, the previously obtained position in ranking can be kept (coefficient of changes-1.0), only through further progressive development of the educational establishment.

Thus positive change of the annual rating position of universities will promote the increase in the actual licensed number of students in a current year. Besides, this change can partly compensate for the loss in the licensed number due to insufficiently effective marketing of educational services in previous years. The principle of efficiency would be implemented in a just way when universities with highest ratings and dynamics provide education for most specialists through accredited educational programs. The main task is to form a maximally objective rating system based on a set of public external indexes of activity in universities. It is essential that the calculations of most indexes should be carried out per one staff member of scientific-pedagogical workers (SPW) in a certain university.

\subsection{Systems of Providing Efficiency for Higher Educational Establishments (System of Internal Provision of Efficiency)}

At the second stage, the authors' mechanism of accumulating the system for stimulating scientific-creative activity of scientific-pedagogical workers with the focus on principles of the grading system has been developed (Nepal 2012). In Ukraine, integrated requirements are used for the 
scientific-pedagogical worker. In the state university, that worker should mandatorily combine research and consulting activities. The authors have suggested a methodological approach, which is focused on certain estimation criteria for the research activities of scientific-pedagogical workers of a certain department. It is essential that this approach could be extended and adapted to different operating conditions. A list of works and the process of their quantitative estimation can be individualized in the system of management of a certain department or university. Therefore the authors' list of important and prospective types of scientific works at the department in the modern Ukrainian university has been suggested. Considering the different levels of complexity and labor-intensiveness, each of them had a conditional score mark (Table 3).

According to the methodological approach, it can be used at planning individual work of scientific-pedagogical workers under conditions of hourly wages with a fixed official salary. The volume loaded to each worker during the academic year can vary from 0.25 to 1.5 of a wage-rate of the official salary. While drawing a plan for the scientific-research work for the next calendar year, every SPW by his/her own selection should foresee any measureable implementation which in total will make it possible to get results not worse than before (multiplication of 3.0 scores per planned average annual rate of SPW). Underperformed scores in fact at the end of the year (multiplication of 3.0 scores by factual average annual rate of SPW minus fact) should be added by SPW to the plan of the next calendar year(multiplication of 3.0 scores per expected average annual rate of SPW).

Table 3. Conditional score mark of essential and prospective types of the scientific activities of a modern Ukrainian university.

\begin{tabular}{|c|c|}
\hline Measure on R\&D & Value, Conditional Score \\
\hline \multicolumn{2}{|l|}{ Defending of dissertations } \\
\hline Doctor of Science & 5.0 \\
\hline Candidate of Science $(P h D)$ & 3.0 \\
\hline \multicolumn{2}{|c|}{ Monographs in publications with category A, B according to the classification SENSE } \\
\hline By one person & 5.0 \\
\hline By a group & $5.0 /$ number of authors \\
\hline \multicolumn{2}{|c|}{ Monographs in publications with category $\mathrm{C}$ according to the classification SENSE } \\
\hline By one person & 3.0 \\
\hline By a group & $3.0 /$ number of authors \\
\hline Contract to create and transfer scientific-technical produce & 0.5 from $10000 \mathrm{UAH} /$ number of performers \\
\hline \multicolumn{2}{|l|}{ Research grant } \\
\hline Leader & 2.0 \\
\hline Group member & 1.0 \\
\hline \multicolumn{2}{|c|}{ Carrying out the research on the account of specialized financing from the state budget } \\
\hline Supervisor & 2.0 \\
\hline Executive & 1.0 \\
\hline \multicolumn{2}{|c|}{ Supervision over student's scientific work to participate in the competition } \\
\hline Participation in the II round & 0.5 \\
\hline Prize place & 1.5 \\
\hline \multicolumn{2}{|l|}{ Article by SPW in the publication which is included in: } \\
\hline Scopus and/or Web of Science Core Collection (quartile Q1 or Q2) & $2.5 /$ number of authors \\
\hline Scopus and/or Web of Science Core Collection (quartile Q3 or Q4) & $2.0 /$ number of authors \\
\hline Emerging Sources Citation Index, Web of Science & $1.5 /$ number of authors \\
\hline Index Copernicus & $1.0 /$ number of authors \\
\hline Professional publication in Ukraine & $0.5 /$ number of authors \\
\hline Article of a student & Norm per article for SPW \\
\hline Supervision over preparation & is divided by a factor of 1.5 \\
\hline Registration of copyrights (author's invention, patent) & 1.0 \\
\hline \multicolumn{2}{|l|}{ Increase in the Hirsch index of SPW (+ one item) } \\
\hline Web of Science, Scopus & 2.0 \\
\hline Google Scholar & 0.5 \\
\hline
\end{tabular}

Source: Developed by the 1st author according to the data (Journal Citation Reports 2018; Research School for Socio-Economic and Natural Sciences of the Environment 2018; SCImago Journal and Country Rank 2018).

Considering the possible cyclic process of scientific-creative activities due to the fact that more is received by the end of the year (multiplication by 3 points per factual average annual rate), 
SPW has the right to include the performance of additional enrollment for the following calendar year. The completion of extra enrollment of measures on research and development work is the reason for the suggestion made by the head of the department to the dean's office and the rector's office, in order to target awarding bonuses to employees of the department.

If such awarding bonuses haven't taken place, SPWs are entitled to transfer the received additional points to the plan of the following calendar year in the amount of $100 \%$ of overworking; instead, if the bonuses took place, the amount should be $50 \%$.

Further development and improvement of the accumulating system for stimulating scientific-creative activities have led to the development of the motivational mechanisms of uneven distribution of the minimal amount of scientific consulting services (contract work) between workers of the department.

The main components of this mechanism are dependencies which, to a certain extent, harmonize the contribution of each worker into the overall result of the department. In particular, a SPW, who in the previous period worked more in the scientific-research activities, has the possibility to plan and provide a smaller amount of scientific consulting services (contract work) next year. Instead, a SPW, who in the previous period worked less in the scientific-research activities, should plan and provide a larger amount of scientific consulting services (contract work) next year.

The mechanism can be seen as the calculation of costs for minimal amounts of rendered services (performed work) in the planned period by a certain scientific-pedagogical worker. The process of calculation is done using the procedures which are described in the form of the linear algorithm (Figure 1).

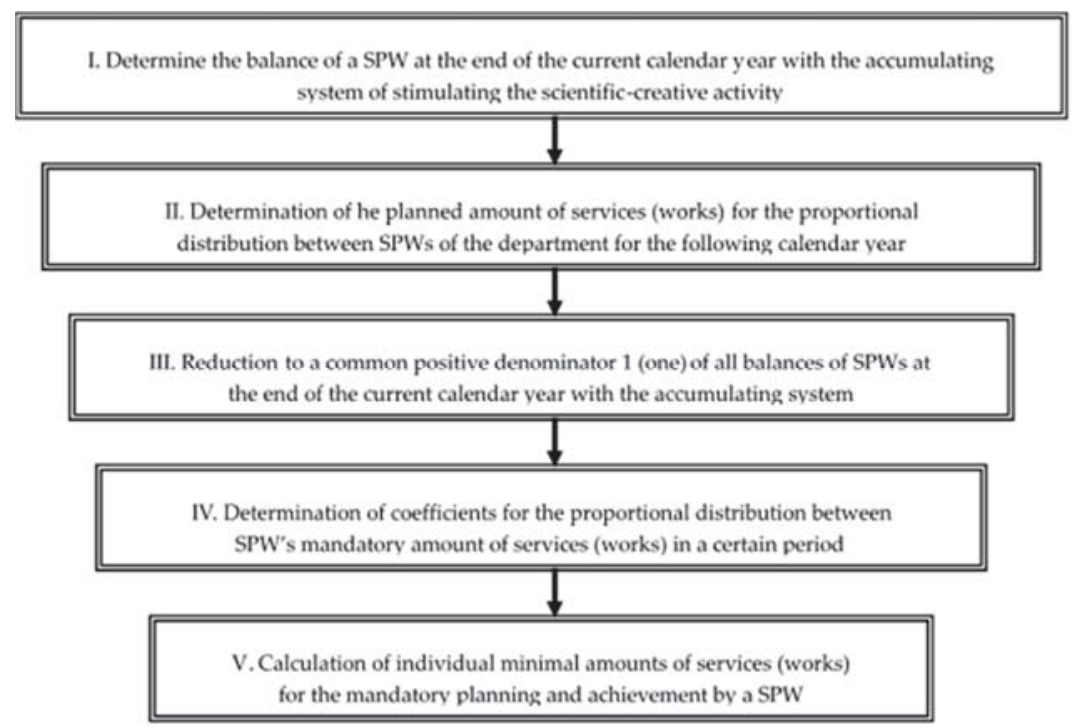

Figure 1. Algorithm for determining the minimal amount of the individual participation of every SPW in the performance of the plan of the department towards the provision of scientific consulting services (carrying out contracted work). Source: Developed by the first author.

Such an algorithm can be applied in practice only after the initial implementation and use of the accumulating stimulation of scientific-creative work of the department staff in the university. Thus the methodological approach objectively considers the possible cyclic type of individual achievements of a SPW both in scientific and consulting activities during a certain period of work. As such, the current growth in indexes of a certain SPW in scientific activities can be compensated by the possibility of 
decreasing indexes in consulting activities and vice versa. It is especially efficient under the conditions of hourly wages.

\section{Results and Discussion}

\subsection{Systems of Providing Efficiency for Higher Educational Establishments (System of External Provision of Efficiency)}

At the first stage of the research, it has been determined that nowadays in Ukraine, scientific-pedagogical workers are often not fully interested in working efficiently, for their input into the communal result in most cases cannot be objectively measured and valued. The evaluation of work efficiency is often conducted subjectively: According to the personal attitude of a manager, his/her will and wish are based on his/her judgment but not with precise measurement. Therefore such an estimation can be precise. As such, the positions can be occupied by persons whose professional activity is not sufficiently efficient. The psychology of university workers with the dominating bureaucratic type of activity often contains a certain set of features. In such a way, only an imitation of activity by the staff takes place. Attempts to avoid individual activity for work results take place. For productive workers in the staff, uncomfortable psychological conditions can be artificially created. The ability to react quickly and proactively to changes is sometimes substituted by references to obsolete formal rules and instructions. This significantly opposes the idea of efficient work of the staff.

Under those conditions the main threat to the spread of the autonomy of universities in Ukraine is a low social responsibility for higher education as well as further bureaucratization of or focus on the low-commercial effect. The main preventer of these effects can be the implementation of a system of self-regulated complex efficiency and social responsibility of higher educational establishments under the conditions of academic, staff and financial freedom. But universities need a corresponding motivation for such a system.

As a result the operational plan for reforms in management of higher education was developed for the Ministry of Education and Science of Ukraine (Figure 2). It is focused on implementing the developed mechanism into the external stimulation of efficiency in educational and scientific activity of Ukrainian universities under the conditions of post-Soviet transformations and integration into the EU models.

The suggested mechanism of stimulating efficiency in scientific-pedagogical activity implies the formation of a multi-vector competitive environment, which in the best path ruins the existing destructive bureaucratic systems. In particular, changes in the environment of public administration could form the acting mechanism of competitiveness in the field of innovative development and real quality of education. By using this system, for example, Sumy, Lviv Ukrainian universities and Mariupol and Uzhgorod Ukrainian universities would become real competitors (which they are unlikely to be now in the competition for regional applicants). This exact process stimulates high-quality transformation of internal management for each university (the spread strategy of preserving jobs will be substituted by the strategy of progressive development). Under the conditions of academic autonomy, the limit of authorities to take additional students will become the consequence of the complex work of universities.

The mission of the National Agency on Provision of Qualitative Education is to form transparent rules for competition between universities. The rating estimation of universities by most indexes should be made per one university worker. After implementation of the suggested mechanism into the university environment, the system of self-regulation of quality will start to work. It can be conditionally compared with the principle of the "invisible hand" in the market economy. It will significantly decrease corruption risks in the higher education, as well as weaken the dependence of universities on administrative preferences at the government level. In such a competitive environment, not a famous but a dynamic university will gradually obtain new advantages in the licensed number of students over more famous universities with slow paces of development. Also a more severe progressive competition of universities for attracting professionals will begin. The main purpose 
is to create conditions and stimuli for dynamic self-development for each university, since the long-term post-Soviet regression of higher education in Ukraine is a major threat to Ukrainian global competitiveness. The main purpose is to create conditions and stimuli for dynamic self-development for each university, since long-term post-Soviet regression of higher education in Ukraine is a major threat to Ukrainian competitiveness in the world.

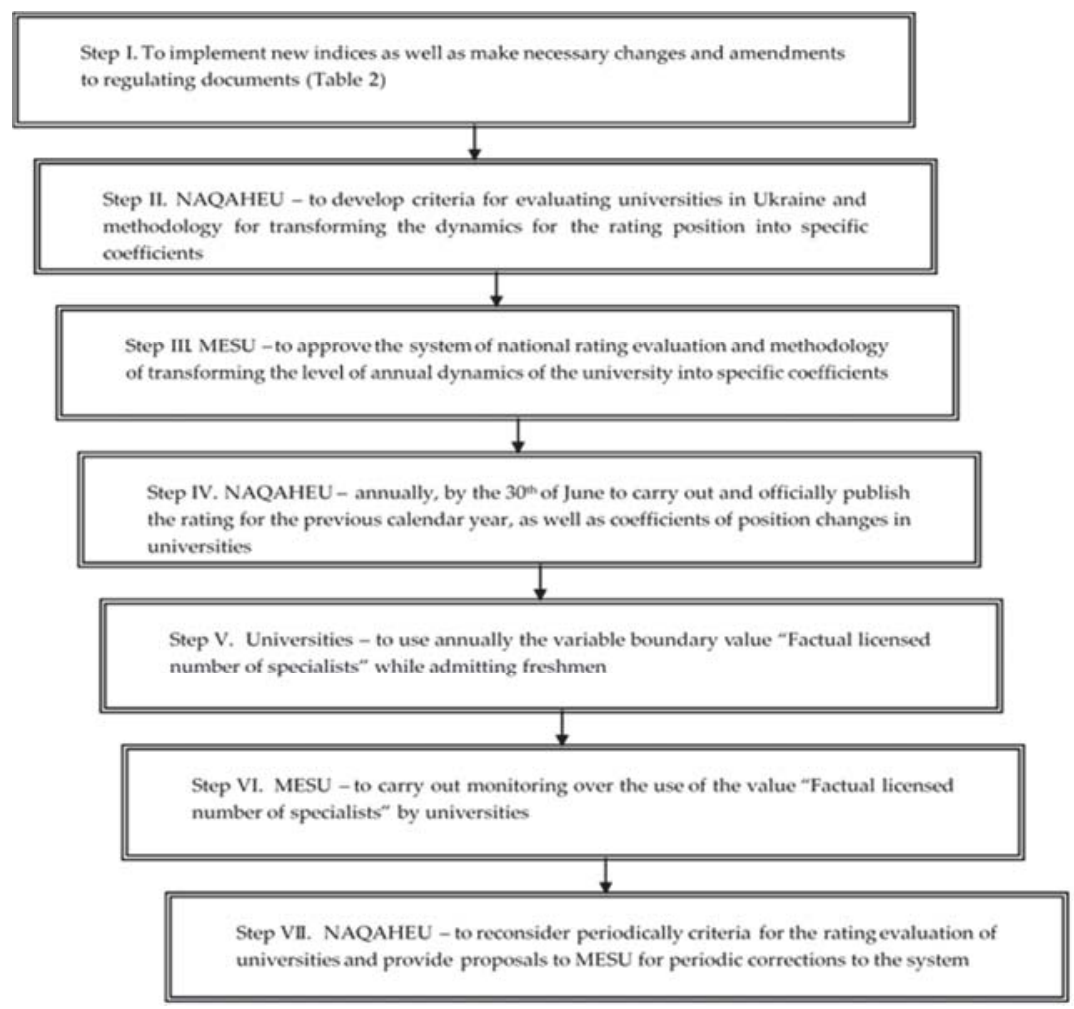

Figure 2. Operational plan of implementing the mechanism of external stimulation of efficiency into educational and scientific activities of Ukrainian universities at the stage of the post-Soviet transformation. Source: developed by the first author.

The best stimulus to innovative development and constant qualitative improvement in Ukrainian universities is not the external or internal control-bureaucratic system (Gedikova 2016; Nalyvaiko 2015), but the intensive environment. Under the suggested conditions, the component of the strategy in the professionally-directed work of most universities will be not only the marketing of educational services but also the system of real innovative management and quality control. As a consequence of thorough and thoughtful but target-focused implementation of such a Ukrainian approach (motivation both in quantity and complex quality), the competitive positions of most Ukrainian universities at the market of domestic and European educational services will obtain better prospects for dynamic growth.

\subsection{Systems of Providing Efficiency for Higher Educational Establishments (System of Internal Provision of Efficiency)}

At the second stage of the research, we analyzed the effectiveness of implementation of the developed accumulating system for stimulating scientific-pedagogical activity in Dnipro State Agrarian 
and Economic University (Ukraine). Within the context of formation of academic autonomy in higher educational establishments and consideration of the existing features of the activity, on the Department of Management and Law, we implemented the internal regulation on the accumulative system of stimulating scientific-creative activity. The regulation has been developed in accordance with Article 33 of Law of Ukraine "On Higher Education" (The Law of Ukraine 2014) considering the implementation of own programs in educational, scientific, scientific-technical and innovative activity. According to the methodology described in Table 3, we carried out the estimation of factual individual productivity of SPW in conditional points (scores). The determined current level of activity of a worker was input into the developed accumulating system. As a consequence of summing the conditional points for the current year to the remaining points from the previous year, we determined the new balance for each SPW. The new balance shows a certain current condition by the end of the accounting period. The condition of the accumulating system by the end of the reporting year 2017 naturally testified to various individual results of implementing necessary planned indexes.

After setting new balances, there was a distribution in the minimal amount of scientific consulting services (contracted works) for the future planned period of 2018 between nine SPWs in the department. In particular, the output data for such distribution between SPWs is the value of the individual balance in conditional points. The procedure of distribution was carried out due to stages of determining the minimal amount of individual participation of each SPW in completion of the department's work plan on provision of scientific-consultation services (Figure 1). The results of calculations by the algorithm are represented in Table 4.

Table 4. Distribution of the minimal amount of the individual participation of a SPW in completion of the plan to provide consulting services at the Department of Management and Law in 2018.

\begin{tabular}{|c|c|}
\hline Step of the Algorithm & Calculation of Data \\
\hline $\begin{array}{l}\text { I. Setting of balance for a SPW at the end of } 2017 \text { by } \\
\text { the accumulating system of stimulating } \\
\text { scientific-creative activity in conditional points }\end{array}$ & $\begin{array}{l}\mathrm{SPW}_{1}(+4.91) ; \mathrm{SPW}_{2}(+4.87) ; \mathrm{SPW}_{3}(-1.035) ; \mathrm{SPW}_{4}(-4.57) ; \\
\mathrm{SPW}_{5}(+1.075) ; \mathrm{SPW}_{6}(+2.825) ; \mathrm{SPW}_{7}(-3.9) ; \mathrm{SPW}_{8}(-0.85) ; \\
\mathrm{SPW}_{9}(-1.6)\end{array}$ \\
\hline $\begin{array}{l}\text { II. Determination of the planned amount of services } \\
\text { (works) for the proportional distribution between } \\
\text { SPWs of the department for } 2018\end{array}$ & $\begin{array}{l}\text { Difference between the general planned amount of services (works) of } \\
\text { the department and amount of services (works), innovative SPW by the } \\
\text { accumulating system }(15,000-4500=10,500 \mathrm{UAH}) \text {. }\end{array}$ \\
\hline $\begin{array}{l}\text { III. Reduction to a common positive denominator } 1 \\
\text { (one) of all balances of SPWs at the end of } 2017 \text { by the } \\
\text { accumulating system }\end{array}$ & $\begin{array}{l}\text { A common positive denominator } 1 \text { (one) point with the minimal balance } \\
\text { of } \mathrm{SPW}_{4}(4.57) \text { required addition of }+5.57 \text { points to all balances of SPWs. } \\
\text { Hence there were the following intermittent results for each } \\
\text { scientific-pedagogical worker: } \mathrm{SPW}_{1}(10.48) ; \mathrm{SPW}_{2}(10.44) ; \\
\mathrm{SPW}_{3}(4.535) ; \mathrm{SPW}_{4}(1.0) ; \mathrm{SPW}_{5}(6.645) ; \mathrm{SPW}_{6}(8.395) ; \mathrm{SPW}_{7}(1.67) ; \\
\mathrm{SPW}_{8}(4.72) ; \mathrm{SPW}_{9}(3.97) \text {. } \\
\text { At that the total sum was } 51.855 \text { conditional points. }\end{array}$ \\
\hline $\begin{array}{l}\text { IV. Determination of indexes for the proportional } \\
\text { distribution between SPWs for the mandatory for the } \\
\text { department amount of services (works) in } 2018\end{array}$ & $\begin{array}{l}\mathrm{SPW}_{1}(51.855 / 10.48=4.947) ; \mathrm{SPW}_{2}(51.855 / 10.44=4.966) ; \\
\mathrm{SPW}_{3}(51.855 / 4.535=11.434) ; \mathrm{SPW}_{4}(51.855 / 1.00=51.855) ; \\
\mathrm{SPW}_{5}(51.855 / 6.645=7.803) ; \mathrm{SPW}_{6}(51.855 / 8.395=6.176) ; \\
\mathrm{SPW}_{7}(51.855 / 1.67=31.05) ; \mathrm{SPW}_{8}(51.855 / 4.72=10.986) ; \\
\mathrm{SPW}_{9}(51.855 / 9.37=13.061) . \\
\text { At that the total sum was } 142.278 \text { conditional points. }\end{array}$ \\
\hline $\begin{array}{l}\text { V. Calculation of individual minimal amounts of } \\
\text { services (works) for mandatory planning and } \\
\text { implementation by SPWs in } 2018\end{array}$ & $\begin{array}{l}\mathrm{SPW}_{1}\left[(4.947 / 142.278)^{*} 10,500=365 \mathrm{UAH}\right] \\
\mathrm{SPW}_{2}\left[(4.966 / 142.278)^{*} 10,500=366 \mathrm{UAH}\right] ; \\
\mathrm{SPW}_{3}\left[(11.434 / 142.278)^{*} 10,500=844 \mathrm{UAH}\right] \\
\mathrm{SPW}_{4}\left[(5.855 / 142.278)^{*} 10,500=3827 \mathrm{UAH}\right] \\
\mathrm{SPW}_{5}\left[(7.803 / 142.278)^{*} 10,500=576 \mathrm{UAH}\right] ; \\
\mathrm{SPW}_{6}\left[(6.176 / 142.278)^{*} 10,500=456 \mathrm{UAH}\right] ; \\
\mathrm{SPW}_{7}\left[(31.05 / 142.278)^{*} 10,500=2291 \mathrm{UAH}\right] ; \\
\mathrm{SPW}_{8}\left[(10.986 / 142.278)^{*} 10,500=811 \mathrm{UAH}\right] ; \\
\mathrm{SPW}_{9}\left[(13.061 / 142.278)^{*} 10,500=964 \mathrm{UAH}\right] \\
\text { At that the total sum was } 10,500 \mathrm{UAH} .\end{array}$ \\
\hline
\end{tabular}

Source: developed by the authors.

Application of the developed algorithm (Figure 1), based on the individual balance of a SPW for the end of the previous accounting period of 2017, made it possible to receive a set of assuming results for planning the 2018 period (Table 4). Those results were shown in financial equivalents 
(thous. UAH). 10,500-is the proportionally distributed minimal amount of services (works) at the department, allocated between the workers of the department for the future period. Moreover the general plan of the department for 2018 was 15,000 UAH. The remaining 4500 UAH was previously independently initiated for 2018 for SPW2 (2500 UAH) and SPW5 (2000 UAH) within the accumulating system of stimulating the scientific-creative activity.

Consequently, the results of calculations of the minimal amount of individual participation by SPWs in the completion of the department's plan on provision of scientific consulting services (performance of the contracted works), turned out quite versatile. However, unlike the results of the accumulating system of stimulating the scientific-creative activity, they were indirectly proportional (Figure 3).

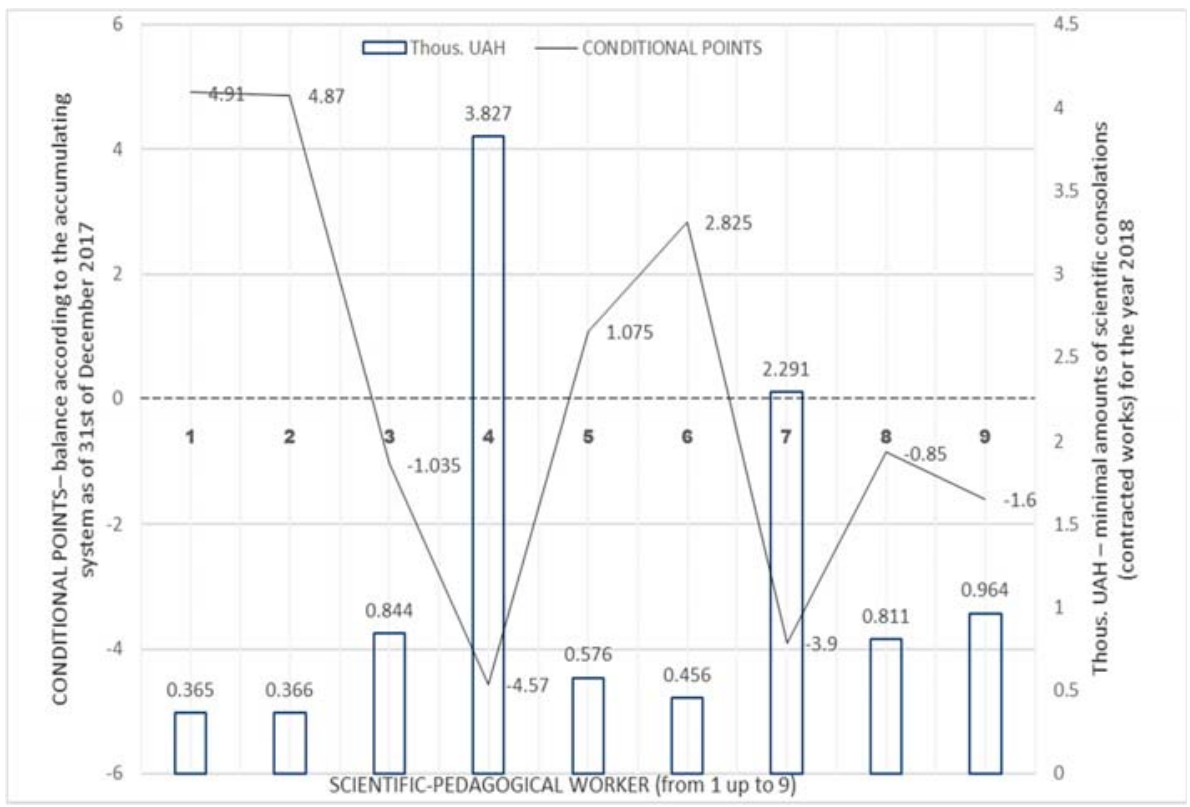

Figure 3. Harmonization in amounts of the individual participation of a SPW in scientific-research and consulting (contracted) work at the Department of Management and Law. Source: Developed by the first author.

Conclusively this makes possible to harmonize the individual part of each SPW both in the scientific-research and in the consulting (contracted) work of the department. Such an approach provides a possibility to support the staff potential more effectively and leads to improvements in efficiency.

The analysis also showed that the main advantages of the accumulating systems were: Clear formulation of minimal requirements with the simultaneous provision of a wide selection choice for each SPW; increase in value of personal results; creation of favorable conditions for implementing individual scientific-creative potential of professors; harmonization of personal inputs for each SPW into general scientific achievements of the department; consideration of the cyclic type of scientific-creative activity; formation of the efficient system for evaluation and stimulation of the scientific-research activity of professors, as well as fairness and transparency.

The suggested mechanism of the accumulating system to stimulate scientific-pedagogical activity to a certain extent is inferior to the globally widespread model of the individual material reward 
of all scientific-pedagogical workers based on periodic rating evaluation (Ebert-May et al. 2015; Lee and Tan 2010; Nepal 2012; Phillips et al. 2014). However the experience of the practical implementation has proved the efficiency of this approach under the existing conditions for Ukrainian scientific-pedagogical workers.

\section{Conclusions}

Increase in the level of efficiency for the contemporary higher education in Ukraine can be achieved through the reformation of post-Soviet bureaucratic systems of management and intensification of multi-vector competitive environment between universities. The mechanism of implementation of such a strategy, developed by the authors, implies:

(1) a focus on principles of re-engineering and motivational management in the system of implementing transformational challenges of the higher education in Ukraine;

(2) implementation of the system of normative indexes for stimulating marketing, innovations and quality as main drivers for internal university reforms;

(3) connection between licensed numbers of enrolled students and results of national and international rating estimation of university activity;

(4) introduction of the accumulating system in order to stimulate scientific-creative activity of university staff;

(5) application of grading principles while planning and estimating the level of completion of essential and prospective types of scientific work carried out by university workers.

Theoretical value. The concept and methodology of the managing efficiency of the post-Soviet transformation of higher education based on re-engineering, rating and grading has been developed. Methodological approaches to motivational management in universities through development of the accumulating system of stimulating scientific-creative work of the research staff have been further developed.

Practical value. A system of normative indexes in the legislation area for stimulating efficiency of educational-scientific and innovation activity in modern Ukrainian universities has been suggested. The mechanism for score estimation of the productivity level in scientific-creative work of the university research staff based on grading has been developed. Efficiency of implementing this mechanism in Dnipro State Agrarian and Economic University (Ukraine) has been experimentally proven.

The results of the research can be used in the system of public administration of higher education as well as in practice for management in universities.

Author Contributions: Conceptualization, O.V. and L.V.; Data curation, L.V.; Formal analysis, O.V.; Funding acquisition, M.K.; Investigation, O.V.; Methodology, O.V.; Project administration, O.V.; Resources, O.V. and M.K.; Software, L.V.; Supervision, O.V.; Validation, O.V., L.V. and M.K.; Visualization, M.K.; Writing-Original Draft, O.V., L.V. and M.K.; Writing-Review \& Editing, L.V.

Funding: This research received no external funding

Acknowledgments: The work has been funded by the Ministry of Education and Science of Ukraine. The research was carried out within the context of tasks for scientific project: "Concept of transformation for organizational-economic mechanisms of management and logistics for enterprises in the system of economic safety of Ukraine" ((No. ID:62198 22.08.2016 (64-1)). The project was recommended by the National Council of The Ministry of Education and Science of Ukraine for financing at the expense of the state budget. The research was carried out also within the context of the tasks of Ukrainian-American international project "Training and Development of the management personnel of the Ukrainian Universities" which was initiated by the investment company "Rayter Inc." (Dallas, TX, USA). The goal of the program is the assistance of the educational reform in Ukraine by the professional development of management employees in Ukrainian Universities.

Conflicts of Interest: The authors declare no conflict of interest. The funders had no role in the design of the study; in the collection, analyses, or interpretation of data; in the writing of the manuscript, and in the decision to publish the results. 


\section{References}

Agasisti, Tommaso, and Carmen Pérez-Esparrells. 2010. Comparing efficiency in a cross-country perspective: The case of Italian and Spanish state universities. Higher Education 59: 85-103. [CrossRef]

Avramovic, Aleksandar. 2016. Higher Education Governance Reforms in Europe and Serbia-Recommendations for the Way Froward. Austria: Danube University Krems.

Berács, József. 2014. Emerging Entrepreneurial Universities in University Reforms: The moderating role of personalities and the social/economic environment. CEPS Journal: Center for Educational Policy Studies Journal 4: 9-15.

Berghman, Liselore, Paul Matthyssens, Sandra Streukens, and Koen Vandenbempt. 2013. Deliberate learning mechanisms for stimulating strategic innovation capacity. Long Range Planning 46: 39-71. [CrossRef]

Bowen, Howard. 2017. Investment in Learning: The Individual and Social Value of American Higher Education. eBook Published. New York: Routledge.

Brooks, Michael, and Nada K. Kakabadse. 2014. Introducing matrix management within a children's services setting-personal reflections. Management in Education 28: 58-63. [CrossRef]

Burbyka, Mykhailo, and Oleksandr Telizhenko. 2015. The problems of the present condition of state control and regulation in the field of economic activity. Problems and Perspectives in Management 13: 254-58. Available online: http:/ / essuir.sumdu.edu.ua/handle/123456789/44310 (accessed on 4 May 2018).

Christensen, Tom. 2011. University governance reforms: Potential problems of more autonomy? Higher Education 62: 503-17. [CrossRef]

Cohen, Louis, Lawrence Manion, and Keith Morrison. 2017. Research Methods in Education, 8th ed. London: Routledge.

Dobbins, Michael, and Christoph Knill. 2017. Higher education governance in France, Germany, and Italy: Change and variation in the impact of transnational soft governance. Policy and Society 36: 67-88. [CrossRef]

Ebert-May, Diane, Terry L. Derting, Timothy P. Henkel, Jessica M. Maher, Jennifer L. Momsen, Bryan Arnold, and Heather A. Passmore. 2015. Breaking the cycle: Future faculty begin teaching with learner-centered strategies after professional development. CBE-Life Sciences Education 14: 22-27. [CrossRef] [PubMed]

Gedikova, Natalia P. 2016. Derzhavnapolityka u sferivyshchoiosvityUkrainy v kontekstiyevropeiskykhosvitnikhstandartiv [State policy in the sphere of higher education in Ukraine within the context of European educational standards]. Suchasnesuspilstvo: Politychninauky, Sotsiolohichninauky, Kulturolohichninauky-Contemporary Society: Political Science, Sociological Science, Cultural Science 1: 4-17. (In Ukrainian)

Goncharuk, Anatoliy G. 2015. Management Education in Research. Journal of Applied Management and Investments 4: 151-55.

Goncharuk, Anatoliy G. 2016. Evaluating the Efficiency of Higher Education. Journal of Applied Management and Investments 5: 82-91.

Gormally, Cara, Mara Evans, and Peggy Brickman. 2014. Feedback about teaching in higher ed: Neglected opportunities to promote change. CBE-Life Sciences Education 13: 187-99. [CrossRef] [PubMed]

Grynko, Tetiana, Oleksandr Krupskyi, Mykola Koshevyi, and Olexandr Maximchuk. 2017. Modern Concepts of Financial and Non-Financial Motivation of Service Industries Staff. Journal of Advanced Research in Law and Economics 8: 1100-12. [CrossRef]

Hansen, Hanne F. 2011. University reforms in Denmark and the challenges for political science. European Political Science 10: 235-47. [CrossRef]

Hoidn, Sabine, and Sibylle Olbert-Bock. 2016. Learning and teaching research methods in management education: Development of a curriculum to combine theory and practice-A Swiss case. International Journal of Educational Management 30: 43-62. [CrossRef]

Hradilova, Alena. 2015. Language centre matrix management structure: Developments in teacher training, Recherche et pratiquespédagogiquesenlangues de spécialité. Cahiers de l'Apliut 34: 90-105.

Huber, Peter J. 2011. Robust statistics. In International Encyclopedia of Statistical Science. Berlin/Heidelberg: Springer. [CrossRef]

Hudym, Kateryna M., and Svitlana M. Khalatur. 2016. Systematisation and analysis of MNCs' models of conduct for entering the national agrarian markets. Economic Annals-XXI 159: 34-37. [CrossRef]

Illés, Csaba B., Hilda Hurta, and Anna Dunay. 2015. Efficiency and profitability along the lifecycle stages of small enterprises. International Journal of Management and Enterprise Development 14: 56-69. [CrossRef] 
Johnes, Geraint, and Jill Johnes. 2009. Higher education institutions' costs and efficiency: Taking the decomposition a further step. Economics of Education Review 28: 107-13. [CrossRef]

Journal Citation Reports. 2018. Identification Information. Available online: https:/ /jcr.incites.thomsonreuters. com (accessed on 28 July 2018).

Koshal, Rajindar K., and Manjulika Koshal. 1999. Economies of scale and scope in higher education: A case of comprehensive universities. Economics of Education Review 18: 269-77. [CrossRef]

Krüger, Karsten, Martí Parellada, Daniel Samoilovich, and Andrée Sursock. 2018. Governance Reforms in European University Systems: The Case of Austria, Denmark, Finland, France, The Netherlands and Portugal. Cham: Springer International Publishing. [CrossRef]

Kwiek, Marek. 2017. A generational divide in the academic profession: A mixed quantitative and qualitative approach to the Polish case. European Educational Research Journal 16: 645-69. [CrossRef]

Lee, Christine Kim-Eng, and Mei Ying Tan. 2010. Rating teachers and rewarding teacher performance: The context of Singapore. Paper presented at the APEC Conference on Replicating Exemplary Practices in Mathematics Education, Koh Samui, Thailand, March 7-12.

Low, Ee-Ling, and Oon-Seng Tan. 2017. Teacher Education Policy: Recruitment, Preparation and Progression. In Teacher Education in the 21st Century. Singapore: Springer. [CrossRef]

Mircea, Marinela, Bogdan Ghilic-Micu, Marian Stoica, and Panagiotis Sinioros. 2016. Inter-organizational Performance and Business Process Management in Collaborative Networks. Economic Computation and Economic Cybernetics Studies and Research 50: 107-22.

Moodie, Gavin. 2014. Everything for sale? The marketisation of UK higher education. Journal of Higher Education Policy and Management 36: 87-95. [CrossRef]

Nalyvaiko, Larysa R. 2015. Transformatsiiaderzhavnoiosvitnoipolityky v Ukraini v umovakhyevrointehratsii [Transformation of government educational policy in Ukraine within the context of European integration]. Pravoisuspilstvo - Law and Society 3: 31-36. (In Ukrainian)

Nepal, Kali P. 2012. An approach to assign individual marks from a team mark: The case of Australian grading system at universities. Assessment \& Evaluation in Higher Education 37: 555-62. [CrossRef]

Oganisjana, Karine, Anna Svirina, Svetlana Surikova, Gunta Grīnberga-Zālīte, and Konstantins Kozlovskis. 2017. Engaging universities in social innovation research for understanding sustainability issues. Entrepreneurship and Sustainability Issues 5: 9-22. [CrossRef]

Phillips, Karen, Rose Balan, and Tammy Manko. 2014. Teacher Evaluation: Improving the Process. Transformative Dialogues: Teaching \& Learning Journal 7: 88-94.

Popova, Elena, Viktor Blaginin, and Wadim Strielkowski. 2017. Leadership in Educational Management Process in Russian and Foreign Higher Educational Institutions. In Leadership for the Future Sustainable Development of Business and Education. Heidelberg: Springer International Publishing.

Ranking Web of Universities. 2018. July New Edition. Identification Information. Available online: http:/ /www. webometrics.info/en/world (accessed on 30 July 2018).

Research School for Socio-Economic and Natural Sciences of the Environment. 2018. Identification Information. Available online: http:/ / www.sense.nl/organisation/documentation (accessed on 28 July 2018).

Sardak, Serhiy, and Volodymyr Sukhoteplyi. 2013. Periodization and forecast of global dynamics of human resources development. Economic Annals-XXI 3-4: 3-6.

Schulz, John. 2017. Visual research methods in educational research. International Journal of Research $\mathcal{E}$ Method in Education 40: 327-28. [CrossRef]

SCImago Journal and Country Rank. 2018. Identification Information. Available online: http:/ /www.scimagojr. com (accessed on 28 July 2018).

Sedláček, Jan. 2017. The Impact of Governance on the Research Performance of European Universities in Cross-Country Comparisons. Review of Economic Perspectives 17: 337-62. [CrossRef]

Slaughter, Shelia, and Gary Rhoades. 2004. Academic Capitalism and the New Economy: Markets, State, and Higher Education. Baltimore: JHU Press.

Taib, Fauziah Md, and Melissa Ng Lee Yen Abdullah. 2016. Governance Reforms in Public Universities of Malaysia. Gelugor: Penerbit USM.

Taylor, Frederick W. 1911. The Principles of Scientific Management. New York: Harper \& Brothers. 
The Law of Ukraine. 2014. The Law of Ukraine "On Higher Education". Passed on 1 July 2014, N 1556-VII. Identification Information. Available online: http:/ / zakon3.rada.gov.ua/laws/show/1556-18 (accessed on 15 March 2018). (In Ukrainian)

Tvaronavičienė, Manuela, Anatoly Shishkin, Peter Lukáč, Nataliia Illiashenko, and Sergii Zapototskyi. 2017. Sustainable economic growth and development of educational systems. Journal of International Studies 10: 285-92. [CrossRef]

Vasylieva, Natalia, and Oleksandr Velychko. 2017. Development of the controlling system in the management of dairy clusters. Eastern-European Journal of Enterprise Technologies 4: 20-26. [CrossRef]

Velychko, Oleksandr. 2015. Integration of SCOR-modeling and logistical concept of management in the system of internal transportation of milk cooperative. Mediterranean Journal of Social Sciences 6: 14-24. [CrossRef]

Velychko, Oleksandr, and Liudmyla Velychko. 2017a. Logistical modelling of managerial decisions in social and marketing business systems. Journal of International Studies 10: 206-19. [CrossRef]

Velychko, Oleksandr, and Liudmyla Velychko. 2017b. Management of inter-farm use of agricultural machinery based of the logistical system «BOA». Bulgarian Journal of Agricultural Science 23: 534-43.

Yang, Rui. 2015. Reassessing China's higher education development: A focus on academic culture. Asia Pacific Education Review 16: 527-35. [CrossRef]

(C) 2018 by the authors. Licensee MDPI, Basel, Switzerland. This article is an open access article distributed under the terms and conditions of the Creative Commons Attribution (CC BY) license (http:/ / creativecommons.org/licenses/by/4.0/). 



\title{
Gender Mainstreaming in Waste Education Programs: A Conceptual Framework
}

\author{
Letícia Sarmento dos Muchangos $1,2, *$ (1) and Philip Vaughter ${ }^{2}$ \\ 1 Graduate School of Media and Governance, Keio University, Kanagawa 252-0882, Japan \\ 2 Institute for the Advanced Study of Sustainability, United Nations University, Tokyo 150-8325, Japan; \\ vaughter@unu.edu \\ * Correspondence: leticia.muchangos@unu.edu
}

Received: 11 January 2019; Accepted: 1 March 2019; Published: 5 March 2019

\begin{abstract}
Gender issues are present in waste management, from daily handling activities through to decision-making processes. In waste education programs, the disregard for views of and contribution by women has resulted in strategies that do not comprehensively address the waste issue, preventing long-standing and sustainable outcomes, while increasing existing gender inequities. Three critical waste matters on education and gender were identified: (1) lack of meaningful involvement and participation of women (and other vulnerable groups) throughout the decision-making processes; (2) lack of inclusion of gender-specific designs and gender-sensitive approaches in the information and education materials; and (3) tendency to devise strategies directed to women only, while exempting the other stakeholders from their responsibilities. This paper presents a closer look into the relationship between waste education and gender, with a proposal of a participatory framework for gender mainstreaming in waste education programs. It includes components to assess the promoting entity of the waste education program and all stages of the program. The framework represents a novel theory and practice contribution for waste education development, to support academics, practitioners, and policymakers, in the quest of achieving equitable and sustainable waste management systems for all.
\end{abstract}

Keywords: gender and waste; gender mainstreaming; waste education

\section{Introduction}

On the gender-and-environment nexus, years of feminist theory have been calling for the development of "frameworks and perspectives that allow an understanding that women and men are not only affected by but also have important roles to play in, enabling environmental sustainability" [1]. It is argued in [2] that to improve the effectiveness of laws and regulations, the specific target groups affected-women and men with all identified gender aspects of cultural diversity—should be addressed appropriately with accompanying measures. Specifically, in environmental education, humans are commonly discussed as homogenous and ungendered, even though significant research has been informed by feminist perspectives [3]. For instance, on Acker's theory of the gendered organization, it is discussed how language, ideology, popular and high culture, dress, and media have been contributing for the gender division of labor [4]. Furthermore, though the division of labor between men and women is changing, women still hold most the responsibility for child-care, therefore having a substantial influence on the development of children's awareness of environmental issues, making women the first environmental educators for many $[5,6]$. Nevertheless, the knowledge and contribution of women to environmental research and frameworks have been systematically marginalized, resulting in strategies that are fundamentally gender-blind $[3,7,8]$. Gender blindness mainly refers to the "failure to recognize that the roles and responsibilities of women/girls and 
men/boys are ascribed to, or imposed upon, them in specific social, cultural, economic and political contexts" [9].

Concerning waste education, despite studies pointing to the influence of gender issues on the views, handling, and management of waste, related policies and programs mostly lack in the inclusion of gender perspectives [10]. Distinctively, there are three key issues surrounding gender and the development of waste education programs. First, the consistent lack of meaningful involvement and participation of women and other vulnerable groups throughout the decision-making processes of planning and implementation of the programs, neglecting their significant role as users and managers of natural resources and waste $[5,11]$. All the more so, in initiatives that consider community participation, "community" is usually seen as a homogenous group, therefore reproducing the unequal power dynamics and reinforcing gender inequalities [12-14].

The second issue is the distortion in messages that recipients receive, with information materials generally not addressing the stakeholders appropriately. In some cases, messages target individuals in general, disregarding specific roles, knowledge, and experience that women and men have, and the fact that messages can potentially increase unpaid work that both parts are already involved in. It has been reported that one of the short-coming of approaches on the women, environment and development arena, including waste, has caused an increase in the unpaid housework and time burdens for women and girls, without them getting the benefits from such approaches $[2,15,16]$. The additional point is that information and education materials that are rooted in gender stereotypes, tend only to be directed at women, overlooking the importance of changing men's behavior and attitudes towards waste management activities $[2,11,17]$.

Connected with the previous issue, the third issue similarly arises when education strategies are directed at consumers and waste generators only, especially women. That phenomenon can also be understood as a critique and moralization of women, and yet again, an added burden to the unpaid reproduction work of female consumers, while exempting the other stakeholders (e.g., authorities, manufacturers, distributors, and retailers) from their responsibilities. Such occurrences are acknowledged as privatization as opposed to the socialization of waste management $[2,18]$.

There are several relevant gender research and practice works on natural resources use and management, as well as on sustainability $[5,10,19-26]$. Nonetheless, fewer initiatives focus on the waste management field, and among the existing ones, the availability of information is dated and limited $[5,10,11,16,18,27-31]$. Moreover, though selected projects have addressed the link between gender and waste, established resourceful and readily-available databases do not exist, and policies and programs, including educational initiatives, have yet to articulate the fundamental questions about gender. In a systematic review analysis of academic journal articles on waste education and the inclusion of the gender perspectives, researchers found that between 2007 and 2017, gender was superficially addressed, and mostly limited to the presentation of sex-disaggregated data to describe the studied groups [32]. Given that, it is timely to have studies, new theories, and reflections on the several aspects about waste and gender, as well as gender mainstreaming in national and local planning $[5,10,11,30]$. Thus, a question that can be posed is, how can the academic and practice community be engaged in the development of waste education programs, and logically integrate gender perspectives and aspects? This paper potentially advances answers to that question, by first providing a closer look into the relationship between waste education and gender, and then proposing a framework for gender mainstreaming in waste education programs. The framework is a tool to guide the (before and after) assessment of the program cycle stages, and help identify the gender inequality unwanted effects and improve the implemented approaches for future initiatives.

The remainder of this paper is organized as follows. Sections 2 and 3 cover literature review on the topics of waste education and waste and gender. Meanwhile, Section 4 presents the grounds of the framework and the description of each component. The concluding points and limitations of the paper are summarized in Sections 5 and 6. 


\section{Waste Education}

Within the sustainable development agenda, waste management is one of the topics of Sustainable Consumption and Production (SCP), and in turn, waste education is a theme within Education for Sustainable Consumption (ESC) [33,34]. ESC has its focus on raising awareness and influencing consumer behavior by providing knowledge, values, and skills to individuals and social groups, with the goals to safeguard the quality of life, enable environmental protection, and provide for the efficient use of resources [33,35]. Education and awareness raising on waste are essential requirements to realize sustainable and effective waste management systems. Hence, public information initiatives and education programs are recognized activities of comprehensive management systems [36,37].

Delivering information on waste has an instructive and a motivating objective, which can be achieved using formal, non-formal, or informal avenues. The instructive one, aims at informing the stakeholders what to do, which is executed through national campaigns and local information by adopting conventional (e.g., posters, media campaigns), as well as innovative and artistic forms (e.g., street theatre, use of social media). On the other hand, the motivating objective has the function to call for stakeholders' attention to the problematic of waste and elucidate their role as part of the solution [38,39]. Therefore, practitioners in the field of waste management should work alongside education professionals to define and design, form, and methodize proper waste management and education strategies [40].

Moreover, the participation of stakeholders such as the government, private sector, civil society, academia, and the public in the development processes for waste education is required. Their participation ensures political and financial support, facilitates involvement, promotes transparency and accountability, and fosters trust and cooperation from the public [38,41]. Also relevant is the design of specific and customized messages and information, to ensure that all stakeholders are aware of the waste issue and its implications [10,36]. Examples of comprehensive information and education strategies for waste management, considering primary stakeholder groups, are presented in Table 1.

Table 1. Selected waste education and information strategies for different stakeholder groups.

\begin{tabular}{|c|c|c|}
\hline Stakeholder Group & Education and Information Objectives & Types of Initiatives \\
\hline General public & $\begin{array}{l}\text { Address cultural practices and beliefs } \\
\text { Emphasize health benefits } \\
\text { Use simple messages and multiple media types } \\
\text { Build on existing community networks }\end{array}$ & $\begin{array}{l}\text { Information campaigns; Green shopping } \\
\text { guidance; Introduction of the waste topic } \\
\text { into the school curriculum }\end{array}$ \\
\hline Government authorities & $\begin{array}{l}\text { Emphasize the economic and health benefits of proper solid } \\
\text { waste management } \\
\text { Frame waste management activities as a topic of great interest } \\
\text { for electorates } \\
\text { Amplify the visibility and credibility of waste management } \\
\text { activities (e.g., by issuing uniforms to workers) } \\
\text { Emphasize the national policy impacts on local operations } \\
\text { Identify instances where local activities support national goals } \\
\text { Communicate about the national benefits of proper local waste } \\
\text { management (e.g., to attract investments) }\end{array}$ & $\begin{array}{l}\text { Institutional training and capacity } \\
\text { building to: } \\
\text { Improve health and safety work conditions } \\
\text { of formal waste workers and assess the } \\
\text { contribution of informal waste workers to } \\
\text { incorporate them into the waste } \\
\text { collection process. } \\
\text { Education and support for green } \\
\text { procurement programs }\end{array}$ \\
\hline
\end{tabular}

\section{Waste and Gender}

Gender represents a social construction of the differences between women and men, as opposed to the consideration of biological characteristics. It determines the attribution of roles and functions, activities, social relations, behaviors, and norms for women and men in society, both in public and private life. There are a set of dynamic cultural determinations and characteristics that create the specific content of being women and men in each historical period, society, and culture $[16,43,44]$. Although both women and men contribute to social production and consumption activities, women often have multiple roles, which translate into inequality issues, particularly in the case of poor women. 
These roles mainly include providing basic needs and wellbeing at the household level through cleaning, cooking, educating children, handling livestock, and farming [5,11]. According to scholars and practitioners working in both the waste and gender fields, four main thematic areas are related to Waste and Gender: the gendered definition of waste; the gendered division of responsibilities for waste; community-based initiatives; and policy and practice $[5,30,31]$.

\subsection{The Gendered Definition of Waste}

Women's and men's individual decisions are shaped by a combination of societal roles and expectations; hence, "waste" is not a (gender) neutral concept. Waste is defined as "something that has no more value" [31]. Nevertheless, what might be useless to an individual, can be considered a resource for enterprise or livelihood to others. For instance, in the household sphere, something that might look like dirt to men can be used as compost or fertilizer by women; and what looks like junk to women, can be used as motor parts to men. Moreover, knowledge of waste issues is different across gender and age. As reported in [30], "women, men, and children are almost certain to have different (and not always overlapping) knowledge of waste disposal places in their neighborhoods." Thus, in discussions and decisions on waste management, it is essential to clarify the different understandings and nuances of what waste and resources are for the target community $[5,30]$.

\subsection{The Gendered Division of Responsibilities for Waste}

The division of responsibilities in regard to waste management roles is also influenced by gender. In several spheres, women are required to be involved in clean up and waste handling activities in the household and at times in the community, without pay. For those who can afford it, they transfer these responsibilities to helpers. In contrast, men are more likely to only deal with waste when is directly connected to their daily activities, or when it is a remunerated effort $[5,11,16,28,30]$. At the household level, women are usually in charge of waste placement for collection and disposal, almost to the exclusion of men's participation due to the understanding that handling waste (especially without pay) will affect their status $[10,11]$. One of the outcomes is that women and children are the most exposed to the health hazards of handling waste, also considering that there are significant biological and behavioral differences between men and women, which influence the epidemiology and pathophysiology response to the exposure of products and substances such as hazardous chemicals and wastes $[1,27,45]$.

Moreover, even though women manage waste at home, there are underlying issues of power dynamics within all households. These issues can limit women's control and access to waste and create conflicts of interest, particularly when waste becomes a source of income $[11,28,31]$.

Another important aspect is the change of the responsibility and ownership that occurs, when the waste goes from being a household property to entering the existing waste management system, by being placed in the outside boundaries, termed 'point of set-out.' This change of boundary can also have implications for the women's autonomy and control of waste materials, and the transition from perceiving waste as a social responsibility to a technical one. Waste management guidelines and infrastructures are usually set up under the male gaze, which tends not to understand the needs and concerns of women regarding waste collection services. An instance where the outcomes of this structure can be observed is in the rise of issues related to the poor selection of location, time, and storage type for waste set-out points $[11,30]$.

Lastly, women and children make a significant part of a large number of informal workers in developing countries dealing with waste collection, sorting, recycling, and selling valuable materials. As such, for women who are informal waste workers, the reproduction of hierarchical gender relations at home, in the workplace, and their respective communities, add to the commonly precarious conditions related to their work activities [46]. 


\subsection{Community-Based Initiatives}

Waste management at the community level is primarily related to the disposal activities at informal (illegal) dump sites and waste collection points, as well as public or communal space cleaning. Small-scale private and community-based enterprises, linked to formal enterprises and local authorities, are commonly in charge of these activities. Women's presence is prevalent by their responsibility to place the waste at the collection and dump sites, and the expectation for them to voluntary keep the community clean and maintain social harmony $[16,18]$. In cases where women move towards institutionalizing and monetizing their otherwise volunteer actions, a shift is usually seen, with men taking over and women being relegated to do stereotypical office work [10,30]. For example, in the e-mail discussion-conference on gender and waste organized by WASTE, Advisers on Urban Environment and Development, a participant noted that "in many Southeast Asian countries the women traditionally are responsible for the household waste and sweeping the streets and compound and take pride in keeping the environment clean and tidy. However, as soon as any of these tasks become paying jobs, men are either targeted for the jobs for various reasons or end up dominating the structures and decision-making systems" [31]. It is also observed that women that participate in waste activities as paid workers are underpaid, work in dangerous social and human conditions, and at times have to take their children to work alongside them. Linked with that is a reinforced cycle that they might face: the work being assigned has low social status, resulting in low pay, then, being paid less, thus being considered low-class citizens $[4,11,16,29,30]$.

Furthermore, women's transition from informal waste picking to micro-enterprising is often faced with limited access to financial resources and family support, and singular association with specific materials such as plastic and textiles, as opposed to other types of materials, of which management is resource-intensive and physically demanding, such as metals and construction debris. Another current issue of social-economic nature is that the participants in women's community initiatives are usually part of the middle and upper classes. These women usually also have connections to the local NGOs and power structures, which can relegate the needs and contribution of women from lower classes [3,5,30]. An example in India regarding affirmative action for leadership positions in local decision-making institutions indicated that "the women belonging to the elite class are more likely to enter local politics, and that they do not necessarily represent poor women's interests" [14].

\subsection{Policy and Practice}

Due to women's often restricted access to public positions and political participation, their views and needs are often not taken into account [47]. Notwithstanding women's relatively high involvement in waste management activities at the local level, integration in the decision-making processes is often (intentionally and unintentionally) neglected. Conversely, men are more likely to have access to decision-making institutions and therefore have their say on policy design, municipal infrastructure and technology planning, selection of service levels, and payment plans [11,28,29]. Also, project funders and managers, seem to lack awareness about the relevance of including gender analysis in the conception, implementation, and assessment of waste programs [30].

The underlying power and societal structures, as well as a lack of political will, are then reflected in the absence of consideration for the practical gendered needs and the strategic gender needs of women in waste management policy, information and education practice $[2,14]$. These two concepts of gender needs (or interests) were first introduced by Maxine Molyneux in 1985, with some arguing that those often overlap. Practical gender needs refer to responding to an immediate perceived necessity in a specific context, without changing the existing gender division of labor or challenging women's subordinate position in society despite these being the causes of women's practical gender needs. General actions to address these needs are related to the improvement of living and working conditions, including water, healthcare, essential housing services, and employment provision, as well as the distribution of food. Meanwhile, strategic gender needs are those that, if met, would transform the unequal power imbalance between women and men. Strategic gender needs vary according 
to circumstances and relate to gender divisions of labor, power, and control. Some of the general issues it addresses include legal rights, domestic violence, equal pay, and women's control over their bodies $[13,14,48]$. For example, in regards to the practical needs of women working in the waste sector, those include the need to improve: work conditions, access to credit, legitimacy status of entrepreneurial initiatives, protection against harassment and, negotiation conditions with authorities and other stakeholders. On the other hand, strategic gender needs relate to addressing the social and cultural barriers to conduct business outside of the household sphere and shift the power relationships with the male-controlled waste management structures [30,46,48].

\section{A Conceptual Framework for Gender Mainstreaming in Waste Education Programs}

In the following, we describe the conceptual framework designed as a gender mainstreaming tool for waste education programs, based on the literature on waste education, and gender and waste. Gender mainstreaming is coined as accounting for the different needs and conditions of women and men, ensuring their rightful participation, and assessing the implications of the planned (waste) policies, strategies, and management interventions, to achieve gender equality $[43,44,47,49]$.

The realization of education programs, similarly to other types of programs and projects, is a systematic, iterative process, mainly comprised of situational analysis and needs assessment, definition and planning, implementation, and monitoring and evaluation [50-52]. These stages overlap and interrelate, and the results of the previous one become the inputs for the next stage [51]. In the proposed framework, adding to the four program stages, an institutional component is included to assess the gender stances and the possible work structures of the program's promoting entity.

Within the framework, the common premise and key requirement for all stages of the program is the inclusion of participatory approaches with gender equality aspects. Participatory approaches allow for interactions, co-learning, and fair representation of stakeholders such as researchers, program managers, target groups, and policymakers, leading to continuous improvement and adaptation of plans and actions for the particular program $[14,26,53]$. Besides this, they usually imply iterative interactions between project promoters and local stakeholders to clarify the specific needs for intervention, and to plan for said intervention and the subsequent evaluation of the outcomes [26,54]. In turn, participation with gender equality considerations aims to facilitate recognition of local knowledge, a process that explicitly includes both men and women from different age groups, which relies on horizontal communication for data collection [48]. Horizontal communication relates to the exchange between individuals, free of consideration of hierarchical aspects, which is mainly characterized by being activity-related and informal [55]. Furthermore, it ensures that the target group is addressed as heterogeneous, with different and at times with conflicting understandings and experiences on the issue, all the while empowering the least powerful groups by enabling their participation in the program development process. As such, the promoting team should be knowledgeable of gender issues, acknowledge the local knowledge from women and men, and be in direct contact with the target group [48]. Practical aspects related to participation with gender equality include $[14,19,44,48,56]$ :

- Creating different opportunities and spaces for women and men (groups according to aspects such as age, marital status, parentage, sexual orientation social composition, when necessary), to present their views and contributions, as well as the opportunity to integrate their inputs collectively.

- Ensure enabling environments, as it relates to the availability of participation, e.g., criteria, time, location.

- The process should also be as transparent as possible, to create adhesion and ownership, with women and men encouraged to participate in the authentication and explanation of the program development. 
Mainstreaming gender in waste programs mainly translates into the integration of both genders' views and priorities for waste, improvement of the division of responsibilities and access to waste handling resources, creation of employment opportunities, and the inclusive participation of women and men in decision-making processes. As such, the inclusion of gender perspectives in waste management and education is a twofold strategy. It should address the untapped potential of women's contribution to solving operational problems of waste systems, as well as the specific issues of gender inequality related to the system $[1,5,28,30]$. Thus, the framework presented in Figure 1 builds on the three previously presented critical issues of waste education and gender:

I. Full participation of women and men in all stages of the program

II. Design and delivery of gender-aware messages; and,

III. Assignment of responsibility among stakeholders.

\begin{tabular}{|c|c|c|c|}
\hline $\begin{array}{l}\text { Program rationale } \\
\text { and background }\end{array}$ & $\begin{array}{ll}: & \text { Waste type (What) } \\
: \quad & \text { Target group (Who) } \\
\text { Relevance (Why) } \\
\text { Period and location (When \& Where) } \\
\text { Gender-specific goal }\end{array}$ & & \\
\hline Components & \multicolumn{2}{|l|}{ Main Issues } & Methodological approaches and tools \\
\hline $\begin{array}{l}\text { Promoting/managing } \\
\text { entity }\end{array}$ & \multicolumn{2}{|l|}{$\begin{array}{l}\text { Team composition } \\
\text { Institutional and individual gender awareness level } \\
\text { - Policies, training. gender units or experts } \\
\text { Knowledge of waste and gender issues }\end{array}$} & $\begin{array}{l}\text { Gender analysis } \\
\text { Gender equality capacity assessment }\end{array}$ \\
\hline \multirow{4}{*}{$\begin{array}{l}\text { Situation analysis and } \\
\text { needs assessment }\end{array}$} & \multicolumn{2}{|c|}{$\begin{array}{l}\text { General background of target group: Demographic, socio, economic, ecologic, political, legal, historical } \\
\text { and cultural profile }\end{array}$} & \multirow[b]{3}{*}{$\begin{array}{l}\text { Gender analysis } \\
\text { Material flow analysis } \\
\text { Gender statistics } \\
\text { Stakeholder analysis }\end{array}$} \\
\hline & Content & Operational & \\
\hline & $\begin{array}{l}\text { Municipal and Community level } \\
\text { Waste flows } \\
\text { Stakeholders groups: role, needs, power, interest, } \\
\text { priorities } \\
\text { Existing waste related initiatives } \\
\text { Gender policies }\end{array}$ & $\begin{array}{l}\text { - Gender (age, education level, class, } \\
\text { and other relevant aspects) } \\
\text { representativeness in the } \\
\text { municipal and community } \\
\text { decision-making bodies } \\
\text { - Gender awareness level } \\
\text { Existing gender-specific groups and } \\
\text { NGOs }\end{array}$ & \\
\hline & $\begin{array}{l}\text { Household level } \\
\text { Women and Men: role and practice, needs, interest, } \\
\text { priorities, and access to waste related resources } \\
\text { Awareness level on waste issues }\end{array}$ & $\begin{array}{l}\text { Willingness to participate in } \\
\text { decision-making processes for } \\
\text { waste } \\
\text { Capacity and factors influencing } \\
\text { participation - opportunities and } \\
\text { limitations }\end{array}$ & $\begin{array}{l}\text { Woste walk-through } \\
\text { Gender stakeholder consultation and } \\
\text { analysis } \\
\text { Gender impact assessment }\end{array}$ \\
\hline \multicolumn{4}{|c|}{$\begin{array}{l}\text { Potential gender-differentiated impacts of the program - distribution of paid and unpaid waste related work; household gender dynamics; sanitary conditions; } \\
\text { representativeness in decision-making processes; assess of waste resources, other relevant aspects. }\end{array}$} \\
\hline $\begin{array}{l}\text { Definition and } \\
\text { planning }\end{array}$ & $\begin{array}{ll}\text { - } & \text { Gender-specific goals and objectives } \\
\text { - } & \text { Program activities, budgeting, and outputs } \\
\end{array}$ & \multirow{3}{*}{$\begin{array}{l}\text { Gender equality training for } \\
\text { program personnel and target } \\
\text { group participants } \\
\text { Conditions for participation from } \\
\text { target group - time; location; } \\
\text { communication strategies } \\
\text { Gender-balance of program } \\
\text { personnel and target group } \\
\text { participants }\end{array}$} & \multirow{3}{*}{$\begin{array}{l}\text { Gender equality capacity assessment } \\
\text { Gender indicators } \\
\text { Gender budgeting } \\
\text { Gender Impact assessment }\end{array}$} \\
\hline Implementotion & - Gender-sensitive messages & & \\
\hline $\begin{array}{l}\text { Monitoring and } \\
\text { evaluation }\end{array}$ & $\begin{array}{l}\text { Assessment of gender indicators } \\
\text { Assessment of target group expectations against the } \\
\text { objectives PGN }\end{array}$ & & \\
\hline
\end{tabular}

Figure 1. Framework for mainstreaming gender in waste education programs.

Gender awareness is understood as the ability to view society from the perspective of gender roles and understand how this has affected women's needs in comparison to the needs of men [57].

\subsection{Mainstreaming Gender in the Promoting Entity}

Irrespective of the commitment to gender equality, societal bodies are not gender-neutral. Gender-neutral refers to various aspects such as language and concepts, not having an association with either men or women $[11,58]$. In the organization's context, traditional and critical approaches have its origins in the male domain, and as a result, are male-centered [4]. Government institutions, civil society organizations, consultants, training organizations, private enterprises, among others, have their institutional culture, values, and experience. Therefore, their views on gender issues are 
based on their identifiers, and the women and men that are part of those institutions will either support or challenge the principle of gender equality $[4,44]$. In the context of gender-aware waste education programs, it is relevant that the promoting entity has policies and strategies in place to address gender equality, and that the individuals part of it understand its importance, and are skillful of tools for gender integration into the program. Thus, it is necessary to assess the gender equality capacity of the entity conducting the waste education program.

Assessing gender in the promoting entity, at the institutional level, includes the evaluation of what gender policies, strategies, and procedures are in place. At the individual level, the focus is on the knowledge, skills, and attitudes on gender equality and the empowerment of women and the integration of these into the daily work. Also pertinent is the appraisal of the composition of the program personnel. The outcomes of this assessment clarify the needs and ways forward for institutional capacity development and training [47,59].

\subsection{Mainstreaming Gender throughout a Waste Education Program Cycle}

\subsubsection{Situation Analysis and Needs Assessment}

The design of an educational initiative often derives from the agreement that specific subjects are still misunderstood, or a particular environmental issue, such as waste, needs to be addressed [51]. Following the determination of the program rationale and background, i.e., the waste problem, target area, and population, the initial task is to analyze how the target waste is used and valued within society at large, and its value to both women and man, before and after the 'point of set-out.' These can be accomplished by conducting waste flow analysis and collecting waste walk-through information from women and men, and by determining the roles, level of awareness in matters of waste management, and involvement in the decision-making process [31,60]. Moreover, it is crucial to clarify how women and men are affected by different political, social, cultural, historical, and legal factors about the given waste problem, what their respective needs are, and their access to use and control resources, goods, and services, related to the target waste [47].

The fundamental goal of this phase is to identify the waste problems, and the opportunities, strengths, challenges, and possible new directions, while deciphering the gender structures that surround these problems, thus avoiding the conception of discriminatory gender programs.

\subsubsection{Definition and Planning}

Following the needs assessment, the next stage is the definition of the primary goal and specific objectives of the program, as well as the details on how these are going to be accomplished [51]. Here, women and men should be called upon to reflect and discuss their priorities for change, to identify their views on how the program should be implemented, and to share their expectations on the program outcomes. It is relevant to assess if the objectives reflect the needs of women and men, if these address gender issues in any way, and also if all genders will benefit from the program (in case it is not a gender-specific program). Also necessary, is making sure of the introduction of gender-specific designs and gender-sensitive approaches on the education materials [61].

In this stage, resource and technical needs that can facilitate the application of gender perspectives are included, such as the introduction of gendered budgeting, procurement, training, and indicators. The selection and development of relevant gender indicators are particularly crucial because progress for each program's objective can be tracked, ensuring, therefore, gender balance within the results $[44,49,53]$.

\subsubsection{Implementation}

This stage included the materialization of the program, the efficient application of resources, and guaranteeing full stakeholders' participation. Central to this stage is the evaluation of gender balance and explicit connections between gender and waste education, and that the message reaches 
all stakeholders effectively while ensuring that gender-sensitive language is used to deliver the information. It also includes tracking the implications of the program on gender aspects, by collecting feedback from the target group or program beneficiaries [47,53].

\subsubsection{Monitoring and Evaluation}

Comprising the systematic information gathering on the activities, characteristics, and results of the program, in regard to gender issues [47,51], monitoring and evaluation in a gender perspective is a reflection tool to aid decision-making regarding the planned developments, inclusive of the promoting entity and the participant stakeholders [62]. Of importance is the concurrent need to understand if the education program brought about positive effects related to the waste issue that it was developed for, to both women and men, and if the project had any impact on gender issues. At this point, the indicators selected on the definition and planning stage are measured and evaluated against the program objectives, with data collected from all involved stakeholders. Moreover, monitoring and evaluation can be used as an iterative process to improve upon education programs $[44,47,51]$.

\section{Conclusions}

Integrating gender perspectives into waste management elements such as education programs has the potential to improve effectiveness, avoid costly mistakes, and ensure equitable access to livelihoods, resources, or benefits deriving from a project [47].

This paper detailed a novel conceptual framework for gender mainstreaming in waste education programs, addressing inclusive participation in decision-making processes, gender-aware content, and stakeholders' accountability. The framework is a tool to aid in the investigation on how to realize the potential twofold role gender inclusion has on the effectiveness of waste education programs and on ensuring gender equality through the program cycle. It fits participatory assessments of the promoting entity, as well as four stages of education programs: needs assessment, definition and planning, implementation, and monitoring and evaluation.

\section{Future Research and Limitations of the Study}

The next stage of this endeavor will entail piloting the feasibility of the framework through its application in concluded, ongoing, and intended waste education programs, in several locations worldwide. Lastly, intersectionality issues of gender and cultural, racial, class, sexuality, (dis)ability, and ethnic identities are not explored and considered in the proposed framework. It is then critical to further understand the influence and power dynamics about the different identity markers between and within genders. Moreover, this study does not consider genders other than male and female. Future research addressing these limitations is required.

Author Contributions: Conceptualization, L.S.d.M. and P.V.; methodology, L.S.d.M.; software, N/A; validation, L.S.d.M. and P.V.; formal analysis, L.S.d.M.; investigation, L.S.d.M.; resources, L.S.d.M.; data curation, L.S.d.M.; writing-original draft preparation, L.S.d.M.; writing-review and editing, L.S.d.M. and P.V.; visualization, L.S.d.M. and P.V.; supervision, P.V.; project administration, L.S.d.M.; funding acquisition, L.S.d.M.

Funding: This research was funded by JAPAN SOCIETY FOR THE PROMOTION OF SCIENCE, via its KAKENHI grant, number JP17F17779.

Acknowledgments: The authors express their gratitude for the contributions offered by the anonymous reviewers of this manuscript.

Conflicts of Interest: The authors declare no conflict of interest.

\section{References}

1. United Nations Environment Programme (UNEP). Global Gender and Environment Outlook; United Nations Environment Programme: Nairobi, Kenya, 2016. 
2. Schultz, I.; Stieß, I. Policies to Promote Sustainable Consumption Patterns WP 1: 'Gender Aspects of Sustainable Consumption Strategies and Instruments'; Institute for Social-Ecological Research (ISOE): Frankfurt/Main, Germany, 2009.

3. Gough, A. Researching Differently: Generating a Gender Agenda for Research in Environmental Education. In International Handbook of Research on Environmental Education; Stevenson, R.B., Brody, M., Dillon, J., Wals, A.E.J., Eds.; Routledge: Abingdon-on-Thames, UK, 2013; pp. 375-383.

4. Acker, J. Hierarchies, jobs, bodies: A theory of gendered organizations. Gend. Soc. 1999, 4, 139-158. [CrossRef]

5. Tiwari, N. Gender Roles in Environmental Household Waste Management: A Case Study in Palmerston North, New Zealand. Ph.D. Thesis, Massey University, Palmerston North, New Zealand, 2001.

6. Saraçli, S.; Yilmaz, V.; Arslan, T. The Effects of Mothers' Educational Levels on University Students' Environmental Protection Commitments and Environmental Behaviors. Eur. J. Educ. Res. 2014, 55, 177-199. [CrossRef]

7. Piñeiro, C.; Díaz, M.-J.; Palavecinos, M.; Alonso, L.-E.; Benayas, J. Responsible consumption with a gender perspective: Consumption discourse and practices surrounding gender equality and sustainability in Madrid / Consumo responsable con perspectiva de género. Discursos y prácticas de consumo en torno a la equidad. Psyecol. Rev. Bilingüe Psicol. Ambient./Biling. J. Environ. Psychol. 2014, 5, 252-283. [CrossRef]

8. Gough, A.; Russell, C.; Whitehouse, H. Moving gender from margin to center in environmental education. J. Environ. Educ. 2017, 48, 5-9. [CrossRef]

9. United Nations Statistics Division (UNSD). Glossary of Terms-Gender Statistics Wiki. 2015. Available online: https: / / unstats.un.org/unsd/genderstatmanual/Glossary.ashx (accessed on 11 July 2018).

10. Wilson, D.C.; Rodic, L.; Modak, P.; Soos, R.; Carpintero, A.; Velis, K.; Simonett, O. Global Waste Management Outlook; United Nations Environment Programme (UNEP): Nairobi, Kenya, 2015.

11. Gender and Water Alliance (GWA) and WASTE. No capacity to waste. In Training Module Gender and Waste; GWA: Dieren, The Netherlands, 2010.

12. Rouhani, L. Unpacking Community Participation: A Gendered Perspective. Curr. Issues Comp. Educ. 2017, 20, 31-44

13. March, C.; Smyth, I.; Mukhopadhyay, M. A Guide to Gender-Analysis Frameworks; Oxfam Publishing: Oxford, UK, 1999; p. 144.

14. Akerkar, S. Gender and Participation; Institute of Development Studies: Brighton, UK, 2001.

15. Asian Development Bank. Balancing the Burden? Desk Review of Women's Time Poverty and Infrastructure in Asia and the Pacific; Asian Development Bank: Mandaluyong City, Philippines, 2015.

16. Samson, M. Dumping on Women: Gender and Privatisation of Waste Management; Municipal Services Project (MSP) and the South African Municipal Workers' Union (Samwu): Gauteng, South Africa, 2003.

17. Autio, M.; Heiskanen, E.; Heinonen, V. Narratives of 'green' consumers-The antihero, the environmental hero and the anarchist. J. Consum. Behav. 2009, 8, 40-52. [CrossRef]

18. Fredericks, R. Gender and the Politics of Trash in Dakar: Participation, Labor and the 'Undisciplined' Woman; Thinking Gender Papers; UCLA Cent. Study Women: Los Angeles, CA, USA, 2008.

19. United Nations Development Programme (UNDP). Gender and Energy for Sustainable Development: A Toolkit and Resource Guide; United Nations Development Programme (UNDP): New York, NY, USA, 2004.

20. Luna, M.; Aguilar, L.; Gilligan, M.; Owren, C.; Prebble, M.; Westerman, K. Women in Environmental Decision Making: Case Studies in Ecuador, Liberia, and the Philippines; The Global Gender Office of IUCN and Conservation International: Washington, DC, USA, 2015; p. 78.

21. Asian Development Bank. Checklist for water Supply and Sanitation; Asian Development Bank: Mandaluyong City, Philippines, 2006.

22. Meinzen-Dick, R.; Kovarik, C.; Quisumbing, A.R. Gender and Sustainability. Annu. Rev. Environ. Resour. 2014, 39, 29-55. [CrossRef]

23. Sexsmith, K. Towards Gender Equality in Global Sustainable Consumption and Production Agreements. In Women Reclaiming Sustainable Livelihoods; Harcourt, W., Ed.; Palgrave Macmillan: London, UK, 2012; pp. 42-61.

24. Fonjong, L.N. Gender Roles and practices in natural resource management in the North West Province of Cameroon. Local. Environ. 2008, 13, 461-475. [CrossRef] 
25. Garcia, A.S.; Wanner, T. Gender inequality and food security: Lessons from the gender-responsive work of the International Food Policy Research Institute and the Bill and Melinda Gates Foundation. Food Secur. 2017, 9, 1091-1103. [CrossRef]

26. Graef, F.; Hernandez, L.E.A.; König, H.J.; Uckert, G.; Mnimbo, M.T. Systemising gender integration with rural stakeholders' sustainability impact assessments: A case study with three low-input upgrading strategies. Environ. Impact Assess. Rev. 2018, 68, 81-89. [CrossRef]

27. The Secretariat of the Basel Rotterdam and Stockholm Conventions. Gender Heroes: From grassroots to global action. In A Collection of Stories Featuring Gender Perspectives on the Management of Hazardous Chemicals and Wastes; Secretariats of the Basel, Rotterdam, Stockholm Conventions (BRS): Châtelaine GE, Switzerland, 2015.

28. Woroniuk, B.; Schalkwyk, J. Waste Disposal \& Equality between Women and Men; Swedish International Development Cooperation Agency (SIDA): Stockholm, Sweden, 1998.

29. IETC. Gender and Waste Management Did You Know ... ? Available online: https://www.ctc-n.org/sites / www.ctc-n.org/files/resources/gender_and_waste_management.pdf (accessed on 1 March 2019).

30. Muller, M.S.; Scheinberg, A. Gender and Waste Electronic Discussion Group, 9-31 May 1998 A Summary; WASTE: Gouda, The Netherlands, 1998.

31. Scheinberg, A.; Muller, M.; Tasheva, E. Gender and Waste. In Integrating Gender into Community Waste Management: Project Management Insights and Tips from an E-mail Conference; WASTE: Gouda, The Netherlands, 1999.

32. Muchangos, L.S.D.; Vaughter, P. Are gender perspectives included in waste education programs? A systematic literature review. In Proceedings SUM2018, Fourth Symposium on Urban Mining; CISA Publisher: Bergamo, Italy, 2018.

33. Thoresen, V.W. HERE and NOW! Education for Sustainable Consumption: Recommendations and Guidelines; United Nations Environment Programme (UNEP): Paris, France, 2010; pp. 1-36.

34. United Nations Environment Programme (UNEP). ABC of SCP Clarifying Concepts on Sustainable Consumption and Production; UNEP: Paris, France, 2010.

35. Didham, R.J.; Choi, M.Y. Education for Sustainable Consumption: Effective Strategies to Promote Responsible Consumer Behaviour; Institute for Global Environment Strategies: Kanagawa Prefecture, Japan, 2010; pp. 1-17.

36. Climate and Clean Air Coalition (CCAC). Raising Awareness about Solid Waste Management; CCAC: Paris, France, 2013.

37. United Nations Environment Programme (UNEP). Solid Waste Management; United Nations Environment Programme (UNEP): Osaka/Shiga, Japan, 2005.

38. Associação Brasileira de Empresas de Limpeza Pública e Resíduos Especiais (ABRELPE) and International Solid Waste Association (ISWA). Solid Waste: Guidelines for Successful Planning; ABRELPE \& ISWA: Sao Paulo, Brazil, 2013; p. 52.

39. Rodic, L.; Wilson, D.C. Resolving governance issues to achieve priority sustainable development goals related to solid waste management in developing countries. Sustainability 2017, 9, 404. [CrossRef]

40. Polanec, B.; Aberšek, B.; Glodež, S. Informal Education and Awareness of the Public in the field of Waste Management. Procedia Soc. Behav. Sci. 2013, 83, 107-111. [CrossRef]

41. Muchangos, L.S.D.; Tokai, A.; Hanashima, A. Application of the Delphi Method to the Identification of Barriers to a Waste Management Policy in Maputo City, Mozambique. J. Sustain. Dev. 2015, 8, 146-157. [CrossRef]

42. Tojo, N.; Neubauer, A.; Bräuer, I. Waste Management Policies and Policy Instruments in Europe—An Overview; Lund Universit: Lund, Sweden, 2006.

43. Alfaro, M.C. Unveiling Gender: Basic Conceptual Elements for Understanding Gender, 1st ed.; ABSOLUTO: San José, Costa Rica, 1999.

44. Swiss Agency for the Development and Cooperation (SDC). Gender in Practice-A Toolkit for SDC and Its Partners; Federal Department of Foreign Affairs (FDFA) Swiss Agency for the Development and Cooperation: Bern, Switzerland, 2003.

45. Regitz-Zagrosek, V. Sex and gender differences in health. Science \& Society Series on Sex and Science. EMBO Rep. 2012, 13, 596-603. [PubMed] 
46. Dias, S.; Ogando, A.C. From Theory to Action: Gender and Waste Recycling: A Toolkit for Teachers, Researchers and Practitioners Book 3: Resources; Women in Informal Employment: Globalizing and Organizing (WIEGO): Belo Horizonte, Brazil, 2015.

47. Organization for Security and Co-operation in Europe (OSCE). Gender and Environment. A Guide to the Integration of Gender Aspects in the OSCE's Environmental Projects; OSCE: Vienna, Austria, 2009.

48. Aguilar, L.; Briceno, G.; Valenciano, I. Seek and ye Shall Find: Participatory Appraisal with a Gender Equity Perspective, 1st ed.; International Union for Conservation of Nature (IUCN): San José, Costa Rica, 2000.

49. European Institute for Gender Equality. Gender Impact Assessment: Gender Mainstreaming Toolkit; Publications Office of the European Union: Luxembourg, 2016.

50. Canadian Cardiovascular Society. A Handbook for Planning Committees Developing Educational Programs; Canadian Cardiovascular Society: Ottawa, ON, Canada, 2012.

51. National Oceanic and Atmospheric Administration (NOAA). Designing Education Projects: A Comprehensive Approach to Needs Assessment, Project Planning and Implementation, and Evaluation; NOAA: Silver Spring, MD, USA, 2009; p. 99.

52. The Institute of Progressive Education and Learning. Curriculum Development Cycle. Available online: http:/ / institute-of-progressive-education-and-learning.org/k-12-education-part-ii/k-12-curriculum/ curriculum-development-cycle/ (accessed on 14 February 2019).

53. Aguilar, L. A Good Start Makes a Better Ending: Writing Proposals with a Gender Perspective, 1st ed.; International Union for Conservation of Nature (IUCN): San José, Costa Rica, 1999.

54. Bradbury-Huang, H. What is good action research? Why the resurgent interest? Action Res. 2010, 8, 93-109. [CrossRef]

55. Pruyn, A.; Peters, O.; Bartels, J.; de Jong, M.; van der Molen, M. Horizontal and vertical communication as determinants of professional and organisational identification. Pers. Rev. 2010, 39, 210-226.

56. Gurung, M.; Leduc, B. Guidelines for a Gender Sensitive Participatory Approach; Icimod: Lalitpur, Nepal, 2009; pp. $1-4$.

57. European Institute for Gender Equality. Gender Awareness; Gender Equality Glossary and Thesaurus: Vilnius, Lithuania, 2018; Available online: http:/ / eige.europa.eu/rdc/thesaurus/terms/1147 (accessed on 11 July 2018).

58. Kabeer, N. Agency, well-being \& inequality: Reflections on the gender dimensions of poverty. IDS Bull. 1996, $27,11-21$.

59. Lahousen, V.; Popovic, N. Gender Equality Capacity Assessment, 2nd ed.; UNWomen: New York, NY, USA, 2016.

60. Anschütz, J.; Jgosse, J.I.; Scheinberg, A. Putting Integrated Sustainable Waste Management into Practice; WASTE: Gouda, The Netherlands, 2004.

61. Public Awareness \& Communication Modules and Materials. Available online: http://www.gdrc.info/ docs / waste/012.pdf (accessed on 1 March 2019).

62. Rodríguez, G.; Meléndez, N.; Velázquez, E.; Fuentes, M.A. Taking the Pulse of Gender: Gender-Sensitive Systems for Monitoring and Evaluation, 1st ed.; International Union for Conservation of Nature (IUCN): San José, Costa Rica, 2000.

(C) 2019 by the authors. Licensee MDPI, Basel, Switzerland. This article is an open access article distributed under the terms and conditions of the Creative Commons Attribution (CC BY) license (http:/ / creativecommons.org/licenses/by/4.0/). 


\title{
Article \\ Selecting Potential Moss Species for Green Roofs in the Mediterranean Basin
}

\author{
Ricardo Cruz de Carvalho ${ }^{1,2, *(D)}$, Zulema Varela ${ }^{1,3} \mathbb{D}$, Teresa Afonso do Paço ${ }^{4,5}$ \\ and Cristina Branquinho ${ }^{1} \mathbb{D}$
}

1 Centre for Ecology, Evolution and Environmental Changes (cE3c), Faculty of Sciences of the University of Lisbon, Campo Grande, 1749-016 Lisbon, Portugal; zulema.varela@usc.es (Z.V.); cmbranquinho@fc.ul.pt (C.B.)

2 MARE-Marine and Environmental Sciences Centre, Faculty of Sciences of the University of Lisbon, Campo Grande, 1749-016 Lisbon, Portugal

3 Ecology Unit, Department of Functional Biology, Facultade de Bioloxía, Universidade de Santiago de Compostela, 15782 Santiago de Compostela, Spain

4 Department of Biosystems Engineering, Instituto Superior de Agronomia, University of Lisbon, Tapada da Ajuda, 1349-017 Lisbon, Portugal; tapaco@isa.utl.pt

5 Linking Landscape, Environment, Agriculture and Food (LEAF), Instituto Superior de Agronomía, University of Lisbon, Tapada de Ajuda, 1349-017 Lisbon, Portugal

* Correspondence: rfcruz@fc.ul.pt

Received: 26 March 2019; Accepted: 23 May 2019; Published: 26 May 2019

\begin{abstract}
Green roofs are important infrastructures to address the effects of climate change in urban areas. However, most studies and applications have been done in cooler and wetter regions of the northern hemisphere. Climate change will lead to more extreme weather events, such as increased drought and decreased precipitation with intense flash rain events. Increase desertification is expected especially in the Mediterranean Basin, where in summer, radiation and temperature are high and water is scarce. Therefore, while vascular plants increase water consumption in green roofs during warmer periods, mosses present themselves as potential candidates due to their poikilohydric nature, responding to the environmental availability of water, completely drying out and recovering upon rehydration. Although criteria for the selection of vascular plants adapted to the Mediterranean and suitable for green roofs have been developed, no information is available regarding the selection of mosses based on scientific criteria. Here we propose selection criteria for moss species based on ecological preferences according to Ellenberg's values and help to define moss traits suitable for a nonirrigated, nature-based green roof that tolerates the Mediterranean climate. The main result is a table of potential candidate mosses that can be either used as standalone or in conjunction with vascular plants to decrease water usage and/or manage stormwater through an easily applicable selection methodology. For green roof practitioners, we proposed that acrocarpous mosses exhibiting turf/cushion life forms and colonist or perennial life strategies best fit the requirements for such a green infrastructure in extreme climate regions with scarce water resources.
\end{abstract}

Keywords: mosses; sustainability; nature-based solutions; traits; urban ecology

\section{Introduction}

The Mediterranean climate is characterised by mild wet winters, autumns and springs with variable temperature and precipitation, and warm to hot, dry summers that are typical of semiarid climates [1]. However, nowadays, against a background of climate change with extreme temperatures (high and low) and precipitation (scarce or very intense flash rain events), drought periods occur in the whole Mediterranean Basin, not only in summer, but also in winter. The decrease in winter 
precipitation and the increase in air temperature have had a serious impact on the region [2], especially in cities, where urban heat islands further increase temperatures, reduce air humidity, and change local wind and precipitation patterns compared to peri-urban and rural areas [3]. Thus, there is growing interest in the development of green infrastructures mitigating climate change effects in urban areas [4].

Green roofs are plant-based spaces that mimic shallow substrate rock outcrops or meadow habitats. They are placed on a waterproof layer on top of houses, factories, offices and other buildings, and complement the ecosystem services provided by other types of green spaces in urban areas [5-8]. Moreover, at the building level, they help to improve thermal regulation by providing a shading increment and better insulation of the roof system, in addition to reducing noise pollution, increasing roof durability, hindering the spread of fires, and reducing energy consumption by mitigating heat loss from the building during winter $[9,10]$. Furthermore, green roofs with herbaceous and small shrubs can reflect $27 \%$ of solar radiation, absorb $60 \%$ through photosynthesis and transmit about $13 \%$ to the growing medium [11]. At the city level, the important contributions of green roofs include biodiversity conservation, improvement of urban aesthetics, increase in carbon sequestration to improve air quality, increased retention and delayed release of stormwater, and reduction of the urban heat island effect [12-15].

Given these benefits, green roofs constitute a highly valuable biological resource to be explored as a nature-based solution to mitigate the effects of climate change in urban areas. Among the plants with potential for green roof use are nonvascular plants, like mosses, as they are adapted to survive in extreme climate conditions (defined here as low and variable water availability and high radiation). Using the ISI Web of Knowledge database (February 2018) with the keywords "green roofs", more than 1000 scientific studies of green roofs published in the last 10 years (January 2008 to December 2017) were identified; but when the search was narrowed including the keyword "moss" or "bryophyte", only 14 studies on the use of mosses on rooftops remained, and only four of those focused on the Mediterranean. Moreover, most of the studies did not specify the species of investigated moss, referring to the plants simply as "mosses" or "bryophytes". Mosses are poikilohydric, being able to completely desiccate under low relative humidity but quickly resuming metabolic activity upon rehydration [16]. The trade-off for the ability of moss species to survive such extreme conditions is a slow growth rate, which no doubt accounts for the lack of studies regarding their use in green infrastructures in this type of climate and thus the absence of a selection list for these plants. Yet, under controlled conditions of light, temperature and humidity, the growth rates can be increased [17].

Biological soil crusts, a complex community of soil particles, mosses, cyanobacteria, fungi and bacteria, have multifunctional roles including soil stability, the fixation of basic nutrients such as carbon (C) and nitrogen $(\mathrm{N}), \mathrm{CO}_{2}$ flux, $\mathrm{N}$ mineralisation $[18,19]$ and serving as a habitat for other organisms. In these communities, mosses can retain several times their weight in water, allowing their self-sustained growth for longer periods than it would be predicted [20].

According to [21], commercial green surfaces that include mosses such as Tortula muralis and Bryum argenteum are slowly gaining favour and the advantage of these plants as a desiccation-tolerant poikilohydric may contribute to sustainable water-use, especially in areas with Mediterranean-like climates. Moreover, they can grow directly on a flat surface, with no or very little soil content, allowing exploration of more sloped surfaces, although establishment might require some roughness. It might also allow existing sloped roofs to be retrofitted where vascular plants would normally only establish with difficulty. However, despite the many benefits of using mosses in green roofs [10,21,22], criteria for the selection of moss species suitable for green covers under this climate have yet to be elaborated.

A study of plant functional traits can facilitate the selection of the species best-adapted to the conditions of the study area besides being less time consuming. A trait-based analysis to select vegetation for Mediterranean green roofs was previously performed for vascular plants [23] and resulted in a list of species appropriate for use under these conditions. In contrast to vascular plants, for which several protocols and databases that include their traits have already been published (e.g., [24]; LEDA: [25]; BROT: [26]; TRY: [27,28]), similar information for mosses is scarce. One such study focused 
on mosses in Great Britain (BRYOATT: [29]) and another on those in the Azores (BryoTraits AZO: [30]). Brandão and co-workers [31] have already shown that the combined green roofs of shrubs, grasses and mosses proved to be the most effective vegetation cover to reduce water use. The presence of the moss layer under the canopy also contributes to increasing the amount of water retention [32]. Hence, the importance of selecting the moss species best suited to local conditions. In the present study we propose the development of a selection method for moss species exhibiting beneficial characteristics and relevant for the green roof industry.

\section{Materials and Methods}

We began our study with two moss checklists: the Mediterranean Basin moss checklist from Ros and co-workers [33], which cited 1168 species, and Hodgetts' bryophyte checklist and country status for European countries [34], which cited 1515 species, of which 1285 are present in the Mediterranean Basin. Afterwards, we inserted each moss genus in an online database for European vegetation [35] based on Ellenberg's ecological preference values [36]. The Ellenberg's ecological preference values are based on an ordinal classification of plants according to the position of their realised ecological niche along an environmental gradient, allowing to generate a list of species classified with respect to light, temperature, humidity, nitrogen fertility, etc. From this list, we selected only the species whose Eilenberg values were typical for a Mediterranean climate and that can be experienced in a green roof from this area: light (8-9: light-loving and full-light plants); temperature (8-9: Mediterranean and sub-Mediterranean plants); and humidity (1-3: extreme dryness to moderately dry sites) and analysed their life form, growth form and lifestyle [37,38]. We also noted confirmed moss occurrence along the countries of the Mediterranean Basin to determine the more cosmopolitan species $[33,34]$.

\section{Results and Discussion}

The result was a list of the 43 most tolerant moss species (Table 1) of the extreme conditions selected, corresponding to $3 \%$ of the moss checklist within the countries of the Mediterranean Basin [33,34]. It is the first time that Ellenberg's values of ecological preferences are used in the selection of mosses for use on green roofs in the Mediterranean and, as we can see in Table 1, these preferences reflect perfectly their functional traits, as expected, since according to the literature, life form, growth form and life strategy are related to plant strategy, climatic factors and land use [24,28-30,37,39]. Likewise, different life forms can be arranged in sequences reflecting water availability and light intensity in different habitats [40].

In this selection method, the predominant life forms are turfs (56\%), followed by cushions $(23 \%)$ and mats $(21 \%)$. Our method confirms the fact that turf and cushion forms predominate in dry and xeric habitats, presenting the perfect structure for retaining water through capillarity and reducing surface area during dry-out events [41], whereas mats are more common in humid, shady areas [42]. Regarding the growth form, acrocarpous mosses are dominant (about $84 \%$ ). The plants with this growth type are smaller than pleurocarpous ones and their colonies are dense, and therefore they equilibrate more slowly with the relative humidity in their surroundings. As such, they tend to be either fully hydrated and metabolically active or desiccated and metabolically inactive [43]. For this, acrocarpous mosses are commonly found in open dry sites, while their pleurocarpous counterparts are more common in moist shady locations [44]. The predominant life strategy was colonist (58\%), followed by perennial (35\%) in its different manifestations (66\% perennial, $27 \%$ stress-tolerant perennial and $7 \%$ competitive perennial) and only $7 \%$ long-lived shuttles (Table 1). As a life strategy, colonist is very common for plants on open naked or shallow surfaces because these species produce countless small spores that easily disperse and colonise large areas after germination [45]. During reported that moss species able to tolerate environmental stress are mostly perennial species or long-lived shuttles [38]. 
Table 1. List of potential moss species to be used in Mediterranean green roofs according to the selection method proposed in the current work using Ellenberg's values for light (L), temperature (T) and humidity $(\mathrm{H})$ [36]. ( $\mathrm{x}$-no specific ecological preference). Life form (Cu, cushion; Ma, mats; $\mathrm{Tf}$, tuft), growth form (Acr, acrocarpous; $\mathrm{Pl}$, pleurocarpous) and lifestyle (C, colonist; $\mathrm{CP}$, competitive perennial; LS, long-lived shuttle; P, perennial; STP, stress-tolerant perennial) are also noted [37,38].

\begin{tabular}{|c|c|c|c|c|c|c|}
\hline Species & $\mathbf{L}$ & $\mathbf{T}$ & $\mathbf{H}$ & Life Form & Growth Form & Lifestyle \\
\hline Abietinella abietina (Hedw.) M.Fleisch & 8 & $\mathrm{x}$ & 3 & $\mathrm{Ma}$ & $\mathrm{Pl}$ & $\mathrm{P}$ \\
\hline Barbula convoluta Hedw. & 8 & $\mathrm{x}$ & 3 & Tf & Acr & C \\
\hline Bryum argenteum Hedw. & 8 & $\mathrm{x}$ & $\mathrm{x}$ & Tf & Acr & $\mathrm{C}$ \\
\hline Bryum canariense Brid. & 9 & $\mathrm{x}$ & 2 & Tf & Acr & $\mathrm{C}$ \\
\hline Campylopus oerstedianus (Müll.Hal.) Mitt. & 8 & 9 & 2 & Tf & Acr & $\mathrm{P}$ \\
\hline Campylopus pilifer Brid. & 9 & 8 & 2 & $\mathrm{Cu}$ & Acr & LS \\
\hline Ceratodon purpureus (Hedw.) Brid. & 8 & $\mathrm{x}$ & 2 & $\mathrm{Tf}$ & Acr & $\mathrm{C}$ \\
\hline Cheilothela chloropus (Brid.) Broth. & 9 & $\mathrm{x}$ & 2 & $\mathrm{Tf}$ & Acr & $\mathrm{C}$ \\
\hline Crossidium crassinerve (De Not.) Jur. & 9 & 8 & 2 & $\mathrm{Tf}$ & Acr & $\mathrm{C}$ \\
\hline Crossidium squamiferum (Viv.) Jur. & 9 & 8 & 1 & $\mathrm{Tf}$ & Acr & C \\
\hline Didymodon cordatus Jur. & 9 & 8 & 1 & $\mathrm{Tf}$ & Acr & $\mathrm{P}$ \\
\hline Didymodon fallax (Hedw.) R.H.Zander & 8 & $\mathrm{x}$ & 2 & $\mathrm{Tf}$ & Acr & $\mathrm{P}$ \\
\hline Fabronia ciliaris (Brid.) Brid. & 8 & 8 & 2 & Ma & $\mathrm{Pl}$ & $\mathrm{P}$ \\
\hline Fabronia pusilla Raddi & 8 & 9 & 3 & $\mathrm{Ma}$ & $\mathrm{Pl}$ & $\mathrm{P}$ \\
\hline Grimmia anodon Bruch \& Schimp. & 9 & $\mathrm{x}$ & 1 & $\mathrm{Cu}$ & Acr & STP \\
\hline Grimmia crinita Brid. & 9 & 8 & 1 & Tf & Acr & $\mathrm{C}$ \\
\hline Grimmia donniana Sm. & 8 & $\mathrm{x}$ & 2 & $\mathrm{Cu}$ & Acr & $\mathrm{C}$ \\
\hline Grimmia lisae De Not. & 8 & 9 & 1 & $\mathrm{Cu}$ & Acr & $\mathrm{C}$ \\
\hline Grimmia tergestina Tomm. ex Bruch \& Schimp. & 9 & 8 & 1 & $\mathrm{Cu}$ & Acr & $\mathrm{C}$ \\
\hline Haplocladium virginianum (Brid.) Broth. & 8 & 8 & 3 & Ma & $\mathrm{Pl}$ & $\mathrm{P}$ \\
\hline Hedwigia ciliata (Hedw.) P.Beauv. & 9 & $\mathrm{x}$ & 2 & Ma & Acr & LS \\
\hline Hedwigia stellata Hedenäs & 8 & 9 & 1 & Ma & Acr & LS \\
\hline Homalothecium aureum (Spruce) H.Rob. & 8 & 9 & 2 & Ma & $\mathrm{Pl}$ & $\mathrm{P}$ \\
\hline Leptobarbula berica (De Not.) Schimp. & 8 & 8 & 2 & $\mathrm{Tf}$ & Acr & $\mathrm{C}$ \\
\hline Orthotrichum cupulatum Hoffm. ex Brid. & 9 & 8 & 1 & $\mathrm{Cu}$ & Acr & $\mathrm{C}$ \\
\hline Pleurochaete squarrosa (Brid.) Lindb. & 9 & 8 & 2 & Tf & Acr & $\mathrm{CP}$ \\
\hline Pottiopsis caespitosa (Bruch ex Brid.) Blockeel \& A.J.E.Sm. & 8 & 8 & 2 & $\mathrm{Tf}$ & Acr & $\mathrm{C}$ \\
\hline Pseudoleskeella tectorum (Funck ex Brid.) Kindb. ex Broth. & 8 & $\mathrm{x}$ & 2 & Ma & $\mathrm{Pl}$ & STP \\
\hline Pterygoneurum sampaianum (Machado-Guim.) Machado-Guim. & 9 & 8 & 3 & Tf & Acr & $\mathrm{C}$ \\
\hline Racomitrium lanuginosum (Hedw.) Brid. & 9 & $\mathrm{x}$ & 3 & Tf & Acr & STP \\
\hline Rhytidium rugosum (Hedw.) Kindb. & 9 & $\mathrm{x}$ & 3 & Ma & $\mathrm{Pl}$ & $\mathrm{P}$ \\
\hline Schistidium confertum (Funck) Bruch \& Schimp. & 9 & $\mathrm{x}$ & 1 & $\mathrm{Cu}$ & Acr & C \\
\hline Schistidium flaccidum (De Not.) Ochyra & 9 & $\mathrm{x}$ & 1 & $\mathrm{Cu}$ & Acr & $\mathrm{P}$ \\
\hline Syntrichia caninervis Mitt. & 9 & 9 & 1 & Tf & Acr & $\mathrm{C}$ \\
\hline Syntrichia laevipila Brid. & 8 & 8 & 2 & Tf & Acr & $\mathrm{C}$ \\
\hline Syntrichia ruralis (Hedw.) F.Weber \& D.Mohr & 9 & $\mathrm{x}$ & 2 & Tf & Acr & $\mathrm{C}$ \\
\hline Tortella nitida (Lindb.) Broth. & 8 & 8 & 2 & $\mathrm{Cu}$ & Acr & STP \\
\hline Tortula acaulon (With.) R.H.Zander & 9 & 9 & 3 & $\mathrm{Tf}$ & Acr & $\mathrm{C}$ \\
\hline Tortula brevissima Schiffn. & 9 & 8 & 2 & $\mathrm{Tf}$ & Acr & $\mathrm{C}$ \\
\hline Tortula inermis (Brid.) Mont. & 8 & 8 & 2 & $\mathrm{Cu}$ & Acr & C \\
\hline Tortula muralis Hedw. & 9 & 8 & 1 & Tf & Acr & $\mathrm{C}$ \\
\hline Tortula revolvens (Schimp.) G.Roth & 9 & 8 & 1 & Tf & Acr & $\mathrm{C}$ \\
\hline Trichostomum crispulum Bruch & 8 & 8 & 2 & Tf & Acr & C \\
\hline
\end{tabular}


For all the above, it makes sense that the 10 most widely distributed species in the 34 countries of Mediterranean Basin are all acrocarpous and with a tuft life form and a colonist strategy $(70 \%$ respectively, Table 2): Bryum argenteum, Tortella nitida and Trichostomum crispulum (32 countries); Tortula muralis (31 countries); Didymodon fallax (30 countries); Grimmia lisae and Syntrichia laevipila (29 countries); and Ceratodon purpureus, Pleurochaete squarrosa and Tortula inermis (27 countries). However, care needs to be taken over the choice of provenance of the propagation material used, in order to minimise risk of disruption to the distribution patterns of local genetic variation within species. Compared with vascular plants, where intraspecific variation has been well-studied in many species, there have been very few investigations of bryophyte species, but the precautionary principle suggest that we assume, in the absence of contrary evidence, that bryophyte species will also be genetically variable. Nevertheless, the establishment of companies to grow these mosses from local populations has a potential for economic development, once the standard growing protocols are established, something that we are currently testing. 


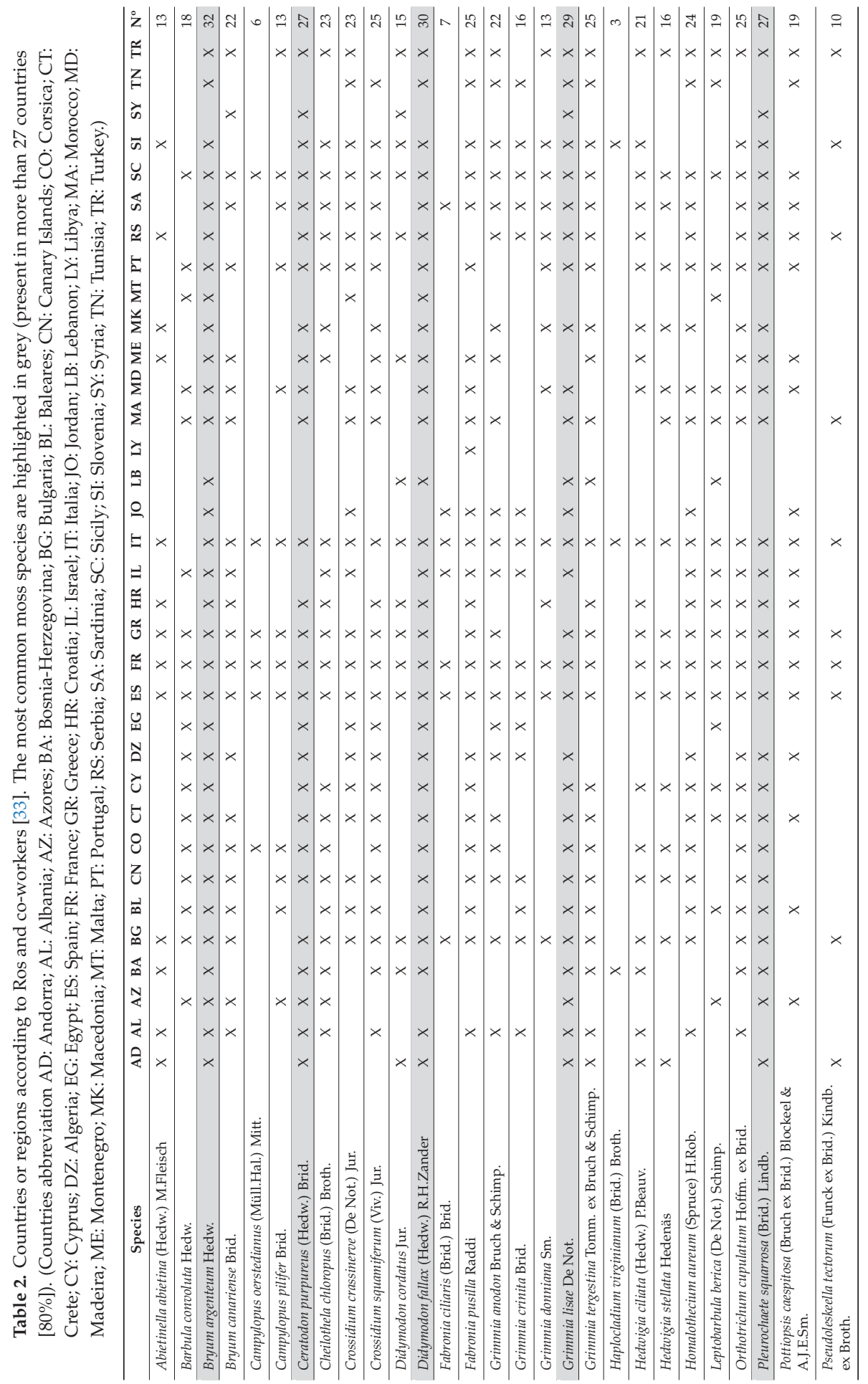


Urban Sci. 2019, 3, 57

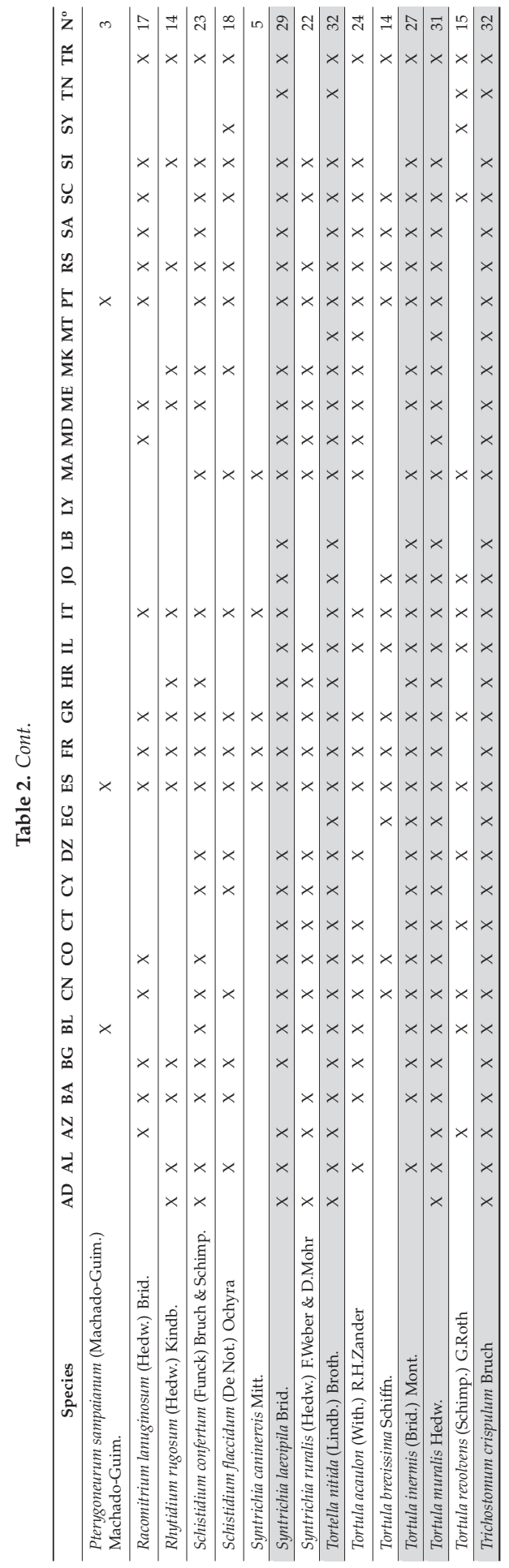




\section{Conclusions}

Even though the poikilohydric nature of mosses and their desiccation tolerance makes them suitable candidates for green roofs in Mediterranean climates, studies are still scarce [31,32]. For this reason, our approach serves as an important tool for the standardisation of this type of vegetation, confirming that functional traits are a perfect tool for the selection of mosses for future use on nonirrigated green roofs in the Mediterranean. Moreover, given the extreme climatic conditions of the Mediterranean Basin, the generated list of moss species provides a valuable resource for the green roof industry. They have the potential to be incorporated directly on top of construction materials that could be tested in the future. Observation of the urban areas shows that they can grow almost on any substrate, with some particular preferences (e.g., calcicole or calcifuge). Many rooftops can present a dark colour that absorbs solar radiation, increasing the temperature inside buildings. This could be attenuated by this green infrastructure. Some bryophytes turn its colour from green to brown, which changes its albedo to absorb more solar radiation so the temperature under the moss will increase. However, the minimum daily and range of humidity is always lower under the moss, meaning that the small amount of water that reaches the moss is well absorbed and can be released in the form of humidity during drier periods (Varela et al., unpublished results). Acrocarpic growth form, turf life form, and a colonist life strategy fit the required profile to survive in extreme climatic conditions, such as the long dryness period typical of Mediterranean climate. It would be necessary to optimise the cultivation of different species of mosses and to assure that the laboratory transplants will not dry out/die and adapt well under green roof conditions. There are already works on moss cultivation in the laboratory for ecological restoration projects, but all of them done in drylands with sandy substrate that would not suit the green roof substrate materials. Therefore, future work will address the selection of mosses from this list, testing their growth rates under controlled conditions and afterwards under green roof conditions.

Author Contributions: R.C.C. and Z.V. conceived the ideas, designed methodology and analysed the data. R.C.C. and Z.V. wrote the original draft. T.A.P. and C.B. contributed critically and edited the drafts in the process of writing the manuscript. All authors gave final approval for publication.

Funding: This study and R. Cruz de Carvalho postdoctoral research grant were supported by the project MedMossRoofs (PTDC/ATP-ARP/5826/2014) funded by the FCT (Foundation for Science and Technology), Portugal. Z. Varela was supported by a postdoctoral research grant awarded by the Autonomous Government of Galicia (Spain).

Conflicts of Interest: The authors declare no conflict of interest.

\section{References}

1. Lionello, P.; Malanotte-Rizzoli, P.; Boscolo, R.; Alpert, P.; Artale, V.; Li, L.; Luterbacher, J.; May, W.; Trigo, R.; Tsimplis, M.; et al. The Mediterranean climate: An overview of the main characteristics and issues. Dev. Earth Environ. Sci. 2006, 4, 1-26. [CrossRef]

2. Hoerling, M.; Eischeid, J.; Perlwitz, J.; Quan, Z.; Zhang, T.; Pegion, P. On the Increased Frequency of Mediterranean Drought. J. Clim. 2012, 25, 2146-2161. [CrossRef]

3. Kuttler, W. The urban climate: Basic and applied aspects. In Urban Ecology; Marzluff, J.M., Shulenberger, E., Endlicher, W., Alberti, M., Bradley, G., Ryan, C., ZumBrunnen, C., Simon, U., Eds.; Springer: Berlin, Germany, 2008; pp. 233-248. [CrossRef]

4. IPCC. Climate Change 2014: Mitigation of Climate Change. Contribution of Working Group III to the Fifth Assessment Report of the Intergovernmental Panel on Climate Change; Edenhofer, O.R., Pichs-Madruga, Y., Sokona, E., Farahani, S., Kadner, K., Seyboth, A., Adler, I., Baum, S., Brunner, P., Eickemeier, B., et al., Eds.; Cambridge University Press: Cambridge, UK; New York, NY, USA, 2014.

5. Oberndorfer, E.; Lundholm, J.; Bass, B.; Coffman, R.R.; Doshi, H.; Dunnett, N.; Gaffin, S.; Köhler, M.; Liu, K.K.Y.; Rowe, B. Green roofs as urban ecosystems: Ecological structures, functions, and services. BioScience 2007, 57, 823-833. [CrossRef] 
6. Carter, T.; Keeler, A. Life-cycle cost-benefit analysis of extensive vegetated roof systems. J. Environ. Manag. 2008, 87, 350-363. [CrossRef] [PubMed]

7. Lundholm, J. Vegetation of Urban Hard Surfaces. In Urban Ecology_Patterns Processes, and Applications; Niemelä, J., Breuste, J.H., Elmqvist, T., Guntenspergen, G., James, P., McIntyre, N.E., Eds.; Oxford University Press: Oxford, UK, 2011; pp. 93-102. [CrossRef]

8. Veisten, K.; Smyrnova, Y.; Klæboe, R.; Hornikx, M.; Mosslemi, M.; Kang, J. Valuation of green walls and green roofs as soundscape measures: Including monetised amenity values together with noise-attenuation values in a cost-benefit analysis of a green wall affecting courtyards. Int. J. Environ. Res. Public Health 2012, 9, 3770-3788. [CrossRef] [PubMed]

9. Jaffal, I.; Ouldboukhitine, S.E.; Belarbi, R. A comprehensive study of the impact of green roofs on building energy performance. Renew. Energy 2012, 43, 157-164. [CrossRef]

10. Berardi, U.; GhaffarianHoseini, A.; GhaffarianHoseini, A. State-of-the-art analysis of the environmental benefits of green roofs. Appl. Energy 2014, 115, 411-428. [CrossRef]

11. Eumorfopoulou, E.; Aravantinos, D. The contribution of a planted roof to the thermal protection of buildings in Greece. Energy Build. 1998, 27, 29-36. [CrossRef]

12. VanWoert, N.D.; Rowe, D.B.; Andresen, J.A.; Rugh, C.L.; Fernandez, R.T.; Xiao, L. Green Roof Stormwater Retention. J. Environ. Qual. 2005, 34, 1036-1044. [CrossRef] [PubMed]

13. Alexandri, E.; Jones, P. Temperature decreases in an urban canyon due to green walls and green roofs in diverse climates. Build. Environ. 2008, 43, 480-493. [CrossRef]

14. Yang, J.; Yu, Q.; Gong, P. Quantifying air pollution removal by green roofs in Chicago. Atmos. Environ. 2008, 42, 7266-7273. [CrossRef]

15. Loder, A. 'There's a meadow outside my workplace': A phenomenological exploration of aesthetics and green roofs in Chicago and Toronto. Landsc. Urban Plan. 2014, 126, 94-106. [CrossRef]

16. Alpert, P.; Oliver, M.J. Drying without dying. In Desiccation and Survival in Plants: Drying without Dying; Black, M., Pritchard, H.W., Eds.; CABI Publishing: Wallingford, UK, 2002; pp. 3-43. [CrossRef]

17. Cruz de Carvalho, R.; Santos, P.; Branquinho, C. Production of moss-dominated biocrusts to enhance the stability and function of the margins of artificial water bodies. Restor. Ecol. 2018, 26, 419-421. [CrossRef]

18. Bowker, M.A.; Mau, R.L.; Maestre, F.T.; Escolar, C.; Castillo-Monroy, A.P. Functional profiles reveal unique ecological roles of various biological soil crust organisms. Funct. Ecol. 2011, 25, 787-795. [CrossRef]

19. Buffam, I.; Mitchell, M.E. Nutrient Cycling in Green Roof Ecosystems. In Green Roof Ecosystems; Sutton, R., Ed.; Springer International Publishing: Basel, Switzerland, 2015; Chapter 5; pp. 107-137. [CrossRef]

20. Rixen, C.; Mulder, C.P. Improved water retention links high species richness with increased productivity in arctic tundra moss communities. Oecologia 2005, 146, 287-299. [CrossRef]

21. Garabito, D.; Vallejo, R.; Montero, E.; Garabito, J.; Martínez-Abaigar, J. Green buildings envelopes with bryophytes. A review of the state of the art. Boletín de la Sociedad Española de Briología 2017, 48-49, 1-16.

22. Glime, J.M. Construction. In Bryophyte Ecology; Glime, J.M., Ed.; Volume 2: Uses; Ebook Sponsored by Michigan Technological University and the International Association of Bryologists: 5 November 2017; Chapter 5; Available online: http://digitalcommons.mtu.edu/bryophyte-ecology/ (accessed on 30 April 2018).

23. Van Mechelen, C.; Dutoit, T.; Hermy, M. Mediterranean open habitat vegetation offers great potential for extensive green roof design. Landsc. Urban Plan. 2014, 121, 81-91. [CrossRef]

24. Cornelissen, J.H.C.; Lavorel, S.; Garnier, E.; Diaz, S.; Buchmann, N.; Gurvich, D.E.; Reich, P.B.; Ter Steege, H.; Morgan, H.D.; Van Der Heijden, M.G.A.; et al. A handbook of protocols for standardised and easy measurement of plant functional traits worldwide. Aust. J. Bot. 2003, 51, 335-380. [CrossRef]

25. Kleyer, M.; Bekker, R.M.; Knevel, I.C.; Bakker, J.P.; Thompson, K.; Sonnenschein, M.; Poschlod, P.; Van Groenendael, J.M.; Klimeš, L.; Klimešová, J.; et al. The LEDA Traitbase: A database of life-history traits of Northwest European flora. J. Ecol. 2008, 96, 1266-1274. [CrossRef]

26. Paula, S.; Arianoutsou, M.; Kazanis, D.; Tavsanoglu, Ç.; Lloret, F.; Buhk, C.; Ojeda, F.; Luna, B.; Moreno, J.M.; Rodrigo, A.; et al. Fire-related traits for plant species of the Mediterranean Basin. Ecology 2009, 90, 1420. [CrossRef]

27. Kattge, J.; Diaz, S.; Lavorel, S.; Prentice, I.C.; Leadley, P.; Bönisch, G.; Garnier, E.; Westoby, M.; Reich, P.B.; Wright, I.J.; et al. TRY-A global database of plant traits. Glob. Chang. Biol. 2011, 17, 2905-2935. [CrossRef] 
28. Pérez-Harguindeguy, N.; Diaz, S.; Gamier, E.; Lavorel, S.; Poorter, H.; Jaureguiberry, P.; Bret-Harte, M.S.; Comwell, W.K.; Craine, J.M.; Gurvich, D.E.; et al. New handbook for standardised measurement of plant functional traits worldwide. Aust. J. Bot. 2013, 61, 167-234. [CrossRef]

29. Hill, M.O.; Preston, C.D.; Bosanquet, S.D.S.; Roy, D.B. BRYOATT: Attributes of British and Irish Mosses, Liverworts and Hornworts; Centre for Ecology and Hydrology: Huntingdon, UK, 2007; ISBN 9781855312364.

30. Henriques, D.S.G.; Ah-Peng, C.; Gabriel, R. Structure and Applications of BRYOTRAIT-AZO, a Trait Database for Azorean Bryophytes. Cryptogam. Bryol. 2017, 38, 137-152. [CrossRef]

31. Brandão, C.; Cameira, M.R.; Valente, F.; Cruz de Carvalho, R.; Paço, T.A. Wet season hydrological performance of green roofs using native species under Mediterranean climate. Ecol. Eng. 2017, 102, 596-611. [CrossRef]

32. Paço, T.A.; Cruz de Carvalho, R.; Arsénio, P.; Martins, D. Green roof design techniques to improve water use under Mediterranean conditions. Urban Sci. 2019, 3, 14. [CrossRef]

33. Ros, R.M.; Mazimpaka, V.; Abou-Salama, U.; Aleffi, M.; Blockeel, T.L.; Brugués, M.; Cros, R.M.; Dia, M.G.; Dirkse, G.M.; Draper, I.; et al. Mosses of the Mediterranean, an Annotated Checklist. Cryptogam. Bryol. 2013, 34, 99-283. [CrossRef]

34. Hodgetts, N.G. Checklist and Country Status of European Bryophytes-Towards a New Red List for Europe; Irish Wildlife Manuals. No. 84; National Parks and Wildlife Service, Department of Arts, Heritage and the Gaeltacht: Ireland, UK, 2015.

35. Karrer, G.; Wiedermann, R. Ökologische Zeigerwerte. Available online: http://statedv.boku.ac.at/zeigerwerte/ (accessed on 30 April 2018).

36. Ellenberg, H.; Weber, H.E.; Düll, R.; Wirth, V.; Werner, W.; Paulissen, D. Zeigerwerte von Pflanzen in Mitteleuropa, 2nd ed.; Goltze: Göttingen, Germany, 1992; Scripta Geobotanica 18; pp. 1-258, ISBN 9783884525180.

37. Dierssen, K. Distribution, Ecological Amplitude and Phytosociological Characterization of European Bryophytes; Bryophytorum Bibliotheca 56; J. Cramer: Stuttgart, Germany, 2001; pp. 1-289, ISBN 978-3-443-62028-8.

38. During, H.J. Ecological classifications of bryophytes and lichens. In Bryophytes and Lichens in a Changing Environment; Bates, J.W., Farmer, A.M., Eds.; Clarendon: Oxford, UK, 1992; pp. 1-31, ISBN 978-0198542919.

39. Frey, W.; Frahm, J.P.; Fischer, E.; Lobin, W. The Liverworts, Mosses and Ferns of Europe; English Edition; Heidelberg, T.L., Ed.; Apollo Books: Vester Skerninge, Denmark, 2006; 527p, ISBN 978-0946589708.

40. Bates, J.W. Is 'life-form' a useful concept in bryophyte ecology? Oikos 1998, 82, 223-237. [CrossRef]

41. Zotz, G.; Schweikert, A.; Jetz, W.; Westerman, H. Water relations and carbon gain are closely related to cushion size in the moss Grimmia pulvinata. New Phytol. 2000, 148, 59-67. [CrossRef]

42. Kürschner, H. Life strategies and adaptations in bryophytes from the Near and Middle East. Turk. J. Bot. 2004, 28, 73-84.

43. Proctor, M.C.F.; Oliver, M.J.; Wood, A.J.; Alpert, P.; Stark, L.R.; Cleavitt, N.L.; Mishler, B.D. Desiccation tolerance in bryophytes: A review. Bryologist 2007, 110, 595-621. [CrossRef]

44. Giordano, S.; Sorbo, S.; Adamo, P.; Adriana Basile, A.; Spagnuolo, V.; Cobianchi, R.C. Biodiversity and trace element content of epiphytic bryophytes in urban and extraurban sites of southern Italy. Plant Ecol. 2004, 170, 1-14. [CrossRef]

45. Kürschner, H. Life strategies of Pannonian loess cliff bryophyte communities: Studies of the cryptogamic vegetation of loess cliffs, VIII. Nova Hedwig. 2002, 75, 307-318. [CrossRef]

(C) 2019 by the authors. Licensee MDPI, Basel, Switzerland. This article is an open access article distributed under the terms and conditions of the Creative Commons Attribution (CC BY) license (http://creativecommons.org/licenses/by/4.0/). 
Article

\title{
Value Assigned to Employees Who Preserve the Social and Organizational Environment
}

\author{
Crisanta-Alina Mazilescu ${ }^{1, *}$ and Bernard Gangloff ${ }^{2}$ \\ 1 Teacher Training Department, Politehnica University Timisoara, Timișoara 300006, Romania \\ 2 Laboratoire Parisien de Psychologie Sociale (LAPPS), Université Paris Ouest Nanterre La Défense, \\ Nanterre 92000, France; bernard.gangloff@univ-rouen.fr \\ * Correspondence: alina.mazilescu@gmail.com or alina.mazilescu@upt.ro; Tel.: +40-256-404-066 \\ Academic Editor: Giuseppe T. Cirella \\ Received: 2 December 2016; Accepted: 21 January 2017; Published: 25 January 2017
}

\begin{abstract}
In this study, we were interested in the behaviors of individuals who preserve the social and organizational environment by ensuring sustainability. More specifically, we are interested in allegiant behaviors. Numerous studies have highlighted the normative character of allegiance. Therefore, we questioned the value attributed to allegiance. We questioned 170 employees on social values that they attribute in terms of desirability and utility to a future colleague (subordinate or peer) starting from the responses that these future colleagues were supposed to have submitted to an allegiance questionnaire. It was observed that desirability and utility make reference to two independent dimensions, utility being often more important. It was also noted there is greater severity assigned to endo-group targets (future peers) than to exo-group targets (future subordinates). Finally, it was noted that there was not so much a valuation of allegiant targets, but rather a rejection of rebel targets, which raises the question of the bi-dimensionality of the valuation-devaluation process.
\end{abstract}

Keywords: allegiance norm; social desirability; social utility

\section{Introduction}

Sustainable development is a paradigm of modern society whose central objective "is to provide to everybody everywhere and at any time the opportunity to lead a dignified life in his or her respective society" [1] (p. 2).

Most studies have focused on economic and environmental sustainability, leaving its social aspects somewhat in the shadow [2]. In the literature, social aspects are usually referred to in terms of occupational health and safety, as well as ergonomics and work environment [3-5].

Social sustainability is a complex term which would require more attention in terms of its conceptual clarification. Chiu made a review of the interpretation given to the concept of social sustainability and identifies three directions [6]:

- A development-oriented interpretation, in which sustainable social development is based on respect for social acceptability as it contributes to social relations, rules, and values;

- An environment-oriented interpretation, when the social structure, social values, and norms are conducive to the sustainability of the environment;

- A people-oriented interpretation, when social sustainability is based on social cohesion, integrity, and social stability and prevents social polarization and exclusion.

Studies on sustainable behaviors in organizations are focused more on sustainability and sustainable leadership skills [7]. In the educational field, studies aim to identify competencies that support sustainable development with particular attention to the development of these skills [8-11]. 
Social psychology has tried to clarify, both in terms of understanding and developing a sustainable behavior, how people can be motivated to actively contribute to the transition to a sustainable society, but also of how that can be turned into a positive attitude towards the changes imposed by global climate changes.

Steg et al. [12] propose a general framework in what concerns the contribution of social and environmental psychology to understanding and promoting sustainable energy behavior by individuals and households: identification and measurement of behaviors to be changed, analysis of user behavior, designing and testing interventions to change behavior in order to reduce $\mathrm{CO}_{2}$ emissions, and the study of the factors that underlie the public acceptability of interventions and changes within the energy systems.

People who engage in sustainable behaviors are people oriented on a pro-environmental direction, acting according to their personal values and principles. The motivational factors, and especially values, are involved in the decision-making process with regard to identifying the efforts that a person is willing to commit to, but also in terms of costs and benefits of a sustainable behavior. Values are seen as a key factor in the development of sustainable behavior. They are motivational factors that can influence the beliefs and actions of those involved in the development of a sustainable society.

Four types of values have been identified as being involved in the development of a sustainable behavior related to sustainable energy use: hedonic values that orient people towards pleasure and comfort, egoistic values that focus people on safeguarding and personal resources, altruistic values that orient people towards the well-being of others and of society, and the biospheric values that focus people on the consequences for nature and the environment $[13,14]$.

There are several psychological strategies that are used to increase people's motivation to engage in sustainable behavior. For example, information strategies are very successful, but strategies of social influence can also be used with good results. Among the latest, the most efficient are face-to-face strategies such as block-approach, behavior modeling, and commitments. Another recommended strategy to be used in order to encourage sustainable behavior is the social norms information strategy, when the others act sustainably [15].

Our research also addresses the field of social norms and values that are attributed to behaviors that preserve the social environment. We were interested in the behaviors of individuals who preserve the social and organizational environment by ensuring sustainability. More specifically, we are interested in allegiant behaviors.

At a corporate level, "an organization is sustainable provided it does not destroy the conditions prevailing at the time it was established" [7] (p. 213). The social valuation of the non-questioning of the social structure and its hierarchy of powers is perceived as a norm of allegiance [13]. The norm of allegiance occupies a particular place in relation to other norms. Indeed, the norm of allegiance corresponds to the non-questioning of a social functioning, and we have seen that the social norms underpin this functioning. Thus, allegiance can be understood as the tendency not to question other norms.

Several studies have demonstrated a professional valuation of employees who adopt allegiant conduct, that is to say a professional valuation of employees who preserve the social environment, especially the hierarchical one, from any questioning, thus ensuring its sustainability [16].

Studies in this field also show that the allegiant employees benefit from better professional success prognostics than their rebel counterparts, meaning non-allegiant [17-19], and that during the selection process, recruiters usually select the former instead of the latter (as part of a broader campaign to recruit workers from the automobile industry, after reviewing 1018 candidates) $[17,19,20]$. Other studies have even shown that the valuation of allegiant individuals may be doubled by a pathologization of rebels, the latter being considered to suffer from mental problems (according to Dagot \& Castra, as compared by 118 advisers for Local Missions [21] or to a pool of ANPE advisers, as compared by recruiters [22]). Moreover, if we make differentiations within the category of allegiance itself and if we examine (by experimentally manipulating) the reasons why individuals behave in an allegiant or a rebel manner, 
we notice that the individuals who adopt allegiant conduct due to their ideology (due to legality, considering that they must obey their superiors because of the latter's higher status) are preferred to mercenary allegiants, who act as such due to opportunism (based on personal interests [23]). We should also note that these results, collected in France, have been supplemented by studies conducted in other countries, such as Switzerland [24] or Argentina. For example, in Argentina it has been observed that managers prefer to work with allegiant subordinates than with rebel subordinates [25], and that the subordinates are aware of this preference [22]. Numerous studies highlight the existence of an allegiance norm [17-26].

To observe that a target (in our case, a person) is socially valued means that this target has some value in terms of desirability and utility [27-30]. Social value is considered to entail two dimensions: a desirable dimension, which refers to the emotional or motivational register, and a useful one, rooted in social functioning and more particularly in the economical field (Peeters speaks about "self-profitability" [31], while Beauvois speaks about "social utility" [32]. The difference that exists at a conceptual level between self-profitability and social utility was not found by Cambon, Djouary, and Beauvois [33] in their empirical studies. Their studies found that what is profitable for oneself is also useful for society. Le Barbenchon, Cambon, and Lavigne found contradictory results in what regards the correlations between desirability and utility: positive correlations, negative correlations, or total lack of correlations [34].

Several scales were used to measure this value. Le Barbenchon, Cambon, and Lavigne have used two scales for desirability which refer to the ability to have friends and to be loved and two scales for utility that relate to salary and the success in professional life [30]. Mazilescu, Abdellaoui, and Gangloff have used another procedure which refers to the value attributed to the fact that an individual has some personality traits related to the 'Big Five' dimensions [35].

These authors considered, on the one hand, that to measure desirability only by the ability to be loved and by the number of friends one has was very restrictive (a similar point can be made for measuring utility), and on the other hand that neither of these measures was methodologically satisfactory, considering, for example, that the opposite of "to have everything to be loved" was not "to have nothing to be loved", but rather "to have everything to be hated", or that the opposite of "to have everything to succeed in one's professional life" was not "to have nothing to succeed in one's professional life" but "to have everything to fail in one's professional life". Mazilescu, Abdellaoui, and Gangloff used two scales for desirability and two scales for utility. The same scales were also used by Gangloff [36], who investigated the value attributed to an information regarding a level of Allegiance (be it ideological or mercenary) of a future work colleague. This study is interested in the social value of information referring to a level of allegiance and not the social value of allegiance. It also seemed pertinent to us to examine the value attributed to allegiance in itself (by examining ideological allegiance and mercenary allegiance in a differentiated manner), the question therefore being: is having to work with an allegiant (vs. a rebel) colleague considered agreeable (or useful); or, more simply put, is an allegiant (vs. a rebel) colleague agreeable or useful? Considering the results of Gangloff [36], we assumed that the value attributed to allegiance may vary according to whether the target was a subordinate or a peer.

These elements have also led, in terms of the main hypotheses, to estimating that allegiance would be more anchored in utility than in desirability, and that rebellion would be more stigmatized when it concerned a subordinate, than when it characterized a peer.

\section{Materials and Methods}

Participants were recruited randomly, on a voluntary basis, from small and medium-sized enterprises in Rouen (France). The criteria were: to be employed in the services sector, to be male (controlled variable), and to have (for some) or not have (for others) subordinates to manage. 170 male managers (of which 89 with subordinates and 81 without any hierarchical responsibility), contacted at their place of work, responded, voluntarily, to two items (one of desirability and the second of utility), 
concerning their valuation of fictitious responses which a future work colleague was supposed to have provided, during a skills assessment, to a questionnaire on allegiance.

The participants were given the following task: "In the following questionnaire, you are asked to imagine that you will soon have a new work colleague (vs. a new subordinate). You only have a little information on that person: you do not know whether they are male or female, or their age, etc. In the following pages, you can read some of the answers that person has provided to a questionnaire during a skills assessment. For example, you find out that the person in question has said: 'I am a dynamic, ambitious person, who loves challenges.' You will then be required to indicate on the one hand if such a person seems agreeable, indifferent, or disagreeable to you, and then explain why; and on the other hand if you believe that such a person would be useful, not useful or, on the contrary, that they would be interfering with your work, and then explain why."

Then followed the fictitious answers given by the future work colleague and the questions on desirability and utility.

The questionnaire to which the future colleague was supposed to have answered is the questionnaire on allegiance/rebellion of Duchon and Gangloff [20]. It includes 12 items (three items of ideological allegiance, three items of ideological rebellion, three items of mercenary allegiance, and three items of mercenary rebellion): Appendix A. Four future colleague profiles have been created: a future colleague who complied for ideological reasons, a future colleague who complied for mercenary reasons, a future rebellious colleague who complied for ideological reasons, and a future rebellious colleague who complied for mercenary reasons.

Among the 89 managers with subordinates, 50 were confronted with the profile of an ideological allegiant future subordinate and with the profile of a mercenary allegiant future subordinate, and 39 with the profile of an ideological rebellious future subordinate and with the profile of a mercenary rebellious future subordinate (the order effect was neutralized). Among the 81 managers without subordinates, 40 were confronted with the profile of an ideological allegiant future peer and with the profile of a mercenary allegiant future peer, and 41 with the profile of an ideological rebellious future peer and with the profile of a mercenary rebellious future peer (the order effect was also neutralized).

After taking knowledge of those profiles, the participants had to express their appreciation of their future colleague, in terms of desirability on the one hand, and in terms of utility on the other hand, answering to the two following questions (coming from Mazilescu et al. [35]: for the justification of these questions):

(1) Do you believe that, while working with that person, you would consider them: someone agreeable; someone who leaves you indifferent; someone disagreeable?

(2) Do you believe that while working with that person, they would be: useful, useless, or interfering?

\section{Results}

Our results have been analyzed from the perspective of four variables studied: the allegiance-non-allegiance dimension, social value (social desirability-social utility), positive-neutral or negative judgments, and peer-subordinate status.

The analysis of the results is structured as follows:

- Identifying the differences between the desirability and the utility of allegiant—non-allegiant (rebel) persons, by also taking into consideration the ideological or mercenary dimension;

- Identifying the differences between positive, neutral, or negative judgments, both in appreciating the desirability of the allegiant behavior, as well as in appreciating its social utility. In this situation, we have also taken into account whether the persons evaluated are work colleagues or subordinates;

- Identifying the differences regarding the evaluation of the allegiant-non-allegiant behavior according to the status of the persons in question (peers or subordinates); 
- Identifying the differences between positive, neutral, or negative judgments regarding the useful or desirable value of allegiant-non-allegiant persons (also taking into consideration the ideological or mercenary dimension).

The collected responses were analyzed by ANOVA, and for calculating the effect size we use Cohen's $d$ in which, conventionally, we considered the three following levels: negligible effect (0 to 0.35 ), intermediate effect (0.35 to 0.65 ), and notable effect (up to 0.65 ). Only the statistics that led to significant results are presented below. The gross results are given in Appendix B.

\subsection{Effects of the Type of Judgment (Desirability/Utility)}

We notice from the very beginning an effect of the type of judgment: desirability and utility do not lead to identical judgments. In terms of positive evaluations, the data is systematically higher for utility than for desirability, while for neutral evaluations, the reverse is valid (Table 1).

Table 1. Means and effects of the type of judgments (desirability and utility), globally.

\begin{tabular}{|c|c|c|c|c|c|c|c|}
\hline \multirow{2}{*}{$\begin{array}{l}\text { Subjects } \\
\text { Targeted }\end{array}$} & \multicolumn{3}{|c|}{ Level of Desirability } & \multicolumn{3}{|c|}{ Level of Utility } & \multirow{2}{*}{ F (Snedecor) and $d$ (Cohen) } \\
\hline & Positive & Neutral & Negative & Positive & Neutral & Negative & \\
\hline sbd. global & 0.26 & - & - & 0.63 & - & - & $\mathrm{F}(1,176)=12.84 ; p=0.0004 ; d=0.54$ \\
\hline peer global & 0.22 & - & - & 0.59 & - & - & $\mathrm{F}(1,160)=11.76 ; p=0.0007 ; d=0.54$ \\
\hline alleg. global & 0.26 & - & - & 0.67 & - & - & $\mathrm{F}(1,178)=15.90 ; p=0.0001 ; d=0.59$ \\
\hline rebel global & 0.23 & - & - & 0.55 & - & - & $\mathrm{F}(1,158)=9.05 ; p=0.003 ; d=0.47$ \\
\hline peer global & - & 0.74 & - & - & 0.48 & - & $\mathrm{F}(1,160)=5.33 ; p=0.022 ; d=0.36$ \\
\hline alleg. global & - & 1.00 & - & - & 0.70 & - & $\mathrm{F}(1,178)=7.76 ; p=0.0059 ; d=0.42$ \\
\hline
\end{tabular}

alleg.--allegiant; sbd.-subordinate; Means were calculated by dividing the number of occurrences by the number of participants (in this case: 89 for subordinates, 81 for peers, 90 for allegiants, and 80 for rebels).

Finer analyses differentiate the ideological targets from the mercenary targets, reinforcing the global results. In terms of ideologists as well as of mercenaries, the positive evaluations are more numerous for utility than for desirability, and the results are reversed for neutral evaluations (for ideologists) and negative evaluations (for mercenaries) (Table 2).

Table 2. Means and effects of the type of judgments (desirability and utility), with differentiation between ideological and mercenary targets.

\begin{tabular}{lccccccc}
\hline \multirow{2}{*}{$\begin{array}{c}\text { Subjects } \\
\text { Targeted }\end{array}$} & \multicolumn{2}{c}{ Level of Desirability } & \multicolumn{3}{c}{ Level of Utility } & F (Snedecor) and $d$ (Cohen) \\
\cline { 2 - 6 } & Positive & Neutral & Negative & Positive & Neutral & Negative & \\
\hline id. sbd. & 0.20 & - & - & 0.43 & - & - & $\mathrm{F}(1,176)=10.95 ; p=0.001 ; d=0.49$ \\
id. peer & 0.15 & - & - & 0.41 & - & - & $\mathrm{F}(1,160)=14.62 ; p=0.0002 ; d=0.60$ \\
id. alleg. & 0.19 & - & - & 0.47 & - & - & $\mathrm{F}(1,178)=17.08 ; p=0.0001 ; d=0.62$ \\
id. rebel & 0.16 & - & - & 0.36 & - & - & $\mathrm{F}(1,158)=8.60 ; p=0.0038 ; d=0.46$ \\
merc. sbd. & 0.06 & - & - & 0.20 & - & - & $\mathrm{F}(1,176)=8.76 ; p=0.0035 ; d=0.45$ \\
merc. peer & 0.07 & - & - & 0.19 & - & - & $\mathrm{F}(1,160)=4.50 ; p=0.0354 ; d=0.33$ \\
merc. alleg. & 0.07 & - & - & 0.20 & - & - & $\mathrm{F}(1,178)=7.12 ; p=0.008 ; d=0.39$ \\
merc. rebel & 0.06 & - & - & 0.19 & - & - & $\mathrm{F}(1,158)=5.85 ; p=0.0166 ; d=0.38$ \\
\hline id. subord. & - & 0.51 & - & - & 0.33 & - & $\mathrm{F}(1,176)=6.05 ; p=0.0148 ; d=0.37$ \\
id. peer & - & 0.43 & - & - & 0.21 & - & $\mathrm{F}(1,160)=9.61 ; p=0.0022 ; d=0.49$ \\
id. alleg. & - & 0.58 & - & - & 0.32 & - & $\mathrm{F}(1,178)=12.57 ; p=0.0005 ; d=0.53$ \\
\hline merc. sbd. & - & - & 0.61 & - & - & 0.45 & $\mathrm{~F}(1,176)=4.48 ; p=0.0350 ; d=0.32$ \\
merc. rebel & - & - & 0.73 & - & - & 0.58 & $\mathrm{~F}(1,158)=4.005 ; p=0.047 ; d=0.32$ \\
\hline
\end{tabular}

\subsection{Effects of the Level of Judgement (Positive, Neutral, Negative)}

We also notice a differentiation according to the level of judgment: we observe (Table 3) that negative evaluations are more numerous than neutral evaluations (except for desirability of allegiants), 
which in turn are more numerous than the positive evaluations; and negative evaluations are more numerous than positive ones.

Table 3. Means and effects of the level of judgment (positive, neutral, negative), globally.

\begin{tabular}{|c|c|c|c|c|c|c|c|}
\hline \multirow{2}{*}{$\begin{array}{l}\text { Subjects } \\
\text { Targeted }\end{array}$} & \multicolumn{3}{|c|}{ Level of Desirability } & \multicolumn{3}{|c|}{ Level of Utility } & \multirow{2}{*}{ F (Snedecor) and $d$ (Cohen) } \\
\hline & Positive & Neutral & Negative & Positive & Neutral & Negative & \\
\hline peers global & - & 0.74 & 1.04 & - & - & - & $\mathrm{F}(1,160)=4.80 ; p=0.030 ; d=0.34$ \\
\hline rebels global & - & 0.45 & 1.21 & - & - & - & $\mathrm{F}(1,158)=19.55 ; p \approx 0.000 ; d=0.69$ \\
\hline alleg. global & - & 1.00 & 0.74 & - & - & - & $\mathrm{F}(1,178)=4.62 ; p=0.032 ; d=0.32$ \\
\hline peers global & - & - & - & - & 0.48 & 0.93 & $\mathrm{~F}(1,160)=13.36 ; p \approx 0.000 ; d=0.57$ \\
\hline rebels global & - & - & - & - & 0.45 & 1.00 & $\mathrm{~F}(1,158)=19.54 ; p \approx 0.000 ; d=0.69$ \\
\hline sbd. global & 0.26 & 0.84 & - & - & - & - & $\mathrm{F}(1,176)=36.70 ; p \approx 0.000 ; d=0.90$ \\
\hline peers global & 0.22 & 0.74 & - & - & - & - & $\mathrm{F}(1,160)=21.89 ; p \approx 0.000 ; d=0.77$ \\
\hline alleg. global & 0.26 & 1.00 & - & - & - & - & $\mathrm{F}(1,178)=53.40 ; p=0.000 ; d=1.09$ \\
\hline rebels global & 0.23 & 0.56 & - & - & - & - & $\mathrm{F}(1,158)=11.68 ; p=0.001 ; d=0.54$ \\
\hline sbd. global & 0.26 & - & 0.90 & - & - & - & $\mathrm{F}(1,176)=36.86 ; p \approx 0.000 ; d=0.91$ \\
\hline peers global & 0.22 & - & 1.04 & - & - & - & $\mathrm{F}(1,160)=47.34 ; p \approx 0.000 ; d=1.08$ \\
\hline alleg. global & 0.26 & - & 0.74 & - & - & - & $\mathrm{F}(1,178)=21.69 ; p \approx 0.000 ; d=0.69$ \\
\hline rebels global & 0.23 & - & 1.21 & - & - & - & $\mathrm{F}(1,158)=75.77 ; p \approx 0.000 ; d=1.38$ \\
\hline peers global & - & - & - & 0.59 & - & 0.93 & $\mathrm{~F}(1,160)=6.148 ; p=0.014 ; d=0.38$ \\
\hline rebels global & - & - & - & 0.55 & - & 1.00 & $\mathrm{~F}(1,158)=10.86 ; p \approx 0.000 ; d=0.52$ \\
\hline
\end{tabular}

alleg.-allegiant; sbd.—subordinate.

In what concerns the effects of the level of judgment (positive, neutral, negative) on ideologists, we notice (Table 4) that in half of the cases, the negative evaluations are more numerous than the neutral evaluations, which in turn are more numerous than the positive evaluations. Nevertheless, we also notice six reversed cases: therefore the positive evaluations may be more intense than the neutral ones (in what concerns the utility of peers, subordinates, allegiants, and rebels) and the negative ones (in what concerns the utility of allegiants), and the neutral may prove more intense than the negative ones (in what concerns the desirability of subordinates).

Table 4. Means and effects of the level of judgment (positive, neutral, negative) on ideologists.

\begin{tabular}{lccccccc}
\hline \multicolumn{1}{c}{$\begin{array}{l}\text { Subjects } \\
\text { Targeted }\end{array}$} & \multicolumn{2}{c}{ Level of Desirability } & \multicolumn{3}{c}{ Level of Utility } & F (Snedecor) and $d$ (Cohen) \\
\cline { 2 - 6 } & Positive & Neutral & Negative & Positive & Neutral & Negative & \\
\hline id. peers & - & - & - & - & 0.21 & 0.38 & $\mathrm{~F}(1,160)=5.94 ; p=0.016 ; d=0.38$ \\
id. rebels & - & - & - & - & 0.21 & 0.43 & $\mathrm{~F}(1,158)=8.66 ; p=0.0037 ; d=0.46$ \\
id. sbd. & 0.20 & 0.51 & - & - & - & - & $\mathrm{F}(1,176)=19.69 ; p \approx 0.000 ; d=0.66$ \\
id. peers & 0.15 & 0.43 & - & - & - & - & $\mathrm{F}(1,160)=17.36 ; p \approx 0.000 ; d=0.65$ \\
id. alleg. & 0.19 & 0.58 & - & - & - & - & $\mathrm{F}(1,178)=33.89 ; p \approx 0.000 ; d=0.87$ \\
id. rebels & 0.16 & 0.35 & - & - & - & - & $\mathrm{F}(1,158)=7.64 ; p=0.006 ; d=0.44$ \\
id. alleg. & 0.23 & 0.58 & - & - & - & - & $\mathrm{F}(1,178)=24.97 ; p \approx 0.000 ; d=0.74$ \\
id. peers & 0.15 & - & 0.42 & - & - & - & $\mathrm{F}(1,160)=15.96 ; p \approx 0.000 ; d=0.63$ \\
id. rebels & 0.16 & - & 0.49 & - & - & - & $\mathrm{F}(1,158)=21.62 ; p \approx 0.000 ; d=0.74$ \\
\hline id. peers & - & - & - & 0.41 & 0.21 & - & $\mathrm{F}(1,160)=7.66 ; p=0.006 ; d=0.43$ \\
id. sbd. & - & - & - & 0.43 & 0.25 & - & $\mathrm{F}(1,176)=6.60 ; p=0.011 ; d=0.38$ \\
id. alleg. & - & - & - & 0.47 & 0.32 & - & $\mathrm{F}(1,178)=3.97 ; p=0.048 ; d=0.29$ \\
id. rebels & - & - & - & 0.36 & 0.21 & - & $\mathrm{F}(1,158)=4.46 ; p=0.036 ; d=0.33$ \\
id. alleg. & - & - & - & 0.47 & - & 0.21 & $\mathrm{~F}(1,178)=13.99 ; p \approx 0.000 ; d=0.55$ \\
id. sbd. & - & 0.51 & 0.29 & - & - & - & $\mathrm{F}(1,176)=8.78 ; p=0.003 ; d=0.44$ \\
\hline
\end{tabular}

In what concerns the effects of the level of judgments (positive, neutral, negative) on the mercenaries, we notice (Table 5) that the negative evaluations are higher than the neutral evaluations (with one exception: the utility of allegiants), which in turn are higher than the positive evaluations; and negative evaluations are more numerous than positive ones. 
Table 5. Means and effects of the level of judgment (positive, neutral, negative) on mercenaries.

\begin{tabular}{|c|c|c|c|c|c|c|c|}
\hline \multirow{2}{*}{$\begin{array}{l}\text { Subjects } \\
\text { Targeted }\end{array}$} & \multicolumn{3}{|c|}{ Level of Desirability } & \multicolumn{3}{|c|}{ Level of Utility } & \multirow{2}{*}{ F (Snedecor) and $d$ (Cohen) } \\
\hline & Positive & Neutral & Negative & Positive & Neutral & Negative & \\
\hline merc. sbd. & - & 0.34 & 0.61 & - & - & - & $\mathrm{F}(1,176)=13.85 ; p \approx 0.000 ; d=0.56$ \\
\hline merc. peers & - & 0.31 & 0.62 & - & - & - & $\mathrm{F}(1,160)=16.95 ; p \approx 0.000 ; d=0.65$ \\
\hline merc. rebels & - & 0.21 & 0.73 & - & - & - & $\mathrm{F}(1,158)=56.58 ; p \approx 0.000 ; d=1.19$ \\
\hline merc. rebels & - & - & - & - & 0.24 & 0.58 & $\mathrm{~F}(1,158)=21.15 ; p \approx 0.000 ; d=0.73$ \\
\hline merc. peers & - & - & - & - & 0.27 & 0.54 & $\mathrm{~F}(1,160)=13.23 ; p \approx 0.000 ; d=0.57$ \\
\hline merc. alleg. & - & - & - & - & 0.38 & 0.20 & $\mathrm{~F}(1,178)=7.12 ; p=0.008 ; d=0.39$ \\
\hline merc. sbd. & 0.06 & 0.34 & - & - & - & - & $\mathrm{F}(1,176)=25.11 ; p \approx 0.000 ; d=0.75$ \\
\hline merc. peers & 0.07 & 0.31 & - & - & - & - & $\mathrm{F}(1,160)=15.61 ; p \approx 0.000 ; d=0.62$ \\
\hline merc. alleg. & 0.07 & 0.42 & - & - & - & - & $\mathrm{F}(1,178)=36.75 ; p \approx 0.000 ; d=0.90$ \\
\hline merc. rebels & 0.06 & 0.21 & - & - & - & - & $\mathrm{F}(1,158)=7.86 ; p=0.006 ; d=0.44$ \\
\hline merc. sbd. & - & - & - & 0.20 & 0.35 & & $\mathrm{~F}(1,176)=4.84 ; p=0.029 ; d=0.33$ \\
\hline merc. sbd. & 0.06 & - & 0.61 & - & - & - & $\mathrm{F}(1,176)=91.47 ; p \approx 0.000 ; d=1.43$ \\
\hline merc. peers & 0.07 & - & 0.62 & - & - & - & $\mathrm{F}(1,160)=77.44 ; p \approx 0.000 ; d=1.38$ \\
\hline merc. alleg. & 0.07 & - & 0.45 & - & - & - & $\mathrm{F}(1,178)=56.33 ; p \approx 0.000 ; d=1.19$ \\
\hline merc. rebels & 0.06 & - & 0.73 & - & - & - & $\mathrm{F}(1,158)=134.41 ; p \approx 0.000 ; d=1.83$ \\
\hline merc. sbd. & - & - & - & 0.20 & - & 0.45 & $\mathrm{~F}(1,176)=13.15 ; p \approx 0.000 ; d=0.54$ \\
\hline merc. peers & - & - & - & 0.19 & - & 0.54 & $\mathrm{~F}(1,160)=25.70 ; p \approx 0.000 ; d=0.79$ \\
\hline merc. alleg. & - & - & - & 0.20 & - & 0.42 & $\mathrm{~F}(1,178)=10.88 ; p=0.001 ; d=0.49$ \\
\hline merc. rebels & - & - & - & 0.19 & - & 0.58 & $\mathrm{~F}(1,158)=29.90 ; p=0.006 ; d=0.86$ \\
\hline
\end{tabular}

alleg.-allegiant; merc.-mercenary; sbd.-subordinate.

\subsection{Effects of Status}

The evaluations also differ according to the status of the target, but only in what concerns the allegiant target (no difference is observed in terms of the rebel target): if we examine the case of the allegiant taken globally (i.e., by associating the ideological and the mercenary), as in each of its two sides (ideological as well as mercenary), we notice that the subordinates are subjected to less negative judgments than peers (both in terms of desirability, as well as utility) (Table 6).

Table 6. Means and effects of status.

\begin{tabular}{|c|c|c|c|c|c|c|c|}
\hline \multirow{2}{*}{$\begin{array}{l}\text { Subjects } \\
\text { Targeted }\end{array}$} & \multicolumn{2}{|c|}{$\begin{array}{c}\text { Negative } \\
\text { Desirability }\end{array}$} & \multicolumn{2}{|c|}{ Neutral Utility } & \multicolumn{2}{|c|}{ Negative Utility } & \multirow{2}{*}{$\mathrm{F}$ (Snedecor) and $d$ (Cohen) } \\
\hline & sbd. & Peers & sbd. & Peers & sbd. & Peers & \\
\hline alleg. global & 0.56 & 0.98 & - & - & - & - & $\mathrm{F}(1,88)=6.09 ; p=0.016 ; d=0.51$ \\
\hline alleg. id. & 0.10 & 0.40 & - & - & - & - & $\mathrm{F}(1,88)=12.48 ; p=0.001 ; d=0.73$ \\
\hline alleg. global & - & - & - & - & 0.38 & 0.95 & $\mathrm{~F}(1,88)=12.29 ; p=0.001 ; d=0.73$ \\
\hline alleg. id. & - & - & - & - & 0.06 & 0.40 & $\mathrm{~F}(1,88)=18.20 ; p \approx 0.000 ; d=0.87$ \\
\hline alleg. merc. & - & - & - & - & 0.32 & 0.55 & $\mathrm{~F}(1,88)=4.98 ; p=0.028 ; d=0.47$ \\
\hline alleg. global & - & - & 0.84 & 0.53 & - & - & $\mathrm{F}(1,88)=5.288 ; p=0.024 ; d=0.49$ \\
\hline
\end{tabular}

\subsection{Effects of Allegiance/Rebellion}

The evaluations of allegiants and respectively rebels (Table 7), taken globally (without taking into account their ideological and mercenary dimensions), show that the rebels are subjected to more negative evaluations (and less neutral or positive evaluations) than the allegiants. We also notice, if we take into consideration the status of the target, that such differences are only observed when the target is a subordinate. We find similar data for ideological allegiance/rebellion and for mercenary allegiance/rebellion (Table 8). 
Table 7. Means and effects of allegiance/rebellion desirability (globally or considering ideologist and mercenary dimensions).

\begin{tabular}{lccccccc}
\hline \multirow{2}{*}{$\begin{array}{l}\text { Subjects } \\
\text { Targeted }\end{array}$} & \multicolumn{6}{c}{ Level of Allegiants Desirability } & \multicolumn{7}{c}{ Level of Rebels Desirability } & & F (Snedecor) and $d$ (Cohen) \\
\cline { 2 - 6 } & Positive & Neutral & Negative & Positive & Neutral & Negative & \\
\hline subjects global & - & - & 0.74 & - & - & 1.21 & $\mathrm{~F}(1,168)=12.56 ; p=0.001 ; d=0.56$ \\
sbd. global & - & - & 0.56 & - & - & 1.33 & $\mathrm{~F}(1,87)=24.26 ; p \approx 0.000 ; d=1.04$ \\
id. & - & - & 0.23 & - & - & 0.49 & $\mathrm{~F}(1,168)=11.75 ; p=0.001 ; d=0.55$ \\
id. sbd. & - & - & 0.10 & - & - & 0.54 & $\mathrm{~F}(1,87)=25.82 ; p \approx 0.000 ; d=1.05$ \\
merc. & - & - & 0.51 & - & - & 0.73 & $\mathrm{~F}(1,168)=8.09 ; p=0.005 ; d=0.45$ \\
merc. sbd. & - & - & 0.46 & - & - & 0.79 & $\mathrm{~F}(1,77)=11.38 ; p=0.001 ; d=0.73$ \\
\hline subjects global & - & 1.00 & - & - & 0.56 & - & $\mathrm{F}(1,168)=14.04 ; p \approx 0.000 ; d=0.59$ \\
sbd. global & - & 1.10 & - & - & 0.51 & - & $\mathrm{F}(1,87)=17.18 ; p \approx 0.000 ; d=0.89$ \\
id. & - & 0.58 & - & - & 0.35 & - & $\mathrm{F}(1,168)=8.55 ; p=0.004 ; d=0.47$ \\
id. sbd. & - & 0.64 & - & - & 0.33 & - & $\mathrm{F}(1,87)=8.88 ; p=0.004 ; d=0.64$ \\
merc. & - & 0.42 & - & - & 0.21 & - & $\mathrm{F}(1,168)=8.43 ; p=0.021 ; d=0.46$ \\
merc. sbd. & - & 0.46 & - & - & 0.18 & - & $\mathrm{F}(1,77)=8.26 ; p=0.005 ; d=0.62$ \\
\hline
\end{tabular}

Table 8. Means and effects of allegiance/rebellion utility (globally or considering ideologist and mercenary dimensions).

\begin{tabular}{|c|c|c|c|c|c|c|c|}
\hline \multirow{2}{*}{$\begin{array}{c}\text { Subjects } \\
\text { Target }\end{array}$} & \multicolumn{3}{|c|}{ Level of Allegiant Utility } & \multicolumn{3}{|c|}{ Level of Rebels Utility } & \multirow{2}{*}{$\mathrm{F}$ (Snedecor) and $d$ (Cohen) } \\
\hline & Positive & Neutral & Negative & Positive & Neutral & Negative & \\
\hline subjects global & - & - & 0.63 & - & - & 1.00 & $\mathrm{~F}(1,168)=6.69 ; p=0.011 ; d=0.42$ \\
\hline sbd. global & - & - & 0.38 & - & - & 1.10 & $\mathrm{~F}(1,87)=19.37 ; p \approx 0.000 ; d=0.92$ \\
\hline id. & - & - & 0.21 & - & - & 0.43 & $\mathrm{~F}(1,168)=8.52 ; p=0.004 ; d=0.47$ \\
\hline id. sbd. & - & - & 0.06 & - & - & 0.49 & $\mathrm{~F}(1,87)=27.67 ; p \approx 0.000 ; d=1.08$ \\
\hline merc. sbd. & - & - & 0.32 & - & - & 0.62 & $\mathrm{~F}(1,77)=8.27 ; p=0.005 ; d=0.61$ \\
\hline subjects global & - & 0.70 & - & - & 0.45 & - & $\mathrm{F}(1,168)=5.67 ; p=0.018 ; d=0.39$ \\
\hline sbd. global & - & 0.84 & - & - & 0.46 & - & $\mathrm{F}(1,87)=7.11 ; p=0.009 ; d=0.57$ \\
\hline merc. & - & 0.44 & - & - & 0.23 & - & $\mathrm{F}(1,77)=4.34 ; p=0.040 ; d=0.45$ \\
\hline sbd. global & 0.78 & - & - & 0.44 & - & - & $\mathrm{F}(1,87)=4.17 ; p=0.044 ; d=0.44$ \\
\hline id. sbd. & 0.54 & - & - & 0.28 & - & - & $\mathrm{F}(1,87)=6.24 ; p=0.014 ; d=0.54$ \\
\hline
\end{tabular}

\subsection{Interactions}

It should also be noted that there are six status $x$ allegiance interactions. They concern negative desirability taken into consideration globally and negative utility taken into consideration globally; negative desirability, positive utility and negative utility attributed to ideological targets; and finally, negative utility attributed to mercenary targets.

\subsubsection{Responses of Overall Negative Desirability and of Overall Negative Utility}

The responses of negative desirability differ significantly $(\mathrm{F}(1,168)=6.631, p=0.011)$ depending on whether we examine global allegiance vs. global rebellion among peers or subordinates. We thus observe that if the target is a subordinate, rebellion leads to a stronger negative desirability than allegiance, whereas this difference fails to occur if the target is a peer. This interaction also means that negative desirability is stronger for peers than for subordinates, but only for allegiance (there is no significant difference in case of rebellion), according to Figure 1a. 


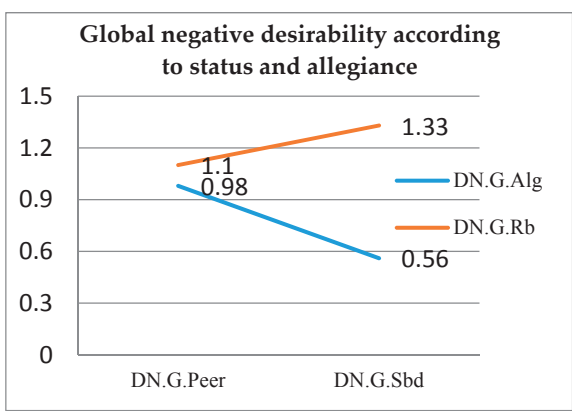

(a)

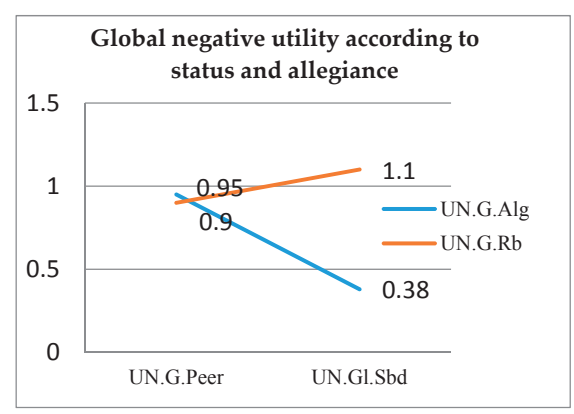

(b)

Figure 1. (a) Responses of global negative desirability (DN) according to status (Peer/Sbd) and the allegiance/rebellion (Alg/ $\mathrm{Rb}$ ) variable; (b) Responses of global negative utility according to status and allegiance/rebellion variable.

The responses of negative utility differ significantly $(\mathrm{F}(1,168)=8.715, p=0.004)$ depending on whether we examine global allegiance vs. global rebellion among peers or among subordinates. We thus observe that if the target is a subordinate, rebellion leads to a stronger negative utility than allegiance, whereas this difference does not appear if the target is a peer. The second significance of this interaction is that negative utility is higher for peers than for subordinates, but solely for allegiance (there is no significant difference for rebellion), according to Figure $1 \mathrm{~b}$.

\subsubsection{Responses of Negative Desirability and of Positive/Negative Utility of Ideologists}

The responses of negative desirability differ significantly $(F(1,168)=8.224, p=0.005)$ depending on whether we examine ideological allegiance vs. ideological rebellion among peers or among subordinates. Thus, we observe a more intense negative desirability towards rebels as compared to allegiants, but solely if the target is a subordinate, and moreover the difference in terms of peer/subordinate negative desirability is significant among ideological allegiants but not among ideological rebels (according to Figure 2a).

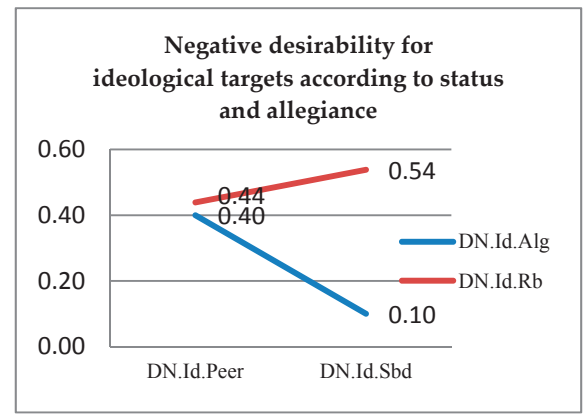

(a)

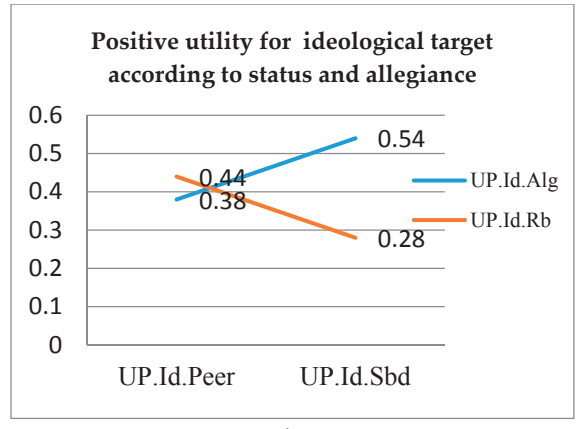

(b)

Figure 2. (a) Responses of negative desirability (DN) for ideological (Id) targets according to status (Peer/Sbd) and the allegiance(Alg)/rebellion(Rb) variable; (b) Responses of positive utility (UP) for ideological(Id) targets according to status (Peer/Sbd) and the allegiance(Alg)/rebellion(Rb) variable.

The responses of positive utility differ significantly $(F(1,168)=4.551, p=0.034)$ depending on whether we examine ideological allegiance vs. ideological rebellion among peers or among 
subordinates. Thus we observe that if the target is a subordinate, ideological allegiance leads to a higher positive utility than the ideological rebellion, whereas there is no difference if the target is a peer (according to Figure $2 b$ ).

The responses of negative utility differ significantly $(\mathrm{F}(1,168)=11.736, p=0.001)$ depending on whether we examine ideological allegiance vs. ideological rebellion among peers or among subordinates. Thus we observe that if the target is a subordinate, ideological rebellion leads to a stronger negative utility than ideological allegiance, whereas this difference fails to occur if the target is a peer. The second signification of this interaction is that negative utility is stronger for peers than for subordinates, but only in terms of ideological allegiance (there is no significant difference in the case of ideological rebellion) (according to Figure 3).

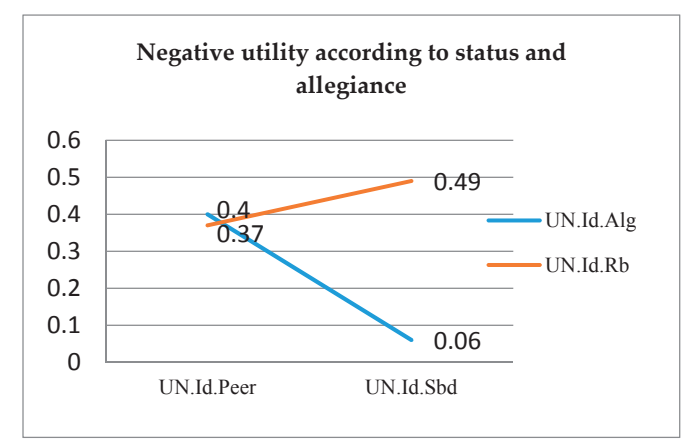

Figure 3. Responses of negative utility (UN) for ideological targets (Id) according to status (Peer/Sbd) and the allegiance $(\mathrm{Alg}) /$ rebellion $(\mathrm{Rb})$ variable.

\subsubsection{Responses of Negative Utility in Case of Mercenaries}

Negative utility responses differ significantly $(\mathrm{F}(1,168)=4.143, p=0.043)$ depending on whether we examine mercenary allegiance vs. mercenary rebellion among peers or among subordinates. Thus, we observe that if the target is a subordinate, mercenary rebellion leads to a stronger negative utility than mercenary allegiance, whereas this difference does not occur if the target is a peer. This interaction also signifies that negative utility is stronger for peers than for subordinates, but solely in terms of mercenary allegiance (there is no significant difference in terms of mercenary rebellion) (according to Figure 4).

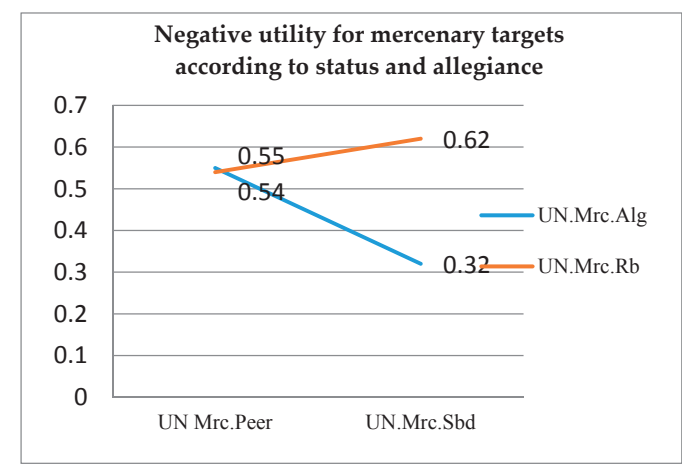

Figure 4. Responses of negative utility for mercenary targets according to status (Peer/Sbd) and the allegiance $(\mathrm{Alg})$ / rebellion $(\mathrm{Rb})$ variable. 


\section{Discussion}

In this article, we have been interested in the social value attributed to allegiant or non-allegiant employees and whether this value is different when we speak of social desirability or social utility, when we speak of positive, neutral or negative judgments, or when we speak of a peer or subordinate allegiant (non-allegiant).

We first notice that each of our four variables has an effect, whether it is about the type or the level of judgment, status, or even allegiance/rebellion.

Several studies have shown that utility and desirability are two distinct dimensions. Thus, Cambon, Djouary, and Beauvois; Dubois; or Testé, Joufre, and Somat $[29,33,37]$ noted that internality (i.e., the tendency to declare oneself responsible for our actions or what happens to us) $[38,39]$ was more rooted in utility than in desirability. Cambon, Djouary, and Beauvois [33] and Dubois [29] observed that this was also the case for self-sufficiency (finding in oneself the answers to the questions we ask ourselves [40]). Conversely, Dubois found that the individual anchor norm (i.e., the tendency to see our psychological reality without reference to our categorical or group membership) is more rooted in desirability [29]. About allegiance, Gangloff [36] has also previously observed (but in a study on the value of information about the allegiance and not, as is the case here, on the value assigned to the allegiance itself: cf. above) that utility and desirability were separate. It is hereby confirmed, according to our hypothesis, that the utility and desirability of allegiance (considered in itself) do not lead to identical judgements, and more particularly that positive judgments are higher for utility than for desirability. In their positive judgments, the evaluators thus attribute more importance to utility than to desirability. It is therefore interesting to observe, in terms of mercenary targets, that it is the judgment of desirability that leads to more intense negative evaluations: mercenaries are therefore further rejected based on emotional reasons than due to a questioning of their utility.

We also notice, in what concerns the level of judgment (positive, neutral, or negative) examined globally or regarding mercenary targets, that the negative evaluations are generally higher than neutral evaluations, which in turn are higher than the positive evaluations. On the contrary, in what concerns the effects of the level of judgment on the ideological targets, the results are more heterogeneous, with practically as many cases in the global sense as in the reverse sense. The fact that this heterogeneity only concerns the ideological targets tends to show a preference for ideologists as compared to mercenaries: an individual that acts opportunistically, such as the mercenary, will be rejected more than the individual responding to an ideology, principles, and regardless of the direction of their behavior (allegiant or rebel). This result joins that obtained by Duchon and Gangloff in 2008 [20].

The evaluations also differ according to the status of the target, but only in what concerns the allegiant target (no difference was observed in terms of the rebel target): whether they are ideologists or mercenaries, peers are subject to more intense negative judgments than the subordinates, both in terms of desirability and utility. Consistent with our hypothesis, they are more severe towards the endo-group than the exo-group.

In what regards the allegiance/rebellion variable, it is observed (both globally, as well as according to their sub-dimension: ideological/mercenary) that even if the allegiant is not subjected to more positive evaluations than the rebel (except for utility), on the contrary, the rebel is always subjected to more important negative evaluations than the allegiant. The fact that the differences of judgments between allegiant targets and rebel targets come mostly from more negative judgments passed on rebels than more positive judgments passed on allegiants opens the way for an inquiry on the bipolarity of the level of judgment, meaning to a reflection on the possible absence of a corollary between valuation and devaluation. Moreover, it is also worth noting, if we take into consideration the status of the target, that such differences are only observed when the target is a subordinate. Therefore, we once more encounter more lenience towards the exo-group.

Finally, the status $\mathrm{x}$ allegiance interaction highlights that the responses on utility or desirability differ according to whether we are examining allegiance vs. rebellion among peers or among subordinates. Therefore, an allegiant subordinate obtains less negative responses, both in terms 
of utility and desirability, as compared to an allegiant peer or a rebel subordinate. We also observe, in the case of ideological allegiance and rebellion, a stronger intensity of negative desirability and utility towards rebels as compared to allegiants, and, in reverse, a stronger intensity of positive utility for allegiants than for rebels, but in all three cases only if the target is a subordinate. Finally, if we examine the case of mercenaries, we notice that mercenary rebellion leads to a stronger negative utility than mercenary allegiance, but again only if the target is a subordinate.

However, we should indicate a certain number of limitations to these results. The first is the absence of any contextualization with regards to the function of the future collaborator. Evidently, expectations may differ according to the type of function exerted by the future collaborator, be it a future peer or a future subordinate. It would therefore be appropriate, in a subsequent study, to refine this aspect and to vary the function in order to operationalize it as an independent variable. But contextualization does not only concern the function of the future collaborator: it may reveal gender, age, etc. Also, since our participants were only male (our results are not necessarily transferable to a female population), it would be interesting to examine the potential effect of the gender of the target, with a factorial plan in which the participants are divided into two groups (one group of males and one group of females): it is not certain that we will obtain similar results for each of the four groups. As it can be observed, the present results open the way to numerous new questions, and therefore to numerous additional studies. However, they already have a number of practical applications. Thus, in terms of recruitment, the focus is often exclusively, at least explicitly, on the technical skills of the candidates, forgetting the relational aspect, the atmosphere at work. The present results could enable recruitment officers as well as job applicants to become more aware of the importance of the relational aspect. Such awareness could enable recruitment officers to operationalize this relational aspect more explicitly, including taking into account the allegiance criterion; consequently, such awareness and such explicitation could also enable job applicants to better prepare for their selection interviews.

\section{Conclusions}

We are interested in presenting an interpretation of our results about allegiant behavior from the perspective of sustainable development. Most often, undertaking a behavior that would support sustainable development involves effort, discomfort, or additional financial costs. Many sustainable behaviors have positive collective consequences, but negative individual ones. Therefore, the person who assumes a sustainable behavior must be motivated and act according to values that support the sustainable development of society.

The decision to assume a sustainable behavior reflects a person's attachment to certain principles, values, and beliefs. By definition, allegiant people are characterized by adhering to and supporting the values of the organization they belong to, contributing through their acts to the maintenance, preservation, and sustainability of social order and the existing organizational structure.

A first result of our work highlights the valuation of allegiant behavior within a company, which means that an allegiant employee is appreciated and valued more than a rebellious employee whose negative assessments are always more numerous than those for the allegiant. Allegiant people are not appreciated because they are more agreeable, although their social desirability is somewhat valued as well. The results show that allegiant persons are appreciated more in terms of their social utility. Being able to integrate within the organizational world without disturbing it, rapidly identifying with the organization, easily complying with the rules and norms of the organization, and especially because they conform to any authority without jeopardizing the hierarchy of power, allegiant people are considered useful for the organization and the social environment they belong to.

By analyzing the results, we identify a preference for the allegiant ideologist, who acts by virtue of certain principles and ideologies, as compared with the allegiant mercenary who has opportunistic purposes and, through his/her obedience, only aims to achieve their personal goals. 
In what regards the status of the persons assessed, be they subordinates or peers, we obtained a greater valorization of allegiant persons if they are subordinates and a lower valorization if they are peers, meaning that a leader appreciates more allegiant subordinates than allegiant peers.

Promoting a transition to a sustainable society must be done with motivated people who would invest time and assume certain additional costs. Within an organization, the issue of sustainability must be approached on the one hand from the perspective of leaders who assume a sustainable leadership, and there are plenty of studies there of that aim to identify the skills necessary for a leader to successfully implement the transition to a sustainable organization [7,41-44].

However, the issue of sustainability must also be approached from the perspective of the employees, who can adhere to the leader's values, thus facilitating the implementation of sustainability, or who can rebel against the leader when the requests of the latter may bring personal prejudices (for example, additional costs) or generate a certain discomfort, and then the rebel person is not willing to accept the leader's demands and will hinder the implementation of the measures established by the leader.

The results of our work on allegiant behavior may have practical implications within the field of implementing sustainability within an organization. When selecting the team with whom one wants to make the transition to a sustainable organization, one must take into account their availability to preserve the social order and encourage ideological reproduction.

An organization undergoing transition towards a durable development, with a sustainable leadership, also requires employees who believe in the leader's values, who believe in the values of sustainability and who would comply with the rules and norms that support sustainable development. Allegiant people acting based on an ideology that values sustainability are loyal, comply with rules, and follow the existing norms imposed by a sustainable leadership, not because they are afraid of repression, but because they are committed and act in accordance with their beliefs on the necessity of implementing sustainable development and because they will not disturb the organizational structure.

Our results highlight a valuation of allegiant behavior within an organization, especially when it comes to a collaboration between the leader and his subordinates that gives confidence in the chances of implementing a transition to a sustainable organization.

Acknowledgments: There are no sources of funding for the study or grants received for the research. There are no resources for publication in free access.

Author Contributions: Crisanta-Alina Mazilescu conceived the experiments and analyzed the data; Bernard Gangloff conceived, designed and performed the experiments; Crisanta-Alina Mazilescu and Bernard Gangloff wrote the paper.

Conflicts of Interest: The authors declare no conflict of interest.

\section{Appendix A. Items of the Questionnaire}

Items of ideological allegiance: Imagine that you will soon have a new work colleague (vs. a new subordinate), and that the only information you have on that person is that they said:

(1) When my boss makes a decision, I never question it, regardless of his/her decision: one should not argue with one's boss!

(2) never try to defend my ideas when I see that they differ from that of my boss: the boss is the boss!

(3) I always follow the orders I get from my boss, even when those orders may seem idiotic: a follower has to follow and that's it!

Items of ideological rebellion: Imagine that you will soon have a new work colleague (vs. a new subordinate), and that the only information you have on that person is that they said:

(1) When I don't agree with my boss, I always tell him/her: the law also grants rights to employees, which should be exerted or otherwise they will be lost! 
(2) When my boss makes bad decisions, I never hesitate to question them: I have principles and I don't see why I should keep silent.

(3) If I disagree with my boss' orders, I will not obey them: only because he/she is the boss does not mean we have to obey him/her like slaves!

Items of mercenary allegiance: Imagine that you will soon have a new work colleague (vs. a new subordinate), and that the only information you have on that person is that they said:

(1) Even if the orders given by my boss sometimes seem absurd, because I want to be rapidly promoted, I always obey them!

(2) I always avoid defending my point of view when it contradicts my boss' point of view: it's better to act like this if I want to get a higher wage.

(3) Because I want to be well-thought of by my boss, I always respect his/her decisions, regardless of what they are!

Items of mercenary rebellion: Imagine that you will soon have a new work colleague (vs. a new subordinate), and that the only information you have on that person is that they said:

(1) When my boss gives me orders which seem to be inadequate, if those orders interfere with me achieving my goals or receiving my bonuses, I never follow them!

(2) When I see that my direct superior has bad ideas, I always inform the "big bosses": one day, I will be rewarded for it!

(3) When I see that the decisions of my boss may prevent me from getting a promotion, I never hesitate to protest!

\section{Appendix B. Gross Results}

Table A1. Distribution of responses provided for allegiance/rebellion taken globally (occurrences and means *).

\begin{tabular}{|c|c|c|c|c|c|c|c|c|c|}
\hline \multirow{2}{*}{\multicolumn{2}{|c|}{ Subjects Targeted }} & \multicolumn{4}{|c|}{ Desirability } & \multicolumn{4}{|c|}{ Utility } \\
\hline & & Positive & Neutral & Negative & Total & Positive & Neutral & Negative & Total \\
\hline \multirow{3}{*}{$\begin{array}{l}\text { alleg. Id. } \\
+ \text { merc }\end{array}$} & peer & $6(0,08)$ & $35(0.43)$ & $39(0.49)$ & $80(1)$ & $21(0.26)$ & $21(0.26)$ & $38(0.48)$ & $80(1)$ \\
\hline & sbd. & $17(0.17)$ & $54(0.54)$ & $29(0.29)$ & $100(1)$ & $39(0.39)$ & $42(0.42)$ & $19(0.19)$ & $100(1)$ \\
\hline & tot & $23(0.13)$ & $89(0.49)$ & $68(0.38)$ & $180(1)$ & $60(0.33)$ & $63(0.35)$ & $57(0.32)$ & $180(1)$ \\
\hline \multirow{3}{*}{$\begin{array}{l}\text { rebel id. } \\
\text { + merc. }\end{array}$} & peer & $12(0.15)$ & $25(0.30)$ & $45(0.55)$ & $82(1)$ & $27(0.33)$ & $18(0.22)$ & $37(0.45)$ & $82(1)$ \\
\hline & sbd & $6(0.07)$ & $20(0.26)$ & $52(0.67)$ & $78(1)$ & $17(0.22)$ & $18(0.23)$ & $43(0.55)$ & $78(1)$ \\
\hline & tot & $18(0.11)$ & $45(0.28)$ & $97(0,61)$ & $160(1)$ & $44(0.28)$ & $36(0.22)$ & $80(0.50)$ & $160(1)$ \\
\hline \multirow{3}{*}{ Total } & peer & $18(0.11)$ & $60(0.37)$ & $84(0,52)$ & $162(1)$ & $48(0.30)$ & $39(0.24)$ & $75(0.46)$ & $162(1)$ \\
\hline & sbd & $23(0.13)$ & $74(0.42)$ & $81(0.45)$ & $178(1)$ & $56(0.31)$ & $60(0.34)$ & $62(0.35)$ & $178(1)$ \\
\hline & tot & $41(0.12)$ & $134(0.39)$ & $165(0,49)$ & $340(1)$ & $104(0.31)$ & $99(0.29)$ & $137(0.40)$ & $340(1)$ \\
\hline
\end{tabular}

alleg.-allegeant; id.-ideologist; merc.-mercenary; sbd.-subordinate; tot.-total; *—means are indicated between parantheses. 
Table A2. Distribution of responses provided for allegiance/rebellion legalists (occurrences and means *).

\begin{tabular}{cccccccccc}
\hline \multirow{2}{*}{ Subjects Targeted } & \multicolumn{5}{c}{ Desirability } \\
\cline { 3 - 9 } & & Positive & Neutral & Negative & Total & Positive & Neutral & Negative & Total \\
\hline \multirow{2}{*}{ alleg. id. } & peer & $4(0.10)$ & $20(0.50)$ & $16(0.40)$ & $40(1)$ & $15(0.375)$ & $9(0.225)$ & $16(0.40)$ & $40(1)$ \\
& sbd. & $13(0.26)$ & $32(0.64)$ & $5(0.10)$ & $50(1)$ & $27(0.54)$ & $20(0.40)$ & $3(0.06)$ & $50(1)$ \\
& total & $17(0.19)$ & $51(0.57)$ & $22(0.24)$ & $90(1)$ & $42(0.47)$ & $29(0.47)$ & $19(0.21)$ & $90(1)$ \\
\hline \multirow{3}{*}{ rebel id. } & peer & $8(0.195)$ & $15(0.365)$ & $18(0.44)$ & $41(1)$ & $18(0.44)$ & $8(0.195)$ & $15(0.365)$ & $41(1)$ \\
& sbd. & $5(0.13)$ & $13(0.33)$ & $21(0.54)$ & $39(1)$ & $11(0.28)$ & $9(0.195)$ & $19(0.49)$ & $39(1)$ \\
& total & $13(0.16)$ & $28(0.35)$ & $39(0.49)$ & $80(1)$ & $29(0.36)$ & $17(0.23)$ & $34(0.43)$ & $80(1)$ \\
\hline \multirow{3}{*}{ total } & peer & $12(0.15)$ & $35(0.43)$ & $34(0.42)$ & $81(1)$ & $33(0.41)$ & $17(0.21)$ & $31(0.38)$ & $81(1)$ \\
& sbd. & $18(0.20)$ & $44(0.50)$ & $27(0.30)$ & $89(1)$ & $38(0.43)$ & $29(0.32)$ & $22(0.25)$ & $89(1)$ \\
& total & $30(0.18)$ & $79(0.46)$ & $61(0.36)$ & $170(1)$ & $71(0.42)$ & $46(0.27)$ & $53(0.31)$ & $170(1)$ \\
\hline
\end{tabular}

alleg.--allegeant; id.--ideologist; sbd.—subordinate; tot.- total; ${ }^{*}$-means are indicated between parantheses.

Table A3. Distribution of responses provided for allegiance/rebellion opportunists (occurrences and means *).

\begin{tabular}{cccccccccc}
\hline \multirow{2}{*}{ Subjects Targeted } & \multicolumn{9}{c}{ Desirability } \\
\cline { 3 - 9 } & & Positive & Neutral & Negative & Total & Positive & Neutral & Negative & Total \\
\hline \multirow{2}{*}{ alleg. } & Peer & $2(0.05)$ & $15(0.375)$ & $23(0.575)$ & $40(1)$ & $6(0.15)$ & $12(0.30)$ & $22(0.55)$ & $40(1)$ \\
merc. & Sbd & $4(0.08)$ & $23(0.46)$ & $23(0.46)$ & $50(1)$ & $12(0.24)$ & $22(0.44)$ & $16(0.32)$ & $50(1)$ \\
& Tot & $6(0.07)$ & $38(0.42)$ & $46(0.51)$ & $90(1)$ & $18(0.20)$ & $34(0.38)$ & $38(0.42)$ & $90(1)$ \\
\hline \multirow{2}{*}{ reb. } & Peer & $4(0.10)$ & $10(0.24)$ & $27(0.66)$ & $41(1)$ & $9(0.22)$ & $10(0.24)$ & $22(0.54)$ & $41(1)$ \\
merc. & Sbd & $1(0.03)$ & $7(0.18)$ & $31(0.79)$ & $39(1)$ & $6(0.15)$ & $9(0.23)$ & $24(0.62)$ & $39(1)$ \\
& Tot & $5(0.06)$ & $17(0.21)$ & $58(0.73)$ & $80(1)$ & $15(0.19)$ & $19(0.23)$ & $46(0.58)$ & $80(1)$ \\
\hline \multirow{2}{*}{ total } & Peer & $6(0.07)$ & $25(0.31)$ & $50(0.62)$ & $81(1)$ & $15(0.19)$ & $22(0.27)$ & $44(0.54)$ & $81(1)$ \\
& Sbd & $5(0.06)$ & $30(0.34)$ & $54(0.60)$ & $89(1)$ & $18(0.20)$ & $31(0.35)$ & $40(0.45)$ & $89(1)$ \\
& Tot & $11(0.06)$ & $55(0.33)$ & $104(0.61)$ & $170(1)$ & $33(0.19)$ & $53(0.31)$ & $84(0.50)$ & $170(1)$ \\
\hline
\end{tabular}

alleg.-allegeant; reb.-rebel; merc.-mercenary; sbd.-subordinate; tot-total; ${ }^{*}$-means are indicated between parantheses.

\section{References}

1. Omann, I.; Spangenberg, J.H. Assessing Social Sustainability. The Social Dimension of Sustainability in a Socio-Economic Scenario. In Proceedings of the 7th Biennial Conference of the International Society for Ecological Economics, Sousse, Tunisia, 6-9 March 2002.

2. Wolbring, G.; Rybchinski, T. Social Sustainability and its Indicators through a disability studies lens. Sustainability 2013, 5, 4889-4907. [CrossRef]

3. Widok, A.H.; Wohlgemuth, V. Definition of Social Sustainability Criteria for the Simulation of OHS in Manufacturing Entities. In Proceedings of the 29th EnviroInfo and 3rd ICT4S Conference, Copenhagen, Denmark, 7-9 September 2015.

4. Cao, Y.; Wang, S.; Yi, L.; Zhou, J. A Social Sustainability Assessment Model for Manufacturing Systems Based on Ergonomics and Fuzzy Inference System. In Sustainable Design and Manufacturing 2016; Setchi, R., Howlett, R.J., Liu, Y., Theobald, P., Eds.; Springer: Berlin/Heidelberg, Germany, 2016; pp. 639-648.

5. Jasiulewicz-Kaczmarek, M.; Saniuk, A. Human factor in Sustainable Manufacturing. In Universal Access in Human-Computer Interaction. Access to the Human Environment and Culture; Antona, M., Stephanidis, C., Eds.; Springer: Berlin/Heidelberg, Germany, 2015; pp. 444-455.

6. Chiu, R. Social sustainability and sustainable housing. In Housing and Social Change: East, West Perspectives; Forrest, R., Lee, J., Eds.; Routledge: London, UK, 2003; pp. 221-239.

7. Dent, P.; Patrick, M.; Ye, X. Property Markets and Sustainable Behaviour; Routledge: New York, NY, USA, 2012.

8. Buil, M.; Aznar, J.P.; Galiana, J.; Rocafort-Marco, A. An Explanatory Study of MBA Students with Regards to Sustainability and Ethics Commitment. Sustainability 2016, 8, 280. [CrossRef] 
9. Gardiner, S.; Rieckmann, M. Pedagogies of Preparedness: Use of Reflective Journals in the Operationalisation and Development of Anticipatory Competence. Sustainability 2015, 7, 10554-10575. [CrossRef]

10. Cebrián, G.; Junyent, M. Competencies in Education for Sustainable Development: Exploring the Student Teachers' Views. Sustainability 2015, 7, 2768-2786. [CrossRef]

11. Sammalisto, K.; Sundström, A.; von Haartman, R.; Holm, T.; Yao, Z. Learning about Sustainability-What Influences Students' Self-Perceived Sustainability Actions after Undergraduate Education? Sustainability 2016, 8, 510. [CrossRef]

12. Steg, L.; Perlaviciute, G.; van der Werff, E. Understanding the human dimensions of a sustainable energy transition. Front. Psychol. 2015, 6, 805. [CrossRef] [PubMed]

13. Steg, L.; Bolderdijk, J.W.; Keizer, K.; Perlaviciute, G. An integrated framework for encouraging pro-environmental behaviour: the role of values, situational factors and goals. J. Environ. Psychol. 2014, 38, 104-115. [CrossRef]

14. Steg, L.; Perlaviciute, G.; van der Werff, E.; Lurvink, J. The significance of hedonic values for environmentally-relevant attitudes, preferences and actions. Environ. Behav. 2014, 46, 163-192. [CrossRef]

15. Abrahamse, W.; Steg, L. Social influence approaches to encourage resource conservation: A meta-analysis. Glob. Environ. Chang. 2013, 23, 1773-1785. [CrossRef]

16. Gangloff, B. La norme d'allégeance. In Psychologie et Recrutement; Laberon, S., Ed.; De Boeck: Bruxelles, Belgium, 2011; pp. 177-197.

17. Bucchioni, S. Rôles Respectifs de L'internalité et de L'allégeance dans L'évaluation Professionnelle; Mémoire non publié; Université de Reims Champagne-Ardenne: Reims, France, 2001.

18. Dagot, L. L'allégeance et l'internalité dans le travail d'aide à l'insertion professionnelle: Le cas du bilan de compétences. In Proceedings of the Communication au 11ème Congrès International de Psychologie du Travail de Langue Française, Rouen, France, 23-25 August 2000.

19. Dagot, L. Normativité de L'allégeance et de L'internalité: Le Cas Des Acteurs du Marché du Travail. Ph.D. Thesis, Université de Bordeaux 2, Bordeaux, France, 2002.

20. Legrain, H.; Dagot, L. Internalité et allégeance. Actes du Colloque AFPA/INOIP/AIPLF. In L'Approche Psychologique du Travail; AFPA/AIPTLF: Lille, France, 2005; pp. 65-70.

21. Dagot, L.; Castra, D. L'allégeance: Un principe des logiques d'aide à l'insertion professionnelle. L'orientat. Sc. Prof. 2002, 31, 417-442. [CrossRef]

22. Dagot, L. Conseiller et recruter: des logiques sociales d'évaluation. Cah. Int. Psychol. Soc. 2004, 63, 93-106.

23. Duchon, C.; Gangloff, B. Differential valorization of the unemployed persons according to the ideological or mercenary reason of their support versus non support for the allegiance norm. In Proceedings of the Actes de la 5th International Conference of Applied Psychology, Timisoara, Roumanie, 2007; Editura Eurobit: Timisoara, Roumanie, 2008; pp. 177-182.

24. Gilles, I.; Scheidegger, R.; Toma, C. Who likes the rebels and who likes the allegiants? The role of membership and status in the judgment of rebel attributions. Rev. Int. Psychol. Soc. 2011, 24, 83-106.

25. Gangloff, B.; Mayoral, L. Influencia del nivel de alineacion y del genero sobre las decisiones de administracion y de reclutamiento de personal en las empresas argentinas. Bol. Psicol. 2008, 94, 23-45.

26. Gangloff, B.; Mayoral, L. La percepcion de los obreros, ejecutivos del nivel medio y sindicalistas argentinos respecto del nivel de alineacion conveniente para ser reclutados. Interam. J. Psychol. 2008, 42, 338-352.

27. Beauvois, J.-L.; Dubois, N.; Peeters, G. L'évaluation personnologique. In La Construction Sociale de la Personne; Beauvois, J.-L., Dubois, N., Doise, W., Eds.; PUG: Grenoble, France, 1999; pp. 259-279.

28. Cambon, L. Désirabilité et utilité sociale, deux composantes de la valeur. Une exemplification dans l'analyse des activités professionnelles. L'Orientat. Sc. Prof. 2002, 31, 75-96. [CrossRef]

29. Dubois, N. Normes sociales de jugement et valeur: Ancrage sur l'utilité et ancrage sur la désirabilité. Rev. Int. Psychol. Soc. 2005, 18, 43-79.

30. Dubois, N.; Beauvois, J.-L. Evaluation et connaissance évaluative: Une théorie dualiste de la connaissance. Nouv. Rev. Psychol. Soc. 2001,1,101-111.

31. Peeters, G. Good and evil as softwares of the brain: On psychological immediates underlying the metaphysical ultimates. Interdiscip. Stud. Philos. Underst. 1986, 9, 210-231.

32. Beauvois, J.-L. La connaissance des utilités sociales. Psychol. Fr. 1995, 40, 375-388.

33. Cambon, L.; Djouary, N.; Beauvois, J.-L. Social norms of judgment and social utility: When it is more profitable to be useful than desirable. Swiss J. Psychol. 2006, 65, 167-180. [CrossRef] 
34. Le Barbenchon, E.; Cambon, L.; Lavigne, F. Désirabilité et utilité sociale de 308 adjectifs de personnalité et 297 professions. L'année Psychol. 2005, 105, 307-322. [CrossRef]

35. Mazilescu, C.A.; Abdellaoui, S.; Gangloff, B. Assessing the social value of personality information. Rev. Cercet. Interv. Soc. 2012, 38, 91-106.

36. Gangloff, B. Utilité et Désirabilité D'informations Normatives sur Des Subordonnés et Des Collègues de Travail. Les Cahiers de Psychologie Politique. 2010. Available online: http://lodel.irevues.inist.fr/ cahierspsychologiepolitique/index.php?id=1678 (accessed on 24 May 2016).

37. Testé, B.; Joufre, S.; Somat, A. L'expression de la préférence pour la consistance est-elle une norme de jugement comparable à l'expression de l'internalité? L'Année Psychol. 2010, 110, 379-399. [CrossRef]

38. Lefcourt, H.M. Internal vs external control of reinforcement: A review. Psychol. Bull. 1966, 65, $206-220$. [CrossRef] [PubMed]

39. Rotter, J.B. Generalized expectancies for internal versus external control of reinforcement. Psychol. Monogr. 1966, 80, 1-28. [CrossRef] [PubMed]

40. Sampson, E.E. Psychology and the American ideal. J. Personal. Soc. Psychol. 1977, 35, 767-782. [CrossRef]

41. Scott, W.; Gough, S. Sustainable Development and Learning. Framing the Issue; Routledge Falmer: London, UK, 2003.

42. Scott, W.; Gough, S. Key Issues in Sustainable Development and Learning, a Critical Review; Routledge Falmer: London, UK, 2003.

43. Fawcett, L.; Bell, A.C. Guiding our environmental praxis: Teaching and learning for social and environmental justice. In Teaching Sustainability at Universities: Towards Curriculum Greening; Leal Filho, W., Ed.; Peter Lang: New York, NY, USA, 2002.

44. Sterling, S. Sustainable Education; Green Books: Totnes, UK, 2001.

(C) 2017 by the authors. Licensee MDPI, Basel, Switzerland. This article is an open access article distributed under the terms and conditions of the Creative Commons Attribution (CC BY) license (http:/ / creativecommons.org/licenses/by/4.0/). 

Article

\title{
Joint Value as a Measure of Sea Trade Port Stakeholder Effect
}

\author{
Iryna Nyenno ${ }^{1, *(\mathbb{D}}$, Natalia Rekova ${ }^{2}$ and Svetlana Minakova ${ }^{3}$ \\ 1 Department of Management and Innovations, Odessa National University after I.I. Mechnikov, \\ 65082 Odessa, Ukraine \\ 2 Department of Enterprise Economics, Donbass State Engineering Academy, 84313 Kramators'k, Ukraine; \\ natarekova@gmail.com \\ 3 Chernovetskii Department of Economics and Management, National Technical University "Kharkiv \\ Polytechnic Institute", 65009 Chernivtsi, Ukraine; smmnkv@gmail.com \\ * Correspondence: inyenno@onu.edu.ua; Tel.: +380-50-585-6574
}

Received: 28 December 2018; Accepted: 11 April 2019; Published: 16 April 2019

\begin{abstract}
This article is devoted to an efficiency measurement of the maritime industry presented through the joint value of industry stakeholders. A list of factors contributing to the efficiency of the state maritime policy and factors in the development of the maritime industry were defined and separated into four groups: group 1 (infrastructural factors): Renewal of port infrastructure; coastal infrastructure of sea stations; ecological and physical safety; and convenience in reaching the port of departure of a cruise ship; group 2 (management factors): The effectiveness of management mechanisms; the level of automatization and effective communications technologies; the coordination of various types of transport; and the efficiency of port services; group 3 (marketing factors): Tariff policies (tariff amounts, number of port fees, flexibility of the price policy); and competition in the ports; group 4 (service factors): Attractiveness of logistics conditions; the development of international tourism; the development of sea leisure; the development of merchant shipping, shipbuilding, ship repair, and instrument making in the port; and the simplification of port entry procedures. The joint value was considered to be a category at both a macroeconomic and microeconomic level, and it was combined with a multivariate regression model performed on the basis of the statistical analysis and data processing system Statistica 8.0. The complex combination of the results of the multifactorial linear model of the joint value created in the maritime industry led to the conclusion that the best alternative to the development of the port industry in Ukraine is the scenario of state modernization and corporatization in the port business model.
\end{abstract}

Keywords: maritime industry; port business model; joint value; stakeholder effect

\section{Introduction}

Thanks to favorable market conditions, the maritime industry development forecast according to the World Maritime Review 2018 (World Maritime Review 2018) is enthusiastic and optimistic. World trade is emerging, while domestic economies are more and more demanding of international products and export impacts. This industry is so very attractive for different role players, such as transport and logistics, crewing companies, marine ports, exporters, and importers, that the issue of its measurement is debatable and has a lot of distinctive ways of implementation. In this article, a new approach to evaluating the effect created by the maritime sector is described. Namely, the relevant effect of different stakeholders is united to check the synergy.

The joint value created by the seaport takes into account the fact that as a result of the activity of each entity, there should be a maximization of utility in all stakeholders effectively performing specified roles. These stakeholders are the state, investors, owners, contractors of ports, the population 
of the port region, regular workers, and invited specialists. At the same time, sustainable development in the maritime industry is achieved by the integration of global value chains through international integration, mergers and takeovers of ports, and the creation of cross-border companies in particular.

Maximization of the usefulness of stakeholders is possible through optimization of the impact of positive and negative externalities in the maritime industry. Among the positive externalities are internationalization, the development of sea tourism and leisure, renovation of coastal infrastructure, simplification of customs clearance, the removal of administrative obstacles, the development of merchant shipping, shipbuilding, ship repair, instrument making, construction of navigable canals, bridges, staff training, employment, and wages. Meanwhile, the negative externalities are competition in ports; increased probabilities of violations of ecological and physical security in the port; the safety of transported cargo, passengers, and luggage; the complexity of coordination of work; and the interactions between different types of transport, cargo owners, forwarders, and stevedores in the port.

To prevent the formation of negative externalities, the common value forms conditions for achieving high ecological status and protection of the resources upon which the economic maritime profit-making activity is based. Thus, within the framework of the concept of sustainable development of ports, the necessary elements are an economic component (regional and macroeconomic development), a social component (raising the living standards of the seaport industry staff), and an ecological component (meeting the requirements of environmental standards). The shared value as a value added process for sustainable development motivates the implementation of an integrated approach for all authorities and management at the sectoral and administrative levels in the maritime industry, which allows for systematic efforts toward synergy and for identifying differences and inefficiencies. Efficiency is a concept that aims for the optimal use of resources. Its relation to the economy is obvious: Best-quality services and products provided with minimal resource use. Stakeholders, for whom joint value is created, influence organization significantly. The joint value rising influences the level of sustainable development.

Efficiency is improved when more outputs of a given quality are produced with the same or fewer resource inputs, or when the same amount of output is produced with fewer resources. For an in-depth explanation of the relationship between the efficiency concept and the joint value effect, it is worth analyzing the understanding of effect and efficiency. The joint value effect in the maritime industry is concerned with the extent of the achievement of stakeholder goals. Meanwhile, in the sense of the efficiency concept, the joint value of the maritime industry is considered to be a united dimension that demonstrates synergetic initiatives and strong partnership energy for the industry's potential development. Efficiency is achieved through a collaborative approach measured by the joint value effect.

\section{Literature Review}

Traditionally, port efficiency has been assessed by methods measuring cargo handling productivity. One of them is a factor based on productivity, while the other one is based on comparing tangible conditions with optimum throughputs over a certain period of time. Moreover, there are also methods originating from the estimation of a port cost function and the computing of total factor productivity. In addition, multiple regression analysis based on port performance and efficiency estimation models have been applied in the literature. However, methods based on calculations of relative efficiency with respect to productive activities have been growing recently (Gokcek and Şenol 2018).

Kelly and Alam (2008) have concluded that managers, investors, and all concerned must accept that in the contemporary world, the wealth of a corporation is not merely the property it owns, the financial resources it accumulates, or even the intellectual property it develops.

MacManus, J., has separated the intrinsic value of stakeholders based on behavioristic characteristics: Trust, motivation, success, relationship, and influence (MacManus 2002). Turki et al. (2012) have emphasized that there is a stakeholder value network. Ping Wang has mentioned that recently the maritime industry has been actively developed through the study of managerial 
disciplines, such as business logistics and strategic management. The maritime economy needs more and more managerial tools to be adequately measured. Business model research takes place with the usage of descriptive and constructive definitions. The constructive ones are concentrated on system building (Osterwalder and Pigneur 2010; Vashakmadze 2012), while descriptive ones set up the characteristics of this category. A range of authors have considered the external impact of the economic environment on modern business models. They have researched their characteristics. The attention of such scientists as Chesbrough (2007), Schweizer (2005), Debelak (2006), and Slywotskiy and Morrison (1997) has been directed to the classification approaches of business models. One still-unsolved task is the introduction of a practical approach to business model analysis. Bereznoy (2014) has emphasized the interdisciplinary nature of the term "business model". This nature explains the incomplete processing of this term in the literature on economic theory, a theory of strategy and organization where the business model is mentioned without giving a precise definition. Summarizing the approaches to "business model" definitions, Soolyatte (2010) noted that major differences in the interpretation of the term "business model" occur among technology-oriented people and business-oriented people. (Slywotskiy and Morrison 1997), in his research "Migration value. What will happen with your business tomorrow?", explored how value migrates due to changes in business models. The purpose of the sea trade port business model is added value creation (Nyenno et al. 2017). Meanwhile, the business model itself ignores the environmental factors of stakeholder influence on value. Thus, we offer here a description of an updated measure of the maritime industry effect called "stakeholders' joint value". The research hypothesis was that joint value created in the maritime industry may evaluate the stakeholder effect related to industry alternative development scenarios. Carlon and Downs (Carlon and Downs 2014) have suggested a stakeholder valuing process by valuing customers with tax expenses (including profit tax). They accounted for primary stakeholders, employees, and customers as intangible assets that are capitalized at historical values and amortized over expected lives (valued by staff costs, social fare, and profit). In other words, stakeholders are reported as assets on the firm's balance sheet, and amortization of the assets is reported as an expense on the income statement. In a continuation of this approach to profit tax, net profit, staff costs, social fare, and depreciation were hypothetically considered to measure the joint value of maritime industry stakeholders. According to the research hypothesis, the elements listed below are relevant to the effect obtained by the following maritime industry stakeholders: The state, the population of the port region (profit tax), investors and owners (net profit, depreciation), contractors of ports, regular workers, and invited specialists (staff costs, social fare).

\section{Methodology}

The overall methodology used in the research to generate results had the following six steps:

1. Justifying the element of the joint value;

2. Finding the formula for the joint value of the multifactorial linear model in the maritime industry;

3. Verifying the formula of the joint value with extrapolation;

4. Verifying the formula of the joint value by using a Fourier series;

5. Using the method of hierarchy analysis for an indication of the influence of objective and subjective factors on joint value;

6. Evaluating the result of the joint value in the maritime industry related to the following alternatives: A scenario of state modernization and corporatization; a scenario for managing the seaport as a concession (public-private partnership); a scenario for changing the owner of the port subject to attracting private capital; a scenario of inertial development of the port provided there is stagnation in the macroeconomic environment.

Through the value of the "the joint value" created in the maritime industry and through constructing a multifactorial model, the following factors significant to our research were separated, namely: 


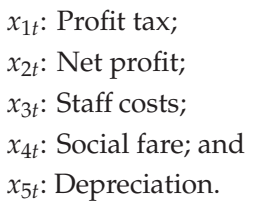

Thus, the research model was based on a validity check of this hypothesis first by verification with the extrapolation and next by using a Fourier series in the case of low dependencies. For further investigation of the influence of objective and subjective indicators on the indicator of the joint value of the seaport services, we made our choice in the use of the method of expert evaluation, namely, the method of analysis of hierarchies.

A general view of the multifactorial model of joint value created in the maritime industry can be represented as follows:

$$
y_{t}=b_{0}+b_{1} x_{1 t}+b_{2} x_{2 t}+\ldots+b_{m} x_{m t}+\varepsilon_{t}, t=1, \ldots, n
$$

where $y_{t}$ is the joint value created in the port maritime industry (result indicator); $b_{0}$ is an unknown parameter (coefficient) that reflects the influence of exogenous macrofactors; $b_{1}, b_{2}, \ldots, b_{m}$ are unknown parameters (coefficients) reflecting the influence of endogenous microenvironment factors; $x_{1 t}, x_{2 t}, x_{3 t}, \ldots, x_{m t}$ are independent variables (factors) in thousands of $\mathrm{UAH} ; \varepsilon_{t}$ is a random component; and $n$ is the number of observations.

A statistical analysis of the source data and a construction of a multifactor model of joint value created in the maritime industry was carried out by using a software package for statistical analysis, Statistics 8.0. We present the source data for a multifactor model of joint value created in the maritime port sector (Table 1).

Given the independent variables of the model (income tax on general activities, net profit, payroll, social contributions, depreciation) and the result indicator (joint value) were measured by thousands of hryvnias, there was no need to perform data normalization. The linear multifactor regression involved linear relationships between variables and the subordination of model balances to the normal distribution law.

The linearity of the relations between variables of the multifactor linear model of joint value created in the maritime industry was proven and is presented in the form of a matrix of scattering diagrams in Figure 1.

A verification of the subordination of the residues of the multifactorial linear model of joint value created in the maritime industry to the normal distribution law is presented in Figure 2.

The results obtained graphically in Figures 2 and 3 show the correct choice of mathematical dependence for a multifactor model of joint value created in the maritime industry, namely a linear one.

The calculated values of the free member and the regression coefficients of the multivariate linear model of joint value created in the maritime industry sector were done in Statistica 8.0. The package was obtained and is presented in Table 2. 
Table 1. Output data for a multifactor model of joint value created in the maritime industry, in thousands of UAH.

\begin{tabular}{|c|c|c|c|c|c|c|}
\hline No. & Profit Tax & Net Profit & Staff Costs & Social Fare & Depreciation & $\begin{array}{l}\text { Joint Value of the } \\
\text { Maritime Industry }\end{array}$ \\
\hline & $X_{1}$ & $X_{2}$ & $X_{3}$ & $X_{4}$ & $X_{5}$ & $\mathrm{y}$ \\
\hline 1 & 2 & 3 & 4 & 5 & 6 & 7 \\
\hline 1 & 4973.11 & $16,417.76$ & $35,095.67$ & 9435.48 & 2268.03 & $56,486.54$ \\
\hline 2 & 7607.69 & $26,722.53$ & $57,470.77$ & $15,788.36$ & 3469.56 & $91,800.98$ \\
\hline 3 & 9976.79 & $35,631.41$ & $76,009.34$ & $21,051.96$ & 4778.73 & $121,617.54$ \\
\hline 4 & $12,537.84$ & $44,778.00$ & $93,179.00$ & $26,456.00$ & 5718.00 & $150,494.84$ \\
\hline 5 & 645.67 & $16,632.98$ & $37,262.80$ & $12,722.39$ & 2928.05 & $54,541.45$ \\
\hline 6 & 931.67 & $28,433.79$ & $56,550.15$ & $18,983.66$ & 4700.70 & $85,915.61$ \\
\hline 7 & 1263.45 & $37,459.45$ & $78,615.61$ & $24,895.35$ & 5947.93 & $117,338.51$ \\
\hline 8 & 1587.78 & $45,365.00$ & $96,374.00$ & $31,286.00$ & 7382.00 & $143,326.78$ \\
\hline 9 & 2162.52 & 5415.82 & $10,835.63$ & 3140.71 & 756.01 & $18,413.97$ \\
\hline 10 & 3253.63 & 8868.65 & $16,029.60$ & 5112.00 & 1156.52 & $28,151.89$ \\
\hline 11 & 4392.87 & $11,441.87$ & $23,103.78$ & 6816.26 & 1592.91 & $38,938.51$ \\
\hline 12 & 5452.00 & $14,379.00$ & $27,318.00$ & 8566.00 & 1906.00 & $47,149.00$ \\
\hline 13 & 3940.00 & $11,908.00$ & $24,268.00$ & 8622.00 & 2282.00 & $40,116.00$ \\
\hline 14 & 6442.00 & $17,147.00$ & $42,790.00$ & $15,623.00$ & 4551.00 & $66,379.00$ \\
\hline 15 & 8817.00 & $21,648.00$ & $59,919.00$ & $22,215.00$ & 6800.00 & $90,384.00$ \\
\hline 16 & $11,366.00$ & $23,699.00$ & $78,169.00$ & $29,124.00$ & 9110.00 & $113,234.00$ \\
\hline 17 & 0.00 & $10,482.00$ & $22,028.00$ & 8293.00 & 2349.00 & $33,700.00$ \\
\hline 18 & 0.00 & $-15,065.00$ & $40,207.00$ & $15,063.00$ & $11,445.00$ & $25,142.00$ \\
\hline 19 & 0.00 & $-21,755.00$ & $51,983.00$ & $19,795.00$ & $19,188.00$ & $30,228.00$ \\
\hline 20 & 1190.00 & $-28,568.00$ & $67,521.00$ & $25,612.00$ & $25,769.00$ & $40,143.00$ \\
\hline 21 & 0.00 & 6552.00 & $17,831.00$ & 6562.00 & 5072.00 & $24,383.00$ \\
\hline 22 & 0.00 & $29,058.00$ & $34,655.00$ & $12,780.00$ & $10,095.00$ & $63,713.00$ \\
\hline 23 & 0.00 & $47,289.00$ & $52,440.00$ & $19,335.00$ & $15,241.00$ & $99,729.00$ \\
\hline 24 & $14,131.00$ & $48,191.00$ & $81,007.00$ & $28,789.00$ & $20,511.00$ & $143,329.00$ \\
\hline 25 & $15,649.27$ & $103,532.59$ & $33,323.22$ & $11,688.17$ & 8260.44 & $152,505.07$ \\
\hline 26 & $26,325.32$ & $139,338.02$ & $51,938.62$ & $17,767.38$ & $13,659.09$ & $217,601.96$ \\
\hline 27 & $33,536.73$ & $176,803.70$ & $76,147.20$ & $27,549.20$ & $18,770.32$ & $286,487.63$ \\
\hline 28 & $42,682.00$ & $187,400.00$ & $89,952.00$ & $31,931.00$ & $23,568.00$ & $320,034.00$ \\
\hline 29 & $12,049.34$ & $73,491.01$ & $37,910.57$ & 7153.98 & 8245.85 & $123,450.92$ \\
\hline 30 & $19,411.44$ & $100,237.17$ & $58,065.26$ & $12,369.00$ & $14,531.68$ & $177,713.87$ \\
\hline 31 & $25,456.35$ & $128,161.84$ & $81,513.05$ & $17,945.21$ & $22,129.31$ & $235,131.24$ \\
\hline 32 & $31,991.00$ & $133,023.00$ & $102,335.00$ & $22,636.00$ & $27,441.00$ & $267,349.00$ \\
\hline 33 & $10,570.63$ & $53,039.43$ & $40,198.30$ & 8514.77 & $10,123.03$ & $103,808.36$ \\
\hline 34 & $14,538.01$ & $78,526.71$ & $66,229.94$ & $13,691.53$ & $17,917.33$ & $159,294.66$ \\
\hline 35 & $19,962.88$ & $93,746.51$ & $93,658.61$ & $19,506.97$ & $24,988.00$ & $207,368.00$ \\
\hline 36 & $24,776.00$ & $101,517.00$ & $114,703.00$ & $24,606.00$ & $32,603.00$ & $240,996.00$ \\
\hline
\end{tabular}

The following mathematical formula for the multifactorial linear model of joint value created in the maritime industry was received:

$$
\begin{aligned}
& y_{t}=387.676+1.0052 x_{1 t}+1.0021 x_{2 t}+0.9295 x_{3 t}+0.1753 x_{4 t}- \\
& -0.0056 x_{5 t}+\varepsilon_{t} .
\end{aligned}
$$

The next step in the process of extrapolation of the result indicator of the multifactor linear model of joint value created in the maritime industry was analytical alignment and the choice of an adequate model for the subsequent extrapolation process of the dynamic series of its independent variables. The verification process covered only those types of analytical dependencies that visually repeated the trend of development of the index (independent variable model) over time (visual inspection) and a determination coefficient that exceeded $95 \%$ (Table 3). 

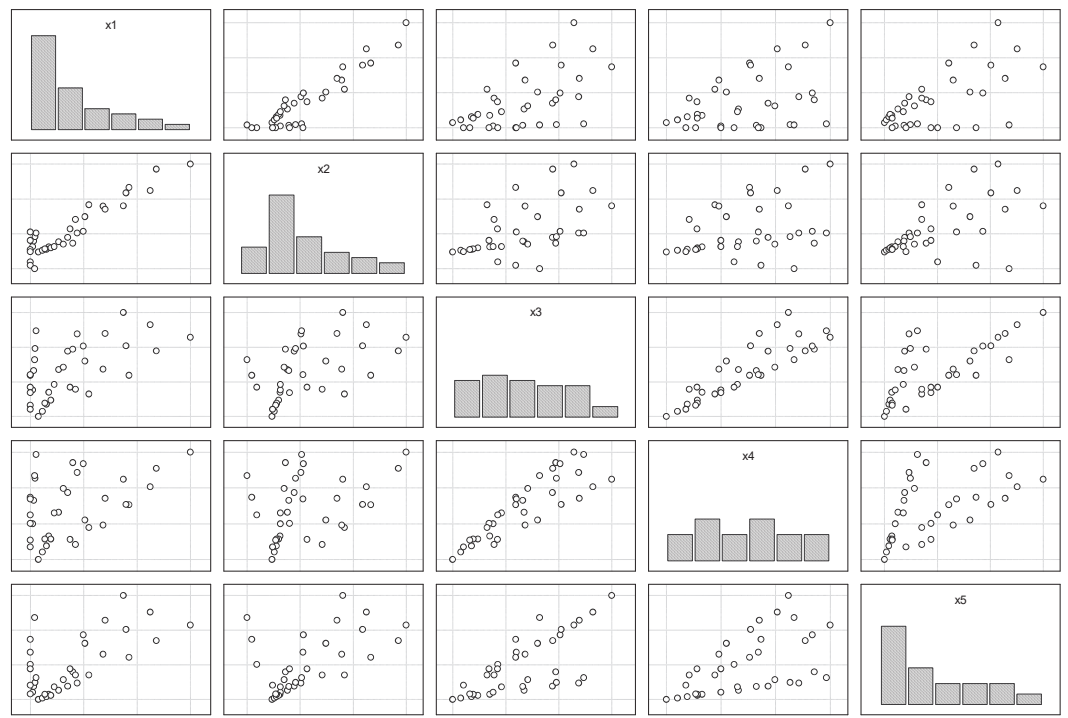

Figure 1. A matrix of scattering diagrams of independent variables of a multifactorial linear model of joint value created in the maritime port sector (in the package Statistics 8.0).

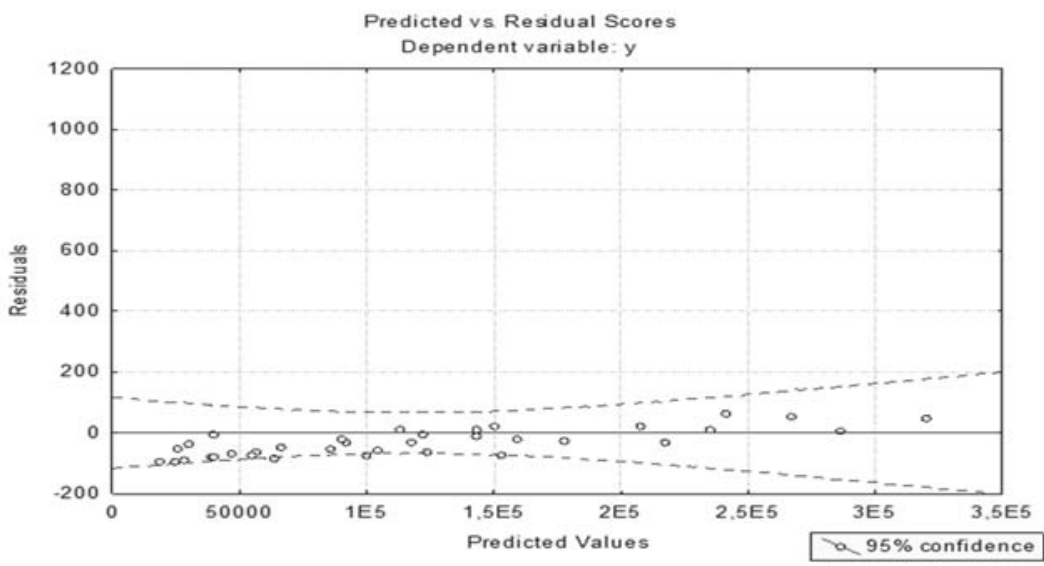

Figure 2. The subordination of the residues of the multifactorial linear model of joint value created in the maritime port sector to the normal distribution law (in Statistica 8.0).

Table 2. Estimated volume of the free member and regression coefficients of the multifactor linear model of joint value created in the maritime industry.

\begin{tabular}{cc}
\hline Conditional Symbol of the Coefficient & Qualitative Volume of the Coefficient \\
\hline$b_{0}$ & 387.6760 \\
$b_{1}$ & 1.0052 \\
$b_{2}$ & 1.0021 \\
$b_{3}$ & 0.9295 \\
$b_{4}$ & 0.1753 \\
$b_{5}$ & -0.0056 \\
\hline
\end{tabular}




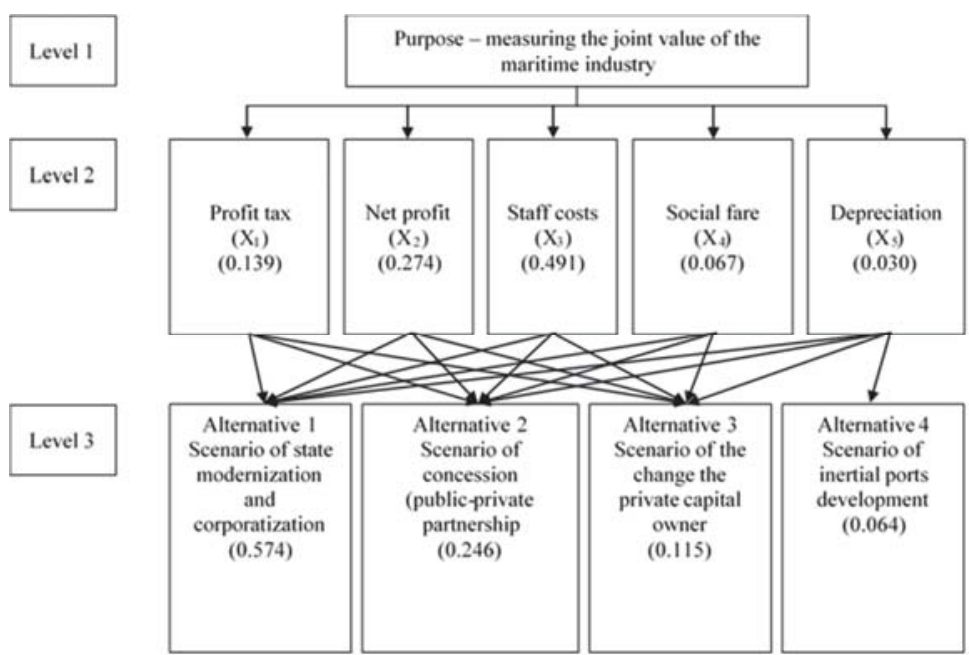

Figure 3. Hierarchy model for evaluation of the joint value of the maritime industry with the fixed global priorities of industry development.

Table 3. Results of visual and statistical verification of analytical dependencies of independent variables of a multifactor linear model of joint value created in the maritime port sector.

\begin{tabular}{|c|c|c|c|c|}
\hline \multirow{2}{*}{$\begin{array}{c}\text { The Name of the } \\
\text { Independent } \\
\text { Variable }\end{array}$} & \multirow{2}{*}{$\begin{array}{l}\text { Type of Analytical } \\
\text { Dependence }\end{array}$} & \multirow{2}{*}{$\begin{array}{l}\text { The Result of the } \\
\text { Visual Check } \\
\text { (Passed/Not Passed) }\end{array}$} & \multicolumn{2}{|c|}{$\begin{array}{l}\text { Result of Verification of the Value of the } \\
\text { Determination Factor (Performed/Not Performed) }\end{array}$} \\
\hline & & & $\begin{array}{l}\text { Numerical Value of the } \\
\text { Determination Factor }\end{array}$ & $\begin{array}{l}\text { Does It Exceed } \\
95 \%(\text { Yes/No)? }\end{array}$ \\
\hline 1 & 2 & 3 & 4 & 5 \\
\hline \multirow{6}{*}{ Profit tax } & Polynomial 1 degree & Not passed & 0.3670 & No \\
\hline & Polynomial 2 degree & Not passed & 0.4522 & No \\
\hline & Polynomial 3 degree & Not passed & 0.5038 & No \\
\hline & Degree & Impossible to build & - & - \\
\hline & Logarithmic & Not passed & 0.1909 & No \\
\hline & Exponential & Impossible to build & - & - \\
\hline \multirow{6}{*}{ Net profit } & Polynomial 1 degree & Not passed & 0.3778 & No \\
\hline & Polynomial 2 degree & Not passed & 0.4601 & No \\
\hline & Polynomial 3 degree & Not passed & 0.5370 & No \\
\hline & Degree & Impossible to build & - & - \\
\hline & Logarithmic & Not passed & 0.2051 & No \\
\hline & Exponential & Impossible to build & - & - \\
\hline \multirow{6}{*}{ Staff costs } & Polynomial 1 degree & Not passed & 0.0946 & No \\
\hline & Polynomial 2 degree & Not passed & 0.2756 & No \\
\hline & Polynomial 3 degree & Not passed & 0.2764 & No \\
\hline & Degree & Not passed & 0.0223 & No \\
\hline & Logarithmic & Not passed & 0.0279 & No \\
\hline & Exponential & Not passed & 0.0890 & No \\
\hline \multirow{6}{*}{ Social fare } & Polynomial 1 degree & Not passed & 0.0107 & No \\
\hline & Polynomial 2 degree & Not passed & 0.0135 & No \\
\hline & Polynomial 3 degree & Not passed & 0.0210 & No \\
\hline & Degree & Not passed & 0.0091 & No \\
\hline & Logarithmic & Not passed & 0.0078 & No \\
\hline & Exponential & Not passed & 0.0204 & No \\
\hline \multirow{6}{*}{ Depreciation } & Polynomial 1 degree & Not passed & 0.5906 & No \\
\hline & Polynomial 2 degree & Not passed & 0.6168 & No \\
\hline & Polynomial 3 degree & Not passed & 0.6191 & No \\
\hline & Degree & Not passed & 0.3985 & No \\
\hline & Logarithmic & Not passed & 0.4100 & No \\
\hline & Exponential & Not passed & 0.5585 & No \\
\hline
\end{tabular}


The obtained results indicated the appropriateness of the use of a Fourier series for the process of approximation and extrapolation of the dynamic series of independent variables.

The general mathematical expression of the Fourier series can be written as follows:

$$
\begin{gathered}
x(t)=\frac{a_{0}}{2}+\sum_{k=1}^{n}\left(a_{k} \cos (k t)+b_{k} \sin (k t)\right), \\
\Delta \mathrm{e} a_{0}=\frac{1}{\pi} \cdot \int_{-\pi}^{\pi} x(t) d t, a_{k}=\frac{1}{\pi} \cdot \int_{-\pi}^{\pi} x(t) \cos n t d t, \\
b_{k}=\frac{1}{\pi} \cdot \int_{-\pi}^{\pi} x(t) \sin n t d t, u=t+1 \Rightarrow d u=d t, \\
d v=\cos n t d t \Rightarrow v=\int \cos n t d t .
\end{gathered}
$$

where $a_{0}, a_{k}, b_{k}$ are coefficients of the Fourier series.

The MathCad package was chosen to determine the coefficients of the Fourier series. The reason for choosing the MathCad package was the universality of its solutions, its high-accuracy error detection, and its visibility and ability to interact with other software products, including products designed to build a risk map and analyze the total risk of a bankrupt merchant marine port using the spectrographic method (which requires collaboration with Microsoft Excel). MathCad has the ability to get a documented metric calculation, that is, to analyze the results in stages. All of the above-mentioned reasons simplify both the collection of data and their subsequent verification.

The process of determining the coefficients of the Fourier series for the indicator "tax on profit from general activity, ths. UAH" in the package MathCad is presented in Figure 3. Similarly, a calculation of the Fourier series coefficients for other independent variables of the multifactor linear model of common value created in the marine port sector was made, and analytical dependencies were obtained.

We performed a verification of the obtained analytical dependencies for the investigated independent variables for adequacy and accuracy of the forecast. The statistical indicators of the adequacy of the analytical dependencies of the independent variables of the multifactor linear model

\begin{tabular}{|c|c|c|c|c|c|c|}
\hline \multirow{3}{*}{ No. } & \multirow{3}{*}{$\begin{array}{l}\text { The Name of the Statistical } \\
\text { Indicator of the Adequacy of the } \\
\text { Analytical Dependence }\end{array}$} & \multicolumn{5}{|c|}{$\begin{array}{l}\text { Mathematical Designation of an Independent Variable of a Multifactor } \\
\text { Linear Model of Joint Value Created in the Maritime Port Sector }\end{array}$} \\
\hline & & $X_{1}$ & $X_{2}$ & $X_{3}$ & $X_{4}$ & $X_{5}$ \\
\hline & & \multicolumn{5}{|c|}{$\begin{array}{c}\text { Numerical Value of the Statistical Indicator of the Adequacy of the } \\
\text { Analytical Dependency }\end{array}$} \\
\hline 1 & Determination factor, \% & 0.999973396 & 0.999995508 & 0.999980087 & 0.999929597 & 0.999953397 \\
\hline 2 & $\begin{array}{l}\text { Average relative error of } \\
\text { approximation, } \%\end{array}$ & 4.7512 & 2.8243 & 1.1927 & 3.2840 & 4.2215 \\
\hline 3 & Average absolute error, \% (MAPE) & 17.58 & 10.62 & 10.05 & 12.17 & 15.81 \\
\hline
\end{tabular}
of common value created in the marine port sector are presented in Table 4.

Table 4. Statistical indicators of the adequacy of the obtained analytical dependencies (Fourier series) of independent variables of the multifactor linear model of joint value created in the maritime industry.

The obtained results indicated the high accuracy of the obtained analytical dependencies of the independent variables of the multifactor linear model of the joint value created in the marine port industry, since the value of the average relative error of approximation did not exceed 5\%. Similarly, the average absolute error rate was in the range of $10 \%$ to $20 \%$, which indicates good accuracy of the forecast with the help of the Fourier series of indicators of the independent variables of the multifactorial linear model of the joint value created in the maritime port sector. All of the determination factors exceeded a value of $95 \%$.

On the basis of the obtained adequate analytical dependencies (Fourier series), we performed a process of approximation, extrapolation, and construction of the upper and lower bounds of the confidence interval for the independent variables of the multifactorial linear model of joint value created in the maritime port sector. The period of bias in the study was two quarters, which did not 
exceed $20 \%$ of the total length of the dynamic range of each independent variable of the multifactorial linear model of joint value created in the maritime port sector.

\section{Results}

\subsection{Efficiency of the State Maritime Policy}

This article is devoted to the development and substantiation of theoretical/methodological and scientific/practical approaches to the formation of measures of efficiency in the maritime sector. The implementation of effective business models of sustainable development in seaports is aimed at maximizing the creation of the joint value at the macro and micro levels of the economy. The list of factors contributing to the efficiency of the state maritime policy was defined and separated into four groups: group 1 (infrastructural factors): Renewal of port infrastructure; coastal infrastructure of sea stations; ecological and physical safety; and convenience in reaching the port of departure by a cruise ship; group 2 (management factors): The effectiveness of management mechanisms; the level of automation and effective communications technologies; the coordination of various types of transport; and the efficiency of port services; group 3 (marketing factors): Tariff policies (size of tariffs, number of port fees, flexibility of price policy); and competition in the ports; group 4 (service factors): Attractiveness of logistics conditions; the development of international tourism; the development of sea leisure; the development of merchant shipping, shipbuilding, ship repair, and instrument making in the port; and the simplification of port entry procedures.

It has been established that the development the maritime business model at the macroeconomic level in state maritime policy has the following sequence: The desire to participate in global value added chains, which is ensured by the production of high-tech products in the areas of port processing and the provision of high-tech services with high added value; the introduction of complex measures of protectionism and free trade and dependence on the availability of national competitive advantages of the marine port industry for influencing the infrastructure, superstructure, and economic structure of the state maritime policy of Ukraine; and the creation of business models of seaports by basic types (creator, distributor, owner (landlord), broker (broker)) and depending on port type (land feudal lord, tool port, service port). At the same time, the following priorities of building a business model appear: An increase in the amount of taxes paid and the level of employment of the population; an increase in cargo turnover; improvement of the quality of transport services; and an increase in the number of tourists. Consideration of the following complementary assets as the basis for port business model development is suggested: Specialization (reputation, brand, formed clusters, distribution networks, experience and qualifications of experts, expertise, port society, information bases) and generalization (infrastructure, equipment, control facilities (customs processing)), computer systems and automation systems, social networks, ERP-networks, and agreements with state institutions and local self-government bodies). Monitoring of a business model's performance at the macro and micro level should be carried out with information and analytical support to prevent the overall risk of bankruptcy of seaports (with the construction of a risk map). Qualitative and quantitative monitoring takes into account the interests of stakeholders in the maritime industry and is based on the creation of added value in port services as the basis for the shared value of the well-being of all stakeholders.

\subsection{The Joint Value as a Measure of the Welfare of Stakeholders in the Maritime Industry}

The joint value was considered to be a category at both a macroeconomic and microeconomic level, and it was combined with a multivariate regression model performed on the basis of statistical analysis and data processing system Statistics 8.0. The extrapolated data of the independent variables of the multifactor linear model of joint value created in the maritime industry field allowed us to proceed to the extrapolation process of the resulting indicator. The results of the approximation process, extrapolation, and the values of the upper and lower bounds of the confidence interval of the resulting indicator are presented in the Statistica 8.0 tool. 
In the course of the calculations, an adequate multifactorial linear model of the joint value created in the marine port sector was obtained. The value of the determination coefficient indicated that the model explained $99.9937 \%$ of the total dispersion of its resulting value of the total value of the seaport services. For further investigation into the influence of objective and subjective indicators on the indicator of the joint value of the seaport services, we decided to use a method of expert evaluation, namely the method of analysis of hierarchies.

Using the hierarchy analysis method in the process of evaluating the common value of maritime merchant port services could allow for its decomposition into simple components, prioritizing each and evaluating the level of their interactions with the resulting indicator based on judgments and expert assessments (since they would be substantiated and supported by their experience), which would fill the information gap in the data analysis and significantly reduce the risk of ineffective management decisions regarding the operation of the maritime industry in Ukraine, especially at the macro level.

In the first step, the process of evaluating the joint value of the maritime trading port services in the form of a hierarchy and determining all elements of each level was performed. The first level of the hierarchical model for assessing the total value of the services of the sea trading port consisted of a single element, namely "The purpose is to assess the joint value of the services of the sea trading port".

The elements of the second level were the independent variables of the multifactor linear model of joint value created in the maritime industry, since the relevance of using previous results in the study of the assessment of the joint value of the services of a maritime trading port had already been proven.

\subsection{Scenarios of Sea Trade Port Industry Development}

Based on the results of the fundamental analysis, structural modeling, and synthesis of approaches to business model development, the business model of the seaport was presented as a mechanism for generating a joint value for all stakeholders, considered through optimizing a logically complete set of economic relations within the framework of modeling the development and implementation of the business model. The results of the aggregate economic relations of stakeholders (the state, investors, owners, contractors of ports, the population of the port region, regular workers, invited specialists) within the framework of developing and implementing a business model were the following:

Alternative 1: A scenario of state modernization and corporatization;

Alternative 2: A scenario for managing the seaport as a concession (public-private partnership);

Alternative 3: A scenario for changing the owner of the port subject to attracting private capital; and Alternative 4: A scenario of inertial development of the port provided there is stagnation in the macroeconomic environment.

The presented alternatives for assessing the total value of the services of the sea trading port were based on the obtained forecast values and the confidence intervals of the independent variables of the multifactor linear model of joint value created in the maritime port sector.

At the third level of the hierarchical model for assessing the joint value of the maritime merchant port services, the above alternatives are presented.

Graphic representation of the hierarchical model for assessing the joint value of the maritime industry is shown in Figure 3.

The next step in working with the hierarchical model for evaluating the joint value of seaport services was to identify local priorities and assess the consistency of judgments.

Using the method of pairwise comparisons, we defined the following indicators: Priorities of the second-level criteria relative to the main goal and priorities of alternatives (scenarios of development) in relation to the second-level criteria.

To this end, we constructed the necessary matrices for pairwise comparisons. For each matrix, we defined the normalized priority vector, the maximal real number, the index, and the relation of the coherence. 
The matrix of pairwise comparisons and the estimates of the priorities of the second-level elements in relation to the main goal obtained in its background are given in Table 5 .

Table 5. Matrix of pairwise comparisons for elements of the second level of the hierarchical model for estimating the joint value of seaport industry services.

\begin{tabular}{ccccccccc}
\hline \multirow{2}{*}{ No. } & Title of the Elements, Compared at the & \multicolumn{5}{c}{ Element No. } & \multirow{2}{*}{ Local Priorities, $\boldsymbol{u}_{\boldsymbol{i}}$} \\
\cline { 3 - 6 } & Second Level of the Hierarchy Model & $\mathbf{1}$ & $\mathbf{2}$ & $\mathbf{3}$ & $\mathbf{4}$ & $\mathbf{5}$ & \\
\hline 1 & Profit tax & 1 & $1 / 3$ & $1 / 5$ & 3 & 7 & 0.139 \\
2 & Net profit & 3 & 1 & $1 / 3$ & 5 & 9 & 0.274 \\
3 & Staff costs & 5 & 3 & 1 & 5 & 9 & 0.491 \\
4 & Social fare & $1 / 3$ & $1 / 5$ & $1 / 5$ & 1 & 3 & 0.067 \\
5 & Depreciation & $1 / 7$ & $1 / 9$ & $1 / 9$ & $1 / 3$ & 1 & 0.030 \\
\hline \multicolumn{2}{c}{$\lambda_{\max }=5.309 ; I U=0.077 ; B U=0.069}$.
\end{tabular}

The components of its own vector of local priorities are calculated by the formulas

$$
\overline{u_{i}}=\sqrt[n]{\prod_{j=1}^{n} a_{i j}} ; i=\overline{1, n}
$$

where $a_{i j}-i$ is an element of the matrix column of the pairwise criteria comparison and $n$ is the number of criteria, and

$$
u_{i}=\frac{\overline{u_{i}}}{\sum_{i=1}^{n} u_{i}} ; i=\overline{1, n} .
$$

Corresponding calculations for the second-level hierarchical model for assessing the value of seaports were as follows:

$$
\begin{aligned}
n=5 ; \overline{u_{1}} & =\sqrt[5]{1 \cdot \frac{1}{3} \cdot \frac{1}{5} \cdot 3 \cdot 7}=1.06961 ; \\
\overline{u_{2}} & =\sqrt[5]{3 \cdot 1 \cdot \frac{1}{3} \cdot 5 \cdot 9}=2.141127 ; \\
\overline{u_{3}} & =\sqrt[5]{5 \cdot 3 \cdot 1 \cdot 5 \cdot 9}=3.68011 ; \\
\overline{u_{4}} & =\sqrt[5]{\frac{1}{3} \cdot \frac{1}{5} \cdot \frac{1}{5} \cdot 1 \cdot 3}=0.525306, \\
\overline{u_{5}} & =\sqrt[5]{\frac{1}{7} \cdot \frac{1}{9} \cdot \frac{1}{9} \cdot \frac{1}{3} \cdot 1}=0.22587 \\
\sum_{i=1}^{5}=1.06961+2.141127+3.68011+0.525306+0.22587=7.642023 & \\
u_{1} & =\frac{1.06961}{7.642023}=0.139 \\
u_{2} & =\frac{2.141127}{7.642023}=0.274 \\
u_{3} & =\frac{3.68011}{7.642023}=0.491 \\
u_{4} & =\frac{0.525306}{7.642023}=0.067 \\
u_{5} & =\frac{0.22587}{7.642023}=0.030 .
\end{aligned}
$$


The maximal proper value of the inverse-symmetric matrix of pairwise comparisons was determined by the following formula:

$$
\lambda_{\max } \approx \sum_{j=1}^{n} u_{j}\left(\sum_{i=1}^{n} a_{i j}\right) ; i=\overline{1, n}
$$

For elements of the second level of the hierarchical model of estimating the joint value of seaport industry services, we defined the following:

$$
\begin{aligned}
& \sum_{i=1}^{5} a_{i 1}=1+\frac{1}{3}+\frac{1}{5}+3+7=11.53 \\
& \sum_{i=1}^{5} a_{i 2}=3+1+\frac{1}{3}+5+9=18.33 \\
& \sum_{i=1}^{5} a_{i 3}=5+3+1+5+9=23.00 \\
& \sum_{i=1}^{5} a_{i 4}=\frac{1}{3}+\frac{1}{5}+\frac{1}{5}+1+3=4.73 \\
& \sum_{i=1}^{5} a_{i 5}=\frac{1}{7}+\frac{1}{9}+\frac{1}{9}+\frac{1}{3}+1=1.70 \\
& \lambda_{\max } \approx 5.309 .
\end{aligned}
$$

The coherence (homogeneity) of the matrices, which reflects the imitation of an expert's logic in expressing his own judgments, is quite important in the process of constructing matrices of pairwise comparisons.

As an indicator of the degree of consistency of the elements of the matrix of pairwise comparisons, a homogeneity index (index of coherence) was used. It was calculated by the formula

$$
I O=I y=\frac{\lambda_{\max }-n}{n-1} .
$$

To assess the acceptability of the degree of consistency of the matrix elements, the ratio of homogeneity (consistency), which was calculated by the following formula, was used:

$$
B O=B y=\frac{I O}{M(I O)},
$$

where $M(I O)$ is the average value of the homogeneity index of a randomly composed matrix of pairwise comparisons, based on experimental data (for $n=5$ the table meaning equals $M(I O)=1,12$ ).

It was acceptable for further use of the obtained matrices of pairwise comparisons to be the value of the homogeneity relation (consistency), which was less than or equal to 0.1 , (that is, $B O \leq 0,10$ ). The excess of the index of homogeneity (coherence) of the value of 0,1 indicated a significant violation of the logic of judgments, which the expert assumed when filling matrices of pairwise comparisons, so the expert should be asked to revise the data to improve this indicator. The result of the matrix of pairwise comparison of elements of the second level $B O$ did not exceed a value of 0.1 , which testified to the loyalty of the judgment logic of the research expert and the possibility of its use in subsequent calculations of the hierarchical model for evaluating the joint value of the services of the sea trading port. 
In the next stage, we filled in matrices of pairwise comparisons for the third-level elements (alternatives) of the hierarchical model for assessing the total value of the services of sea merchant ports according to all of the criteria of the second level, and we determined their local priorities. The matrices of pairwise comparisons of elements of the third level according to all of the criteria of the second level of the hierarchical model for assessing the total value of services in the maritime industry are presented in Tables 6-10.

Table 6. Matrix of pairwise comparisons for the elements of the third level by the criteria "profit tax".

\begin{tabular}{ccccccc}
\hline & \multirow{2}{*}{$\begin{array}{c}\text { Elements to Be Compared in the } \\
\text { No. }\end{array}$} & \multicolumn{4}{c}{ Element No. } & Local Priorities, $V_{i 1}$ \\
\cline { 3 - 6 } & Third Level of the Hierarchy Model & $\mathbf{1}$ & $\mathbf{2}$ & $\mathbf{3}$ & $\mathbf{4}$ & \\
\hline 1 & Alternative 1 & 1 & 3 & 5 & 7 & 0.565 \\
2 & Alternative 2 & $1 / 3$ & 1 & 3 & 5 & 0.262 \\
3 & Alternative 3 & $1 / 5$ & $1 / 3$ & 1 & 3 & 0.118 \\
4 & Alternative 4 & $1 / 7$ & $1 / 5$ & $1 / 3$ & 1 & 0.055 \\
\hline
\end{tabular}

$\lambda_{\max }=4.119 ; I \mathrm{Y}=0.040 ; B \mathrm{Y}=0.044$.

Table 7. Matrix of pairwise comparisons for the elements of the third level by the criteria "net profit".

\begin{tabular}{|c|c|c|c|c|c|c|}
\hline \multirow{2}{*}{ No. } & \multirow{2}{*}{$\begin{array}{l}\text { Elements to Be Compared in the Third } \\
\text { Level of the Hierarchy Model }\end{array}$} & \multicolumn{4}{|c|}{ Element No. } & \multirow{2}{*}{ Local Priorities, $V_{i 2}$} \\
\hline & & 1 & 2 & 3 & 4 & \\
\hline 1 & Alternative 1 & 1 & 3 & 7 & 9 & 0.594 \\
\hline 2 & Alternative 2 & $1 / 3$ & 1 & 5 & 3 & 0.257 \\
\hline 3 & Alternative 3 & $1 / 7$ & $1 / 5$ & 1 & 3 & 0.094 \\
\hline 4 & Alternative 4 & $1 / 9$ & $1 / 3$ & $1 / 3$ & 1 & 0.056 \\
\hline
\end{tabular}

Table 8. Matrix of pairwise comparisons for the elements of the third level by the criteria "Staff costs".

\begin{tabular}{|c|c|c|c|c|c|c|}
\hline \multirow{2}{*}{ No. } & \multirow{2}{*}{$\begin{array}{l}\text { Elements to Be Compared in the Third } \\
\text { Level of the Hierarchy Model }\end{array}$} & \multicolumn{4}{|c|}{ Element No. } & \multirow{2}{*}{ Local Priorities, $V_{i 3}$} \\
\hline & & 1 & 2 & 3 & 4 & \\
\hline 1 & Alternative 1 & 1 & 3 & 5 & 5 & 0.549 \\
\hline 2 & Alternative 2 & $1 / 3$ & 1 & 3 & 3 & 0.248 \\
\hline 3 & Alternative 3 & $1 / 5$ & $1 / 3$ & 1 & 3 & 0.129 \\
\hline 4 & Alternative 4 & $1 / 5$ & $1 / 3$ & $1 / 3$ & 1 & 0.074 \\
\hline
\end{tabular}

Table 9. Matrix of pairwise comparisons for the elements of the third level by the criteria "social fare".

\begin{tabular}{|c|c|c|c|c|c|c|}
\hline \multirow{2}{*}{ No. } & \multirow{2}{*}{$\begin{array}{l}\text { Elements to Be Compared in the Third } \\
\text { Level of the Hierarchy Model }\end{array}$} & \multicolumn{4}{|c|}{ Element No. } & \multirow{2}{*}{ Local Priorities, $V_{i 4}$} \\
\hline & & 1 & 2 & 3 & 4 & \\
\hline 1 & Alternative 1 & 1 & 5 & 9 & 9 & 0.680 \\
\hline 2 & Alternative 2 & $1 / 5$ & 1 & 3 & 3 & 0.177 \\
\hline 3 & Alternative 3 & $1 / 9$ & $1 / 3$ & 1 & 3 & 0.091 \\
\hline 4 & Alternative 4 & $1 / 9$ & $1 / 3$ & $1 / 3$ & 1 & 0.052 \\
\hline
\end{tabular}

On the basis of the obtained results, we used the synthesis principle to determine the global priorities of the third-level elements. They were defined as the sum of applications of the local priorities of each element at the third level to the global priorities of the second-level elements of the hierarchical model for evaluating the joint value of the services of the maritime industry:

$$
W_{i}=V_{i j} \cdot u_{i}
$$


where $V_{i j}$ is the local priority of the $i$ element of the third level in relation to the $j$ element of the second level.

Table 10. Matrix of pairwise comparisons for the elements of the third level by the criteria "depreciation".

\begin{tabular}{|c|c|c|c|c|c|c|}
\hline \multirow{2}{*}{ No. } & \multirow{2}{*}{$\begin{array}{l}\text { Elements to Be Compared in the Third } \\
\text { Level of the Hierarchy Model }\end{array}$} & \multicolumn{4}{|c|}{ Element No. } & \multirow{2}{*}{ Local Priorities, $V_{i 5}$} \\
\hline & & 1 & 2 & 3 & 4 & \\
\hline 1 & Alternative 1 & 1 & 5 & 3 & 9 & 0.599 \\
\hline 2 & Alternative 2 & $1 / 5$ & 1 & 3 & 3 & 0.211 \\
\hline 3 & Alternative 3 & $1 / 3$ & $1 / 3$ & 1 & 3 & 0.134 \\
\hline 4 & Alternative 4 & $1 / 9$ & $1 / 3$ & $1 / 3$ & 1 & 0.056 \\
\hline
\end{tabular}

For the submitted alternatives at the third level of the hierarchical model for assessing the joint value of the services of the maritime industry of Ukraine:

$$
\begin{aligned}
& W_{1}=0.139 \cdot 0.565+0.274 \cdot 0.594+0.491 \cdot 0.549+0.067 \cdot 0.680+ \\
& +0.030 \cdot 0.599=0.574 ; \\
& W_{2}=0.139 \cdot 0.262+0.274 \cdot 0.257+0.491 \cdot 0.248+0.067 \cdot 0.177+ \\
& +0.030 \cdot 0.211=0.246 ; \\
& W_{3}=0.139 \cdot 0.118+0.274 \cdot 0.084+0.491 \cdot 0.129+0.067 \cdot 0.091+ \\
& +0.030 \cdot 0.134=0.115 \\
& W_{4}=0.139 \cdot 0.055+0.274 \cdot 0.056+0.491 \cdot 0.074+0.067 \cdot 0.052+ \\
& +0.030 \cdot 0.056=0.064
\end{aligned}
$$

The complex combination of results from the multifactor linear model of joint value created in the maritime port sector and the hierarchical model for assessing the joint value of the maritime merchant port services allowed us to obtain a calculated confirmation of the best further alternative for developing the port industry in Ukraine: Namely, a scenario of state modernization and corporatization.

\section{Conclusions}

The creation of a joint value as a measure of the welfare of stakeholders in the maritime industry was measured by using a statistical and mathematical regression model based on statistics. The elements of the effective indicator were income tax on general activities, net profit, payment of wages, deductions for social events, and amortization. This model allowed us to take into account the causal relationships of changes among independent variables outlined by the study and the result indicator, and acted as a convenient tool in the process of forming operational plans of activity and risk management of individual seaports and the port industry as a whole.

The joint value was considered to be a category at both a macroeconomic and microeconomic level, because it combined endogenous and exogenous factors of influence. The complex combination of results from the multifactorial linear model of joint value created in the maritime industry led to the conclusion that the best alternative to the development of the port industry in Ukraine is the scenario of state modernization and corporatization.

The added value of the study for practice is the development of a maritime industry effect measurement relevant to each of its stakeholders. The contribution to the literature concerns a new interpretation of the industry effect implemented in the joint value.

Author Contributions: Conceptualization, I.N.; methodology, N.R.; software, N.R.; validation, I.N.; formal analysis, I.N.; investigation, I.N.; resources, I.N.; data curation, I.N.; writing-original draft preparation, I.N.; writing-review and editing, S.M.; visualization, N.R.; supervision, N.R.; project administration, I.N.; funding acquisition, I.N. 
Funding: This research received no external funding.

Conflicts of Interest: The authors declare no conflicts of interest.

\section{References}

Bereznoy, A. 2014. Innovative business-model in competitive strategy of the big company. Issues of Economy 9: 65-81.

Carlon, Donna, and Alexis Downs. 2014. Stakeholder Valuing: A Process for Identifying the Interrelationships between Firm and Stakeholder Attributes. Administrative Sciences 4: 137-54. [CrossRef]

Chesbrough, G. 2007. Open Innovations. Creation of the Profitable Technologies. Moscow: Generation.

Debelak, Don. 2006. Business Models Made Easy. Irvine: Entrepreneur Press.

Gokcek, Veysel, and Yunus Emre Şenol. 2018. Efficiency Analysis of Mediterranean Container Ports. Journal of ETA Maritime Science 6: 129-40. [CrossRef]

Kelly, Martin, and Manzurul Alam. 2008. Management Accounting and the Stakeholder Value Model. JAMAR 6: 75-86.

MacManus, J. 2002. The influence of stakeholders' value on project management. Management Services 46: 8-15.

Nyenno, Iryan, Vitalii Nitsenko, Irian Kryukova, Tatyana Kalyna, and Mariia Plotnikova. 2017. Business model for a sea commercial port as a way to reach sustainable development goals. Journal of Security and Sustainability Issues 7: 155-66. [CrossRef]

Osterwalder, Alexander, and Yves Pigneur. 2010. Business Model Generation. Hoboten: John Wiley \& Sons, Inc., $288 \mathrm{p}$.

Schweizer, Lars. 2005. Concept and evolution of business models. Journal of General Management 31: 37-56. [CrossRef]

Slywotskiy, Adrian, and David Morrison. 1997. The Profit Zone. How Strategic Business Design Will Lead You to Tomorrow Profit. New York: Ramdom House, 342p.

Soolyatte, A. 2010. Business-model-A key to business development, based on innovations. Innovation Management 1: 6-15.

Turki, Slim, Marija Bjeković-Obradović, and Corentin Vermeulen. 2012. Sustainable and Responsible Investment: Stakeholders' Value Network. Journal of Financial Studies \& Research 2012: 1-8.

Vashakmadze, T. 2012. The comparative analysis of the enterprise business-models. Economy and Life 16: 35-45.

World Maritime Review. 2018. U.S. Merchant Marine \& World Maritime Review: Annual Review. Annapolis: U.S. Naval Institute, May, pp. 98-104.

(C) 2019 by the authors. Licensee MDPI, Basel, Switzerland. This article is an open access article distributed under the terms and conditions of the Creative Commons Attribution (CC BY) license (http://creativecommons.org/licenses/by/4.0/). 



\title{
Consumer Empowerment in the Digital Economy: Availing Sustainable Purchasing Decisions
}

\author{
Patrizia Gazzola ${ }^{1, *}$, Gianluca Colombo ${ }^{2}$, Roberta Pezzetti ${ }^{1}$ and Luminița Nicolescu ${ }^{3}$ \\ 1 Department of Economics, University of Insubria, 21100 Varese, Italy; robertarita.pezzetti@uninsubria.it \\ 2 Department of Management, Università della Svizzera Italiana, USI, 6900 Lugano, Switzerland; \\ gianluca.colombo@usi.ch \\ 3 Department of International Business and Economics, Bucharest University of Economic Studies, \\ 010374 Bucharest, Romania; luminita.nicolescu@rei.ase.ro \\ * Correspondence: patrizia.gazzola@uninsubria.it; Tel.: +39-0332-395529
}

Academic Editor: Giuseppe T. Cirella

Received: 19 March 2017; Accepted: 21 April 2017; Published: 27 April 2017

\begin{abstract}
The advent of the digital economy and, implicitly, of competition in the online marketplace has triggered new challenges in terms of consumer protection approaches. Online, consumer skills are expected to be improved and the level of consumer awareness and engagement increased. These are the baseline prerequisites of the sustainable purchasing decision and, thus, should be considered as pillars of responsible online consumption. Consistent with the novel consumption challenges, the current paper is intended to advance and test a research model integrating five main constructs, namely, competition in the online marketplace, online consumer skills, online consumer awareness, online consumer engagement and sustainable purchasing decision. A total of 318 college students-a representative population of the new Millennials generation-accepted the invitation to participate in a questionnaire-based survey. In order to pertinently analyze the collected data, a structural equation modeling technique based on partial least squares was employed for the assessment of the measurement and the structural model. The findings indicated that the model explained 24.4 percent of the variance of sustainable purchasing decisions, while the highest influence was exerted by the improvement of online consumer skills. This implies that online providers should revisit their products sustainability standards on purpose to preserve a competitive advantage.
\end{abstract}

Keywords: competition; online consumer skills; consumer awareness; consumer engagement; sustainable purchasing decision

\section{Introduction}

Over the past several years, the digital economy has set itself up as a complex structure comprising a fast-growing number of nodes and links, assets and services which are connected via complex networks made of intertwined value chains [1-3]. Based on technologies involving a strong connection to the Internet [1] (p. 15), the digital economy poses new challenges in terms of the extension of products and customer service markets with an unprecedentedly rapid rhythm, as different facts and figures report [4] (p. 12). For example, the gross revenues generated by only one sector in the digital economy, namely the collaborative economy, doubled in the European Union (EU) in 2015 when compared to 2014, and reached an estimated $€ 28$ billion [5] (p. 1). Moreover, at the moment, nearly $40 \%$ of the world's population has access to the digital economy (or the Internet economy) [6] (p. 5), and while the Internet-the means of access to this system-"remains unavailable, inaccessible, and unaffordable to a majority of the world's population", mostly living in India, China, and the countries outside of the top 20, the situation is rapidly changing [6] (p. 8), [7]. 
As the digital economy welcomes constant innovation and competition in the business sector, it also triggers consumer welfare [8]. By making available to consumers services and products that they were not previously able to access, the increasing incorporation of digital technologies in both the business and public sectors stimulate trade operations [6] (p. 12), reframe marketing practices [9] and generate a substantive shift in people's behavior [10-14].

The expected positive results of the digital revolution, steadily taking over the world economies, are accompanied by a series of concerns regarding the capacity to control the ongoing transformative processes. New business models challenge the existing policy framework at various levels: competition policy, consumer protection, privacy, taxation, and intellectual property rights [1] (p. 9), [15]. Without complementary developments, such as regulation and the improved skills and institutions to help implement these regulations, the accelerated growth opportunities that the digital technology may offer could be replaced by unexpected risks [6] (p. 5). For example, the automation of Internet-based services leads to low marginal costs that are related to large economies of scale and favor natural monopolies that could be detrimental to consumers in the absence of regulation to protect their interests [6] (p. 13). As the existing regulatory and standards frameworks tend to evolve slower than the digital revolution blooms, various concerns regarding the fact that "consumer protection mechanisms are being outmoded and outpaced by the speed of change in the digital economy" have already been voiced [16] (p. 1).

Much of the existing research related to connections between the digital technology and the economic sector focuses on the need to create new legislation and to enforce it. While regulatory frameworks differ in the EU, North America and other parts of the globe, both consumer protection and competition policies are topics of interest [1,16-22]. Consumer protection would be effectively increased only by additional or revised legislation, and by the political and/or regulatory intervention along with direct consumer demand [23]. These factors have been noted as key drivers of the inherent advances between 2012 and 2015 [16] (p. 3), [4] (p. 12).

The power that consumers have over companies in the new economic model, where formal regulations sometimes lack or they are difficult to apply, has been briefly addressed in recent years [18]. At the EU level, a Consumer Empowerment Index (integrating consumer skills, awareness of legislation on consumer rights and consumer engagement) was calculated, although it does not entirely apply to the particularities of the digital economy [24]. Still, it is a relevant starting point for interpreting the influence of competition — as availed by the digital economy—on consumers' actions and reactions in the online marketplace.

Empowered consumers are liable to drive innovation, productivity and competition [25] by means of education, access to relevant information and capacity to assess information correctly, in order to make optimal decisions as buyers [26] (pp. 12-16). They leverage the possibility to exchange opinions and views to the extent that a new type of consumer emerges: "the prosumer" [27], a rational consumer who gathers knowledge about products and services, participates actively in the market by sharing her/his knowledge on purpose to reduce uncertainty [28-31]. They have capitalized the opportunity to make purchasing decisions and, now, the well-informed, educated and active consumers play the role of the driver of competition in the marketplace [18] (p. 27).

Building on this logic and on the seminal literature linking competition, consumer empowerment and sustainable purchasing decisions, the current paper is intended to address the relationships among these main constructs. As previously mentioned, consumer empowerment is operationalized by means of three pillars (i.e., consumer skills, awareness of legislation on consumer rights, and consumer engagement), according to Nardo et al.'s [24] taxonomy. The approach is in line with the European Commission's position acknowledging that "consumer empowerment is both a function of the skills, knowledge and assertiveness of consumers themselves, and the protection, rules and institutions designed to support them as they play their part" [32] (p. 8). Thus, it depends simultaneously on good cognitive skills, knowledge of consumer rights and specific authorities, and accessible means of redress.

The emphasis of this research is laid on the young generation, the so-called Millennials, thus giving credit to the Organisation for Economic Co-operation and Development (OECD)'s findings [33] 
regarding the differences by age group in terms of consumption patterns and interest in sustainable consumption. The OECD's study gathered data from seven European countries, including Italy, and posited that Millennials "tend to be very conscious of the need to reduce environmental pollution, improve human health and increase respect for human rights on a global scale. They believe their generation is consuming too much and want more information on how to reduce the negative ecological and social impacts of their consumption" [33] (p. 47).

Taking into consideration the aforementioned arguments, the article is structured as follows: the second section depicts the theoretical background and the development of hypotheses; the third section describes the materials and methods, namely the data collection and sample, measures and measurement and structural model assessment; the fourth and fifth sections are focused on the results and discussion of findings in terms of research contribution and originality, theoretical and practical implications and limitations, and future research directions.

\section{Theoretical Background and Hypotheses Development}

The first correlation approached within the conceptual model refers to the relationship between competition and consumer empowerment. Hereby, competition is defined in line with the classical definition of Clark cited in Delp and Mayo [34], which integrates three pivotal components, that is, the existence of rivalry among product or service providers, the free choice of consumers to purchase from different sellers and the providers' endeavors to leverage the attractiveness of their offers. This perspective lays the foundation of competition in the digital economy, of e-commerce in particular, as contended by Delp and Mayo in 2016 [34] (p. 17)—“(1) Firms exhibit overt rivalry in their quest for consumer patronage; (2) Consumers have choices among vendors, readily demonstrate their ability to change vendors, and vendors ( ... ) have the ability and propensity to expand output to satisfy consumer demands; (3) Rivalry among vendors manifests itself in desirable economic performance metrics, including price, output, quality, investment, and innovation".

Within this framework and pursuant to the European Commission's [32] (p. 11) vision, consumer empowerment sets itself up as "a multifaceted compound measure", operationalized through the data on consumer skills, knowledge of consumer rights and consumer engagement. In the light of an increasingly dynamic competition and digital information overload, consumer empowerment derives as a key factor in making optimal choices in liberalized markets. In order to become empowered, consumers are determined to: (1) thoroughly understand the choices available to them in terms of providers' offerings, thus improving their online skills (i.e., compare offers and check where to buy the cheapest desired product, check online sales or promotions, talk to the customer service assistant about additional product details, resort to customers' online reviews regarding their experience in buying from a certain website before acting, perform cost-benefit analyses before buying products online); (2) be aware of and know their rights and recognize detriment, thus improving their online awareness (i.e., be aware of my consumers' rights when buying on sales online, of the agencies (government and voluntary) offering consumers guidance, of the legal action of governmental and non-governmental institutions on protecting consumers, of consumers' distance-purchasing rights, of different sources of information about consumer affairs, of consumer online communities debating on consumers policies) and (3) engage themselves in specific redress actions whenever their rights are breached (i.e., give a poor quality product back to the online seller and demand money refund, demand replacement of a poor quality product bought online for a good one, give a poor quality product back to the manufacturer for repair (production plant/factory) on the basis of the warranty card) [32] (p. 24). In the context of the present research, the sub-pillar of consumer engagement, namely detriment and redress, was primarily considered, as the most prominent facet of consumer behavior, hence, going beyond attitude towards action.

Given the operationalization of the two constructs—competition and consumer empowermentand of the latter's components (consumer skills, awareness and engagement), the relationship between the variables identified has been widely acknowledged by the extant literature. According to Fatas 
and Lyons [35] (p. 29), competition objectivized through "firms fight for customers by offering them a better deal in terms of price, quality, range, reliability or associated services" triggers the imperative that consumers acquire information on these alternative offers and act rationally based on this information. Likewise, Laitenberger [36] (pp. 6-8) and Bauer and Erixon [37] (pp. 4-8) clearly state that information technology and, implicitly, competitive digital businesses possess a substantive potential to integrate markets and empower consumers "so that markets work better and consumer welfare is enhanced" [36] (p. 8).

The same line of thought is revealed by the OECD [38] (p. 7) which contends that "digital technologies are rapidly reshaping existing markets" in terms of competition dynamics, providing novel ways to connect customers with suppliers and to empower consumers to adjust their behavior in response to the information acquired. Moreover, the OECD [39] (pp. 8-9) firmly recognizes the dynamic and competitive nature of the e-commerce arena, "which enables consumers to gather, compare, review and share information about goods and services, and fosters the development of new business models, some of which facilitate consumer-to-consumer transactions ( . . ) dispute resolution and redress". Beranek and Kamerschen [40] put it simply, by pointing to one of the major foundations of competition which resides in "the existence of alternatives to the product the consumer wants. (... ) They must be discovered, their costs identified, and their usefulness evaluated". All these endeavors engender shopping skills which involve the knowledge to collect an information base regarding the offerings envisioned by consumers. In this vein, the authors underscore that "in sum, competition can bring a whole constellation of net consumer improvements ( . . ). Potential immediate benefits from enhanced individual skills are only beginning to be recognized; but society has yet to realize the immense secondary benefits from added competition".

In the overall framework of competition and consumer empowerment, the relationship between competition and online consumer skills has been intensively discussed in the European Union. As the OECD emphasizes: "growth in the use of online technologies for work, leisure, electronic commerce and other activities has greatly increased the need for consumers to develop digital competence" [38] (p. 12). The imperative is that consumers enhance their knowledge of technology, to properly disentangle a wide spectrum of online offers to their best interests. The fierce competition in the digital marketplace forces consumers to improve their level of understanding and instrumental competence to manage online purchases.

Drawing upon online consumer skills, the OECD [38] affirms that empowered consumers are able to better explore and identify optimal prices (sales, promotions), the highest quality (by asking the customer service assistant about additional product details, by read other customers' online reviews regarding their experience in buying) and perform responsible choices in terms of cost-benefit analyses. Browsing for the best alternatives to the products of interest is, thus, a prominent derivative of effective competition. Offerings are not available per se, they are supposed to be discovered, the prices analyzed, and the deliverables carefully assessed. In this respect, all the activities performed require improved online consumer skills [32,38]. This is why the digital economy and e-commerce, in particular, create major prerequisites for consumer control over decision-making, especially when the choice is wider [40,41]. That being the case, we infer that:

Hypothesis 1. Competition in the online marketplace has a positive influence on online consumer skills.

Given the fast-growing competition in the digital marketplace, consumers are also directed towards the importance of knowing their rights and responsibilities when performing online purchases [38] (p. 13). It is not enough to only have knowledge of technology and media, it is necessary to gain awareness of consumer rights and legal protection tools when conducting online transactions. As the OECD [39] (p. 18) advances, "awareness programmes aimed at providing them with relevant knowledge and skills to access and use digital technology to participate in e-commerce" are of the essence. Similarly, Mwakatumbula et al. [41] (pp. 9-10) urge that consumers should possess 
a reasonable knowledge of their rights and obligations and become aware of complaint procedures and tools. Starting from this premise, we presume that:

Hypothesis 2. Competition in the online marketplace has a positive influence on online consumer awareness of the legislation on consumer rights.

With a view to ensure consumers efficiently engage in the online marketplace, consumer empowerment in terms of the establishment and exercise of consumer protection laws and regulations is paramount [41] (p. 9). Pursuant to Mwakatumbula et al. [41] (pp. 9-10), "for consumers to fully exploit the intended benefits extended by these competitive markets, they should actively engage in the market". One of the most obvious forms of consumer engagement, from a behavioral perspective, is manifested whenever consumers' rights are breached and they actually act to get redress. By playing their role in an efficient manner, consumers are liable to potentiate their welfare and drive competition for the growth of the entire industry. This approach is also indicative of the European Commission's vision in that "empowered consumers who complain and assert their rights are the most effective consultants in helping businesses to innovate and improve" [32] (p. 24). In this light, online customers militate for empowerment, not control and "this evolution from control to empowerment means a change in the basic building blocks of customer engagement" [42]. Focusing on this perspective, we infer that:

Hypothesis 3. Competition in the online marketplace has a positive influence on online consumer engagement.

Linking consumer empowerment to sustainable purchasing decisions, Case [43] defines the latter as the process of buying products with improved sustainability footprints, thus, conforming to price, performance and quality requirements. On this front, consumers dispose of a variety of tools to set the parameters for sustainable purchasing, for example, buying products online (as providers are more controlled by the authorities), contrasting offers against various product specifications (products certified to environmental leadership standards), comparing products in terms of quality and sustainability (by analyzing environmental labels, identifying the greener, healthier products), and acquiring information from other customers' experiences and reviews. In other words, sustainable purchasing decisions emerge at the crossroads of online consumer skills, awareness and engagement.

According to Maher et al. [44], the choices made by consumers entail substantial social, economic and environmental implications as regarding sustainability. Over the last several years, different stakeholders paid heed to developing ways to gain consumers' support for sustainable consumption and for sustainable purchasing decisions. At this level, one of the main goals to be achieved focuses on consumer empowerment by means of " $(i)$ increasing awareness of the importance and benefits of sustainability, both for individuals and society, (ii) developing practical knowledge of what consumers can do to support sustainable consumption, and (iii) providing necessary skills and attitudes for putting this knowledge into everyday practices" [44] (p. 9).

This is why success on achieving sustainable consumption mainly relies on the prerequisites of decision making [45], and as Wright, Newman and Dennis content, "the ultimate decisions are made by consumers through their various abilities to exercise their choices of whether to buy or not to buy. (... ) These are consumer empowerments" [46] (p. 926). Whenever online consumers exercise their skills and ability to compare the unit prices and specification of products, supported by EU law, they step towards optimal decision-making as regards sustainable purchasing [32] (p. 10). Here, it is worth mentioning that online customers may be interested in collecting data on specific environmental issues, but they also may be interested in consulting with other parties for validation, in sharing success stories and the lessons learned [47,48]. "Labelling, branding and design can aid consumers in making personal messages about the sustainability of their purchases" [33] (p. 47), but as Case [47] posits, there a lots of situations where online consumers "don't want to know that a product meets someone else's definition of green. They want to review the data and decide for themselves". Based on this logic, we presume that: 
Hypothesis 4. Online consumer skills have a positive influence on the sustainable purchasing decision.

Even though there are voices who stress the fact that consumer protection plays a leading role in building a safer world $[14,49,50]$, preventing sellers from increasing their sales by means of deceptive marketing or by engaging in unfair practices [51], Euromonitor International's report [52] argues that the real power pertains to empowered consumers. In this respect, Millennials are credited among the most empowered consumers, being described as a generation highly dependent on technology and permanently "wired" [52,53]. They consistently develop a socially responsible view on consumption and adhere to a sustainability framework in their general orientation, demanding transparency and sustainable actions from the companies they interact with [54-57]. Put in simple words, these empowered consumers vote with their wallets by paying heed to product labels and making responsible purchasing choices. Young change-makers show an increasing interest in placing authenticity and sustainability above convenience and hazard, that is, Millennials "seek products that are sustainable, ethical, artisanal, repairable and long-lasting" [52] (p. 4).

According to the European Commission's perspective [32] (p. 9), generally there is a "low level of knowledge regarding consumer rights with potentially significant implications for consumer detriment and decision-making". A better awareness of the existing rights and of their application would improve consumers' welfare and strengthen their responsible decisions in terms of sustainable purchasing. By investing in their awareness and knowledge on consumer policy, Millennials are steadily growing in their influence [58], putting pressure on businesses to be more sustainable. Companies that fail to prove their reliability in environmental and social responsibility risk estranging the Millennials group both as customers [59] and employees [60].

Young adults are also able to influence the purchasing habits of their families as sustainability is a key concern for the Millennials generation [61]. Several empirical surveys identify Millennials as the most sustainable generation to date [52,62-64]. In particular, the search for sustainable behavior is pushing Millennials to adopt new consumer habits, more in line with their values [40], which translate into their willingness to pay more for eco-friendly and ethical products and services. In line with Nielsen's Millennials Drive Sustainability Survey [62], a simple act of selecting a product or service becomes a potential statement about their identity and personal values, which are more important than personal benefits (such as cost or convenience).

In fact, half of Millennials believe that brands "say something" about "how they fit in the world as a whole, and 59\% are willing to pay more for a brand that portrays the right image" [62]. A myriad of studies indicate that sustainability awareness is driving Millennials' purchase choices and loyalty attitudes in various sectors and industries such as: the food and beverage industry, clothing, healthcare and wellness industry, household and personal care industry, the interactive technologies industry, etc. $[61,62,64-72]$. By corroborating the arguments, we infer that:

Hypothesis 5. Online consumer awareness of legislation on consumer rights has a positive influence on the sustainable purchasing decision.

Stepping forward, online consumer engagement by means of an active response to detriment, namely the appeal to redress mechanisms, has been acknowledged as the underpinning of sustainable purchasing decisions in many studies [31,32,41,42]. "Being able to recognize frauds or scams is fundamental to consumer empowerment, not only to avoid detriment, but to report the problem and, possibly, to obtain redress" [32] (p. 8). Furthermore, sustainable purchasing decision-making is an expression of empowered consumers who share knowledge on their purchase experiences within specialized online communities, therefore rewarding vendors' professionalism and sanctioning deceptive practices (p. 11). Therefore, we presume that:

Hypothesis 6. Online consumer engagement has a positive influence on the sustainable purchasing decision. 
Focusing on Millennials, Euromonitor International's Global Consumer Trends Survey, conducted in 2016 , concluded that " $53 \%$ of all respondents across all countries felt they could make a difference to the world through their choices and actions". Millennials were the most optimistic, having a strong belief in their ability to make an impact. They believe in their potential as change-making consumers, thus, in driving positive change and in giving back to the community [52].

By corroborating the aforementioned relationships between constructs ( $\mathrm{H} 1$ to $\mathrm{H} 6$ ) into a final assumption, we presume that:

Hypothesis 7. Competition in the online marketplace has a positive influence on the sustainable purchasing decision.

All in all, based on the theoretical developments and hypotheses described, this study advances the following research model (Figure 1):

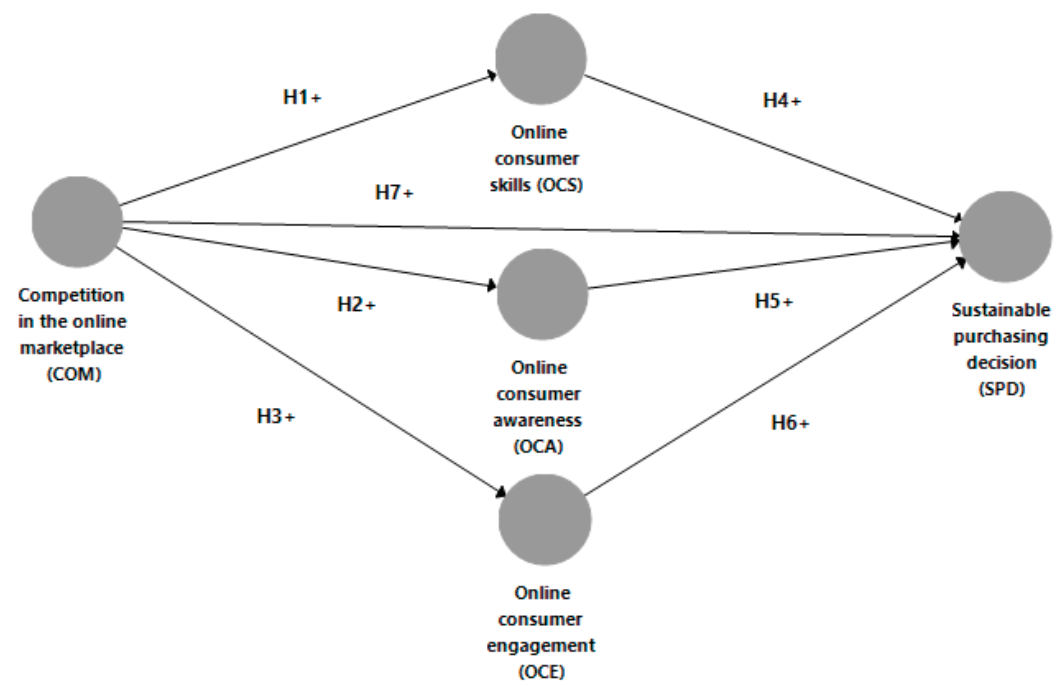

Figure 1. Research model with hypotheses.

\section{Materials and Methods}

\subsection{Data Collection and Sample}

A questionnaire-based survey was conducted with 318 college students from an Italian university, a representative population of the new Millennials generation. Subjects were invited to take part in a survey regarding online consumption and purchasing decisions by filling out an online form. The investigation unfolded between 14 February and 10 March 2017.

Upon acceptance, the participants completed a self-administered questionnaire comprising closed-ended questions. The constructs consisted of multiple items, measured on a five-point Likert scale which ranged from "strongly disagree" (1) to "strongly agree" (5) (2 = disagree, $3=$ neither disagree, nor agree, $4=$ agree).

\subsection{Measures}

The questionnaire items addressed five main areas, discussed previously, related to participants' activity in terms of online consumption; namely online consumer skills, awareness and engagement issues, competition in the online market place and online purchasing decisions. Questions falling 
into the first three categories are in line with the Consumer Empowerment Index advanced by Nardo et al. [24], the European Commission [32] and the OECD [38,39], which was further adapted to the specifics of the digital economy. In this vein, 25 items were developed. Most of the indicators for each dimension were illustrative of prior measurement scales employed in the testing of online consumption (as mentioned in Table 1). Both exogenous and endogenous variables of the research model were designed as subjective measures, relying on participants' self-reported insights.

Table 1. Constructs and items.

\begin{tabular}{|c|c|c|}
\hline Construct & Item & Sources \\
\hline \multirow{4}{*}{$\begin{array}{c}\text { Competition in the } \\
\text { online marketplace } \\
\text { (COM) } \\
\text { (Formative) }\end{array}$} & $\begin{array}{l}\text { COM1. Firms providing the same/similar products online offer } \\
\text { similar prices. }\end{array}$ & {$[34-40]$} \\
\hline & $\begin{array}{l}\text { COM2. Firms providing the same/similar products online offer similar } \\
\text { qualitative characteristics. }\end{array}$ & {$[34-40]$} \\
\hline & $\begin{array}{l}\text { COM3. Firms providing the same/similar products online use similar } \\
\text { user-friendly interfaces (the buying process is intuitive). }\end{array}$ & [34-40] \\
\hline & $\begin{array}{l}\text { COM4. Firms providing the same/similar products online offer } \\
\text { relevant and detailed information on the products on their websites. }\end{array}$ & [34-40] \\
\hline \multirow{5}{*}{$\begin{array}{c}\text { Online } \\
\text { consumer skills } \\
\text { (OCS) } \\
\text { (Formative) }\end{array}$} & $\begin{array}{l}\text { OCS1. I use to compare offers and check where I can buy online the } \\
\text { cheapest desired product. }\end{array}$ & {$[12,15,24,32,38,40,41,52,53]$} \\
\hline & $\begin{array}{l}\text { OCS2. I use to check if there are any sales or promotions online } \\
\text { regarding the desired product. }\end{array}$ & {$[18,26,27,32,38,40,41]$} \\
\hline & $\begin{array}{l}\text { OCS3. I use to talk to the customer service assistant about additional } \\
\text { product details when I buy products online. }\end{array}$ & {$[24,27]$} \\
\hline & $\begin{array}{l}\text { OCS4. I use to read other customers' online reviews regarding their } \\
\text { experience in buying from a certain website before acting }\end{array}$ & {$[26,27,30,32,38,40,41,52,53]$} \\
\hline & $\begin{array}{l}\text { OCS5. I use to perform cost-benefit analyses before buying } \\
\text { products online. }\end{array}$ & {$[30,32,38,40,41,52,53]$} \\
\hline \multirow{8}{*}{$\begin{array}{c}\text { Online } \\
\text { consumer } \\
\text { awareness } \\
\text { (OCA) } \\
\text { (Reflective) }\end{array}$} & OCA1. I am aware of my consumers' rights when I buy on sales online. & {$[11,15,24,38,39,41,58-60]$} \\
\hline & $\begin{array}{l}\text { OCA2. I am aware of my consumers' rights when I buy online or in } \\
\text { mail order. }\end{array}$ & {$[11,15,24]$} \\
\hline & $\begin{array}{l}\text { OCA3. I am aware of the agencies (government and voluntary) offering } \\
\text { consumers guidance. }\end{array}$ & {$[24,38,39,41,50]$} \\
\hline & $\begin{array}{l}\text { OCA4. I am aware of the legal action of governmental and } \\
\text { non-governmental institutions on protecting consumers. }\end{array}$ & {$[1,24,38,39,41,50]$} \\
\hline & OCA5. I am aware of consumers' guarantee rights. & {$[11,15,24,50]$} \\
\hline & OCA6. I am aware of consumers' distance-purchasing rights. & {$[24,38,39,41,58-60]$} \\
\hline & $\begin{array}{l}\text { OCA7. I am aware of different sources of information about } \\
\text { consumer affairs. }\end{array}$ & {$[24,38,39,41,58-60]$} \\
\hline & $\begin{array}{l}\text { OCA8. I am aware of the existence of lots of consumer online } \\
\text { communities debating on consumers policies. }\end{array}$ & {$[24,26-28,39,41,58-60]$} \\
\hline \multirow{3}{*}{$\begin{array}{c}\text { Online consumer } \\
\text { engagement } \\
\text { (OCE) } \\
\text { (Reflective) }\end{array}$} & $\begin{array}{l}\text { OCE1. I gave a poor quality product back to the online seller and } \\
\text { demand money refund. }\end{array}$ & {$[24,27,42-46,52]$} \\
\hline & $\begin{array}{l}\text { OCE2. I demanded replacement of a poor quality product bought } \\
\text { online for a good one. }\end{array}$ & {$[24,27,42-46,52]$} \\
\hline & $\begin{array}{l}\text { OCE3. I gave a poor quality product back to the manufacturer for repair } \\
\text { (production plant/factory) on the basis of the warranty card. }\end{array}$ & {$[24,27,52]$} \\
\hline \multirow{5}{*}{$\begin{array}{l}\text { Sustainable } \\
\text { purchasing decision } \\
\text { (SPD) } \\
\text { (Reflective) }\end{array}$} & SPD1. I often buy products online. & {$[32,52,53]$} \\
\hline & $\begin{array}{l}\text { SPD2. I buy products online because online shops are more controlled } \\
\text { by the authorities in the field of consumer protection. }\end{array}$ & {$[14,32,43-46,50,52,53]$} \\
\hline & $\begin{array}{l}\text { SPD3. I buy products online because I can compare and contrast offers } \\
\text { against various product specifications. }\end{array}$ & {$[32,43-46,52,53]$} \\
\hline & $\begin{array}{l}\text { SPD4. I buy products online because I can carefully compare products } \\
\text { in terms of quality and sustainability. }\end{array}$ & {$[32,43-46,52,53]$} \\
\hline & $\begin{array}{l}\text { SPD5. I buy products online because I trust in the other customers' } \\
\text { experiences and reviews. }\end{array}$ & {$[32,43-48,52,53]$} \\
\hline
\end{tabular}

A final section addressed the respondents' characteristics in terms of gender, age, level of education and their experience in online consumption measured by means of the period of time 
they have been purchasing online and through the number of online providers they have purchased from). A synopsis in this respect is presented in Table 2.

Table 2. The profile of respondents.

\begin{tabular}{|c|c|c|c|c|}
\hline & Frequency & Percentage & Mean & Std. Deviation \\
\hline Age & - & - & 23.08 & 4.55 \\
\hline \multicolumn{5}{|c|}{ Gender } \\
\hline Females & 183 & $57.5 \%$ & - & - \\
\hline Males & 135 & $42.5 \%$ & - & - \\
\hline \multicolumn{5}{|c|}{ Level of education } \\
\hline Undergraduate & 210 & $66 \%$ & - & - \\
\hline Graduate & 108 & $34 \%$ & - & - \\
\hline \multicolumn{5}{|c|}{ Experience in online purchasing (years) } \\
\hline Less than a year ago & 38 & $11.9 \%$ & - & - \\
\hline Between 1 and 3 years ago & 111 & $34.9 \%$ & - & - \\
\hline Between 3 and 5 years ago & 94 & $29.6 \%$ & - & - \\
\hline More than 5 years ago & 75 & $23.6 \%$ & - & - \\
\hline \multicolumn{5}{|c|}{ Number of online providers } \\
\hline Less than 3 online sellers & 101 & $31.8 \%$ & - & - \\
\hline Between 3 and 7 online sellers & 151 & $47.4 \%$ & - & - \\
\hline More than 7 online sellers & 66 & $20.8 \%$ & - & - \\
\hline
\end{tabular}

\subsection{Measurement and Structural Model Assessment}

In order to properly assess the measurement and structural model, a component-based partial least squares (PLS) analysis was performed. The choice for a variance-based technique was supported in the framework of an exploratory endeavour and of a research model integrating both formative and reflective factors, pursuant to Hair, Ringle and Sarstedt [73] and Henseler et al. [74]. The structural equation modeling (SEM) technique was performed by means of SmartPLS Version 3 (SmartPLS $\mathrm{GmbH}$, Bönningstedt, Germany), a statistical tool which is currently considered in a myriad of studies from behavioral sciences.

The model goodness-of-fit $(\mathrm{GoF})$ was examined taking into consideration the Euclidean distance between the model-implied and the empirical correlation matrix, that is, the standardized root mean square residual indicator (SRMR). The indicator mentioned was coined by $\mathrm{Hu}$ and Bentler [75] and then validated by Henseler et al. [76] as the most adequate GoF estimation for PLS path modeling. In the case of the current research model, the value of SRMR (i.e., 0.072) was below the recommended threshold of 0.08 , consequently supporting the model's GoF.

The psychometric properties of the constructs (presented in Table 3) were analysed according to Barclay, Higgins and Thompson's guidelines [77], which involve the testing of the convergent validity and discriminant validity of the measurement model.

On this front, the convergent validity was appraised by taking into account the factor loadings and cross-loadings in the case of the reflective constructs, average variance extracted (AVE), composite reliability (CR) and reliability (Cronbach alpha and rho_alpha) (as illustrated in Tables 3 and 4). The factor loadings of each indicator were greater than 0.65 and the AVE values were higher than the 0.60 threshold. Composite reliability assessment was also performed as it is given credit to be more accurate than Cronbach alpha [78,79]. However, Cronbach's alpha values of all indicators were above 0.6 while the reflective construct measure loadings exceeded the 0.70 level for composite reliability, thus, conforming to the criteria established by Yi and Davis [80]. As presented in Table 3, CR values varied from 0.88 to 0.92 while AVE varied from 0.59 to 0.73 . 
Table 3. Psychometric properties of reflective constructs.

\begin{tabular}{|c|c|c|c|c|c|c|c|}
\hline Construct & CR & $\begin{array}{c}\text { Cronbach } \\
\text { Alpha }\end{array}$ & Rho_Alpha & AVE & Indicator & $\begin{array}{c}\text { Weight } \\
\text { (Formative) }\end{array}$ & $\begin{array}{c}\text { Loading } \\
\text { (Reflective) }\end{array}$ \\
\hline \multirow{4}{*}{$\begin{array}{c}\text { COM } \\
\text { (Formative) }\end{array}$} & \multirow{4}{*}{ - } & \multirow{4}{*}{ - } & \multirow{4}{*}{1} & \multirow{4}{*}{ - } & COM1 & 0.680 & \multirow{4}{*}{ - } \\
\hline & & & & & COM2 & 0.588 & \\
\hline & & & & & COM3 & 0.540 & \\
\hline & & & & & COM4 & 0.785 & \\
\hline \multirow{5}{*}{$\begin{array}{c}\text { OCS } \\
\text { (Formative) }\end{array}$} & \multirow{5}{*}{ - } & \multirow{5}{*}{ - } & \multirow{5}{*}{1} & \multirow{5}{*}{-} & OCS1 & 0.588 & \multirow{5}{*}{ - } \\
\hline & & & & & OCS2 & 0.666 & \\
\hline & & & & & OCS3 & 0.488 & \\
\hline & & & & & OCS4 & 0.761 & \\
\hline & & & & & OCS5 & 0.566 & \\
\hline \multirow{8}{*}{$\begin{array}{c}\text { OCA } \\
\text { (Reflective) }\end{array}$} & \multirow{8}{*}{0.92} & \multirow{8}{*}{0.90} & \multirow{8}{*}{0.91} & \multirow{8}{*}{0.59} & OCA1 & \multirow{8}{*}{ - } & 0.795 \\
\hline & & & & & OCA2 & & 0.813 \\
\hline & & & & & OCA3 & & 0.732 \\
\hline & & & & & OCA4 & & 0.753 \\
\hline & & & & & OCA5 & & 0.762 \\
\hline & & & & & OCA6 & & 0.801 \\
\hline & & & & & OCA7 & & 0.781 \\
\hline & & & & & OCA8 & & 0.716 \\
\hline \multirow{3}{*}{$\begin{array}{c}\text { OCE } \\
\text { (Reflective) }\end{array}$} & \multirow{3}{*}{0.89} & \multirow{3}{*}{0.81} & \multirow{3}{*}{0.83} & \multirow{3}{*}{0.73} & OCE1 & \multirow{3}{*}{ - } & 0.850 \\
\hline & & & & & OCE2 & & 0.911 \\
\hline & & & & & OCE3 & & 0.794 \\
\hline \multirow{5}{*}{$\begin{array}{c}\text { SPD } \\
\text { (Reflective) }\end{array}$} & \multirow{5}{*}{0.88} & \multirow{5}{*}{0.83} & \multirow{5}{*}{0.84} & \multirow{5}{*}{0.60} & SPD1 & \multirow{5}{*}{ - } & 0.778 \\
\hline & & & & & SPD2 & & 0.786 \\
\hline & & & & & SPD3 & & 0.830 \\
\hline & & & & & SPD4 & & 0.791 \\
\hline & & & & & SPD5 & & 0.703 \\
\hline
\end{tabular}

Composite reliability $(\mathrm{CR})=$ (square of the summation of the factor loadings) $/[$ (square of the summation of the factor loadings) + (square of the summation of the error variances)]; Average variance extracted (AVE) = (summation of squared factor loadings)/(summation of squared factor loadings) (summation of error variances).

Table 4. Cross loadings.

\begin{tabular}{cccc}
\hline Reflective Variables & OCA & OCE & SPD \\
\hline OCA1 & 0.795 & 0.251 & 0.279 \\
OCA2 & 0.813 & 0.280 & 0.267 \\
OCA3 & 0.732 & 0.272 & 0.144 \\
OCA4 & 0.753 & 0.229 & 0.126 \\
OCA5 & 0.762 & 0.229 & 0.213 \\
OCA6 & 0.801 & 0.250 & 0.149 \\
OCA7 & 0.781 & 0.323 & 0.141 \\
OCA8 & 0.716 & 0.244 & 0.178 \\
OCE1 & 0.278 & 0.850 & 0.248 \\
OCE2 & 0.321 & 0.911 & 0.210 \\
OCE3 & 0.258 & 0.794 & 0.182 \\
SPD1 & 0.235 & 0.239 & 0.778 \\
SPD2 & 0.230 & 0.239 & 0.786 \\
SPD3 & 0.178 & 0.149 & 0.830 \\
SPD4 & 0.160 & 0.227 & 0.791 \\
SPD5 & 0.204 & 0.131 & 0.703 \\
\hline
\end{tabular}

The discriminant validity of the measurement model was examined by means of comparing the square roots of the AVEs with other correlation scores in the correlation matrix (as illustrated in Table 5). The values analysis confirmed that none of the construct correlations (non-diagonal entries) was above the corresponding square root of AVE (diagonal entries). At this level, the data met the 
guidelines mentioned by Fornell and Larcker [81], thus supporting the discriminant validity and the reliability adequacy of the overall measurement items.

Table 5. Discriminant validity of measurement model.

\begin{tabular}{llllll}
\hline & OCA & OCE & OCS & COM & SPD \\
\hline OCA & 0.770 & & & & \\
OCE & 0.336 & 0.853 & & & \\
OCS & 0.208 & 0.255 & & & \\
COM & 0.242 & 0.147 & 0.128 & & \\
SPD & 0.255 & 0.253 & 0.456 & 0.111 & 0.779
\end{tabular}

Diagonals stand for the square root of the average variance extracted while the off-diagonals are correlations among constructs.

Focusing on Diamantopoulos and Siguaw's [82] criteria on the usage of the variance inflation factor (VIF) for multicollinearity testing, we further computed the VIF values. The results provided evidence that all the VIF scores were below the 3.3 threshold (ranging from 1.03 to 2.54), indicating the absence of multicollinearity among constructs.

The structural model was also assessed in accordance with Hair et al.'s criteria [83], which involved the computation of $R^{2}$, beta and $t$-values. The bootstrapping procedure with 5000 resamples brought about the effect sizes $\left(f^{2}\right)$ while the blindfolding procedure engendered the predictive relevance $\left(Q^{2}\right)$ configurations (Table 6).

Table 6. Results of the structural model analysis (hypotheses testing).

\begin{tabular}{|c|c|c|c|c|c|c|c|c|}
\hline Hypothesis & Relationship & Std. Beta & Std. Dev. & $t$-Value & Decision & $R^{2}$ & $f^{2}$ & $Q^{2}$ \\
\hline H1 & COM $->$ OCS & 0.128 & 0.129 & 0.988 & Not supported & 0.016 & 0.017 & 0.003 \\
\hline $\mathrm{H} 2$ & COM $\rightarrow$ OCA & 0.242 & 0.099 & 2.447 * & Supported & 0.059 & 0.062 & 0.030 \\
\hline H3 & $\mathrm{COM} \rightarrow>\mathrm{OCE}$ & 0.147 & 0.076 & 1.924 & Not supported & 0.022 & 0.022 & 0.011 \\
\hline $\mathrm{H} 4$ & OCS $->$ SPD & 0.400 & 0.063 & $6.356^{* *}$ & Supported & - & 0.194 & - \\
\hline H5 & OCA $\rightarrow$ SPD & 0.134 & 0.062 & $2.165 *$ & Supported & - & 0.020 & - \\
\hline H6 & OCE -> SPD & 0.104 & 0.058 & 1.802 & Not supported & - & 0.012 & - \\
\hline H7 & COM $->$ SPD & 0.013 & 0.057 & 0.222 & Not supported & - & 0.000 & - \\
\hline $\begin{array}{l}\text { Overall } \\
\text { model }\end{array}$ & $\begin{array}{c}\text { COM }->\text { OCS, OCA, } \\
\text { OCE }->\text { SPD }\end{array}$ & - & - & - & 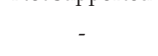 & 0.244 & - & 0.129 \\
\hline
\end{tabular}

As indicated in the table above, the $R^{2}$ value was 0.244 , suggesting a good model [83]. The bootstrapping procedure allowed the computation of the change in $R^{2}$ in case a specific exogenous dimension was extracted from the research model. In line with Cohen's [84] parameters, three out of seven relationships indicated small effect sizes (above 0.02).

The measurement of the predictive relevance was ensured by the multi-item endogenous reflective variable which also ensured a blindfolding procedure to be performed. As illustrated in Table 6, two out of the four relationships indicated a small (0.03) and a medium-to-large predictive relevance (0.129), as Hair et al. [83] posit.

\section{Results}

The results of the PLS structural model are presented in Figure 2. In the case of the Italian college students who participated in the survey, the model accounts for almost $25 \%$ of variance in sustainable purchasing decision. 


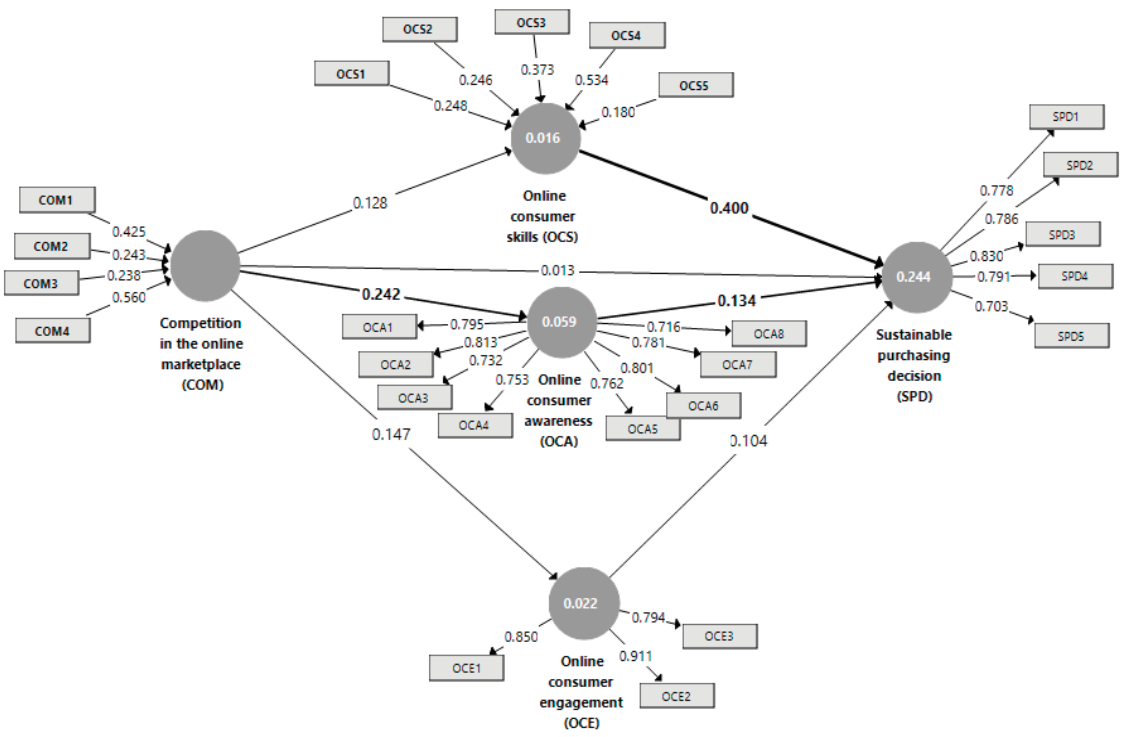

Figure 2. Partial least squares (PLS) test of the proposed structural model.

As presented in Figure 2, competition in the online market place has no significant influence on the development of online consumer skills $(p>0.05)$, thus, not supporting Hypothesis 1 . The situation is similar in the case of the relationship between competition in the online marketplace and online consumer engagement given the fact that the former construct does not exert a significant positive influence on the latter $(p>0.05)$. That being the case, Hypothesis 3 is also rejected. A different pattern is met in the relationship between competition in the online marketplace and awareness of the legislation on consumer rights $(\beta=0.242, p<0.05)$. The investigation supported Hypothesis 2 , providing evidence that the level of awareness is positively influenced by competition among online providers.

Focusing on the relationship between online consumer skills and sustainable purchasing decisions, the results indicated the highest significant positive influence among the model constructs $(\beta=0.400$, $p<0.001$ ), hence, conforming Hypothesis 4. Similarly, but to a smaller extent, the online consumer awareness of legislation on consumer rights exerts a significant positive influence on the sustainable purchasing decision $(\beta=0.134, p<0.05)$, supporting Hypothesis 5 .

Although online consumer engagement plays an important role in the equation of the sustainable purchasing decision, the present research has not brought forward a significant relationship between the two constructs $(p>0.05)$. Consequently, Hypothesis 6 was not supported in the framework of this study. Likewise, the data did not confirm the existence of a significant direct and positive influence of competition in the online marketplace on the sustainable purchasing decision $(p>0.05)$. This triggers the rejection of Hypothesis 7, as well.

To conclude, three out of the seven hypotheses were supported in the phenomenological context of a sample comprising Italian college students.

\section{Discussion}

\subsection{Research Contribution and Originality: Theoretical and Practical Implications}

The present paper aimed at developing a research model integrating the dynamics of the digital economy, in general, and of competition in the online market place, in particular, and the sustainable purchasing decision. The model presumed the existence of three main relationship mediators, namely 
online consumer skills, online consumer awareness and online consumer engagement. On this front, the model accounts for almost $25 \%$ of the variance in sustainable purchasing decisions.

As previously depicted, three out of the seven hypotheses formulated were supported in the context of the population investigated. In support of Hypothesis 2, the empirical analysis brought evidence of a significant positive relationship between competition in the online market place (i.e., multiple firms offering similar products in terms of prices, qualitative characteristics, buying process and specifications) and online consumer awareness (i.e., awareness of consumers' rights when buying on sales, of the agencies offering consumers guidance, of the legal action of governmental and non-governmental institutions on protecting consumers, of consumers' guaranteed rights, of consumers' distance-purchasing rights, of different sources of information about consumer affairs, of many online communities debating consumer policy). The evidence is in line with previous studies on the topic $[15,24,58-60]$ which have drawn upon the emerging business models within the digital economy and on the subsequent substantive shift in people's attitudes and conduct. In this vein, new issues have been raised regarding consumer protection $[38,39]$ and, thus, regarding the imperative to be aware of the legislation on consumer rights [15,24,41].

Focusing on the relationship between online consumer skills (i.e., comparing offers, checking sales or promotions, consulting the customer service assistant about additional product details, reading other customers' online reviews, performing cost-benefit analyses before buying products online) and the sustainable purchasing decision (i.e., buying products online: because online shops are more controlled by the authorities, because of the opportunity to compare and contrast offers against various product specifications and against quality and sustainability criteria, to use other customers' experiences and reviews), the findings confirmed the existence of a significant positive influence, the highest within the research model (Hypothesis 4). The results are consistent with the specialized literature in the field which posits that a new generation of empowered consumers is able to drive a positive social change by means of education, access to relevant information and capacity to assess information correctly [38,52,53], thus making optimal and sustainable decisions [26,27,32]. At this level, the college students questioned-who are representative of the Millennials generation-are a point of reference in promoting socially responsible views on consumption and in adhering to a sustainability framework in their general orientation [53,55].

In its own right, the investigation of the relationship between online consumer awareness of legislation on consumer rights and the sustainable purchasing decision supported the existence of a significant positive influence between the two constructs, thus confirming Hypothesis 5 . The findings are in line with the theoretical standpoints underlined in the literature review [24,50,52] and acknowledge that consumer awareness constitutes an important prerequisite of responsible consumption, a milestone in the study of the Millennials generation [52,53].

As previously shown, online consumer engagement (i.e., the return of a poor quality product to the online seller and demand of a refund, the demand to replace a poor quality product bought online for a good one, the return of a poor quality product to the manufacturer on the basis of the warranty card) does not exert any influence on the sustainable purchasing decision in the case of the college students questioned. The findings do not confirm the evidence supplied by other studies on the topic $[23,27,42-46,52]$. A possible explanation on this front may refer to the narrower scope of the consumer engagement construct, which only addressed the actual behavior when touching on problems for which there is a legitimate cause for complaint.

By corroborating the aforementioned empirical results, the present study had a twofold contribution to the extant literature. To start with, to the best of our knowledge, the relationship between the digital economy, in general, and competition in the online marketplace, in particular, and the sustainable purchasing decision has been scarcely discussed in the case of Millennials. Moreover, a phenomenological investigation within the European Union (i.e., Italy) was yet to be conducted. Even though the findings are country-specific (lacking statistical representativeness at the European level), they may be treated as a reference point when conducting similar research, all the more so as 
the OECD's report [33] — based on a survey conducted in seven European countries—suggested that young people tend to embrace a rather generation-centric sustainable orientation than a nation-based approach. This pattern may be interpreted in the light of the similar effects catalysed by EU integration and globalization processes, in terms of media access and the exposure of Millennials at a global scale. Moreover, pursuant to the OECD's policies [33,38,39], many European countries have been implementing sustainable consumption programmes and courses as part of a more general consumer education in universities, thus ensuring cross-national awareness and engagement in the case of students.

Secondly, the study relied on the exploration of online consumers' sustainable purchasing decisions by employing a relevant and novel statistical procedure, that is, the structural equation modeling based on partial least squares. The usage of PLS-SEM in the testing, measurement and assessment of the research model supported the proper identification of the extant effects and the explanation of variance within an exploratory framework.

From a more practical perspective, the current findings are indicative of the new business models which should be effectively capitalized on by online providers in order to preserve their performance. As new generations of online consumers emerge with a clear focus on sustainable, ethical, long-lasting and feasible products, on responsible consumption and rational decision-making, organizations competing in the online marketplace should attach greater importance to adjusting to the topical market conditions.

In this framework, the current study reveals major challenges for online providers. Firstly, vendors should better understand the contexts in which consumers exercise their choices, rationale and emotions. Firms are, thus, pushed towards the employment of a wide range of qualitative and quantitative research techniques to assess consumers' need for empowerment and sustainable consumption. Secondly, preserving the competitive advantage in the fiercely-augmented competition of the digital marketplace requires leading-edge strategies, integrating both tangible and intangible factors to foresee and keep pace with consumers' expectations related to sustainable purchasing. Furthermore, online providers are challenged to get rid of the linear thinking business models which were mainly focused on keeping up with the competitors and concentrate on multidimensional consumer specificity, especially on improved online consumer skills and awareness, as $\mathrm{H} 2, \mathrm{H} 4$ and $\mathrm{H} 5$ confirmed.

This challenge is much more imperative in the case of Millennials. As the recent survey conducted in 2016 by Kearney [72] with 149 Millennials reveals, their purchasing attitudes toward products and brands are intrinsically grounded in sustainability. Millennials show an increasing propensity to be loyal to products and brands they can personally use to live sustainable lives. They represent a new market segment steadily growing its influence in the digital marketplace. As a consequence, companies have to adapt processes, practices and value propositions to make their products sustainable, in order to seize the opportunities created.

\subsection{Limitations and Future Research Directions}

As with any other research, the present study would benefit from further improvements.

On the one hand, the conceptual model may be enriched in terms of scope through the inclusion of other constructs (i.e., consumer experience, consumer knowledge sharing, etc.). On this point, a future study envisioning other multi-item factors would provide a more thorough insight into online marketplace dynamics. Additionally, future studies may go deeper into refining relationships among the proposed concepts, for example, by testing mutual interactions among the online consumer skills, awareness and engagement constructs.

On the other hand, the investigation of the advanced hypotheses with larger samples or in the case of other populations would expand the analysis, offering a more accurate perspective and ensuring multiple-context comparisons. For example, replication of the survey using similar samples from other countries in Europe or elsewhere would provide further evidence on the relationships inferred, for both the supported and rejected hypotheses. In this vein, conducting confirmatory examinations would generate compelling insights in terms of debunking effects and testing model fit. 
Supplementary Materials: The following are available online at www.mdpi.com/2071-1050/9/5/683/s1: The survey database in Excel format.

Acknowledgments: No grants were used for the research and publication of the article. Only personal funds were employed.

Author Contributions: Patrizia Gazzola, Gianluca Colombo and Roberta Pezzetti reviewed the literature, conducted the survey, analyzed the data, discussed the implications of the results and performed the article revision. Luminița Nicolescu designed the questionnaire items and developed the methodological and empirical sections.

Conflicts of Interest: The authors declare no conflict of interest.

\section{References}

1. Van Gorp, N.; Batura, O. Challenges for Competition Policy in A Digitalised Economy. 2015. Available online: http:/ / www.europarl.europa.eu/RegData/etudes/STUD/2015/542235/IPOL_STU(2015) 542235_EN.pdf (accessed on 14 November 2016).

2. Vătămănescu, E.M.; Andrei, A.G.; Leovaridis, C.; Dumitriu, D.L. Exploring Network-Based Intellectual Capital as a Competitive Advantage: An Insight Into European Universities From Developing Economies. In Proceedings of the 7th European Conference on Intellectual Capital (ECIC 2015), Cartagena, Spain, 9-10 April 2015; Navarro, J.G.C., Ed.; Academic Conferences and Publishing International Limited: Reading, UK, 2015; pp. 350-358.

3. Alexandru, V. Global value chains from a multidimensional perspective. A preliminary insight. In Strategica. Opportunities and Risks in the Contemporary Business Environment; Brătianu, C., Zbuchea, A., Pînzaru, F., Leon, R.D., Vătămănescu, E.M., Eds.; Tritonic: Bucharest, Romania, 2016; pp. 324-331.

4. Monopolkomission. Competition Policy: the Challenge of Digital Markets. Available online: http://www. monopolkommission.de/images/PDF/SG/s68_fulltext_eng.pdf (accessed on 12 November 2016).

5. European Commission (EC). The Collaborative Economy Factsheet. Available online: http://ec.europa.eu/ DocsRoom/documents/16955/attachments/1/translations (accessed on 4 December 2016).

6. World Bank (WB). World Development Report 2016: Digital Dividends. Available online: http:/ / www-wds.worldbank.org/external/default/WDSContentServer/WDSP/IB/2016/01/13/

090224b08405ea05/2_0/Rendered/PDF/World0developm0000digital0dividends.pdf (accessed on 7 October 2016).

7. Zbuchea, A.; Vătămănescu, E.M.; Pînzaru, F. M-commerce-Facts and Forecasts. A Comparative Analysis within a Triad Framework: India, Romania, and the United States. Manag. Dyn. Know. Econ. 2016, 4, 387-408.

8. Hapenciuc, C.V.; Pînzaru, F.; Vătămănescu, E.M.; Stanciu, P. Converging Sustainable Entrepreneurship and the Contemporary Marketing Practices. An Insight into Romanian Start-Ups. Amfiteatru Econ. 2015, 17, 938-954.

9. Dincă, V.M. Privatization of Water. Available online: http://www.jsde.ro/wp-content/uploads/2015/06/ PRIVATISATION-OF-WATER-DINCA-Violeta-Mihaela.pdf (accessed on 6 February 2017).

10. Pînzaru, F. Marketing: It's all about digital. In Strategica. Local versus Global; Brătianu, C., Zbuchea, A., Pînzaru, F., Leon, R.D., Vătămănescu, E.M., Eds.; Tritonic: Bucharest, Romania, 2015; pp. 751-754.

11. Prensky, M. Digital Natives, Digital Immigrant. Available online: http://www.marcprensky.com/ writing/Prensky\%20-\%20Digital\%20Natives, \%20Digital\%20Immigrants\%20-\%20Part1.pdf (accessed on 24 November 2016).

12. Simões, F.D. Consumer behavior and sustainable development in China: The role of behavioral sciences in environmental policymaking. Sustainability 2016, 8, 897. [CrossRef]

13. Andrei, A.G.; Zait, A.; Vătămănescu, E.M.; Pînzaru, F. Word of mouth generation and brand communication strategy: Findings from an experimental study explored with PLS-SEM. Ind. Manag. Data Sys. 2017, 117, 478-495. [CrossRef]

14. Andrei, A.G.; Zait, A. Branding insights: An interdisciplinary journey from perception to action. In Strategica. Management, Finance, and Ethics; Brătianu, C., Zbuchea, A., Pînzaru, F., Vătămănescu, E.M., Eds.; Tritonic: Bucharest, Romania, 2014; pp. 593-604. 
15. Kerber, W. Digital Markets, Data, and Privacy: Competition Law, Consumer Law, and Data Protection. Available online: https://www.uni-marburg.de/fb02/makro/forschung/magkspapers/paper_2016/142016_kerber.pdf (accessed on 14 November 2016).

16. Consumers International (CI). State of Consumer Protection Survey 2014/15 Summary. 2014. Available online: www.consumersinternational.org/media/.../ci-survey-summary-2015-english.pdf (accessed on 14 October 2016).

17. Organisation for Economic Co-operation and Development (OECD). The Interface between Competition and Consumer Policies. Available online: www.oecd.org/regreform/sectors/40898016.pdf (accessed on 14 November 2016).

18. Madill, J.; Mexis, A. Consumers at the Heart of EU Competition Policy. Available online: ec.europa.eu/ competition/publications/cpn/2009_1_7.pdf (accessed on 12 December 2016).

19. Erbach, G. EU and US Competition Policies. Similar Objectives, Different Approaches. Available online: http:/ / www.europarl.europa.eu/RegData/bibliotheque/briefing/2014/140779/LDM_BRI(2014) 140779_REV1_EN.pdf (accessed on 14 November 2016).

20. HM Government (HMG). Review of the Balance of Competences between the United Kingdom and the European Union. Competition and Consumer Policy Report. Available online: https://www.gov.uk/government/uploads/system/uploads/attachment_data/file/332779/Review_of_ the_Balance_of_Competences_between_the_United_Kingdom_and_the_European_Union.pdf (accessed on 18 September 2016).

21. European Commission (EC). Report on Competition Policy 2015. Available online: ec.europa.eu/ competition/publications/annual_report/2015/part1_en.pdf (accessed on 11 November 2016).

22. European Commission (EC). EU Competition Policy in Action: COMP in ACTION. Available online: ec.europa.eu/competition/publications/kd0216250enn.pdf (accessed on 27 November 2016).

23. Gutierrez, A.; Thornton, T.F. Can consumers understand sustainability through seafood eco-labels? A US and UK case study. Sustainability 2014, 6, 8195-8217. [CrossRef]

24. Nardo, M.; Loi, M.; Rosati, R.; Manca, A. The Consumer Empowerment Index. A Measure of Skills, Awareness and Engagement of European Consumers. Available online: http:/ /ec.europa.eu/consumers/ consumer_empowerment/docs/JRC_report_consumer_empowerment_en.pdf (accessed on 14 February 2016).

25. Andrei, A.G.; Iacob, A. From user's motivations to branding: The case of social networks. In Proceedings of the 4th International Conference on Globalization and Higher Education in Economics and Business Administration-GEBA 2010, Iasi, Romania, 21-23 October 2010; Airinei, D., Pintilescu, C., Asandului, M., Andries, A.M., Eds.; Alexandru Ioan Cuza University of Iasi Publishing House: Iasi, Romania, 2011; pp. 139-144.

26. The benefit of competition policy for consumers. In Proceedings of the United Nations Conference on Trade and Development (UNCTAD), Geneva, Switzerland, 8-10 July 2014.

27. Office of Competition and Consumer Protection (OCCP). Awareness of Consumer Rights and Analysis of Barriers Preventing Consumers from Safe and Satisfactory Participation in the Market. Available online: https:/ / uokik.gov.pl/download.php?plik=8519 (accessed on 7 November 2016).

28. Vătămănescu, E.M.; Andrei, A.G.; Dumitriu, D.L.; Leovaridis, C. Harnessing network-based intellectual capital in online academic networks. From the organizational policies and practices towards competitiveness. J. Knowl. Manag. 2016, 20, 594-619. [CrossRef]

29. Bolisani, E.; Borgo, S.; Oltramari, A. Using knowledge as an object: Challenges and implications. Knowl. Manag. Res. Practi. 2012, 10, 202-205. [CrossRef]

30. Brătianu, C.; Bolisani, E. Knowledge strategy: an integrated approach for managing uncertainty. In Proceedings of the 16th European Conference on Knowledge Management, Udine, Italy, 3-4 September 2015; Massaro, M., Garlatti, A., Eds.; Academic Conferences and Publishing International Limited: Reading, UK, 2015; pp. 169-177.

31. Bolisani, E.; Scarso, E.; Zieba, M. How Small KIBS Companies Manage Their Intellectual Capital? Towards an Emergent KM Approach. In Proceedings of the 7th European Conference on Intellectual Capital (ECIC 2015), Cartagena, Spain, 9-10 April 2015; Cegarra Navarro, J.G., Ed.; Academic Conferences and Publishing International Limited: Reading, UK, 2015; pp. 25-33. 
32. European Commission. Commission Staff Working Paper. Consumer Empowerment in the EU. Available online: http:/ /ec.europa.eu/consumers/consumer_empowerment/docs/swd_consumer_empowerment_ eu_en.pdf (accessed on 10 April 2017).

33. Organisation for Economic Co-Operation and Development (OECD). Promoting Sustainable Consumption. Good Practices in OECD Countries. Available online: https://www.oecd.org/greengrowth/40317373.pdf (accessed on 9 April 2017).

34. Delp, A.B.; Mayo, J.W. The Evolution of "Competition": Lessons for 21st Century Telecommunications Policy. Rev. Ind. Organ. 2016. [CrossRef]

35. Fatas, E.; Lyons, B. Consumer Behaviour and Market Competition. In Behavioural Economics in Competition and Consumer Policy; Mehta, J., Ed.; ESRC Centre for Competition Policy: Norwich, UK, 2013; pp. 27-38.

36. Laitenberger, J. Staying Abreast of Digital Markets in the European Union: Taking a Closer Look at e-Commerce. In Proceedings of the Annual Conference on International Antitrust Law and Policy, New York, NY, USA, 22 September 2016; pp. 1-8.

37. Bauer, M.; Erixon, F. Competition, Growth and Regulatory Heterogeneity in Europe's Digital Economy. Available online: http://ecipe.org/publications/competition-growth-and-regulatory-heterogeneity-ineuropes-digital-economy/ (accessed on 9 February 2017).).

38. Organisation for Economic Co-operation and Development (OECD). Consumer Education Policy Recommendations of the OECD'S Committee on Consumer Policy. Available online: http:/ /www.oecd.org/ dataoecd/32/61/44110333.pdf (accessed on 9 April 2017).

39. Organisation for Economic Co-operation and Development (OECD). Consumer Protection in E-commerce: OECD Recommendation. Available online: http://www.oecd.org/sti/consumer/ECommerceRecommendation-2016.pdf (accessed on 9 April 2017).

40. Beranek, W.; Kamerschen, D.R. Consumers Are More Important Than Generally Believed. Available online: https://ncsu.edu/ffci/publications/2013/v18-n1-2013-spring/beranek-kamerschen.php (accessed on 10 April 2017).

41. Mwakatumbula, H.; Moshi, G.C.; Mitomo, H. Determinants of Consumers' Knowledge on their Rights in Telecommunication Markets: Case of Tanzania. Int. J. Manag. Public Sect. Inf. Commun. Technol. 2016, 7, 9-21. [CrossRef]

42. Bonchek, M.; Cornfield, G. Focus on Keeping up with Your Customers, Not Your Competitors. Available online: https://hbr.org/2016/04/focus-on-keeping-up-with-your-customers-not-your-competitors (accessed on 10 April 2017).

43. Case, S. Sustainable Purchasing 101: Tools for Buying Greener Products. Available online: http:/ / www.triplepundit.com/special/setting-the-standard/sustainable-purchasing-101-tools-buyinggreener-products/ (accessed on 10 April 2017).

44. Maher, M.; Reynolds, P.; Muysert, P.; Wandschneider, F. Resetting Competition Policy Frameworks for the Digital Ecosystem. Available online: http:/ / www.gsma.com/publicpolicy/wp-content/uploads/2016/10/ GSMA_Resetting-Competition_Report_Oct-2016_60pp_WEBv2.pdf (accessed on 10 February 2017).).

45. Păduraru, T.; Vătămănescu, E.M.; Andrei, A.G.; Pînzaru, F.; Zbuchea, A.; Maha, L.G.; Boldureanu, G. Sustainability in relationship marketing: An exploratory model for the industrial field. Environ. Eng. Manag. J. 2016, 15, 1635-1647.

46. Wright, L.T.; Newman, A.; Dennis, C. Enhancing Consumer Empowerment. Eurp. J. Mark. 2006, 40, $925-935$. [CrossRef]

47. Case, S. Transparency and Certification: The Yin and Yang of Sustainability. Available online: http:/ / www.triplepundit.com/special/setting-the-standard/yin-yang-sustainability-communicationenvironmental-labels-environmental-product-declarations / (accessed on 10 April 2017).

48. Newell, A. Two Years Later. Attitudes toward Green Are Looking Up. Available online: http://www. triplepundit.com/2013/10/attitudes-improved-years/ (accessed on 10 April 2017).

49. Vestager, M. e-Commerce: A Fair Deal for Consumers Online. Available online: https://ec.europa.eu/commission/ commissioners/2014-2019/vestager/announcements/e-commerce-fair-deal-consumers-online_en (accessed on 10 April 2017).

50. Vătămănescu, E.-M.; Nistoreanu, B.G.; Mitan, A. Competition and Consumer Behavior in the Context of the Digital Economy. Amfiteatru Econ. 2017, 19, 354-366. 
51. Gazzola, P.; Sepashvili, E.; Lo Parco, A. The road of sustainable development: Sustainable enterprises. In Proceeding of the 11th International Silk Road Conference on Innovations in Business, Education and Sciences, Tbilisi, Georgia, 20-21 May 2016; Ustunyer, I., Ed.; LLC International Black Sea University: Tbilisi, Georgia, 2016; pp. 63-68.

52. Euromonitor International. Global Changemakers: Real Market Impact of Empowered Consumers. 2017. Available online: http:/ / go.euromonitor.com/white-paper-industry-2016-Global-Changemakers-MarketImpact-Empowered-Consumers.html (accessed on 27 February 2017).

53. Pînzaru, F.; Vătămănescu, E.M.; Mitan, A.; Săvulescu, R.; Vițelar, A.; Noaghea, C.; Bălan, M. Millennials at Work: Investigating the Specificity of Generation Y versus Other Generations. Manag. Dyn. Knowl. Econ. 2016, 4, 173-192.

54. Sutherland, A.; Tompson, B. Kidfuence: The Marketer's Guide to Understanding and Reaching Generation Y-Kids, Tweens and Teens; McGraw Hill: New York, NY, USA, 2003.

55. Mitan, A. Do Romanian Youngsters Envision a CSR-Oriented World? A Research Regarding Digital Natives' Values. In Strategica. Management, Finance, and Ethics; Brătianu, C., Zbuchea, A., Pînzaru, F., Leon, R.D., Vătămănescu, E.M., Eds.; Tritonic: Bucharest, Romania, 2014; pp. 763-779.

56. Gazzola, P.; Pezzetti, P.; Pavione, P. Sustainable consumption in the luxury industry: Towards a new paradigm in the China's high-end demand? In Proceedings of the 2nd Czech-China Scientific Conference, Ostrava, Czech Republic, 7 June 2016; Gottvald, J., Praus, P., Eds.; InTech: Rijeka, Croatia, 2017; Chapter 12. [CrossRef]

57. Zhou, G.; Hu, W.; Huang, W. Are Consumers Willing to Pay More for Sustainable Products? A Study of Eco-Labeled Tuna Steak. Sustainability 2016, 8, 494. [CrossRef]

58. Pomarici, E.; Vecchio, R. Millennial generation attitudes to sustainable wine: An exploratory study on Italian consumers. J. Clean. Prod. 2014, 66, 537-545. [CrossRef]

59. Gurău, C. A life-stage analysis of consumer loyalty profile: Comparing Generation X and Millennial consumers. J. Consum. Mark. 2012, 29, 103-113. [CrossRef]

60. Gazzola, P.; Mella, P. Can CSR influence employees satisfaction? Ann. Univ. Oradea Econ. Sci. Ser. 2016, 25, 485-493.

61. Ordun, G. Millennial (Gen Y) consumer behavior their shopping preferences and perceptual maps associated with brand loyalty. Can. Soc. Sci. 2015, 11, 40-55.

62. Nielsen, N.V. The Nielsen Global Survey of Corporate Social Responsibility and Sustainability. Available online: http:/ / www.nielsen.com/it/it.html (accessed on 9 January 2017).

63. Lemee, A. Agents of Change: How Millennial Consumerism Drives Corporate Sustainability. Available online: http:/ / www.sustainablecap.com/featured-news/agents-of-change-how-millennial-consumerismdrives-corporate-sustainability/ (accessed on 30 October 2016).

64. Cheng, A. Fair Trade's Becomes a Fashion Trend. Available online: http://www.wsj.com/articles/fair-tradebecomes-a-fashion-trend-1436307440 (accessed on 6 November 2016).

65. Balsiger, P. The Fight for Ethical Fashion: The Origins and Interactions of the Clean Clothes Campaign; Routledge: New York, NY, USA, 2016.

66. Business Insider. How Important Is Sustainabilty to Millennials. An Emerging Retail Trend Is Key for Attracting Millennials. Available online: http://www.businessinsider.com/how-important-is-sustainabilityto-millennials-2015-10?IR=T (accessed on 27 October 2015).

67. Hanks, K.; Odom, W.; Roedl, D.; Blevis, E. Sustainable Millennials: Attitudes towards Sustainability and the Material Effects of Interactive Technologies. In Proceedings of the SIGCHI Conference on Human Factors in Computing Systems, CHI 2008, Florence, Italy, 5-10 April 2008; ACM: New York, NY, USA, 2008; pp. 333-342.

68. Donnelly, C.; Scaff, R. Who Are The Millennial Shoppers? And What Do They Really Want? Available online:. Available online: https://www.accenture.com/us-en/insight-outlook-who-are-millennial-shoppers-whatdo-they-really-want-retail (accessed on 18 January 2017).

69. Smith, K.T. Millennials' interpretations of green terminology. Acad. Mark. Stud. J. 2014, 18, 55-68.

70. Vătămănescu, E.M.; Pînzaru, F.; Andrei, A.G.; Zbuchea, A. Investigating SMEs sustainability with partial least squares structural equation modeling. Transform. Bus. Econ. 2016, 15, 259-273.

71. Soto-Acosta, P.; Cismaru, D.M.; Vătămănescu, E.M.; Ciochină, R.S. Sustainable Entrepreneurship in SMEs: A Business Performance Perspective. Sustainability 2016, 8, 342. [CrossRef] 
72. Kearney, A.T. Don't Give up on Millennials. Available online: https://www.atkearney.com/america250/ don-t-give-up-on-millennials (accessed on 30 January 2017).

73. Hair, J.F.; Ringle, C.M.; Sarstedt, M. From the Special Issue Guest Editors. J. Mark. Theory Pract. 2011, 19, 135-138.

74. Henseler, J.; Dijkstra, T.K.; Sarstedt, M.; Ringle, C.M.; Diamantopoulos, A.; Straub, D.W. Common beliefs and reality about PLS comments on Rönkkö and Evermann. Organ. Res. Method 2014, 17, 182-209. [CrossRef]

75. Hu, L.; Bentler, P.M. Cutoff criteria for fit indexes in covariance structure analysis: Conventional criteria versus new alternatives. Struct. Equ. Model. Multidiscip. J. 1999, 6, 1-55. [CrossRef]

76. Henseler, J.; Hubona, G.; Ray, P.A. Using PLS path modeling in new technology research: Updated guidelines. Ind. Manag. Data Sys. 2016, 116, 2-20. [CrossRef]

77. Barclay, D.; Higgins, C.; Thompson, R. The partial least squares (PLS) approach to causal modeling: Personal computer adoption and use as an illustration. Technol. Studi. 1995, 2, 285-309.

78. Chin, W.W. The partial least squares approach to structural equation modeling. In Modern Methods for Business Research; Marcoulides, G.A., Ed.; Lawrence Erlbaum: Mahwah, NJ, USA, 1998; pp. $295-358$.

79. Henseler, J.; Ringle, C.M.; Sinkovics, R.R. The use of partial least squares path modeling in international marketing. Adv. Int. Mark. 2009, 20, 277-320.

80. Yi, M.Y.; Davis, F.D. Developing and validating an observational learning model of computer software training and skill acquisition. Inf. Sys. Res. 2003, 14, 146-169. [CrossRef]

81. Fornell, C.; Larcker, D.F. Evaluating structural equation models with unobservable variables and measurement error. J. Mark. Res. 1981, 18, 39-50. [CrossRef]

82. Diamantopoulos, A.; Siguaw, J.A. Formative versus reflective indicators in organizational measure development: A comparison and empirical illustration. Br. J.Manag. 2006, 17, 263-282. [CrossRef]

83. Hair, J.F.; Hult, G.T.M.; Ringle, C.M.; Sarstedt, M. A Primer on Partial Least Squares Structural Equation Modeling (PLS-SEM); Sage Publication: Los Angeles, CA, USA, 2014.

84. Cohen, J. Statistical Power Analysis for the Behavioral Sciences; Lawrence Erlbaum: Mahwah, NJ, USA, 1988.

(C) 2017 by the authors. Licensee MDPI, Basel, Switzerland. This article is an open access article distributed under the terms and conditions of the Creative Commons Attribution (CC BY) license (http:/ / creativecommons.org/licenses/by/4.0/). 



\title{
Article \\ Debt and Deficit Growth Rate Reporting for Post-Communist European Union Member States
}

\author{
Andrzej Paczoski ${ }^{1, *(\mathbb{C})}$, Solomon T. Abebe ${ }^{2}$ (I) and Giuseppe T. Cirella ${ }^{3, *(1)}$ \\ 1 Department of Economic Policy, Faculty of Economics, University of Gdansk, 80309 Gdansk, Poland \\ 2 Polo Centre of Sustainability, 18100 Imperia, Italy; solomtu6@gmail.com \\ 3 Faculty of Economics, University of Gdansk, 80309 Gdansk, Poland \\ * Correspondence: andrzej.paczoski@ug.edu.pl (A.P.); gt.cirella@ug.edu.pl (G.T.C.)
}

Received: 30 April 2019; Accepted: 4 June 2019; Published: 5 June 2019

\begin{abstract}
A focalized analysis and reporting on the problems of general government debt (GGD) and government deficit (GD) and their influencing factors on economic growth rate tell the story of positive, neutral, and negative economies. Research was conducted over a nineteen-year period between 2000 and 2018 on all eleven post-communist European Union Member States (MS). MSs are divided in to three regional blocks: (1) the Baltic countries, (2) Central and Eastern European countries, and (3) the Balkan countries. Reviewed literature examined different types of GGD and GD with denoted influence on each MS's economy and government. GGD and GD increase as a result of State intervention by reacting to economic fluctuations needed in creating redistributive-related fiscal policy. A breakdown of the problems of fiscal policy is explained. Datasets were compiled and systematically analyzed using Eurostat indicators. European regulatory benchmarking was used for GGD and GD as a percentage of gross domestic product. Results were divided at the regional group level. Comparative tax systems based on total general government revenue as well as total tax and contribution rate were evaluated. Histo-geographical research was considered and a comparative examination of GGD, GD and growth rate illustrated. In terms of GGD, GD, and growth rate, the Baltic countries were best situated, while all other countries were generally stable-with the exception of Hungary, Croatia, and Slovenia. In all, negative or stagnant periods revealed a general positive trend throughout the study with the exception of the world financial crisis of 2008, in which a deteriorative impact on growth rate was evident in all MS - especially from 2009. In the latter years, MSs' economic promise signals a high potential for renewed public finance and stability initiatives.
\end{abstract}

Keywords: general government debt; government deficit; economic growth rate; post-communist EU countries

\section{Introduction}

General government debt (GGD) is defined as all liabilities deriving predominately from credits of public institutions (i.e., a government's central budget, public territorial entities, funds, and agencies). A lengthened definition would include the sum of previous years' government deficit (GD) as well as liabilities from the State from credits to cover such GD (Marciniak 2013; Yang et al. 2018; Hyman 2018). In most cases, GGD occurs when State indebtedness from domestic and foreign creditors is issued through treasury bills, notes and bonds as well as bank credit. GGD and GD are interlaced with public finance and fundamentally influence economic growth, particularly via investment. Concerns of high GGD and GD can rebound and negatively affect a country's economic success. A principal reason for the augmentation of GGD is the necessity of credit to cover GD. This sometimes creates a cyclic process if only GD is addressed and GGD is not. As a result, public credit is used to pay off GD from returnable inflows from a central budget, while financing credit for GGD generates costs of public finance (Kosek-Wojnar et al. 1994; OECD 2013). These costs are usually stretched over time, 
often having a generational effect and forcing future governments to deal with an unremitting GGD. In an examination of fiscal policy in post-communist European Union (EU) Member States (MS), the connection with GGD and GD and the core question of how they destabilize economic growth is reported on (Van Der Veer and Haverland 2018). Additional inquiries look at tools that best alleviate GGD and GD and relating negative influences from political determinants (e.g., policy), historical relations, and cultural norms.

A simple yet unsound method of overcoming GGD is inflation generated, by the printing of money, by central banks-an action generally forbidden in most developed countries. When a central bank (i.e., monetary authority) decides on this type of policy, it is usually based on short-term interest to immediately decrease purchasing power parity within the dominant part of society and limit entrepreneurial activity. Central banks operate independently from State government and are responsible for monetary policy, which has a direct effect on the inflation rate (Pegkas 2018). During periods of inflation, a negative outcome will affect everyone except the State, which experiences a taxflation effect (i.e., when inflation decreases GGD and GD from higher inflows of taxation). These inflows do not change public finance indexation since core adjustments to the taxation threshold are based on consumer price index limits. Moreover, since annual budgetary expenditure does not change, based on budget threshold, public finance will remain a key beneficiary of any implemented inflation-based tax (i.e., core to annual budgetary expenditure). The OECD (OECD 2017) considers several types of GGD as essential to an economy's health and key to the sustainability of government finance, they include: (1) domestic vs. foreign-both dependent on currency value and ownership of debt (i.e., citizenry or institutions); (2) short-term (i.e., liquidity for an established budget) against long-term expenditure (e.g., property); (3) gross (i.e., the ability to cover public liabilities either of domestic or foreign entities that are not part of the public sector) versus net (i.e., gross GGD minus the liabilities from nonpublic entities within the public sector); (4) nominal value of liabilities versus real value (i.e., nominal values revised by inflation); (5) real (i.e., required liabilities of balance) versus potential (i.e., guarantees provided by the public sector); (6) central (i.e., the central State) versus local (i.e., self-government); and (7) declared versus hidden (i.e., other financial contracts and State liabilities for future expenditures (e.g., retired persons and annuitants)) (Dzwonkowski 2013; Tobera 2013; Łaszek 2013; Altiparmakov 2018; Högenauer and Howarth 2019). These types of GGD allow us to consider the specific origin of debt by making it easier to understand, observe, and reduce it. To better piece together this problem, we analyzed GGD utilizing two strategic perspectives of debt: valuably recognized and comparative. Valuably recognized debt is the sum of money, of a given currency, which government has indebted for creditors. Comparative debt elucidates the percentage ratio of GGD to gross domestic product (GDP) and applies it to GGD in an annual percentage format of GDP. In this paper, we observed historical fiscal data in all eleven post-communist EU MSs utilizing these observational perspectives. GGD and GD increase as a result of State intervention, which can react to economic fluctuations needed in creating redistributive-related policy (Wiśniewski 2015; Ćwikliński 2004; Neck and Sturm 2008). A breakdown of the paper is structured as follows: Section 2 explores problems in fiscal policy, Section 3 contains the methodology, Section 4 illustrates the results, Section 5 elucidates a discussion on tax system evaluation and conditions of public finance, and Section 6 the conclusion.

\section{Problems of Fiscal Policy}

\subsection{Government Deficit}

Government budget is used to define the methods of calculating income and outcome. GD, a negative balance in the government budget, occurs when such a budget exceeds its income in a given year. To account for the negative balance, capital inflow is usually eliminated in public sector entities (Neumann and Paczoski 2014). As such, different methodologies have been employed to assess how countries balance their budget, with notable primary bodies including the International Monetary 
Fund (IMF) and the EU. The IMF's methodology uses government finance statistics by categorizing government-run public sectors via the central budget, State and local budgets, social security funds (e.g., resort enterprises), and noncommercial institutions that control and finance the State. Within an IMF framing, expenditures are monetary sources relevant to equivalent and non-equivalent, current and capital, and grants and loans. All of these means are consolidated by excluding transactions between public entities (Wernik 2001; Kim et al. 2018).

Within the EU, public finance is based on the European System of National and Regional Accounts. This accounting system measures assets and liabilities that adjust throughout the public sector (Wernik 2001). Difference in assets include cash, deposits, other securities, given loans, stocks and capital shares, mercantile credit, and advance payments. The balancing of one's budget was standard until the 19th Century when the economic crisis of 1929 hit the world. In Keynesian theory, GD was seen as a solution for such an economic situation. Instituted, it meant the implementation of a systematic budget in which GD was an acceptable manner of activating an economy, forcing expenditures to become cumbersome fiscal structures; nonetheless, this idea was backed with the concept that it would stimulate global demand. Supporters were attentive in postponing GD and its payback without taking loss. This activity, to the detriment of much of the world, brought inflation and increased interest rates to financial markets (Gradoń 2003; Ari et al. 2018; Ortiz-Rodríguez et al. 2018).

Another form of budgetary management is a cyclical budget. In such a budget, it is expected that GD during a recession will neutralize budget surplus and stall economic growth. Henceforward, the State is forced to support the economy by augmenting public expenditure and, thus, its GD. One concern with the use of a cyclical budget approach are political targets or government motivation to persuade its electorate of social expenditure requisites and shortcomings (Gaudemet and Molinier 2000). However, based on impasse theory, it is possible to evaluate a cyclical budget's GD in terms of threshold and given conditions. Impasse is defined as all impositions above income, foreseen within an annual budget, dependent on the status quo for the future economy. As a result, GD may occur as a result of the following two conditions, when: (1) Supplementary money is issued without increasing volume of production to avoid inflation and depreciation of the currency; and (2) utilizing a higher inflation mechanism to increase savings, and supply of goods and services (i.e., by applying a quantity impasse approach) (Gradoń 2003). To that end, GD can also be structural and correlate with the full rate of employment. In terms of these practices, cyclical fluctuations can be averted, which can influence budget and automatic economic stabilizers for better-active and passive-fiscal policy (Gradoń 2003). Using these methods, GD can be used to correct for inflation and instability.

\subsection{General Government Debt and the Effect of Instability in Public Finance}

In Keynesian theory, a school of thought based on the welfare state, active economic policy—particularly fiscal policy—has had negative, far-reaching effects on GGD and GD. Nonetheless, governments that spend money on investments utilizing GGD have found added value, irrespective of consequence. These investments have been found to bring financial return through taxation of private companies that are users of public investment. For example, government investment on transport infrastructure will develop private sector entities that cater to a transport niche. As such, according to Keynesian theory, GGD and GD will decrease savings while still stimulating an aggregated supply. Higher GD (i.e., in this case, from a decrease in savings) will result in the raising of interest rates to stimulate the crowding effect on private investment (Ball and Mankiw 1995). The stability of prices will bring increased production and better economic success. Even though GD can be considered a beneficial tool for the economy, during a recession, some argue for the use of automatic stabilizers as better mechanisms in neutralizing economic fluctuations (Ćwikliński 2004)—as such a number of outlooks should be considered.

In Ricardian theory, the GD is neutral; it has no influence on national savings or aggregated supply due to a decreasing emphasis on public savings. It utilizes the comparative advantage principle by pressing consumers to offset GD with the notion that higher taxes will be implemented in the 
future, allowing them to spend more of their income in the present. As such, any changes in taxes and public expenditure have no influence on aggregated demand (Barro 1988). In contrast with each other, Keynesian theory and Ricardian theory both attempt to better fiscal policy and reduce GD by creating economic improvement and stability. A notable example contrasting the two theories can be found in Giavazzi and Pagano's (Giavazzi and Pagano 1990) research comparing Denmark and Ireland throughout the 1980s.

As such effects of restrictive fiscal policy are not linear (i.e., non-Keynesian), the same policy in different conditions can bring unexpected and, often, atypical results. When public finance is in good order (i.e., GGD and GD are under control and not abnormally high), solutions from fiscal policy can often resemble Keynesian-like aftereffects. Restrictive fiscal policy can sometimes improve an economic situation by accelerating a variety of economic conditions (Brzozowski et al. 2006; Alesina and Ardagna 1998; Hemming et al. 2002; Compant et al. 2005; Ardagna 2004). A useful example includes permanent income in which reaction to demand reflects the attitude of the consumer. In retrospect, it is particularly important to take into account how consumers react to fiscal policy (i.e., changes to taxes and public expenditures). A high GGD and GD can often create a dire situation for public finance in which consumers expect higher taxes which, retrospectively, will decrease income. In this way, demand is lessened and the potential for recession high. Conversely, when governments avoid high levels of GGD and GD, permanent income and demand go up, complementing consumers' expectation that no changes in taxes or expenditure will be problematic. In this case, fiscal policy mitigation is advantageous yet limited in terms of its long-term effectiveness.

As a result, when we take into consideration why economic crises commence, there are a number of correlating reasons that are connected to high levels of GGD. Effects of crises exert pressure on government to decrease GD by lowering wages in the public sector and cutting social transfers. Another relating issue incorporates high interest rates via the banking sector, which causes withdrawal of foreign capital and, ultimately, leads to a decrease in investment and financial trouble for enterprises-increasing the probability of bankruptcy and default. This dangerous precedent shocks the banking sector, which is often a contributing factor to most financial crises. High inflation can be an aftereffect, with consequential factors including the decrease in production, increase in unemployment, and a worsen standard of living (Romer et al. 2000).

Changes to the amount and structure of income, as well as expenditure, can affect economic progress. A country's level of savings can also influence economic growth (i.e., via the endogenous growth model) in terms of pace and return rate from private capital (Brzozowski et al. 2006). Expenditures, which are productive in developing infrastructure, can stimulate economic development society-wide (Kneller et al. 1999; Barro and Sala-i-Martin 2004). As such, crowding effects may arise if repayment of GGD leads to a decrease in public and private investment (Minea and Villieu 2010). Economic growth can be lowered and even halted if household consumption and domestic savings drastically fall (Saint-Paul 1992). High foreign debt can also service GGD by influencing the economy and investors alike (Neck and Sturm 2008). Foreign creditors can engender business thinking as well as GDP repayment of foreign debt (Krugman 1988; Alaimo et al. 2008). Similarly, this works for countries that do not have a problem with GGD by establishing high foreign investment correlating high external, international influence.

Conversely, instability in economic policy (i.e., on a macroeconomic level) directly relates to the risk of losing on investment (Eaton 1993; Serven 1997; Agénor and Montiel 2005). As such, most studies indicate the influence of GGD on economic growth (i.e., related to investments) as negative (Deshpande 1997; Pattollo et al. 2011; Clements et al. 2003; Shah et al. 2017; Smyth and Hsing 1995; Lin and Sosin 2001; Brzozowski et al. 2006). Cross-sectional analysis comparing developed and developing countries indicates GGD as a negative factor on economic growth (N'Zue 2018; Brzozowski et al. 2006; Pegkas 2018). Positive indicators include political stability, rule of law, and a high-quality, functional public sector. Inversely, negative indicators encompass a high rate of inflation, increasing taxes and disadvantageous changes to the law. These problems can severely influence private entrepreneurial 
activities and overall profit. Hence, if the quality of public institutions in a given country is high, there is most likely limited to no problem with GGD and the negative influence of GGD on the economy.

One important comparison in examining the influence of GGD on the economy is to consider positive and negative side-effects. The following are problematic GGD concerns relating to this dilemma. They include: (1) the possibility of raising taxes for higher inflows for the budget (i.e., the need for repayment of public debt) and repossession of private savings; (2) a poor international reputation which may have high value for public debt; (3) the cost of financial attendance; (4) the risk related to the exchange rate if GGD is issued in a foreign currency; (5) financial instability and bankruptcy; (6) the crowding out effect; (7) the deterioration and balancing of current accounts to balance out payments; (8) unstable rules for entrepreneurs; and (9) the decrease of a dynamism to the economy (Neumann and Paczoski 2014). As such, instability in public finance is a problem at the international level. Specifically, to test this problem, the paper applied the Maastricht Treaty and the Stability and Growth Pact (SGP) as two legislative benchmarks for best practices reporting. The Maastricht Treaty defines GD as net borrowing (i.e., increased indebtedness minus increased liabilities). These legislative regulations implemented at the European level, specifically within post-communist EU MSs, can foster economic destabilization, oblige the private sector and citizenry to pay higher taxes due to repayment requisites, and have a prolonged effect on future generations. At length, the paper reports and focalizes, in relation to the problems of fiscal policy, on integrating stabilization recommendations within the concerned MSs' economic systems and highlights best practices to decrease GGD and GD.

\section{Methodology}

A systematic literature review was conducted using the following electronic journal databases: Science Direct, Web of Knowledge, Scopus, Science Direct, ProQuest, Sage, Directory of Open Access Journals, Google Scholar, and Google. In particular, we utilized a three-stepladder search by adding keywords to each step (i.e., $\mathrm{s}^{\mathrm{x}}$ ), where " $\mathrm{x}$ " = each keyword in step 1. The following English language keywords frame step 1: "general government debt", "government deficit", "economic policy", "economic growth rate", " post-communist economy", "economic consequences", "economic trends", "regional variation", "political stability", "government avoidance", "economic change", "GDP", "European economic treaties", "stability + regulations", "Maastricht Treaty", "Stability and Growth Pact", "debt tools", and "economic development". Next, step two repeated the process with each of the following EU MS: " $\mathrm{s}^{\mathrm{x}}+$ Estonia", "s $\mathrm{s}$ + Latvia", " $\mathrm{s}^{\mathrm{x}}+$ Lithuania", " $\mathrm{s}^{\mathrm{x}}+$ Czech Republic", "s $\mathrm{s}^{\mathrm{x}}+$ Hungary", "s $\mathrm{s}^{\mathrm{x}}+$ Poland", "s $\mathrm{s}^{\mathrm{x}}+$ Slovakia", "s $\mathrm{s}^{\mathrm{x}}+$ Bulgaria", " $\mathrm{s}^{\mathrm{x}}+$ Croatia", "s + Romania", and "s ${ }^{\mathrm{x}}+$ Slovenia". Finally, step three repeated the process by searching for grouped blocks (i.e., regions) plus adding the word "countries" as well as jointly-searching countries from each block: " $\mathrm{s}^{\mathrm{x}}+$ Baltic + countries", " $\mathrm{s}^{\mathrm{x}}+$ Estonia + Latvia + Lithuania", "s $\mathrm{x}+$ Central European + Eastern European + countries", " $\mathrm{s}^{\mathrm{x}}+$ Czech Republic + Hungary + Poland + Slovakia", " $\mathrm{s}^{\mathrm{x}}+$ Balkan + countries", and " $\mathrm{s}^{\mathrm{x}}$ + Bulgaria + Croatia + Romania + Slovenia".

The literature was compiled, and the publications were systematically analyzed so as to identify those that presented specific findings relating to regulation-reporting of GGD and GD of $60 \%$ and $3 \%$ of GDP, respectively. These benchmark figures are taken from the Maastricht Treaty and the SGP (European Council 1997; Neck and Sturm 2008). We examined post-communist EU MSs' GGD and GD using strategic and critical reading methods (Matarese 2013; Renear and Palmer 2009). As part of the systematic review process, we also identified past and existing terminology related to GGD and GD and synthesized and updated it so as to provide a way forward with the benchmark research.

The study examined all eleven post-communist EU MSs. We clustered these countries into three regional blocks and compared them by analyzing Eurostat indicators via its database, as follows: (1) the Baltic countries: Estonia, Latvia, and Lithuania; (2) Central and Eastern European countries: Czech Republic, Hungary, Poland, and Slovakia; and (3) the Balkan countries: Bulgaria, Croatia, Romania, and Slovenia (Figure 1). 


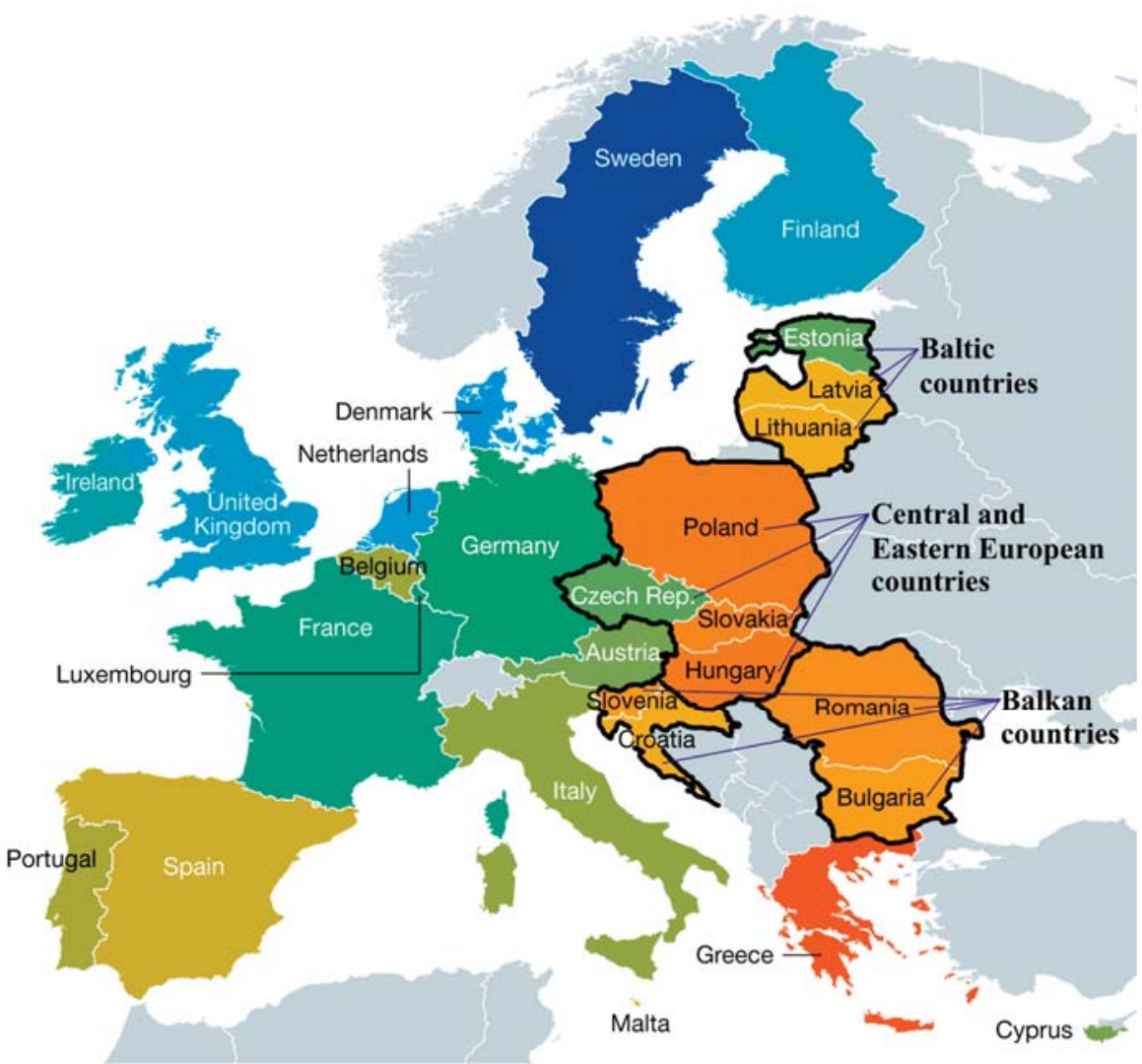

Figure 1. Map of the study area with defined regional blocks and relating European Union Member States.

From the regional blocks, we used macroeconomic data to create datasets within a nineteen-year period between 2000 and 2018. We then compared GGD and GD with economic growth, according to high and low indicators, among countries within each regional block. We charted each country to define national and regional trends, dynamic variability, and fiscal policy conditions of GGD and GD. Then, fiscal policy was examined by observing influence-related trends on growth rate and an overall analysis between regional groups-defined via country-specific economic policy. Finally, Section 5 addresses the tax systems in each MS by comparing datasets from Eurostat and the World Bank.

\section{Results}

Each of the three regional blocks (i.e., (1) the Baltic countries, (2) Central and Eastern European countries, and (3) the Balkan countries) is presented as a separate subsection. Regional blocks are illustrated in two parts: tabular data and two graphical charts.

\subsection{The Baltic Countries}

The Baltic countries had stable and normalized GGD and GD for most of the nineteen-year study (Table 1). In terms of the lowest level of GGD, Estonia was in the top position-worldwide, in fact. Its government surplus throughout all of the study remained in single digits, with the exception of 2014 when GGD reached 10.4\%. Between 2000 and 2007, the country recorded exceptionally low 
levels of GGD before a slight augmentation during the then world financial crisis and recession period of 2009-2010 (Figure 2). As a consequence, Estonia's growth rate remained low during the period of 2013-2018, with the GD floating around 9\% of GDP - slightly higher from the previous decade, 2000-2010 (Figure 3). It should be noted that the country is in good standing in terms of GD and obtained a government surplus via its GD in 2000, 2008-2009, 2012-2013, and 2017-2018.

Table 1. The Baltic countries' GGD percentage of GDP, GD percentage of GDP, and growth rate percentage change from previous year, 2000-2018.

\begin{tabular}{cccccccccc}
\hline \multirow{2}{*}{ Year } & \multicolumn{3}{c}{ Estonia } & \multicolumn{3}{c}{ Latvia } & \multicolumn{3}{c}{ Lithuania } \\
\cline { 2 - 10 } & GGD & GD & GR & GGD & GD & GR & GGD & GD & GR \\
\hline 2000 & 5.1 & -0.1 & 9.9 & 12.1 & -2.7 & 5.3 & 23.5 & -3.2 & 3.6 \\
2001 & 4.8 & 0.2 & 6.2 & 13.9 & -2.0 & 7.3 & 22.9 & -3.5 & 6.7 \\
2002 & 5.7 & 0.4 & 6.2 & 13.2 & -2.2 & 7.1 & 22.1 & -1.9 & 6.8 \\
2003 & 5.6 & 1.8 & 8.1 & 13.9 & -1.6 & 7.7 & 20.4 & -1.3 & 10.3 \\
2004 & 5.1 & 2.4 & 6.2 & 14.3 & -1.0 & 8.8 & 18.7 & -1.4 & 7.4 \\
2005 & 4.5 & 1.1 & 9.4 & 11.8 & -0.4 & 10.7 & 17.6 & -0.3 & 7.7 \\
2006 & 4.4 & 2.9 & 10.3 & 9.9 & -0.6 & 11.9 & 17.2 & -0.3 & 7.4 \\
2007 & 3.7 & 2.7 & 7.7 & 8.4 & -0.7 & 9.9 & 15.9 & -0.8 & 11.1 \\
2008 & 4.5 & -2.7 & -5.4 & 18.7 & -4.1 & -3.6 & 14.6 & -3.1 & 2.6 \\
2009 & 7.0 & -2.2 & -14.7 & 36.6 & -9.1 & -14.3 & 29.0 & -9.1 & -14.8 \\
2010 & 6.6 & 0.2 & 2.3 & 47.5 & -8.5 & -3.8 & 36.2 & -6.9 & 1.6 \\
2011 & 5.9 & 1.2 & 7.6 & 42.8 & -3.4 & 6.4 & 37.2 & -8.9 & 6.0 \\
2012 & 9.5 & -0.3 & 4.3 & 41.4 & -0.8 & 4.0 & 39.8 & -3.1 & 3.8 \\
2013 & 9.9 & -0.2 & 1.4 & 39.1 & -0.9 & 2.6 & 38.8 & -2.6 & 3.5 \\
2014 & 10.4 & 0.8 & 2.8 & 40.8 & -1.6 & 2.1 & 40.7 & -0.7 & 3.5 \\
2015 & 9.7 & 0.4 & 1.4 & 36.4 & -1.3 & 2.7 & 42.7 & -0.2 & 1.8 \\
2016 & 9.5 & 0.3 & 1.6 & 40.1 & 0.0 & 2.0 & 40.2 & 0.3 & 2.3 \\
2017 & 9.2 & -0.4 & 4.9 & 40.0 & -0.6 & 4.6 & 39.4 & 0.5 & 4.1 \\
2018 & 8.4 & -0.6 & 3.9 & 35.9 & -1.0 & 4.8 & 34.2 & 0.7 & 3.5 \\
\hline
\end{tabular}

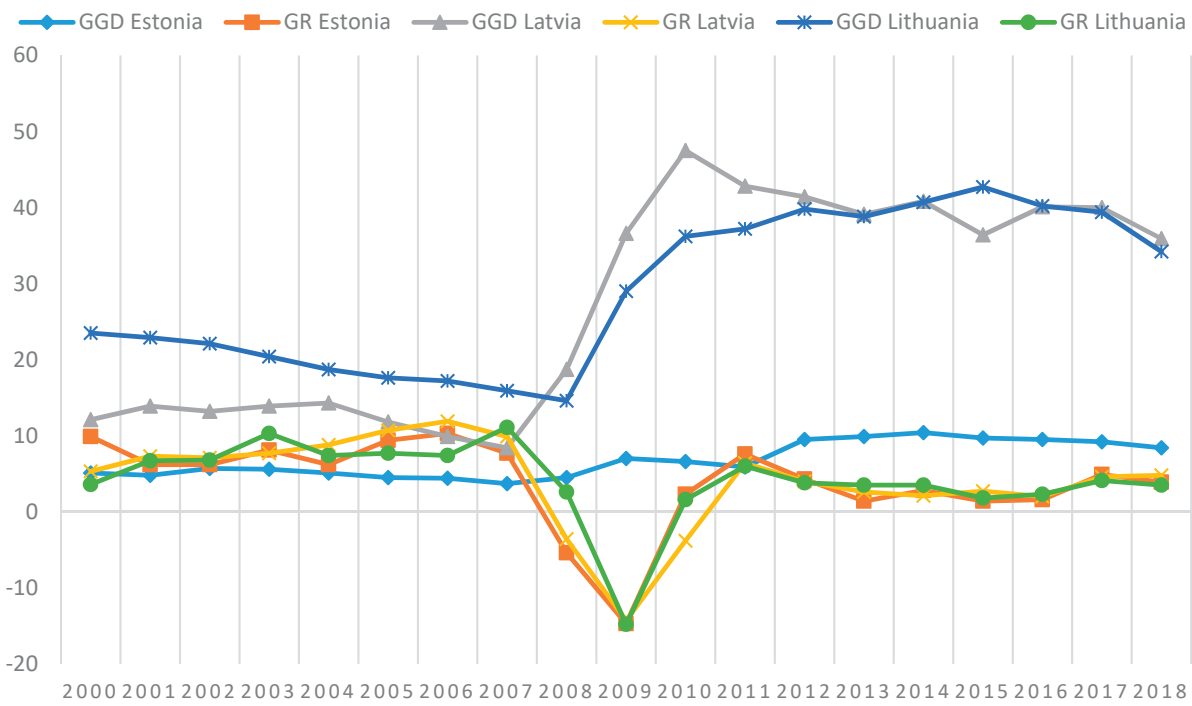

Figure 2. The Baltic countries' GGD percentage of GDP versus growth rate percentage change from previous year, 2000-2018; Source: Eurostat. 


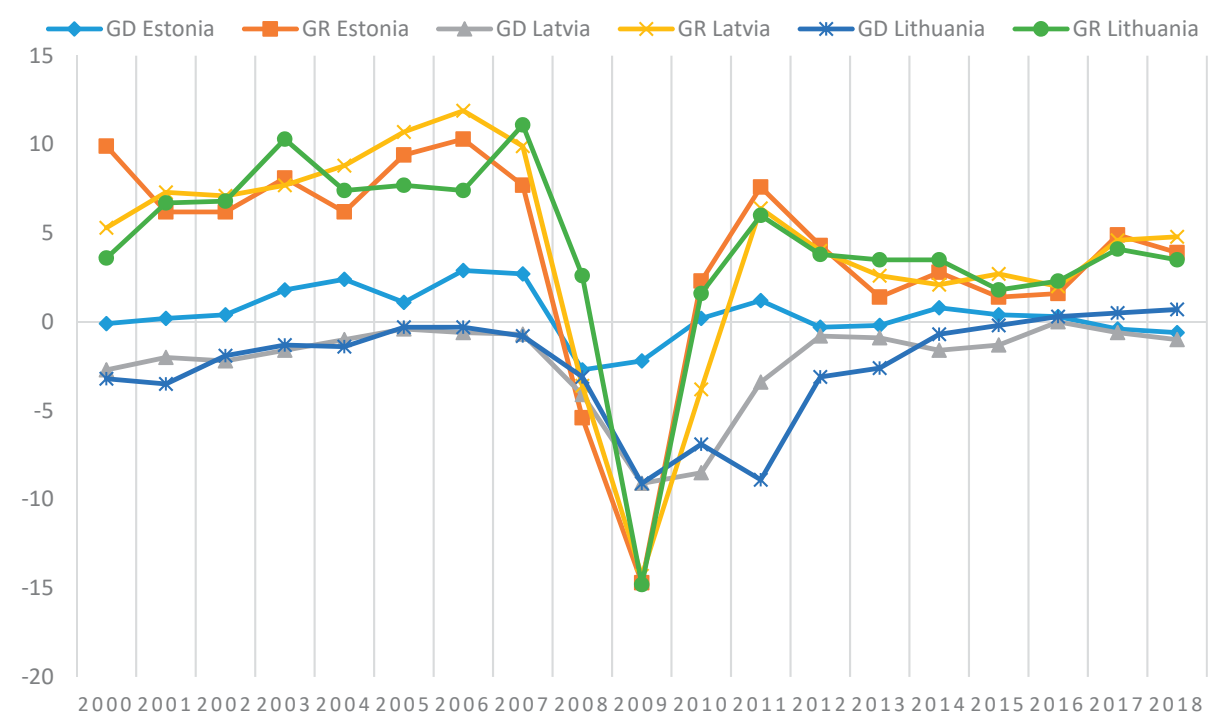

Figure 3. The Baltic countries' GD percentage of GDP versus growth rate percentage change from previous year, 2000-2018; Source: Eurostat.

For the study period, both Latvia and Lithuania's GGD remained below the recommended level of $60 \%$ (Table 1). Latvia safely controlled its GD until the financial crisis of 2008-2011, by managing to retain the recommended level after 2011 (Figure 2). On other hand, Lithuania's GD remained higher than 3\% of GDP in 2000-2001 and was up to 3\% GDP between 2008 and 2012. Lithuania recorded the recommended level before the financial crisis (Figure 3). Latvia's growth rate was high from 2000-2007 then during the recorded recession between 2008 and 2010. After 2010, the Latvian economy started to grow. Despite a slowing down from 2009, both Latvia and Lithuania recorded high growth rates up to 2007. Interestingly, Lithuania's growth had a different accelerated rate from $1.6 \%$ to $4.1 \%$ GDP in 2010-2017. In summary on a regional scale, the Baltic countries achieved the best public financial outputs among the three regional blocks. Their economic growth was high while registering low levels of GGD and GD.

\subsection{Central and Eastern European Countries}

In Central and Eastern European countries, a relatively safe level of GGD was recorded-with the exception of Hungary in 2005, which had more than the recommended $60 \%$ of its GDP in 2005 (Table 2). The Czech Republic recorded a low GGD (i.e., below 30\% of GDP) in 2000-2008 while maintaining a moderately high growth rate between 2003 and 2007. The world financial crisis decreased the country's growth rate to $4.8 \%$ in 2009 , which most probably forced the GGD to rise to more than $40 \%$ of its GDP in the following years. There was some fluctuation after 2009, but it stabilized after 2014, when the GGD of GDP finally decreased below $40 \%$ (Figure 4). Recently, in the last three years, a downward trend in GGD emerged from $37.2 \%$ in 2016 to $32.7 \%$ in 2018. The Czech Republic's GD remained somewhat problematic, hovering above the recommended level of 3\% of GDP in the years of 2000-2003, 2005, 2009-2010, and 2012 (Figure 5). Treads indicate the country decreased its GD from 2013 onwards, with its highest recorded GGD of $45.1 \%$ that same year.

Among all of the post-communist EU MSs, Hungary had the highest GGD. In 2000-2006, its growth rate was somewhat dynamic before decreasing from 2007-being hard hit with recession between 2009 and 2012-and somewhat bouncing back from 2016-2018. In 2013, Hungary's GGD started to decrease, while its growth rate remained unstable (Figure 4). The country has had a persistent 
problem maintaining GD at the recommended level from 2000-2011; however, the GD remained below 3\% of GDP in 2012-2018 (Figure 5).

Table 2. Central and Eastern European countries' GGD percentage of GDP, GD percentage of GDP, and growth rate percentage change from previous year, 2000-2018.

\begin{tabular}{|c|c|c|c|c|c|c|c|c|c|c|c|c|}
\hline \multirow{2}{*}{ Year } & \multicolumn{3}{|c|}{ Czech Republic } & \multicolumn{3}{|c|}{ Hungary } & \multicolumn{3}{|c|}{ Poland } & \multicolumn{3}{|c|}{ Slovakia } \\
\hline & GGD & GD & GR & GGD & GD & GR & GGD & GD & GR & GGD & GD & GR \\
\hline 2000 & 17.0 & -3.5 & 4.2 & 55.1 & -3.0 & 4.2 & 36.5 & -3.0 & 4.3 & 49.6 & -12.0 & 1.4 \\
\hline 2001 & 22.8 & -5.3 & 3.1 & 51.7 & -4.1 & 3.7 & 37.3 & -4.8 & 1.2 & 48.3 & -6.4 & 3.5 \\
\hline 2002 & 25.9 & -6.3 & 2.1 & 55.0 & -8.9 & 4.5 & 41.8 & -4.8 & 1.4 & 42.9 & -8.1 & 4.6 \\
\hline 2003 & 28.1 & -6.4 & 3.8 & 57.6 & -7.1 & 3.9 & 46.6 & -6.1 & 3.9 & 41.6 & -2.7 & 4.8 \\
\hline 2004 & 28.5 & -2.7 & 4.7 & 58.5 & -6.4 & 4.8 & 45.3 & -5.1 & 5.3 & 40.6 & -2.3 & 5.1 \\
\hline 2005 & 28.0 & -3.1 & 6.4 & 60.5 & -7.8 & 4.0 & 46.7 & -4.0 & 3.6 & 33.9 & -2.9 & 6.7 \\
\hline 2006 & 27.9 & -2.3 & 6.9 & 64.7 & -9.3 & 3.9 & 47.2 & -3.6 & 6.2 & 30.8 & -3.6 & 8.5 \\
\hline 2007 & 27.8 & -0.7 & 5.5 & 65.6 & -5.1 & 0.4 & 44.2 & -1.9 & 7.0 & 29.9 & -1.9 & 10.8 \\
\hline 2008 & 28.7 & -2.1 & 2.7 & 71.6 & -3.6 & 0.9 & 46.6 & -3.6 & 4.2 & 28.2 & -2.3 & 5.6 \\
\hline 2009 & 34.1 & -5.5 & -4.8 & 78.0 & -4.6 & -6.6 & 49.8 & -7.3 & 2.8 & 36.0 & -7.9 & -5.4 \\
\hline 2010 & 38.2 & -4.4 & 2.3 & 80.6 & -4.5 & 0.7 & 53.3 & -7.5 & 3.6 & 40.8 & -7.5 & 5.0 \\
\hline 2011 & 39.9 & -2.7 & 2.0 & 80.8 & -5.5 & 1.7 & 54.4 & -4.9 & 5.0 & 43.3 & -4.1 & 2.8 \\
\hline 2012 & 44.7 & -3.9 & -0.8 & 78.3 & -2.3 & -1.6 & 54.0 & -3.7 & 1.6 & 52.4 & -4.3 & 1.7 \\
\hline 2013 & 45.1 & -1.3 & -0.5 & 76.8 & -2.6 & 2.1 & 56.0 & -4.0 & 1.4 & 55.0 & -2.7 & 1.5 \\
\hline 2014 & 42.7 & -1.9 & 2.7 & 76.2 & -2.3 & 4.0 & 50.5 & -3.3 & 3.3 & 53.9 & -2.7 & 2.6 \\
\hline 2015 & 41.1 & -0.4 & 4.5 & 75.3 & -2.0 & 3.1 & 51.3 & -2.6 & 3.8 & 52.9 & -3.0 & 3.8 \\
\hline 2016 & 37.2 & 0.6 & 2.4 & 74.1 & -1.8 & 2.0 & 54.4 & -2.4 & 2.7 & 51.9 & -1.7 & 3.3 \\
\hline 2017 & 34.7 & 1.6 & 4.4 & 73.4 & -2.2 & 4.1 & 50.6 & -1.5 & 4.8 & 50.9 & -0.8 & 3.2 \\
\hline 2018 & 32.7 & 0.9 & 2.9 & 70.8 & -2.2 & 4.9 & 48.9 & -0.4 & 5.1 & 48.9 & -0.7 & 4.1 \\
\hline
\end{tabular}

Source: Eurostat.

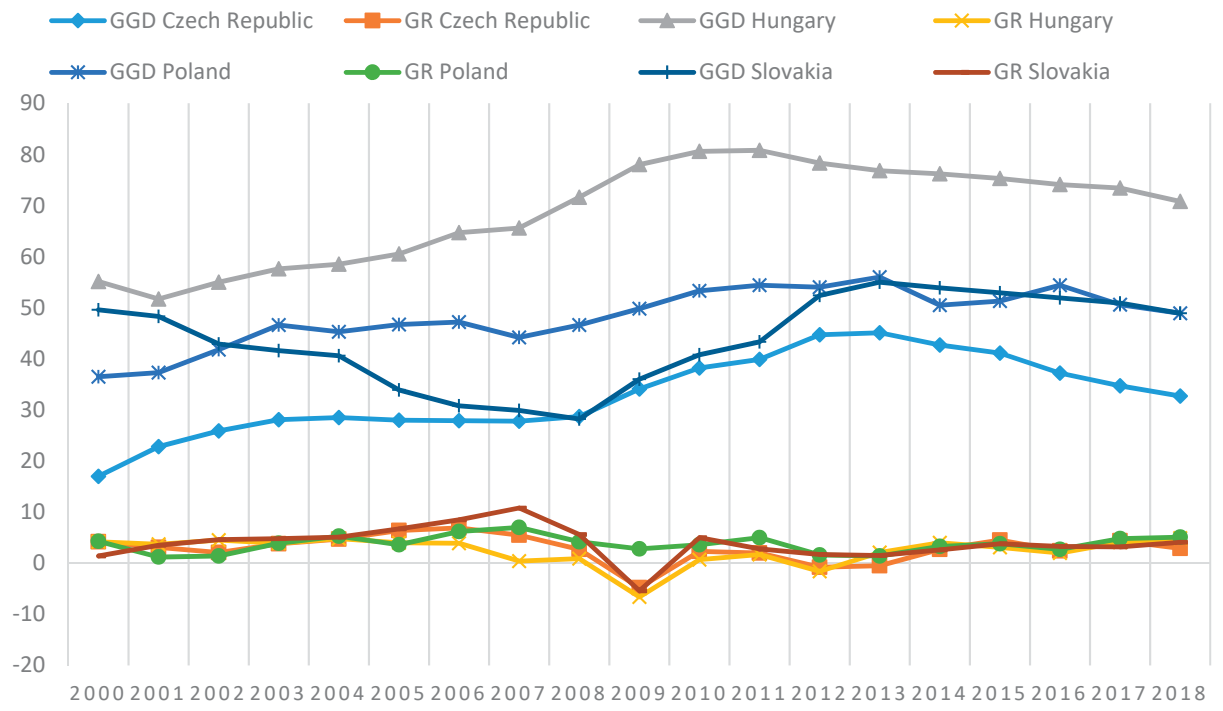

Figure 4. Central and Eastern European countries' GGD percentage of GDP versus growth rate percentage change from previous year, 2000-2018; Source: Eurostat. 


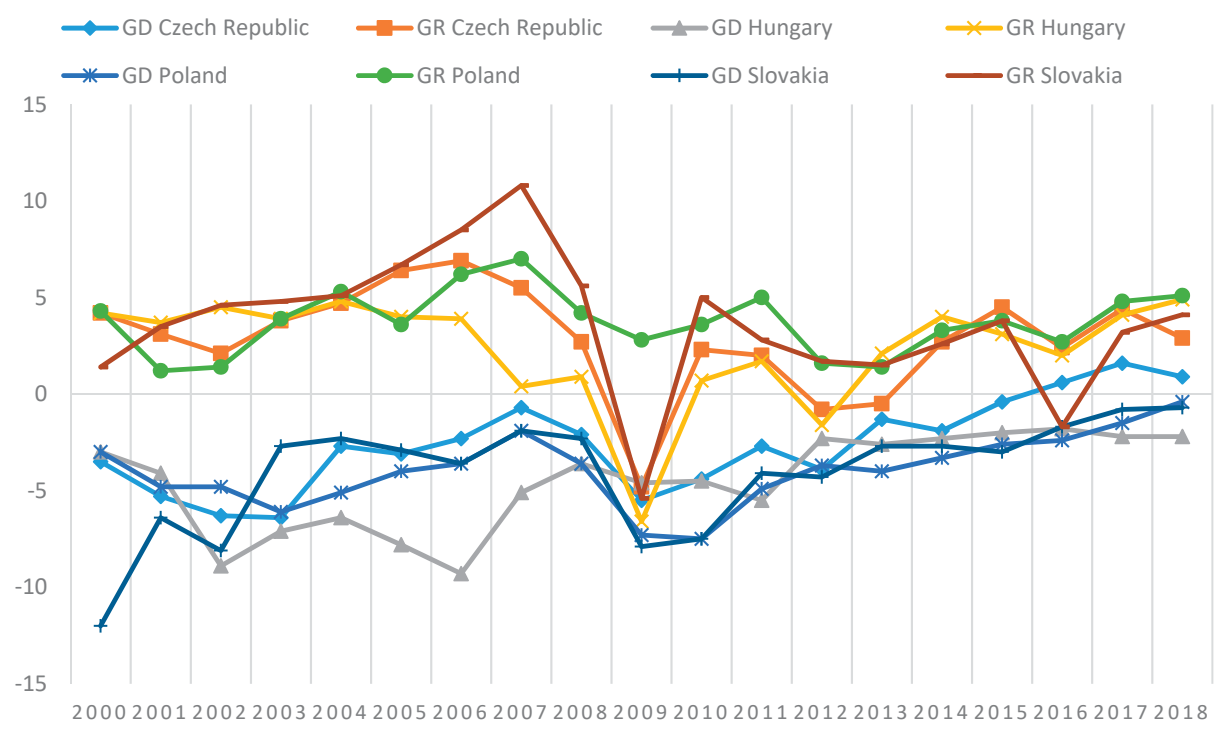

Figure 5. Central and Eastern European countries' GD percentage of GDP versus growth rate percentage change from previous year, 2000-2018; Source: Eurostat.

By contrast, Poland and Slovakia were successful in dropping and maintaining their GGD at the recommended level throughout the whole nineteen-year study period (Figure 4). Poland had problems with an elevated GD with the exception of the years of 2007 and 2015-2018, while Slovakia exceeded the recommended level in 2000-2002, 2006, and 2009-2012 (Figure 5). In the analyzed period, Poland had an indecisive growth rate, whereas Slovakia's was slow yet somewhat dynamic. At the regional level, an overview of the GGD among the countries shows a decreasing trend, with increasing growth rates in 2000-2008. A noticeable increment in GGD is evident after the 2008 world financial crises until 2013 before a general decrease is apparent from 2014 onward.

\subsection{The Balkan Countries}

Within the four EU Balkan countries, GGD and GD as a percentage of GDP illustrated some volatility over the nineteen-year study (Table 3). Bulgaria, from 2003 onward, and Romania, throughout the whole study period, demonstrated two of the lowest GGDs EU-wide, with very dynamic growth rates throughout 2002-2008. They both experienced low growth from the recession in 2009, in which Bulgaria rose to above 3\% from 2015 onward while Romania did not (Figure 6). Bulgaria's GD was under control with the exception of when it grew up to 3\% of GDP in the years of 2009-2010 and 2014. Romania's GD remained above 3\% in 2000-2001 and 2008-2012 (Figure 7). Bulgaria recorded a few years and minimal amount of government surplus, while Romania none.

The GGD in Croatia demonstrated a tendency to grow. The growth rate was dynamic from 2001-2007, after which an inversion occurs in which GGD was above the recommended level in 2011-2018 (Figure 6). The country had a problem with GD throughout the considered period with the exception of 2006-2007 and, more recently, 2016-2018 (Figure 7). The growth rate was slightly slow during the recession period of 2009-2014.

In 2000-2012, Slovenia had a low GGD before it began to grow above the recommended $60 \%$ of GDP (Figure 6). Its economic growth rate shows a dynamic fluctuation between 2000 and 2008, recession in 2009 and 2012-2013, and then growth from 2013 onward. Its GD was problematic in 2001 and from 2008-2014, with 2013 recording the worst GD result (i.e., -15.0\%) study-wide (Figure 7). 
In summary, the Balkan countries experienced low levels of GGD and GD, allowing them to record a dynamic economic growth rate with the exception of the financial crisis period of 2009.

Table 3. The Balkan countries' GGD percentage of GDP, GD percentage of GDP, and growth rate percentage change from previous year, 2000-2018.

\begin{tabular}{ccccccccccccc}
\hline \multirow{2}{*}{ Year } & \multicolumn{3}{c}{ Bulgaria } & \multicolumn{3}{c}{ Croatia } & \multicolumn{3}{c}{ Romania } & \multicolumn{3}{c}{ Slovenia } \\
\cline { 2 - 12 } & GGD & GD & GR & GGD & GD & GR & GGD & GD & GR & GGD & GD & GR \\
\hline 2000 & 71.2 & -0.5 & 5.5 & N/A & N/A & N/A & 22.4 & -4.6 & 2.5 & 25.9 & 3.6 & 3.9 \\
2001 & 64.7 & 1.1 & 6.3 & N/A & N/A & 6.5 & 25.7 & -3.4 & 5.7 & 26.1 & -3.9 & 2.8 \\
2002 & 51.1 & -1.2 & 8.3 & 36.6 & -3.5 & 5.1 & 24.8 & -1.9 & 8.7 & 27.3 & -2.4 & 3.7 \\
2003 & 43.5 & -0.4 & 5.9 & 38.1 & -4.7 & 5.6 & 21.3 & -1.4 & 6.0 & 26.7 & -2.6 & 2.8 \\
2004 & 35.8 & 1.8 & 7.4 & 40.4 & -5.2 & 4.0 & 18.6 & -1.1 & 9.0 & 26.8 & -2.0 & 4.3 \\
2005 & 26.6 & 1.0 & 7.1 & 41.3 & -3.9 & 4.1 & 15.7 & -0.8 & 4.2 & 26.3 & -1.3 & 4.0 \\
2006 & 20.9 & 1.8 & 6.9 & 38.9 & -3.4 & 4.8 & 12.3 & -2.1 & 8.1 & 26.0 & -1.2 & 5.7 \\
2007 & 16.2 & 1.1 & 7.3 & 37.7 & -2.4 & 5.2 & 12.7 & -2.8 & 6.9 & 22.8 & -0.1 & 6.9 \\
2008 & 13.0 & 1.6 & 6.0 & 39.6 & -2.8 & 2.1 & 13.2 & -5.5 & 8.5 & 21.8 & -1.4 & 3.3 \\
2009 & 13.7 & -4.1 & -3.6 & 49.0 & -6.0 & -7.4 & 23.2 & -9.5 & -7.1 & 34.6 & -5.9 & -7.8 \\
2010 & 15.5 & -3.2 & 1.3 & 58.3 & -6.2 & -1.7 & 29.9 & -6.9 & -0.8 & 38.4 & -5.6 & 1.2 \\
2011 & 15.3 & -2.0 & 1.9 & 65.2 & -7.8 & -0.3 & 34.2 & -5.4 & 1.1 & 46.6 & -6.7 & 0.6 \\
2012 & 16.8 & -0.3 & 0.0 & 70.7 & -5.3 & -2.2 & 37.4 & -3.7 & 0.6 & 53.9 & -4.1 & -2.7 \\
2013 & 17.1 & -0.4 & 0.9 & 82.2 & -5.3 & -1.1 & 38.0 & -2.1 & 3.5 & 71.0 & -15.0 & -1.1 \\
2014 & 27.0 & -5.4 & 1.3 & 86.5 & -5.5 & -0.5 & 39.8 & -0.9 & 3.1 & 81.0 & -5.0 & 3.1 \\
2015 & 26.7 & -2.1 & 3.6 & 86.7 & -3.2 & 1.6 & 38.4 & -0.7 & 3.9 & 83.2 & -2.9 & 2.3 \\
2016 & 29.5 & 0.0 & 3.4 & 84.2 & -0.8 & 2.9 & 37.6 & -3.0 & 4.8 & 79.7 & -1.8 & 2.5 \\
2017 & 25.6 & 1.2 & 3.8 & 77.8 & 0.8 & 2.9 & 35.2 & -2.7 & 7.0 & 74.1 & 0.0 & 4.9 \\
2018 & 22.6 & 2.0 & 3.1 & 74.6 & 0.2 & 2.6 & 35.0 & -3.0 & 4.1 & 70.1 & 0.7 & 4.5 \\
\hline
\end{tabular}

Source: Eurostat 2019.

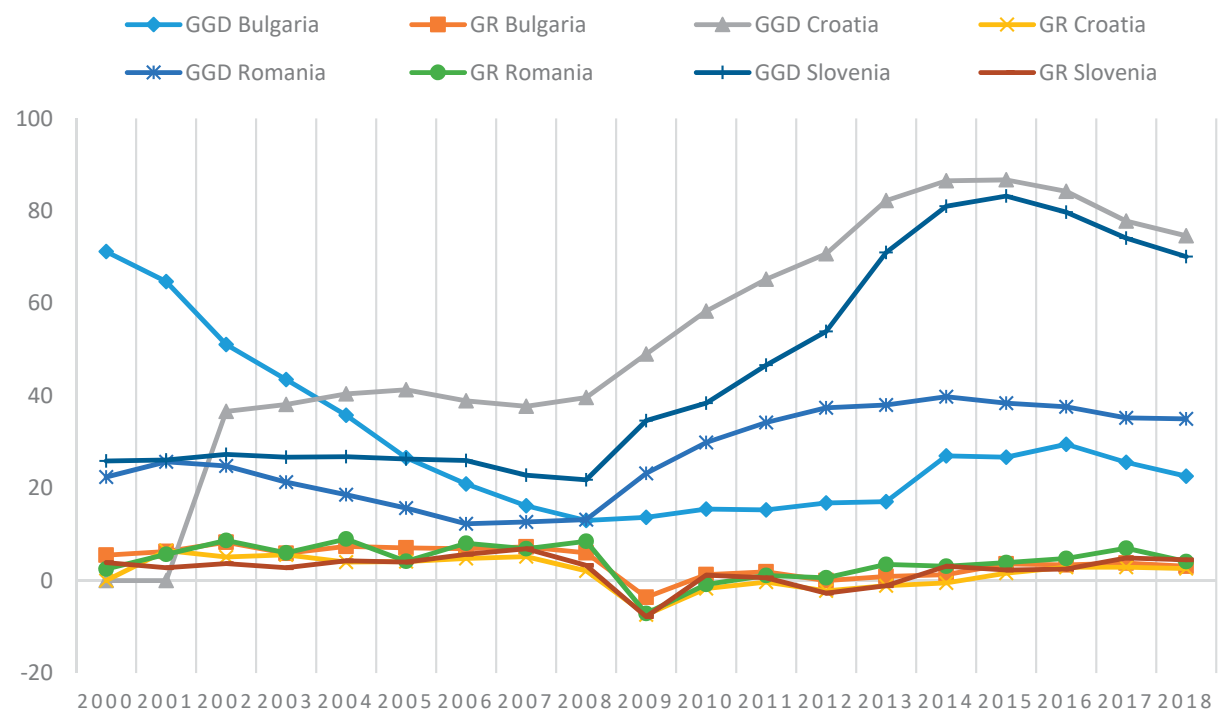

Figure 6. The Balkan countries' GGD percentage of GDP versus growth rate percentage change from previous year, 2000-2018; Source: Eurostat. 


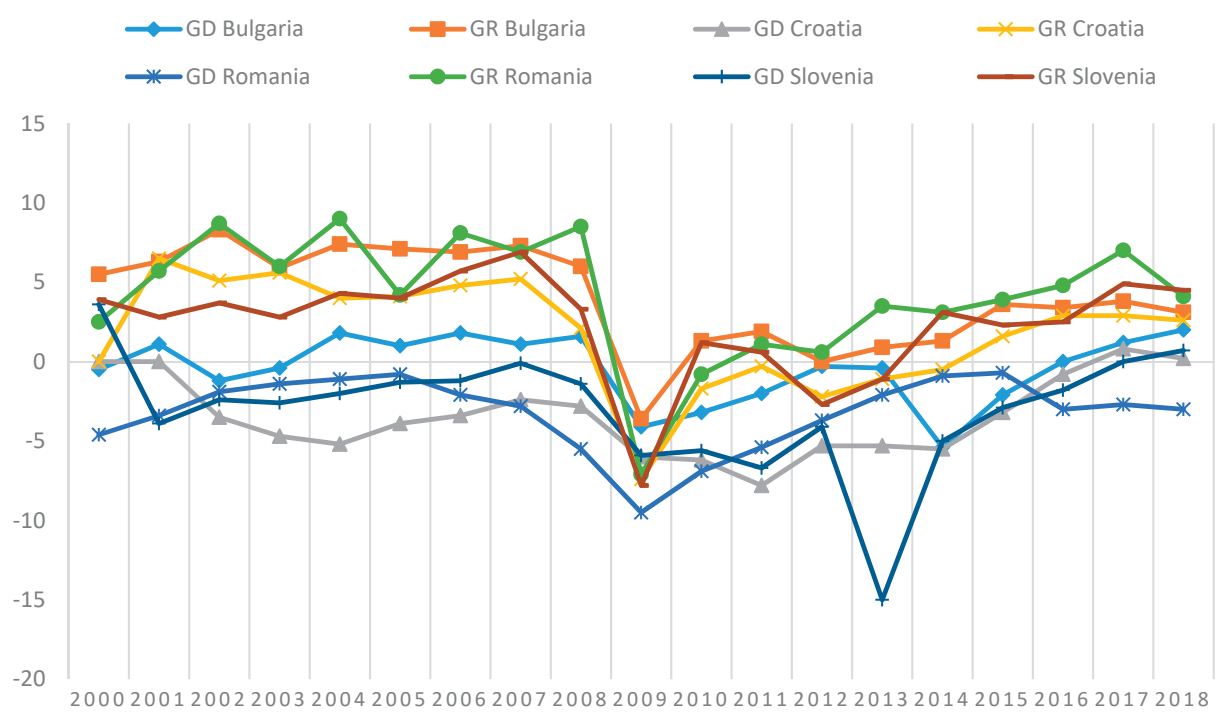

Figure 7. The Balkan countries' GD percentage of GDP versus growth rate percentage change from previous year, 2000-2018; Source: Eurostat.

\section{Discussion}

\subsection{Tax System Evaluation}

An evaluation of the varying tax systems from each of the eleven EU MSs were assessed to further understand comparability and best practices. Two tax baseline indicators were considered in order to identify and better characterize how each MS acquires state-level finance (i.e., total general government revenue (GGR) and total tax and contribution rate of profit). First, an examination of the total GGR as a percentage of GDP was looked at between 2000 and 2018 (Table 4). Over the nineteen-year period, within the Baltic countries, total GGR mostly remained under $40 \%$, with few exceptions apart from Latvia, which increased after the financial crisis of 2008 to $48.8 \%$ in 2014 and $44.7 \%$ in 2018. For Central and Eastern European countries, GGR as a percentage of GDP was generally moderate apart from the particular case of Hungary. Over the entire nineteen-year period, Hungary consistently implemented some of, and if not, the highest GGR rates of any post-communist EU MS. Hungary's economic policy is reflective of high spending and poor fiscal management. In the case of the Balkan countries, overall, there was a distinct split between Bulgaria and Romania (i.e., two former independent communist countries) and Croatia and Slovenia (i.e., two internal former parts of Yugoslavia). Bulgaria and Romania are distinctly characterized as countries with low GGR rates, with Romania having the lowest of any country study-wide. By contract, the two ex-Yugoslavian MSs imposed inverse schemes by having some of the highest GGR rates, after Hungary, in comparison to the rest of the countries studied. In all, a generalization of the total GGR as a percentage of GDP for all of the post-communist EU MSs indicated lower rates in the north and east, mid-levels in the center, and higher in the south.

Second, a contemporary assessment of restrictive fiscal policy was compared using the indicator of total tax and contribution rate (i.e., all taxes and contributions from the private sector) as a percentage of profit in 2018 (Figure 8). The mean tax rate for the all countries was $38.5 \%$. The Baltic and Central and Eastern European countries as well as Romania showed somewhat high private sector tax and contribution rates above $40 \%$, with the exception of Latvia at 36.0\%. Slovakia and Estonia sported particularly higher rates at $49.7 \%$ and $48.7 \%$, respectively. These higher rates are better suited toward the Baltic countries and the Czech Republic due to fiscal policy stability and simplicity. In the Balkan countries, with the exception of Romania, we found the lowest rates of total tax and contribution from 
all private sector entities. Croatia sported the lowest rate, study-wide, at $20.5 \%$, which is reflective of a high shadow-economy that parallels other ex-Yugoslavian non-EU MSs (Medina and Schneider 2018). As such, low levels indicate poor repayment financing of GDD and GD. In reflection, exploratory findings throughout the three regional blocks point toward the importance of developing effective taxation systems that are simple in structure, minimally reformed once a target level is achieved and, as a general rule, low. Recommendations would include building stable taxation that citizenry and the private sector feel is fair to accommodate inflows.

Table 4. Total GGR as a percentage of GDP for all post-communist EU MSs, 2000-2018.

\begin{tabular}{cccccccccccc}
\hline \multirow{2}{*}{ Year } & \multicolumn{3}{c}{ Baltic Countries } & \multicolumn{3}{c}{ Central and Eastern European Countries } & \multicolumn{3}{c}{ Balkan Countries } \\
\cline { 2 - 10 } & Estonia & Latvia & Lithuania & Czech Rep & Hungary & Poland & Slovakia & Bulgaria & Croatia & Romania & Slovenia \\
\hline 2000 & 36.4 & 34.4 & 36.2 & 37.4 & 44.1 & 39.1 & 40.0 & 40.5 & N/A & 33.9 & 42.5 \\
2001 & 35.0 & 35.3 & 33.6 & 37.7 & 43.1 & 40.3 & 38.0 & 42.0 & 43.7 & 32.9 & 43.1 \\
2002 & 36.1 & 37.0 & 33.3 & 38.5 & 42.0 & 40.6 & 37.1 & 38.2 & 47.0 & 33.0 & 43.4 \\
2003 & 35.2 & 40.5 & 32.3 & 42.5 & 41.9 & 39.7 & 37.2 & 38.5 & 45.2 & 32.9 & 43.2 \\
2004 & 34.3 & 38.5 & 32.6 & 40.2 & 42.1 & 38.5 & 35.5 & 39.9 & 43.6 & 32.7 \\
2005 & 34.0 & 39.3 & 33.7 & 39.3 & 41.6 & 40.4 & 36.9 & 38.1 & 43.0 & 32.7 & 43.4 \\
2006 & 33.6 & 38.7 & 34.0 & 39.2 & 42.2 & 41.1 & 35.2 & 35.7 & 43.1 & 33.5 & 43.0 \\
2007 & 34.1 & 37.6 & 34.4 & 39.7 & 44.8 & 41.4 & 34.4 & 38.8 & 43.0 & 34.7 \\
2008 & 39.7 & 38.4 & 35.0 & 38.7 & 45.0 & 40.7 & 34.5 & 38.7 & 42.5 & 32.3 & 42.1 \\
2009 & 46.1 & 42.1 & 35.8 & 38.7 & 45.9 & 37.8 & 36.3 & 35.3 & 42.3 & 30.3 & 42.5 \\
2010 & 40.5 & 42.0 & 35.4 & 39.3 & 44.8 & 38.5 & 34.7 & 33.1 & 41.7 & 33.1 & 43.6 \\
2011 & 37.4 & 42.3 & 33.5 & 40.3 & 44.1 & 39.1 & 36.5 & 31.9 & 40.6 & 34.1 & 43.3 \\
2012 & 39.3 & 41.9 & 33.0 & 40.5 & 46.1 & 39.1 & 36.3 & 34.1 & 42.5 & 33.7 \\
2013 & 38.5 & 41.9 & 32.9 & 41.4 & 46.7 & 38.5 & 38.7 & 37.3 & 42.4 & 33.3 & 44.5 \\
2014 & 37.8 & 48.8 & 34.0 & 40.3 & 46.9 & 38.7 & 39.3 & 37.7 & 42.9 & 34.1 & 44.4 \\
2015 & 39.6 & 40.6 & 34.6 & 41.1 & 48.2 & 39.0 & 42.5 & 38.8 & 45.2 & 35.4 & 44.9 \\
2016 & 39.5 & 38.0 & 34.4 & 40.2 & 45.1 & 38.9 & 39.2 & 35.2 & 46.3 & 31.8 & 43.4 \\
2017 & 39.3 & 37.4 & 33.6 & 40.5 & 44.7 & 39.7 & 39.4 & 36.2 & 46.1 & 30.9 & 43.2 \\
2018 & 39.5 & 44.7 & 34.7 & 41.7 & 44.2 & 41.2 & 39.9 & 36.8 & 46.6 & 32.0 & 43.1 \\
\hline
\end{tabular}

Source: Eurostat 2019.

60.0

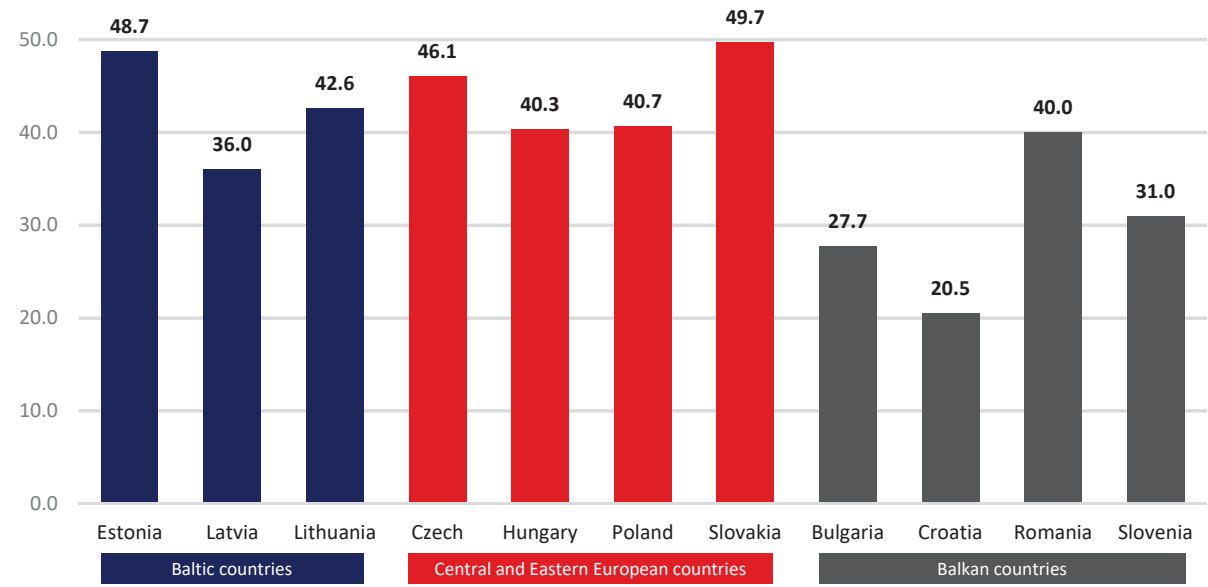

Figure 8. Total tax and contribution rate as a percentage of profit in post-communist EU MSs in 2018; Source: The World Bank. 


\subsection{Conditions of Public Finance}

Within the EU, the fiscal policy of GGD and GD is regulated and controlled under the law. EU MSs are required to respect their level of GGD and GD under the press of European institutional restrictions. This research is integral in effectively developing and adding a knowledge base within the EU's public finance continuum and at the international level in reporting on and adding to MSs' economic profiles. As such, a noteworthy concern is when government finance becomes excessively elevated (i.e., high GGD and GD), thereby reinforcing a need for economic policy reform of government income and expenditure. As governments continue to look for and experiment with optimal fiscal policy on how to improve and influence citizenry and the private sector, there is an important need in understanding the essence of GGD- and GD-related approaches developed to deal with these problems. At present, since economies are measured and evaluated by economic growth rate, the interdependency with GGD and GD interlaces the importance of government finance decision making. One can hypothesize public finance level in relation to GGD and GD as directly influencing economic growth. This idea expounds problems of fiscal policy and challenges a number of economic theories-specifically Keynesian theory, Ricardian theory and, to some degree, the theory of supply. As such, we treat GGD and GD as a negative problem which needs reactionary resolve via knowledgeable economic reform and policy. Explaining this viewpoint elucidates the stance and position on how potential policy recommendations can be put forth.

The idea of researching post-communist EU MSs plays on the fact that all these countries experienced, to some degree, specific transformative processes after communism and, again, with European enlargement. Three distinct transformative states exist, namely: former Soviet Union countries (i.e., Estonia, Latvia, and Lithuania), former independent communist countries that remain intact today (i.e., Poland, Hungary, Romania, and Bulgaria) and former larger communist countries that are now smaller ones (i.e., Czechoslovakia that became the Czech Republic and Slovakia, and Yugoslavia that became six countries in which only Croatia and Slovenia are EU MSs). This histo-geographical analysis is stimulating since we find the former Soviet Union countries are the only core group of countries that match this study's regional groupings (i.e., blocks). With this in mind, a comparative examination of GGD, GD, and growth rate clearly illustrates the Baltic countries are faring best. We can infer these results are not related to being a part of the ex-Soviet Union but rather due to being relatively small in size, small in population, homogeneous, entrepreneurial, free market-friendly, noncorrupt, with a high level and regard for the law, highly educative, as well as with high levels of infrastructure throughout the three countries. The Baltic countries as a block are often noted as supportive of each other with strong infrastructural ties, which relates to a triad of economic policy that is liberal market-oriented. However, it should be stated, GGD, GD, and growth rate were generally stable in all countries - with the exceptions of Hungary, Croatia, and Slovenia. In all, negative or stagnant periods throughout the study often revealed a positive trend when digging a little deeper at the country profile level. On a wider scale, it was evident that the world financial crisis of 2008 had a deteriorative impact on growth rate on all countries-especially from 2009. The latter years of the study period presented promising findings in which a precedent amount of data gave signal to a rebirthing of stability and public finance in all MSs.

To better cognize the avoidance of problems with GGD and GD, there needs to be an open, effective free market economy. In theorizing this requisite, the need to build an equal or surplus central budget that decreases GGD is crucial. Additionally, each government should consider savings in State expenditures as well as preparing itself (i.e., internationally, nationally, and locally) to best deal with public finance crises or economic slowdown. Possible reactive securities and safety net approaches would be beneficial. A key advantage to dealing with the problems of fiscal policy is first recognizing the issues at hand and piecing together the reporting. As such, dataset collection is an important piece of the puzzle and useful tool in developing effective best practices via historical reporting. Since the problem within all post-communist EU MSs is short in comparison to Western Europe and North America, these countries have had to transform and absorb very quickly (i.e., liberal free market 
economics) in the past three decades. Trend-based approaches offer an immediate snapshot of what has worked versus not, consequently making it easier to manage and control GGD and GD in the future.

\section{Conclusions}

The reporting conducted on all eleven post-communist EU MSs, over the nineteen-year period of 2000-2018, on GGD and GD reveals a number of influencing factors relating to economic growth. The research examined different types of GGD and GD, with emphasis on MSs' economy and government fiscal policy. It is evident that GGD and GD increase as a result of State intervention by reacting to economic fluctuations needed in fashioning more efficient fiscal policy initiatives. The data created by this study exemplify how Eurostat statistics are vital to EU progress, knowhow, and transparency. Negative or stagnant periods throughout the study revealed a general positive trend over the long term. Unmistakably, the world financial crisis of 2008 had a somewhat detrimental effect on all MSs - with some arguing Poland's exemption. In the latter years of the data, economic promise signaled high potential for renewed public finance and stability-oriented initiatives. It was found that GGD and GD are interlaced with public finance and fundamentally influence economic growth, particularly via investment. As such, high GGD and GD can put significant pressure on economic success. The evaluation on tax systems summarizes an interwoven block-oriented scope; that is, the Baltic countries can be considered as having lower rates of total GGR as a percentage of GDP, Central and Eastern European countries mid-level rates, and the Balkan countries higher-noting a number of exemptions to this generalization.

Additional inquiries should examine tools that best alleviate GGD and GD by associating negative influences with political, historical, and traditional or cultural factors. Unfortunately, a few disadvantages of the research restricted us to using only one economic factor to interconnect with GGD and GD (i.e., economic growth rate). To improve the study, increasing the use of variables, Eurostat parameters, and overall macroeconomic data could be beneficial. Supplementary indicators could include GDP per capita, unemployment, rate of investments, rate of exchange (i.e., stable or not), and balance of payments. By adding additional indicators, a more objective and distinct evaluation of the potential influence of GGD and GD on the economy could be achieved.

Furthermore, the analyzing period could also be spread over a longer period of time, including updated annual reporting. Enlarging the study with the rest of the EU could also be undertaken, with comparative East-West differences in GGD and GD with important findings relating to GDP. As such, it would be interesting to comparatively examine the more successful and stronger market economies from Western Europe which would, inferentially, immediately move the study's goalposts in a more competitive direction.

Author Contributions: Conceptualization, Data curation, A.P.; Methodology, Software, Validation, Formal analysis and Writing-Original Draft preparation, A.P. and G.T.C.; Investigation, Resources, Writing-Review and Editing, A.P., S.T.A., and G.T.C.; Visualization and Supervision, Project administration, and Funding acquisition, G.T.C.

Funding: This research received no external funding.

Conflicts of Interest: The authors declare no conflict of interest.

\section{References}

Agénor, Pierre-Richard, and Peter J. Montiel. 2005. Development Macroeconomics, 4th ed. Princeton: Princeton University Press. ISBN2 9780691165394.

Alaimo, Katherine, Elizabeth Packnett, Richard A. Miles, and Daniel J. Kruger. 2008. Fruit and Vegetable Intake among Urban Community Gardeners. Journal of Nutrition Education and Behavior 40: 94-101. [CrossRef] [PubMed]

Alesina, Alberto, and Silvia Ardagna. 1998. Tales of Fiscal Adjustment. Economic Policy 13: 487-545. [CrossRef]

Altiparmakov, Nikola. 2018. Another Look at Causes and Consequences of Pension Privatization Reform Reversals in Eastern Europe. Journal of European Social Policy 28: 224-41. [CrossRef] 
Ardagna, Silvia. 2004. Fiscal Stabilizations: When Do They Work and Why. European Economic Review 48: 1047-74. [CrossRef]

Ari, Ibrahim, Muammer Koc, Ibrahim Ari, and Muammer Koc. 2018. Sustainable Financing for Sustainable Development: Understanding the Interrelations between Public Investment and Sovereign Debt. Sustainability 10: 3901. [CrossRef]

Ball, Laurence, and Nicholas Gregory Mankiw. 1995. What Do Budget Deficits Do? Cambridge: National Bureau of Economic Research. [CrossRef]

Barro, Robert. 1988. The Ricardian Approach to Budget Deficits. Cambridge: National Bureau of Economic Research. [CrossRef]

Barro, Robert J., and Xavier Sala-i-Martin. 2004. Economic Growth. Cambridge: MIT Press. ISBN2 9780262025539.

Brzozowski, Michał, Paweł Gierałtowski, Dominika Milczarek, and Joanna Siwińska-Gorzelak. 2006. Instytucje a Polityka Makroekonomiczna i Wzrost Gospodarczy. Warsaw: Uniwersytet Warszawski.

Clements, Benedict, Rina Bhattacharya, and Toan Quoc Nguyen. 2003. External Debt, Public Investment, and Growth in Low-Income Countries. IMF Working Paper Number 03/249. Washington, DC, USA: Fiscal Affairs Department, International Monetary Fund.

Compant, Stéphane, Birgit Reiter, Angela Sessitsch, Jerzy Nowak, Christophe Clément, and Essaïd Ait Barka. 2005. Endophytic Colonization of Vitis vinifera L. by Plant Growth-Promoting Bacterium Burkholderia Sp. Strain PsJN. Applied and Environmental Microbiology 71: 1685-93. [CrossRef] [PubMed]

Ćwikliński, Henryk. 2004. Polityka Gospodarcza. Gdańsk: Wydawnictwo Uniwersytetu Gdańskiego. ISBN2 83-7326-233-4.

Deshpande, Ashwini. 1997. The Debt Overhang and the Disincentive to Invest. Journal of Development Economics 52: 169-87. [CrossRef]

Dzwonkowski, Henryk. 2013. Deficyt i Dług Publiczny. Łódz: University of Łódz Lecture Series.

Eaton, Jonathan. 1993. Sovereign Debt: A Primer. The World Bank Economic Review 7: 137-72. [CrossRef]

European Council. 1997. Resolution of the European Council on the Stability and Growth Pact Amsterdam, 17 June 1997. Amsterdam: European Council.

Gaudemet, Paul Marie, and Joel Molinier. 2000. Finanse Publiczne. Warsaw: Polskie Wydawnictwo Ekonomiczne S.A.. ISBN2 83-208-1234-8.

Giavazzi, Francesco, and Marco Pagano. 1990. Can Severe Fiscal Contractions Be Expansionary? Tales of Two Small European Countries. Cambridge: MIT Press. [CrossRef]

Gradoń, Witold. 2003. Deficyt Budżetowy-Wybrane Problemy Interpretacyjne: Deficyt Budżetowy i Dlug Publiczny w Wybranych Krajach Europejskich. Białystok: Wyższa Szkoła Finansów i Zarządzania w Białymstoku.

Hemming, Richard, Michael Kell, and Selma Mahfouz. 2002. The Effectiveness of Fiscal Policy in Stimulating Economic Activity: A Review of the Literature. Working Paper WP/02/208. Washington, DC: International Monetary Fund.

Högenauer, Anna-Lena, and David Howarth. 2019. The Democratic Deficit and European Central Bank Crisis Monetary Policies. Maastricht Journal of European and Comparative Law. [CrossRef]

Hyman, Richard. 2018. What Future for Industrial Relations in Europe? Employee Relations 40: 569-79. [CrossRef]

Kim, Dong-Hyeon, Yu-Bo Suen, Shu-Chin Lin, and Joyce Hsieh. 2018. Government Size, Government Debt and Globalization. Applied Economics 50: 2792-803. [CrossRef]

Kneller, Richard, Michael F. Bleaney, and Norman Gemmell. 1999. Fiscal Policy and Growth: Evidence from OECD Countries. Journal of Public Economics 74: 171-90. [CrossRef]

Kosek-Wojnar, Maria, Stanisław Owsiak, and Krzysztof Surówka. 1994. Podstawy Teorii Finansów Publicznych. Cracow: Wyd. Akademia Ekonomiczna w Krakowie.

Krugman, Paul. 1988. Financing vs. Forgiving a Debt Overhang. Journal of Development Economics 29: 253-68. [CrossRef]

Łaszek, Aleksander. 2013. Metodologia Szacowania Długu Ukrytego. Warsaw: Forum Obywatelskiego Rozwoju.

Lin, Shuanglin, and Kim Sosin. 2001. Foreign Debt and Economic Growth. The Economics of Transition 9: 635-55. [CrossRef]

Marciniak, Stefana. 2013. Makro i Mikroekonomia. Warsaw: Wydawnictwo Naukowe PWN.

Matarese, Valerie. 2013. Using Strategic, Critical Reading of Research Papers to Teach Scientific Writing: The Reading-research-writing Continuum. In Supporting Research Writing: Roles and Challenges in Multilingual Settings. Oxford: Chandos Publishing, pp. 73-89. [CrossRef] 
Medina, Leandro, and Friedrich Schneider. 2018. Shadow Economies Around the World: What Did We Learn Over the Last 20 Years? IMF Working Paper No. 18/17. Washington, DC, USA: International Monetary Fund. [CrossRef]

Minea, Alexandru, and Patrick Villieu. 2010. Endogenous Growth, Government Debt and Budgetary Regimes: A Corrigendum. Journal of Macroeconomics 32: 709-11. [CrossRef]

N'Zue, Felix Fofana. 2018. The Ivorian Debt: Should We Worry? Journal of Economics and International Finance 10: 11-21. [CrossRef]

Neck, Reinhard, and Jan-Egbert Sturm. 2008. Sustainability of Public Debt. Cambridge: MIT Press.

Neumann, Lilia, and Andrzej Paczoski. 2014. Wskaźniki Polityki Budżetowej Państw UE Wobec Paktu Stabilności i Wzrostu Oraz Ich Wpływ Na PKB per Capita. Polityka Gospodarcza 22: 73-77.

OECD. 2013. Fiscal Federalism 2014. Paris: Organisation for Economic Co-operation and Development. ISBN2 9789264204560. [CrossRef]

OECD. 2017. Understanding Financial Accounts. Edited by Peter van de Ven and Daniele Fano. Paris: Organisation for Economic Co-operation and Development. [CrossRef]

Ortiz-Rodríguez, David, Andrés Navarro-Galera, and Francisco J. Alcaraz-Quiles. 2018. The Influence of Administrative Culture on Sustainability Transparency in European Local Governments. Administration $\mathcal{E}$ Society 50: 555-94. [CrossRef]

Pattollo, Catherine, Hélène Poirson, and Luca Antonio Ricci. 2011. External Debt and Growth. Review of Economics and Institutions 2. [CrossRef]

Pegkas, Panagiotis. 2018. The Effect of Government Debt and Other Determinants on Economic Growth: The Greek Experience. Economies 6: 10. [CrossRef]

Renear, Allen H., and Carole L. Palmer. 2009. Strategic Reading, Ontologies, and the Future of Scientific Publishing. Science 325: 828-32. [CrossRef] [PubMed]

Romer, David, Adam Szeworski, and Andrzej Malawski. 2000. Makroekonomia Dla Zaawansowanych. Warsaw: Wydawnictwo Naukowe PWN.

Saint-Paul, Gilles. 1992. Fiscal Policy in an Endogenous Growth Model. The Quarterly Journal of Economics 107: 1243-59. [CrossRef]

Serven, Luis. 1997. Uncertainty, Instability, and Irreversible Investment: Theory, Evidence, and Lessons for Africa. Policy Research Working Paper Series; Washington, DC: World Bank.

Shah, Mohammad Aminur Rahman, Anisur Rahman, and Sanaul Huq Chowdhury. 2017. Sustainability Assessment of Flood Mitigation Projects: An Innovative Decision Support Framework. International Journal of Disaster Risk Reduction 23: 53-61. [CrossRef]

Smyth, David J., and Yu Hsing. 1995. In Search Of An Optimal Debt Ratio For Economic Growth. Contemporary Economic Policy 13: 51-59. [CrossRef]

Tobera, Paweł. 2013. Dług Publiczny-Istota, Przyczyny Powstania, Instrumenty Finansowania: Ludzie, Zarządzanie, Gospodarka. Miscellanea Oeconomicae: Studia i Materiały 1: 428-29.

Van Der Veer, Reinout A., and Markus Haverland. 2018. Bread and Butter or Bread and Circuses? Politicisation and the European Commission in the European Semester. European Union Politics 19: 524-45. [CrossRef] [PubMed]

Wernik, Andrzej. 2001. Deficyty Budżetowe i Metody Ich Liczenia. Biuro Studiów i Ekspertyz, Kancelaria Sejmu 239: 5-8.

Wiśniewski, Jan. 2015. Budget Deficit and Government Debt as Major Challenges to Public Finance in Today's Economy. Prace Naukowe Wyższej Szkoły Bankowej w Gdańsku 39: 17-25.

Yang, Lu, Jason Ma, Shigeyuki Hamori, Lu Yang, Jason Z. Ma, and Shigeyuki Hamori. 2018. Dependence Structures and Systemic Risk of Government Securities Markets in Central and Eastern Europe: A CoVaR-Copula Approach. Sustainability 10: 324. [CrossRef]

(C) 2019 by the authors. Licensee MDPI, Basel, Switzerland. This article is an open access article distributed under the terms and conditions of the Creative Commons Attribution (CC BY) license (http://creativecommons.org/licenses/by/4.0/). 

MDPI

St. Alban-Anlage 66

4052 Basel

Switzerland

Tel. +41616837734

Fax +41 613028918

www.mdpi.com

MDPI Books Editorial Office

E-mail: books@mdpi.com www.mdpi.com/books

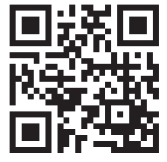



MDPI

St. Alban-Anlage 66

4052 Basel

Switzerland
Tel: +41616837734

Fax: +41 613028918

ISBN 978-3-03928-555-6
MDPI 